CONSEJO EDITORIAL

DIRECCIÓN/ EDITOR

José Siles González

COMITÉ EDITORIAL

Luis Cibanal Juan - Carmen Solano Ruiz

\section{CONSEJO DE REDACCIÓN}

COORDINADORA

Ana Lucia Noreña Peña

\section{MIEMBROS CONSEJO REDACCIÓN}

Miguel Ángel Fernández Molina

Eva Ma Gabaldón Bravo

Elena FerrerHernández

Flores Vizcaya Moreno

José Ramón Martínez Riera

$M^{a}$ Mercedes Rizo Baeza

Mercedes Nuñez del Castillo

Miguel Castells Molina

Rosa Pérez-Cañaveras

Manuel Lillo Crespo

Isabel Casabona Martínez

Departamento de Enfermería.

Universidad de Alicante

COORDINADOR INFORMÁTICO Y PÁGINA WEB

Pablo Díez Espinosa

\section{DIRECCIÓN FINANCIERA}

Organización Colegial de Enfermería de la Comunidad Valenciana

- Francisco Mulet Falcó. Enfermero. Tesorero del Consejo de Enfermería de la Comunidad Valenciana (CECOVA).

- Belén Paya Pérez. Enfermera, Presidenta del Colegio Oficial de Enfermería de Alicante.

- Juan José Tirado Dauder. Enfermero. Presidente del Colegio Oficial de Enfermería de Valencia.

- Francisco J. Pareja Lloréns. Enfermero. Presidente del Colegio Oficial de Enfermería de Castellón.

\section{COMITÉ CIENTÍFICO 0 ASESOR}

\section{Manuel Amezcua Martínez}

Presidente de la Fundación Index. Profesor asociado Universidad de Granada (España).

Carmen Chamizo Vega

Enfermera. Doctora por la Universidad de Alicante. Profesora Universidad de Oviedo. Oviedo (España)

\section{César Hueso Montoro}

Doctor por la Universidad de Alicante. Profesor Universidad de Granada (España).

\section{Manuel García Martínez}

Enfermero y licenciado en Antropología social y cultural. Doctor por la Universidad de Sevilla. Profesor asociado Universidad de Sevilla (España).

\section{Guillermo Silva Magaña}

Doctor por Universidad de Alicante. Profesor titular. (Universidad de Colima, Méjico.

\section{Carlos Lousada Lopes Subtil}

Profesor titular Escola/Faculdade: Escola Superior de Enfermagem. Viana do Castelo (Portugal)
Antonio C. García Martínez

Licenciado en Historia. Doctor en Historia Profesor Titular Universidad de Huelva (España)

\section{María Elisa Moreno-Fergusson}

Profesora Asociada de la Facultad de Enfermería y Rehabilitación de la Universidad de La Sabana Colombia. Editora de la revista Aquichan.

Esperanza de la Peña Tejeiro Enfermera. Profesora Titular Escuela de Enfermería. Universidad de Extremadura (España)

Cecilio Eseverri Cháverri

Enfermero e Historiador de la enfermería Centro Asistencial San Juan de Dios. Palencia (España)

\section{Francisca Hernández Martín}

Enfermera y Licenciada en Historia. Presidenta del Seminario de Historia de la Enfermería. Doctora por la Universidad Complutense de Madrid. Profesora Titular Escuela de Enfermeria, Universidad Complutense de Madrid. Madrid (España)

\section{Francisco Herrera Rodríguez}

Doctor en Medicina. Historiador de la Enfermería. Catedrático de la Escuela Universitaria de Ciencias de la Salud. Universidad de Cádiz (España)

\section{Amparo Nogales Espert}

Enfermera. Licenciada en Historia. Doctora por la Universidad de Valencia. Profesora Titular. Facultad de Ciencias de la Salud. Universidad Rey Juan Carlos I, Madrid (España)

\section{Natividad Sánchez González}

Enfermera. Profesora Escuela de Enfermería y Fisioterapia. Universidad de Albacete (España)

\section{Francisco Ventosa Esquinaldo}

Enfermero. Historiador de la Enfermería. Superior Gerente del Hospital San Juan de Dios "Juan Grande" Jerez/Cádiz (España) Carmen de la Cuesta Benjumea Ph.D en Enfermería. Profesora Visitante Universidad de Alicante (España)

\section{Marilyn Douglas}

Doctora en Enfermería. Profesora, School of Nursing University of California, San Francisco (EEUU)

\section{Fernando Porto}

Doctor en enfermería por la escuela de Enfermagem Anna Nery/UFRJ. Professor Adjundo da Escola de Enfermagem Alfredo Pinto da UNIRIO (Brasil)

\section{Beatriz Morrone}

Profesora Titular de la Facultad de Ciencias de la Salud, Universidad Nacional de Mar del Plata. Investigadora Categorizada II. Integrante del Banco Nacional de Evaluadores para Proyectos de Investigación del Ministerio de Cultura y Educación (Argentina).

\section{Ximena Isla Lund}

Magister en Enfermería. Doctora por la Universidad de Alicante. Profesora Universidad del Bio-Bio. (Chile)

\section{Raquel Spector}

Doctora en Enfermeria. School of Nursing Boston College. Boston (EEUU)
Rick Zouche

Enfermero. Doctor en Enfermería. Profesor Asociado. Universidad Duquenese Pittsburgh PA (EEUU)

\section{Taka Oguiso}

Enfermera y licenciada en derecho. Doctora Universidad de São Paulo. Profesora Titular Emérita. Universidad de São Paulo (Brasil)

Genival Fernandes de Freitas

Enfermero y licenciado en Derecho. Doctor por la Universidad de São Paulo. Profesor Titular. Universidad de São Paulo (Brasil)

Cultura de los Cuidados. Revista Sociofundadora del Consejo de Editores de Revistas de Enfermería Iberoamericanas.

\section{INDIZADA E INSCRITA EN:}

Cultura de los Cuidados está incluida en las bases de datos:

- CAPES/QUAL. Base de datos de revistas del Ministerio de Educación de Brasil.

- LATINDEX. Sistema Regional de Información en Línea para Revistas Científicas de América Latina, el Caribe, España y Portugal.

- "Scientific Commons" Details at a Glance: Publications: 31,839,799 - Repositories: 1,157

- BDIE, ENFISPO, EBSCO, PUBLISHING, CUIDATGE, CUIDEN CINHAL y hemerotecas digitales como: Cantárida y RUA (repositorio Institucional Universidad de Alicante: http://rua.ua.es/dspace/ handle/10045/831)

"Inscrita y miembro del en Servicio CrossRef (DOI prefix is: 10.7184)"

Coordinadora RUA. Ana L. Noreña

\section{SUSCRIPCIONES:}

Consejo de Enfermería de la Comunidad Valenciana (CECOVA) C/. Xàbia, 4 - $3^{\circ}$ Pta. 10 - 46010 Valencia Tarifas 3 números (1 año). España y Portugal: 12,02 euros

Alumnos Enfermería: 7,21 euros

Extranjero: 18,03 euros

\section{CORRESPONDENCIA}

Carmen Solano Ruiz. Departamento de Enfermería. Universidad de Alicante. Campus de Sant Vicente del Raspeig

Ap 99. E-03080 Alacant - Alicante

Revista «on line»:

http://rua.ua.es/dspace/handle/10045/831

ISSN:1138-1728-Dep.Legal: A-1309-1997

Título clave: Cultura de los Cuidados

Título abreviado: Cul. Cuid.

Tirada/ Producción: 3.000 ejemplares

\section{IMPRESIÓN Y ACABADO:}

Edita: Consejo de Enfermería Comunidad Valenciana (CECOVA)

Diseño editorial, maquetación e impresión: AROA Diseño y Comunicación. Alicante (España)

LA DIRECCIÓN DE LA REVISTA NO SE HACE RESPONSABLE DE LOS CONTENIDOS DE LOS ARTÍCULOS. MARCA ESPAÑOLA N $N^{\circ} 2.816 .560$ DENOMINADO CULTURA DE LOS CUIDADOS BOE. 16/04/2008. 


\section{SUMARIO}

NORMAS DE PUBLICACIÓN

4

Criterios de evaluación y selección de artículos 7

\section{EDITORIAL}

Decisiones y elecciones: El diseño de la investigación cualitativa.

CARMEN DE LA CUESTA BENJUMEA

Walt Whitman, Poesía y Cuidados

JOSÉ SILES

\section{FENOMENOLOGÍA}

El concepto del Baby Café como red internacional de apoyo a la lactancia materna

ISABEL BAÑO PIÑERO, CÉSAR CARRILLO GARCIA, UMA THAMBIDURAI,

MARIA EMILIA MARTINNEZ ROCHE

Camino de Soria

FRANCISCO HERRERA RODRIGUEZ

Dos islas, una frontera, un mestizaje: Una metáfora sobre la comunicación y el cuidado

JUAN CARLOS DELGADO ANTOLIN

Un día de Hambre

JAVIER FERNANDEZ ALVAREZ.

\section{HISTORIA}

Primeras intervenciones higiénico - sanitarias en el ámbito escolar: el caso de Navarra

REBECA EMA MATÉ, MAIDER EMA MATÉ.

Las campañas de vacunación contra la poliomielitis en Jerez de la Frontera (1963-1965).

FRANCISCO HERRERA-RODRÍGUEZ

El cuidado de enfermería y su evolución histórica: una revisión integrativa

CAMILA NEUMAIER ALVES, ANA CANDIDA LOPES CORREA, MARILU CORREA SOARES,

SONIA MARIA KÖNZGEN MEINCKE

Cultura de los cuidados: el debate entre historia y enfermería pre-profesional

en las acuarelas de Jean-Baptiste Debret (1816-1831)

PAULO FERNANDO DE SOUZA CAMPOS.

\section{ANTROPOLOGÍA}

Los cuidados paliativos y la muerte en los gitanos 106

MIGUEL ANGEL BADIA VALERA, CRISTINA MARCOSLEZCANO, MARIA JESÚSAGUARRÓN.

Experiencia de cooperación en Turkana (Kenia). Una mirada enfermera ...

ANDRÉS CLIMENT RUBIO, JOSÉ RAMÓN MARTINEEZ RIERA, ELENA GARCIA HIGÓN

\section{TEORÍA Y MÉTODO}

O enfermeiro que atua em Unidades de Terapia Intensiva: Perfil e Capacitação Profissional

FABIANA CRISTINA SANTOS; SILVIA HENRIQUES CAMELO.

Normas técnicas para o processo de esterilização de materiais em unidades de saúde:

uma proposta da enfermagem

MARCIA DANIELI SCHMITT, PAMELA NADIA BINDA,

KAREN CRISTINA JUNG RECH Y ROSANA AMORA ASCARI.

\section{MISCELÁNEA}

BIBLIOTECA COMENTADA

Reseña: Varela, N., Escudero, V. y López, S. (2012) Familias y enfermedad física.

Manual de intervención familiar y multifamiliar Madrid: Editorial Grupo 5.net.

LUIS CIBANAL 


\section{ESTRUCTURA DE LA REVISTA Y NORMAS DE PUBLICACIÓN}

Aunque sujeta a variaciones, en aras de su filosofía contextualizadora, la revista constará de secciones tales como :

- Editorial.

- Fenomenología: sección destinada a la publicación de originales y/o revisiones sobre fenomenología clínica. Asimismo tendrán cabida en este apartado las experiencias clínicas de los profesionales sea cual sea la forma de expresión: narrativa, ensayo, poética o plástica. Por último, también serán susceptibles de publicación los originales que, a juicio del comité de redacción, contribuyan al desarrollo humanístico de la enfermería (en cualquiera de sus vertientes).

- Historia: destinada a la publicación de originales y/o revisiones de historia de enfermería.

- Antropología: sección reservada para la inclusión de originales y/o revisiones de trabajos antropológicos en materia de cuidados enfermeros.

- Teoría y métodos enfermeros: apartado dedicado a la publicación de originales y/o revisiones que contribuyan tanto al desarrollo teórico-filosófico de la enfermería como a sus métodos y aplicaciones prácticas.

- Miscelánea: Sección dedicada a la divulgación de actividades, noticias, agenda etc, revisión de novedades editoriales.

- Cartas al Director

\section{PRESENTACIÓN DE LOS TRABAJOS}

- Estructura del manuscrito: En la primera página figurará el título del artículo en minúscula en tres idiomas en este orden: español, inglés y portugués, seguido del nombre de los autores (no más de 6),en minúscula. En primer lugar las iniciales en mayúsculas separadas por un punto y seguido por los apellidos en minúsculas por ejemplo: $\mathrm{M}^{\mathrm{a}}$.C. Solano Ruiz. Mediante un asterisco (superíndice) escribir su rango académico más elevado o profesional y la dirección de contacto del primer autor junto con su correo electrónico y teléfono. En la segunda página: resumen del trabajo no superior a 200 palabras (en inglés, portugués y español. Se incluirán, además de cuatro a cinco palabras clave en los tres idiomas. Las siguientes páginas incluirán el contenido del artículo evitando poner subíndices y notas al pie de página, con una extensión no superior a los 17 folios; la última página estará dedicada a la bibliografía.

- El sistema de citas adoptado en la revista está de acuerdo a la normativa Harvard-APA: en el texto sólo aparecerá el apellido en minúsculas y la fecha del autor entre paréntesis, ej: (López,1998). La bibliografía consultada al final del artículo no llevará numeración y quedará ordenada alfabéticamente por el apellido del autor ej:

Sánchez, J. (1997) Historia de la revista panacea. Paidós, Barcelona (Libro)

Sánchez, J. (1997) Historia de la revista panacea. Enfermería Científica 8 22-27 (Artículo revista)

Sánchez, J. (1997) Historia de la revista panacea. En: Cibanal, L.. ed. Las revistas españolas de enfermería ,Síntesis, Madrid: 88-102 (Capítulo de Libro).

Para citar documentos/ artículos "on line":

Pagani, R.. (2002) Informe técnico. El crédito europeo y el sistema educativo español. 425 Available http: www.eees.ua.es/http:aneca.es/ modal_eval/docs/doc. downloaded 426 27th July 2008.

- Las ilustraciones, gráficas y fotografías se enviarán en otro archivo, indicando su número de orden y título a pie de página o en su reverso en el caso de las fotografías. Las gráficas, preferentemente, deberán presentarse en blanco y negro.

- Presentación: letra Times New Roman, tamaño letra12, a doble espacio.

- Los autores deberán realizar el" check list" disponible en este enlace, previo a la remisión del artículo. 


\section{STRUCTURE OF JOURNAL AND NORMS OF PUBLICATION}

Although subject to variations in the interest of contextualizing the journal philosophy, will include sections such as:

- Editorial.

- Phenomenology section devoted to the publication of original and / or reviews of clinical phenomenology. They will also take place in this section, the clinical experience of professionals in whatever form of expression, narrative, essay, poetry or art. Finally, also be eligible for the original publication, in the opinion of the editorial board, contribute to the development of humanistic nursing (in any of its aspects).

- History: intended for publication of original and / or revisions of nursing history.

- Anthropology: section reserved for the inclusion of original and / or revisions of anthropological work on nursing care.

- Theory and methods nurses: section dedicated to the publication of original and / or reviews that contribute to both theoretical and philosophical development of nursing as their methods and practical applications.

- Other: Section dedicated to the dissemination activities, news, calendar etc., reviews, new books.

- Letters to the Editor

\section{PRESENTATION OF WORK}

- Structure of the manuscript: On the first page will contain the article title inlowercase in three languages in this order: Spanish, English and Portuguese,followed by the name of the authors (no more than 6), in lowercase. First initial capital letters separated by a period followed by the surnames in lowercase eg: $\mathrm{M}$ ${ }^{a}$.C. Solano Ruiz. By an asterisk (superscript) write their highest academic level or professional contact and address of the first author with his email and phone. On the second page: abstract of the work not exceeding 200 words (in English, Portugueseand Spanish. shall include in addition to four to five keywords in these languages. The following pages include the contents of the article to avoid subscripts andfootnotes footer, with an extension not exceeding 17 pages, the last page is devoted to the literature.

- The citation system is adopted in the journal according to the Harvard law-APA: the text will only appear in lower case the name of the author and the date in brackets, eg (Lopez, 1998). The bibliography at the end of the article will benumbered and arranged alphabetically by author's surname eg

Sanchez, J. (1997) History of the Journal panacea. Polity Press, Barcelona (Book)

Sanchez, J. (1997) History of the Journal panacea. Nursing Science 8 22-27 (Journal Article)

Sanchez, J. (1997) History of the Journal panacea. In: Cibanal, L. ed. The Spanish journals nursing, Synthesis, Madrid. 88-102 (Chapter in Book).

To cite documents / articles "on line":

Pagani, R.. (2002) Technical Report. The European credit and the Spanish educational system. Availablehttp:www.eees.ua.es/ http:aneca.es/modal_eval/docs/doc 425. downloaded 42627th July 2008.

- The illustrations, charts and pictures will be sent to another file, indicating your order number and title in footer or the reverse in the case of the photographs. Graphs,preferably, should be submitted in black and white.

- Presentation: Times New Roman, size letra12, double-spaced.

- The authors should make the "check list" available here, prior to the submission of the article. 


\section{ESTRUTURA DA REVISTA E NORMAS DE PUBLICAÇĀO}

Embora sujeita a variações no interesse de contextualizar a sua filosofia, a revistavai incluir recursos como:

- Editorial.

- A secção dedicada à Fenomenologia da publicação do original e / ou opiniões da fenomenologia clínica. Eles também serão realizados nesta seção, a experiênciaclínica dos profissionais, independentemente da forma de expressão, a narrativa, o ensaio de poesia, ou de plástico. Finalmente, também será elegível para a publicação original, na opinião do conselho editorial, contribuir para o desenvolvimento da enfermagem humanística (em todos os seus aspectos).

- História: destinadas a publicação do original e / ou revisões de história da enfermagem.

- Antropologia: seção reservada para a inclusão de original e / ou revisões detrabalho antropológico sobre cuidados de enfermagem.

- enfermeiras Teoria e métodos: secção dedicada à publicação de opiniõesoriginais e / ou que contribuam para o desenvolvimento teórico e filosófico da enfermagem como os seus métodos e aplicações práticas.

- Outros: Seção dedicada a actividades de divulgação, notícias, calendário etc,resenhas de livros novos.

- Cartas ao editor

\section{DE APRESENTAÇÃO DE TRABALHO}

- Estrutura do manuscrito: Na primeira página vai conter o título do artigo em letras minúsculas em três idiomas, nesta ordem: Espanhol, Inglês e Português, seguido do nome dos autores (não mais que 6), em letras minúsculas. Primeira letra inicial maiúscula, separados por um ponto seguido pelo sobrenome em minúsculas, por exemplo:. M ${ }^{\text {a }}$ C. Solano Ruiz. Por um asterisco (sobrescrito) escrever seu mais alto grau acadêmico ou contato profissional e endereço do primeiro autor com o seu e-mail e telefone. Na segunda página:.. Resumo do trabalho não superior a 200 palavras (em Inglês,
Português e Espanhol, para além de quatro a cinco palavras-chave em todas as três línguas As páginas seguintes incluem o conteúdo do artigo para evitar subscritos e notas rodapé, com uma área não superior a 17páginas, a última página é dedicada à literatura.

- O sistema de nomeação é adotado na revista de acordo com a Harvard-lei APA: o texto não aparece apenas em letras minúsculas o nome do autor ea data entre parênteses, por exemplo (Lopez, 1998). A bibliografia no final do artigo serão numerados e dispostos em ordem alfabética pelo sobrenome do autor, por exemplo

Sanchez, J. (1997) História da panacéia Journal. Polity Press, Barcelona (Book)

Sanchez, J. (1997) História da panacéia Journal. Enfermagem da Ciência 8 22-27 (Journal Article)

Sanchez, J. (1997) História da panacéia Journal. In: Cibanal, L. ed. Os espanhóisperiódicos de enfermagem Síntese, Madrid. 88-102 (Capítulo de Livro).

Para citar documentos / artigos "on line":

Pagani, R.. (2002) Relatório Técnico. O crédito Europeu e do sistema educativo espanhol. Disponível http:www.eees.ua.es/http:aneca. es/modal_eval/docs/doc 425.baixado 42627 de julho de 2008.

- As ilustrações, gráficos e fotografias serão enviadas para um outro arquivo, indicando o seu número de ordem e título em rodapé ou o inverso no caso das fotografias. Gráficos, de preferência, devem ser apresentadas em preto e branco.

- Apresentação: Times New Roman, tamanho letra12, com espaçamento duplo.

- Os autores devem fazer o "check list", disponível aqui, antes da apresentação do artigo. 


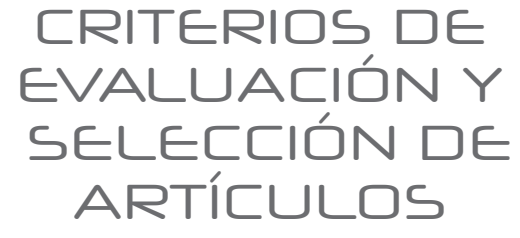

La revista Cultura de los Cuidados publica artículos en español, portugués e inglés. La recepción de los mismos pasa por un proceso de selección en una primera revisión por el Consejo editorial verificando el cumplimiento de los requisitos propios de la revista, descritos en las indicaciones a los autores, en caso de no cumplir estas condiciones se le notifica al autor o autores para que realicen los cambios oportunos.

Posteriormente tras la clasificación temática y preservación del anonimato del manuscrito los documentos son enviados a dos especialistas de reconocido prestigio en el área de conocimiento, para que procedan a su evaluación. Una vez recibidos los conceptos de los pares académicos se toma una decisión conjunta con el Consejo Editorial que puede ser de aceptación con ajustes, de aceptación definitiva o de rechazo comunicándolo al autor o autores a través de correo electrónico o postal.

En caso de que la decisión del Consejo Editorial sea la de rechazo se remitirá el informe de los evaluadores junto con la decisión adoptada por el Consejo Editorial que fundamente esta decisión.

Los manuscritos que sean considerados para publicación previa modificación, se notificarán con una propuesta concreta de modificación o con el informe de los evaluadores. Los autores dispondrán de un máximo de 2 semanas para comunicar a la secretaria de redacción su decisión en la modificación del mismo y en el plazo máximo de dos meses se comprometerán a entregar la versión revisada.

La revista se reserva el derecho de realizar revisiones de estilo que faciliten la claridad y la comprensión del texto.

Los factores donde se fundamenta la decisión sobre la aceptación o rechazo de los trabajos por parte de la redacción de la revista son los siguientes:

- La originalidad, novedad y actualidad del tema.

- Relevancia y aplicabilidad de los resultados.

- Calidad metodológica. Fiabilidad y validez

- Presentación, buena redacción, organización y coherencia lógica del texto.

- La inclusión en los manuscritos enviados de, al menos, una cita de artículos publicados en Cultura de los Cuidados.

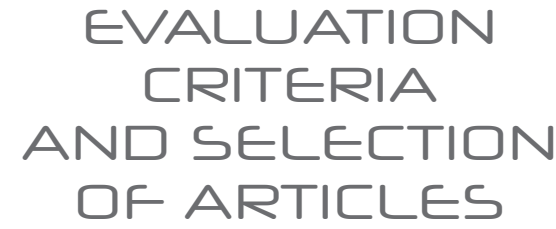

"Cultura de los Cuidados" (The Culture of Care) Journal publishes articles in Spanish, Portuguese and English. Admission will be subject to a selection process in a first review by the Editorial Board to verify compliance with the requirements of the Journal, as stated in the instructions for authors. In the case these conditions are not met, the author or authors will be notified in order to make the necessary changes.

After accomplishment of topic classification and preservation of the anonymity of the paper, documents are submitted to two specialists of recognized prestige in the corresponding area of knowledge for evaluation. Once peer academic report is produced, decision is reached together with the Editorial Board to either accept with adjustments, final acceptance o rejection that will be notified to the author or authors by email or post.

Should the decision of the Editorial Board be to reject, the evaluators' report will be sent together with the decision of the Editorial Board that substantiates this decision.

Manuscripts to be considered for publication after amendment shall be notified with a specific proposal for amendment or with the evaluators' report. Authors will have a maximum of 2 weeks to inform the Assistant Managing Editor of their decision of amendment and the deadline for submitting the revised version is two months maximum.

The Journal reserves the right to make revisions in style to facilitate clarity and understanding of the text.

The factors which ground the decision on acceptance or rejection of papers by the Journal Editor are:

- Originality, novelty and contemporary issues.

- Relevance and applicability of the results

- Methodological quality, reliability and validity

- Presentation, good writing, organization and logical consistency of the text.

- The inclusion in manuscripts submitted to at least one citation of articles published in Culture Care. 


\section{CRITÉRIOS DE AVALIAÇĀO E SELEÇĀO DE ARTICOS}

A Revista Cultura de los Cuidados publica artigos em Espanhol, Português e Inglês. O recebimento dos mesmos está sujeito a processo de seleção, em primeira revisão, pelo Conselho Editorial, no qual verifica-se o cumprimento dos requisitos próprios da Revista, descritos nas indicações aos autores. Em caso de cumprimento dessas condições, será notificado o autor ou autores para que realizem as mudanças oportunas.

Em seguida, depois da classificação temática e preservação do anonimato do manuscrito, os documentos serão enviados a dois especialistas de reconhecido prestígio na área de conhecimento, para que procedam à avaliação. Uma vez recebidos os conceitos dos dois pares acadêmicos, toma-se decisão conjunta com o Conselho Editorial, que pode ser de aceitação com ajustes, de aceitação definitiva ou de recusa, comunicando-se a decisão ao autor ou autores, por meio de correio eletrônico ou postal.

Se a decisão do Conselho Editorial for de recusa do artigo, será informado ao autor ou autores acerca dessa decisão adotada pelo referido Conselho, apresentando-se os fundamentos que a justificam.

Os manuscritos que forem aprovados para publicação, porém com prévia modificação, far-se-á notificação ao autor ou autores com uma proposta concreta de modificação e com informe dos avaliadores. Os autores disporão de no máximo 2 semanas para se comunicarem com a Secretaria de redação acerca da modificação proposta e no prazo máximo de dois meses se comprometerão a devolver a versão corrigida, caso tenham concordado com as correções.

A Revista reserva para si o direito de realizar revisões de estilo que facilitem a clareza e compreensão do texto.

Os fatores que fundamentam a decisão sobre a aceitação ou recusa dos trabalhos, por parte da redação da Revista são os seguintes:

- A originalidade, novidade e atualidade do tema;

- Relevância e aplicabilidade dos resultados;
- Qualidade metodológica, confiança e validade;

- Apresentação, boa redação, organização e coerência lógica do texto.

- A inclusão em manuscritos submetidos a pelo menos uma citação de artigos publicados nos Cuidados de Cultura. 


\section{Editorial}

\section{Decisiones y elecciones: El diseño de la investigación cualitativa}

\section{Decisions and choices: The design of qualitative research}

\section{Decisões e escolhas que: $\mathrm{O}$ desenho de pesquisa qualitativa}

Carmen de la Cuesta Benjumea

Profesora titular Departamento de Psicología de la Salud. Universidad de Alicante.

Cómo citar este relato en edición digital: de la Cuesta Benjumea, C. (2015). Decisiones y elecciones: El diseño de la investigación cualitativa. Cultura de los Cuidados (Edición digital) 19, 43. Disponible en: <http://dx.doi.org/10.14198/cuid.2015.43.01>

Correspondencia: Departamento de Psicología de la Salud. Universidad de Alicante. CP 03080, Alicante.

Correo electronico: ccuesta@ua.es

Recibido: Autora invitada

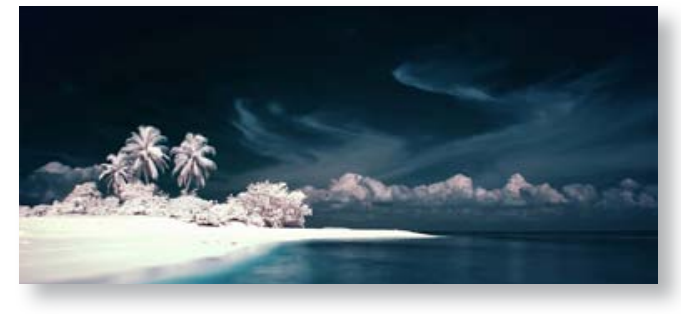

\section{ABSTRACT}

In this editorial the author reflects on the different forms of decisions and choices about the design in qualitative research.

Keywords: Qualitative Research; nursing.

\section{RESUMO}

Neste editorial, o autor reflecte sobre as diferentes formas de decisões e escolhas sobre o design na pesquisa qualitativa.

Palavras chave: Pesquisa qualitativa; enfermagem.

\section{RESUMEN}

En esta editorial la autora reflexiona sobre las diferentes formas de decidir y elegir acerca del diseño en investigación cualitativa.

Palabras clave: Investigación Cualitativa; enfermería.
La ejecución de un estudio de investigación implica tomar una serie de decisiones y hacer elecciones. La primera, es optar entre llevar a cabo un estudio cualitativo o cuantitativo, superado este escollo, que no es poco, quien investiga se ve enfrentado en elegir una estrategia, enfoque o diseño. Ante él o ella se abre un abanico de múltiples, desconocidas y a veces, extrañas posibilidades.

¿Cómo poder elegir si de ante mano se ignora la naturaleza de los diversos métodos? ¿Cómo saber si se será capaz de llevarlos a cabo? En este punto se suele buscar consejo e información, pero la verdad es que en los inicios se va a algo tientas y con la sensación de quizás, haberse equivocado. La información parece insuficiente y en realidad lo es, pues hasta que los métodos no se experimentan no se les conoce verdaderamente. Entrar a diseñar un proyecto con esta incertidumbre, que la llevamos hasta el trabajo de campo, no es malo mas bien es ventajoso, aunque reconozco que incomodo. La sensación de no saberlo todo, sitúa a quien investiga próximo a las vidas de los participantes. La fragilidad y 
vulnerabilidad que se siente al plantear un estudio y al llevarlo a cabo, abre a la experiencia del otro y a escuchar lo que tiene que decir. $\mathrm{Al}$ mundo hay que salir aunque sea cojeando, decía Foucault cuando sus estudiantes le pedían certidumbres, y creo que en la investigación cualitativa, un nuevo mundo para muchos, se sale de esta manera. Cojeando, ipero no empujado! Es decir, con cierto saber sobre la elección hecha.

Dado por sentado que se ha optado por estudiar el mundo de la manera cualitativa, la cuestión ahora es, cómo entrar teóricamente en él. En la investigación en salud confluyen los métodos cualitativos que provienen de diversas disciplinas, cada una con su lenguaje, sus particularidades pero también sus puntos en común, el campo de la salud es en verdad multidisciplinar. Así que, lo primero para hacer una buena elección, es poder entender el lenguaje del método y distinguir equivalencias y diferencias. Por ejemplo, lo que en la etnografía se denomina punto de vista "emic" en la teoría fundamentada se llama la "experiencia del interior" y en la fenomenología "experiencia vivida”. Estos términos son equivalentes, pero no iguales, las bases disciplinares de cada uno de ellos va a dar el matiz particular. Además de hacerse con un lenguaje, es necesario familiarizarse con el marco teórico que sustenta una metodología dada. Esto no significa que quien investiga se haga sociólogo, filósofo o teórico crítico. Significa, que conozca y luego comparta, los supuestos teóricos que subyacen en el método. Esto ayudará a plantear el problema a investigar y en el diseño del estudio, a que la elección hecha tome cuerpo.

Es común que al principio todo parezca igual y a la vez distinto, que la confusión sea grande y que quien se acerca por primera vez a los métodos cualitativos, se sienta algo abrumado o abrumada. Aquí la tentación suele ser tomar un poco de cada método, pues la verdad, es que todos parecen atractivos; la elección no suele ser fácil. Se está poco acostumbrado a tener que elegir entre diversos métodos, lo tradicional en el área de la salud ha sido el monoteísmo metodológico, es decir la creencia de que para investigar solo hay un método verdadero. Mezclar entre métodos no es aconsejable, sobretodo a quienes inician la andadura. Lo que la práctica muestra, es que con el tiempo los investigadores cualitativos tienen preferencias e inclinaciones que hace que se especialicen en un método o estrategia cualitativa de investigación. Se especializan, pero no se quedan ahí sino que, con la práctica, lo desarrollan. Los métodos se crean de nuevo en cada proyecto, por investigadores que llevan su trabajo a un estándar, afirma Sandelowski (2008).

En los inicios, la decisión sobre qué camino metodológico tomar es producto de un dialogo que quien va a investigar tiene consigo mismo o consigo misma. En este dialogo considera sus gustos e inclinaciones, su vocación, biografía y cómo no, la persona que va orientar el trabajo. Pero no todo esta claro ni es racional, a la intuición se la debe también escuchar. Una vez elegido el método cualitativo, el compromiso metodológico es flexible, nada es irrevocable. Es en la práctica donde se dirimen estas cuestiones. Así que la decisión es provisional, permite salir cojeando y avanzar.

Resuelta la cuestión del enfoque metodológico, en cada proyecto y estudio de investigación quien investiga se enfrentara a un sin numero de decisiones. El primer acercamiento a la bibliografía le irá orientando el camino, pasará de desarrollar el problema a investigar 
a plantear la estrategia para hacerlo. Aquí, las decisiones de orden metodológico que tome, son bastantes prácticas además de éticas. Tendrá que valorar honestamente si tal como está planteando el estudio lo puede llevar a cabo y si lo debe llevar a cabo.

Una vez en el campo, la estrategia se pone a prueba así como la capacidad de quien investiga para resolver los problemas que surjan. A los diseños los limita las restricciones que hay en la practica (Denzin y Lincoln 1994), pero se desconocen de antemano. En verdad, el diseño cualitativo consiste en tomar decisiones; quien investiga no actúa por diseño sino que al actuar, es decir al ejercer como investigador o investigadora, diseña su estudio. La consulta bibliográfica, la reflexividad, la intuición y los diálogos con orientadores y pares ayudaran a que tome las mejores decisiones. Pero las elecciones no finalizan aquí, en el análisis se enfrenta, primero, a decidir lo que será dato para su estudio de investigación y luego qué asuntos perseguir. Una vez más, aquí afronta la cuestión de que no puede analizarlo todo y los ecos positivistas de lo exhaustivo, resonarán en su interior. Tendrá que elegir y confiar en que su familiaridad con el tema en estudio y lo que aprendió durante el trabajo de campo, le indicarán el camino. También podrá pensar que lo que descarta lo puede reservar para otro estudio (Charmaz 2014).

Cómo comunicar lo aprendido durante el estudio, es la ultima elección que hace y aquí no encuentro mejor metáfora que la de pensar en un pintor que, ante un paisaje, decide donde mejor situar su caballete. Este es un proceso de visualizar la estructura del informe hasta dar con aquella que se deja escribir. A medida que desarrolla su escrito quien investiga decide qué decir, donde mejor decirlo y qué recursos literarios usar; de esta manera, diseña su escrito para hacer justicia a las vidas de los participantes del estudio.

Investigar cualitativamente no es seguir a ciegas prescripciones metodológicas ni aplicar recetas; implica tomar decisiones algunas informadas, otras intuitivas y otras sugeridas, es en este proceso donde el estudio toma una forma particular, única y específica que reflejará el self de quien investiga. La incertidumbre acompaña todo el proceso y esta es, precisamente, una condición para que prospere el trabajo cualitativo de investigación.

\section{REFERENCIAS}

- Charmaz, K. (2014). Constructing Grounded Theroy. Los Angeles: Sage.

- Denzin, K. y Linclon, YS (1994). Introduction: Entering the Field of Qualitative Research. En: K. Denzin y Y:S. Lincoln (Eds.), Handbook of Qualitative Research, (pp 1-17). California: Sage, Thousand Oaks.

- Sandelowski, M. (2008). Foreword. En: S. Thorne (Ed.), Interpretative description, (pp. 11-14). Ca: The Left Coast Press. 


\title{
Walt Whitman, Poesía y Cuidados
}

Walt Whitman, Poetry and Care

\section{Walt Whitman, Poesia e Cuidados}

\author{
José Siles González
}

Departamento de Enfermería. Universidad de Alicante (España).

Cómo citar esta editorial en edición digital: Siles, J. (2015). Walt Whitman, Poesía y Cuidados. Cultura de los Cuidados (Edición digital) 19, 43. Disponible en: <http://dx.doi.org/10.14198/cuid.2015.43.02>

Correspondencia: Departamento de enfermería Universidad de Alicante. CP 03080, Alicante.

Correo electronico: jose.siles@ua.es

Recibido: Autor invitado

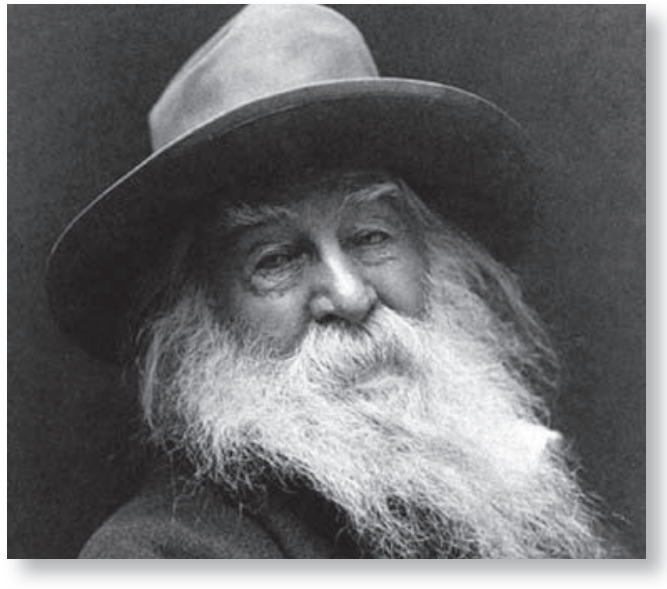

Walt Whitman.

Fuente: http://www.findagrave.com/cgi-bin/fg.cgi?page $=p v$ \&GRid=1098\&PIpi=26565980

\section{ABSTRACT}

To understand the impact of Whitman in the poetry and sociopoetics of care is essential to know the environment in which the American poet improvised developed his work as a nurse in a historical context marked by a bitter civil war. Only in this way you can grasp the interaction between his poetry, his person and his work as a nurse. In this editorial, the author analyzes the most significant works of the author in relation to their impact with his experience as a caregiver : Leaves of Grass" and drum-Taps".

Key words: Poetry and Care, Walt Whitman, aesthetic and nursing.

\section{RESUMO}

Para compreender o impacto da poesia e da sociopoética cuidados de Whitman é essencial conhecer o ambiente em que o poeta americano improvisados desenvolveu seu trabalho como enfermeira em um contexto histórico marcado por uma guerra civil. Só desta forma pode compreender a interação entre sua poesia, sua pessoa e seu trabalho como enfermeira. Neste editorial, o autor analisa as obras mais significativas do autor em relação ao seu impacto em sua experiência como cuidador:. "Leaves of Grass" e "Drum-Taps".

Palavras Chave: poesia de cuidado, Walt Whitman, estética e de enfermagem, e sociopoética de enfermagem.

\section{RESUMEN}

Para entender la incidencia de Whitman en la poesía de los cuidados y la sociopoética resulta imprescindible conocer el entorno en el que el poeta americano desarrolló su labor como enfermero improvisado en un contexto histórico marcado por una cruel contienda civil. Sólo de esta forma se puede captar la interacción entre su poesía, su persona y su actividad como enfermero. En esta editorial, el autor analiza las obras más significativas del autor en relación a su incidencia con su experiencia como cuidador.: "Hojas de Hierba" y "Redobles de Tambor". 
Palabras clave: poesía de los cuidados, Walt Whitman, estética y enfermería, sociopoética y enfermería.

\section{INTRODUCCIÓN}

Para entender la incidencia de Whitman en la poesía de los cuidados y la sociopoética resulta imprescindible conocer el entorno en el que el poeta americano desarrolló su labor como enfermero improvisado en un contexto histórico marcado por una cruel contienda civil. Sólo de esta forma se puede captar la interacción entre su poesía, su persona y su actividad como enfermero. En consecuencia, en esta breve editorial nos ocuparemos, en primer lugar, de hacer un recorrido resumido pero significativo de la vida del autor de "Hojas de Hierba” (Reyes, 2011). Posteriormente se analizará parte de su obra poética, aquella que más relación guarda con su actividad como enfermero durante la guerra civil: "Redobles de Tambor", procurando desentrañar los vínculos entre la estética, la poesía y la sociopoética de los cuidados.

Walt Whitman y el contexto en el que de-sarrolló su labor como enfermero (Estados Unidos: 1819-1892)

Al comenzar la Guerra civil norteamerica-na, en 1862, Walt Whitman, ya era conocido por su obra más reputada "Hojas de Hierba". Tenía más de cuarenta años y no se sintió con fuerzas ni ánimo para imitar a sus hermanos menores que se alistaron para luchar contra el enemigo del Sur (Reyes, 2011). Walt Whitman, trabajó como enfermero cuidando heridos $y$ enfermos en diversos hospitales durante una disputa civil donde la crueldad propia de las guerras se acentuaba por el carácter fratricida que conlleva todo enfrentamiento entre distintos sectores de un mismo país. Temeroso por la vida de su hermano George, al que creía herido, Whitman emprendió un largo y penoso viaje hacia Virginia dado que se quedó sin dinero y tuvo que valerse de la generosidad de un antiguo amigo escritor para poder proseguir su periplo. El propio poeta fue consciente desde el principio sobre el hecho de que la tarea de cuidar heridos en los hospitales por los que pasó iba a constituir la enseñanza más transcendental de su vida.

Esta experiencia como enfermero le motivó para escribir un diario "Memoranda $\mathrm{Du}$ ring The War" un diario en el que reflejaría sus experiencias sobre la guerra que le serviría como base experiencial y estética para escribir en 1865 el poemario "Drum Taps" ("Redobles de Tambor"). Pasado el tiempo, en la edición definitiva de su obre cumbre "Hojas de Hierba”, Whitman integró buena parte del material del diario y de "Redobles de Tambor" justificando dicha decisión porque: "la guerra y mi libro son la misma cosa" de donde se deduce que el sufrimiento de los seres humanos y la piedad y solidaridad que le inspiró dicha congoja causó en él un profundo impacto que le llevó a convertirse en enfermero voluntario en una coyuntura tan turbadora y difícil como aquella.

Pero la adversidad a la que se enfrentaba Whitman no se limitaba a la crueldad inherente de la guerra y al sufrimiento de los heridos, sino que, paralelamente, dicha contienda significaba el enfrentamiento de una nación que él había glosado como indisoluble y unida por el amor entre hermanos en "Hojas de Hierba"; los mismos hermanos que durante la guerra se estaban matando en una lucha encarnizada. Ante la mutilación del país se sucedía en un 
proceso tan fatídico como lógico la amputación de sus jóvenes en los campos de batalla; jóvenes a los que él cuidó dándoles el afecto que en aquellos momentos necesitaban, leyéndoles o escribiéndoles las cartas de los seres queridos, haciendo todo tipo de encargos y vigilando sus heridas para prevenir a los médicos sobre su evolución.

\section{Walt Whitman o la estética como teoría del conocimiento de lo sensible y de sí mismo en el universo.}

Walt Whitman nos puede servir de ejemplo para entender las características de la teoría estética que se integra en la ciencia filosófica como teoría del conocimiento vulgar (de lo sensible). El conocimiento estético está separado del racional porque está fundamentado en la individualidad de la sensibilidad humana, pero, empero, las ideas estéticas son necesarias para dotar de representación a las ideas racionales mediante el diseño de una forma estética (sensible). Cuando Gadamer sostiene que es la experiencia del arte, entre todo lo que nos sale al encuentro en la naturaleza y en la historia, aquello que nos comunica de forma inmediata, cercana, familiar, como si todo encuentro con una obra de arte significara un encuentro con nosotros mismos; afirma la universalidad de los sentimientos. Es en este contexto de encuentro con nosotros mismos donde mejor se puede interpretar la obra y la principal motivación poética de Walt Whitman, dado que es en el poema nuclear de Hojas de Hierba, “The song of myself” (Cántico de mi mismo) donde nos revela el propósito fundamental de su poesía: reconocerse, reencontrarse y crecer construyéndose como persona al compás de los versos mediante los que va armando la nave de su poesía. Emerson llegó a describir a Whitman como una concordancia original con el universo a través de una incesante búsqueda del yo. No sólo había descendido y emergido de sí mismo como una experiencia común de sus compatriotas, sino con las ideas y sentimientos de la humanidad en todas las épocas y naciones (Parra, 2014; Reyes, 2011). De hecho, el mismo Whitman, como consecuencia de esta catarsis y búsqueda existencial inherente a su poesía, llega a afirmar que su poemario no es un simple objeto material, un vulgar libro, sino que es la prolongación de su ser. Así, en "So long!" llega a aseverar que quien toca un libro no toca un libro..., toca a un ser humano que ha depositado en ese artefacto una parte esencial y trascendente de su alma. Este proceso de catarsis que implica la búsqueda de lo primordial en uno mismo tiene paralelismos con la pedagogía de la liberación y con la deconstrucción de estereotipos que mantienen la enfermería en un contexto dependiente del tecnicismo cerrado y decadente que sigue obstaculizando su evolución incluso dentro del propio sistema educativo (Freire, 1987; Siles y Solano, 2015,). La catarsis poética puede contribuir en gran medida a la búsqueda existencial de la enfermería en su faceta menos accesoria redescubriendo sus cimientos y reivindicando lo más significativo de su naturaleza ayudando a realizar un proceso de reencuentro con aspectos tan esenciales como el humanismo y la perspectiva holística de los cuidados.

\section{Arte, Cuidados y Poesía}

Es en este contexto de encuentro de experiencia con el arte de los cuidados donde Whitman desarrolla la sensibilidad suficiente como para ver reflejado el rostro de su hermano George en las caras pálidas y ensangrentadas de los soldados a los que cuida. Esta empatía tan característica del ser humano en situaciones de cuidados le ayuda a tomar 
conciencia respecto de la universalidad de los sentimientos (estética) que se generan durante dicho proceso.

Gadamer señala que la estética supera a la hermenéutica, en tanto que ésta constituye un puente para salvar la distancia histórica, humana o cultural entre las personas, mientras que la estética rompe directamente esa separación debido a la universalidad de los sentimientos; el conocimiento estético de los cuidados supera en inmediatez al potencial de comunicación de la hermenéutica (Gadamer, 1996). Para Whitman, la estética constituye la herramienta más eficaz para pulverizar las diferencias entre hermanos, porque todos son sus hermanos cuando su vida depende de sus cuidados, al igual que a la Piedad de Miguel Ángel le duele la muerte de todos los hijos paridos por mujer cuya tragedia se refleja simbólicamente en la agonía y sacrificio de su hijo.

Las ideas estéticas están a medio camino entre el instinto y lo conceptual, entre la sensibilidad y el entendimiento, no producen conocimiento racional, pero si lo regulan dotándolo de forma y de un difuso contenido intuitivo que muchas veces supera en significado e intensidad al conocimiento racional; en consecuencia, los conceptos de cuidado, enfermedad, salud, dolor, muerte, etcétera, están regulados mediante sus correspondientes formas estéticas y la poesía de los cuidados constituye una fuente para su reflexión y estudio, conformando la obra de Whitman, especialmente "Redobles de Tambor" una fuente de gran relevancia para entender la naturaleza humana inmersa en la marea de contradicciones en la que se mece (Siles y Solano, 2015). En el diario que Whitman escribe durante los días de la guerra civil, se constata el horror que el hombre es capaz de generar contra sí mismo dejando caer su dignidad por un precipicio sin fondo en aras de propósitos tan insondables como falaces:

"En el exterior, al pie de un árbol, a unos veinte metros de la mansión, veo un montón de pies amputados, piernas, brazos, manos, etc., todo un cargamento para un carro de un solo caballo. Cerca yacen varios cadáveres, cada uno cubierto con su manta de lana marón. En el patio, en dirección al río, tumbas frescas, la mayoría de oficiales, sus nombres en tiras de barril o en trozos de tablas, clavadas en el barro" (Whitman, 2005, Parra, 2014).

La estética de los cuidados a nivel individual resulta extremadamente relevante, pues el profesional de enfermería puede emplear la poesía de los cuidados (entendida como "expresión artística de los sentimientos involucrados en los cuidados") como una herramienta que le facilita la reflexión sobre los sentimientos que confluyen en su ser durante su interacción con las personas que cuida. Le puede, además, servir de catarsis para desarrollar procesos de "purificación" que le faciliten la concienciación del humanismo inherente a la enfermería. Esto es, tomar conciencia sobre una contradicción tan radical como que cuanto más evidente es un hecho, tanto más intangible aparece: Evidente es que la "materia prima" de la enfermera es la más delicada de todas las artes porque es única, frágil, original e irrepetible: el ser humano. La enfermera realiza su obra -el cuidado- sobre esa materia prima que es la persona (ser humano) y no existe ni en la pintura (lienzo y pinturas), ni en la escultura (mármol, piedra), ni en ninguna otra arte considerada "mayor" material prima alguna que supere al ser humano en complejidad y potencial de interacción con el "artistaenfermero". Pero ese hecho incontrovertible es tan obvio que resulta prácticamente invisible a la apreciación social. 
Es quizás a seres muy especiales, como Whitman, a los que les resulta extremadamente sencillo este proceso de concienciación respecto la auténtica naturaleza del cuidado, debido, sobre todo, a su gran sensibilidad y a su capacidad de reflexión sobre sus sentimientos (reflexión estética) (Siles y Solano, 2015).

En este contexto donde tanto la poesía de los cuidados como la sociopoética son posibles merced la nitidez con la que se percibe el sujeto de los cuidados (materia prima original), es donde hay que interpretar la iniciativa de Gauthier (1999) quien desarrolló un neologismo "confectos" para intentar sintetizar el mundo conceptual y el afectivo (tan vinculado al de los sentimientos). Sin duda Whitman actúa como enfermero impulsado por sentimientos ligados a ideas y creencias, es decir, "confectos" porque también el transcurso del proceso de interacción entre el cuidador Whitman y los soldados cuidados, se van a ver involucrados una serie de afectos que los revisten de subjetividad y humanismo.

\section{El intersubjetivismo o la sociopoética como puente entre el arte y la ciencia en Walt Whitman.}

La sociopoética constituye un acercamiento entre la ciencia y el arte y básicamente puede emplearse como un método de investigación que estudia las formas de expresión que, a través de los sentidos, provocan en las personas situaciones de intersubjetividad en procesos de la vida cotidiana, enseñanza aprendizaje, cuidados, etc. (Chocarro, 2013; Cody, 1995, Siles, 2014). La sociopoética de los cuidados se puede definir como el estudio de la estética de los cuidados desde la intersubjetividad (Santos, 2005); o dicho de otra forma, de los sentimientos suscitados o que emergen en las personas durante el proceso de interacción enfermera - paciente. Por tanto, la sociopoética implica interpretación (estaríamos dentro del paradigma hermenéutico), pero es una interpretación coral que no se limita a la subjetividad inherente a los sentimientos derivados de la interacción entre un paciente y un enfermero de forma aislada; sino que se trata, más bien, de valorar la intersubjetividad mediante el análisis del conjunto de sentimientos emergentes que afectan a un colectivo compuesto por una serie de intersubjetividades (vivencias subjetivas de situaciones de cuidados similares) (Siles y Solano,2015).

Whitman piensa que lo que siente cuando cuida a los soldados no es algo estrictamente individual, sino que forma parte de algo más genérico y esencial: es un sentimiento común y universal que es compartido por todos los seres humanos en tanto y en cuanto supone una forma primaria y pre-racional de empatizar. Whitman piensa que el ser humano puede compartir sentimientos de la misma naturaleza e intensidad frente a experiencias comunes: cuidar heridos, por ejemplo, puede interpretarse como la consecuencia de una catarsis producida por sentimientos que, ante la enormidad pavorosa del dolor ajeno, impelen de una forma pre-racional a la piedad, el altruismo, la solidaridad o a una suerte de amor que puede anidar, a poco que se active el mecanismo estético, en toda alma que habita el universo. Esta mezcolanza entre la inmensidad del dolor y la reacción solidaria es lo que algunos autores consideran como momentos sublimes de los cuidados de los que tantos ejemplos nos han dejado artistas de todos los tiempos (Siles y Solano, 2015). Esta sensación universal de sentimiento comparitdo la refleja Whitman en muchos de sus poemas, pero especialmente en "Poets to Come": 


\section{Poetas del futuro/ Poets to come}

¡Poetas del futuro! ¡Oradores, cantantes, músicos futuros!/No es el presente el que me justifica ni el que asegura que/ yo esté un día con vosotros,/ Son ustedes, la raza nueva y autóctona, atlética, continental,/ la mayor de cuantas son conocidas;/¡Arriba! Porque ustedes me justificarán./ Yo no hago más que escribir una o dos palabras para el futuro,/ Sólo me adelanto un instante, para retornar luego a las sombras./ Soy un hombre que,/ vagabundo, siempre sin hacer alto,/ echo sobre ustedes una mirada al azar, y sigo,/ Dejándoles la encomienda de probarla y definirla,/ Aguardando de vosotros la realizacíón de la magna obra.

Para Parra (2014) "Redobles de Tambor" constituye un espejo donde se refleja la evolución de Whitman durante la guerra: de una posición inicial de admiración ante la gallardía de los jóvenes defensores de la democracia, el ánimo del poeta desemboca en una actitud de pavoroso desconcierto ante la horrorosa realidad de la guerra. En los poemas postreros del poemario se evidencia el discurrir de esta trayectoria:

Un espectáculo en el gris y tenue amanecer del campamento,/Saliendo de mi tienda desvelado tan temprano,/Deambulando lentamente por la senda y sintiendo el aire fresco de un camino cercano./El del hospital de campaña,/ Tres formas que distingo en camillas recostados, echados hacia fuera/Tirados y desatendidos,/Sobre cada uno la manta de lana marrón extendida/Cobijándolos,/La gris y pesada manta plegada sobre sus cuerpos, cubriéndolos a todos./. . .Entonces vislumbro entre ellos,/ el tercero, un rostro ni de niño ni de viejo, muy tranquilo, /De marfil de color amarillo-blanco hermoso;/De un hombre joven que creo conocer, sí creo que esta es el rostro,/ La cara del mismo Cristo,/ Muerto y divino y hermano de todos, y aquí yace de nuevo.

El desastre y el terror engrandecen la universalidad intersubjetiva de Whitman, pues es precisamente en los momentos de mayor penumbra, como en el asesinato del presidente Abraham Lincoln, cuando Whitman elabora dos de sus mejores poemas de guerra y desconsuelo que suscitan la piedad por la vía de la catarsis colectiva (Parra, 2014). Así se puede comprobar en el poema titulado "La última vez que florecieron las lilas en el jardín":

"Ataúd que pasas por caminos y calles, / de día y de noche con la nube inmensa que ensombrece la tierra, / con la pompa de las banderas festoneadas, con las ciudades enlutadas / (...) / con el tañido perpetuo de las campanas que doblan, / aquí, ataúd que pasas lentamente, / te doy mi rama de lilas".

Otro ejemplo de esta postrera grandeza poética cultivada en los caladeros del magnicidio y el terror lo constituye el que tal vez sea su poema más universal: ¡Oh Capitán! ¡Mi Capitán!:

“¡Oh Capitán!, ¡mi Capitán!,/ ha terminado nuestro medroso viaje, / el navío ha salvado todos los escollos,/ hemos ganado el premio que buscábamos, / el puerto está cerca, oigo las campanas,/ el pueblo entero está exultante".

Recapitulando sobre todo lo expuesto, la vida y la poesía de Whitman constituyen una fuente pertinente para el estudio de la estética y la poesía de los cuidados. Obras como su "Diario de la guerra Civil" y "Redobles de Tambor", ofrecen los datos adecuados para desentrañar los vínculos entre la creatividad, la experiencia estética individual en cuidados y la expresión resultante mediante la poesía, la 
cual nos abre la puerta al estudio intersubjetivo del fenómeno mediante el desarrollo de la sociopoética enfermera.

\section{REFERENCIAS}

- Chocarro, L. (2013). La intersubjetividad y su relevancia en los cuidados de Enfermería. Index de Enfermería. Index Enferm (edición digital), 22(4). Disponible en http:// www.index-f.com/index-enfermeria/ v22n4/9244.php

- Cody, W. (1995). Intersubjectivity: Nursing's contribution to the explication of its postmodern meaning. Nursing Science Quarterly, 8(2), 52-54.

- Folson, E. \& Price, K.M. (1999) Walt Whitman. Disponible en: http://www.whitmanarchive.org/archive1/biography/biography.htm

- Freire, P. (1987). Pedagogía del Oprimido. Río de Janeiro: Paz e Terra.

- Parra, D. (2014). Redobles de tambor, de Walt Whitman. Cincuentopía. Disponible en: http://cincuentopia.com/ redobles-de-tambor-de-walt-whitman/

- Reyes, S.L.. (2011). Walt Whitman. La revolución americana en "Hojas de Hierba" Aparte Magazine. Literatura, 3. Disponible en: http://www.apartemagazine. es/2011/06/walt-whitman-la-revolucion-americana-enhojas-de-hierba/

- Santos, I. (2005). Sociopoética: un puente para "cuidar - investigar" en enfermería Index Enferm, 14 (50), 35-37. Disponible en: http://dx.doi.org/10.4321/S113212962005000200007

- Santos, I., Gauthier, J. (1999). Enfermagem-Análise Institucional e Sociopoética. Rio de Janeiro: Ed. Anna Nery / UFRJ.

- Siles, J. (2014) El humanismo en enfermería a través de la sociopoética y la antropoética. Cultura de los Cuidados, 18(38), 9-13 Disponible en: http://dx.doi.org/10.7184/ cuid.2014.38.01>

- Siles, J. y Solano, C. (2011). Cultural history and aesthetics of nursing care. Rev. Latino-Am. Enfermagem, 5, 1096-1105.

- Siles, J. \& Solano, C. (2015). Sublimity and beauty A view from nursing aesthetics. Nursing Ethics. Nurs Ethics, 28, 1-13. Disponible en: doi: 10.1177/0969733014558966

- Whitman, W. (2005) Redobles de tambor. Drum taps. (Diarios de Guerra. "Memoranda during the war"). Madrid: Hiperión. 


\title{
Fenomenología
}

\section{El concepto del Baby Café como red internacional de apoyo a la lactancia materna}

\section{The Baby Café concept as an international network of support to} breastfeeding

\section{$\mathrm{O}$ conceito do Baby Café como rede internacional de apoio à ama- mentação materna}

\author{
Isabel Baño Piñero ${ }^{1}$, César Carrillo García ${ }^{2}$, Uma Thambidurai ${ }^{3}$, María Emilia Martínez Roche ${ }^{4}$ \\ ${ }^{1}$ Matrona, Máster en Antropología y Doctoranda por la Universidad de Murcia
}

${ }^{2}$ Doctor en Enfermería. Técnico de Formación Sanitaria Especializada. Dirección General de Recursos Humanos del Servicio Murciano de Salud. Universidad de Murcia.

${ }^{3}$ Mother and Child Pte Ltd (Singapur). Matrona, IBCLC $y$ Directora de Mother and Child (Singapur).

${ }^{4}$ Profesora titular de Universidad y Coordinadora de la Unidad Docente de Matronas. Facultad de Enfermería. Universidad de Murcia y Servicio Murciano de Salud

Cómo citar este relato en edición digital: Baño Piñero, I., Carrillo García, C., Thambidurai, U. y Martínez Roche, Ma E. (2015).

El concepto del Baby Café como red internacional de apoyo a la lactancia materna. Cultura de

los Cuidados (Edición digital) 19, 43. Disponible en:< http://dx.doi.org/10.14198/cuid.2015.43.03>

Correspondencia: Facultad de Enfermería. Campus Universitario de Espinardo. Edificio 23. 30100 Murcia.

Correo electronico: isabel.bano1@um.es

Recibido: 11/03//2015; Aceptado: 10/08/2015

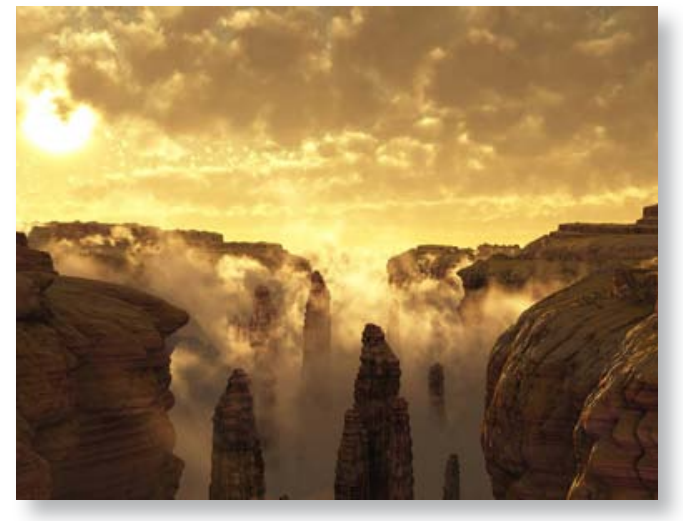

ABSTRACT

The general objective of this work is to reflect on the phenomenon of The Baby Café as a novel and convenient concept in a world of promotion, protection and support of breastfeeding worldwide.

The Baby Café is an initiative to support breastfeeding that coordinates an international network of centers that combines formal support from health professionals who specialize in lactation with informal support groups or networks of breastfeeding.

With the ultimate goal of the promotion, protection and support of breastfeeding, the introduction of The Baby Café initiative encourages more studies of such nature to be conducted, eventually demonstrating the true impact of such initiatives on society; we have developed, through the theoretical framework and a field diary, a qualitative study, which has allowed us to explore the phenomenon of the Baby Cafe in the 10th district of Singapore, during the month of March 2015.

Keywords: Baby Café, Support, International Initiative, Breastfeeding. 


\section{RESUMO}

O objetivo geral deste trabalho consiste em refletir sobre o fenómeno do bebe café como novo e conveniente recurso dentro do mundo da promoção, proteção e apoio a amamentação materna a nível internacional.

O bebe café é uma iniciativa de apoio a amamentação materna que coordena uma rede internacional de centros nos quais se combina o apoio formal proveniente dos profissionais sanitários especializados em amamentação, e no apoio informal próprio dos grupos o redes de apoio a amamentação.

Com o fim de promover, proteger e apoiar a amamentação materna aprofundando a iniciativa do bebe café e incentivando a que se realizem mais estudos que avaliem o verdadeiro impacto que este tipo de iniciativa tem sobre a sociedade; temos desenvolvido, mediante o estado da questão e um diário de campo, um estudo qualitativo, que nos permitiu explorar o fenómeno do bebe café no distrito de Singapura durante o mês de Março 2015.

Palavras chave: Baby Café, Apoio, Iniciativa Internacional, Amamentação Materna.

\section{RESUMEN}

El objetivo general de este trabajo consiste, en reflexionar sobre el fenómeno del Baby Café como recurso novedoso y conveniente dentro del mundo de la promoción, protección y apoyo a la lactancia materna a nivel internacional.

El Baby Café es una iniciativa de apoyo a la lactancia materna, que coordina una red internacional de centros en los que se combina el apoyo formal proveniente de los profesionales sanitarios especializados en lactancia y el apoyo informal propio de los grupos o redes de apoyo a la lactancia.

Con el fin último de promover proteger y apoyar a la lactancia materna, adentrándo- nos en la iniciativa del Baby Café y animando a que se realicen más estudios que avalen el verdadero impacto que éste tipo de iniciativas tienen sobre la sociedad; hemos desarrollado, mediante el estado de la cuestión y un diario de campo, un estudio cualitativo, que nos ha permitido explorar el fenómeno del Baby Café en el distrito 10 de Singapur, durante el mes de marzo de 2015.

Palabras clave: Baby Café, Apoyo, Iniciativa Internacional, Lactancia Materna.

\section{INTRODUCCIÓN}

El Baby Café es una iniciativa de apoyo a la lactancia materna, que coordina una red internacional de centros que brindan apoyo formal e informal a las madres y familias de los lactantes. Es un sistema novedoso ya que combina el apoyo formal proveniente de los profesionales sanitarios especializados en lactancia y el apoyo informal propio de los grupos o redes de apoyo a la lactancia (The Baby Café Charitable Trust, 2015).

El objetivo general de este trabajo consiste, en reflexionar sobre el fenómeno del Baby Café como recurso novedoso y conveniente dentro del mundo de la promoción, protección y apoyo a la lactancia materna a nivel internacional. Hablamos de fenómeno, ya que consideramos que la iniciativa del Baby Café se debe estudiar bajo el contexto de la fenomenología, entendiendo por ésta, como el estudio del fenómeno en sí mismo (Siles \& Solano, 2007) o dicho de otro modo, el estudio de las cosas tal y como se manifiestan y se muestran de manera empírica e intuitiva. Es por ello que hemos utilizado como principal instrumento en la investigación, el diario de campo desarrollado en el Baby Café de Singapur.

Para completar la reflexión sobre el fenó- 
meno del Baby Café, nos planteamos como objetivos específicos del estudio, en primer lugar:

- Explorar el concepto de la promoción, protección y apoyo a la lactancia materna, como objetivo internacional de salud; reflexionando sobre la efectividad de la combinación del apoyo formal e informal, como método efectivo para conseguir un apoyo eficaz, cercano y de calidad para las familias de los lactantes en todo el mundo.

- Profundizar en el fenómeno del Baby Café como iniciativa novedosa y modelo de apoyo formal e informal a la lactancia a nivel internacional, desarrollando su evolución desde su nacimiento, hasta nuestros días.

- Y por último, descubrir las percepciones, necesidades y experiencias de las usuarias del Baby Café de Singapur, por medio de un diario de campo.

Es por ello, que comienza nuestro estudio con el estado de la cuestión, en el que se abordan los cuatro primeros objetivos específicos planteados anteriormente; seguidamente desarrollaremos, en el apartado de material y método, el trabajo de campo desarrollado en el Baby Café de Singapur, completando de tal modo los cinco objetivos específicos del estudio.

\section{ESTADO DE LA CUESTIÓN}

Promoción, protección y apoyo a la lactancia materna como objetivo internacional de salud

La Organización Mundial de la Salud (OMS), afirma que la lactancia materna reduce la mortalidad infantil y tiene beneficios sanitarios que llegan hasta la edad adulta; estos beneficios no sólo son para el niño, también lo son para la madre, la comunidad y el medio ambiente en general. Para toda la población, se recomienda la lactancia materna exclusiva durante los seis primeros meses de vida y a partir de entonces, su refuerzo con alimentos complementarios, al menos hasta los dos años de edad del niño (OMS, 2015). Pero a pesar de conocer estos beneficios, encontramos que el abandono precoz y los bajos índices de lactancia materna suponen un problema común a nivel internacional (Baño Piñero, Canteras Jordana, Carrillo García, López Araez \& Martínez Roche, 2015). García Méndez (2010), afirma que la lactancia materna es uno de los fenómenos naturales más influenciados por la cultura (proceso bio-cultural). Tal vez por esta razón, podamos entender que existan grandes variaciones en los porcentajes de lactancia materna a lo largo de la historia y en distintas poblaciones dentro del mismo momento temporal.

Existe evidencia científica a cerca de los factores protectores y desfavorecedores de la lactancia materna, y aunque éstos difieran de un autor a otro, la mayoría coincide en que los profesionales sanitarios juegan un papel fundamental a la hora de apoyar, promocionar $y$ proteger la lactancia materna. Así mismo, establecer medidas de apoyo a la lactancia en los servicios en donde se trabaja con lactantes y técnicas de ayuda proporcionado por personal cualificado y consejeras de lactancia resulta de gran ayuda para mejorar los porcentajes de lactancia materna (Hernández Aguilar \& Aguayo Maldonado, 2005).

En el documento "Pruebas Científicas de los Diez Pasos hacia una Feliz Lactancia Natural", publicado en 1998 por la OMS, se identifican trece estudios controlados aleatorios o comparativos en los que se comprueba la efectividad del apoyo tras el alta sobre la lactancia materna. Crear un ambiente seguro y 
amigable, que brinde apoyo a las familias tras el post-parto es fundamental para proteger $y$ promover la lactancia materna. Sin embargo, no hay suficientes estudios que demuestren el potencial de los grupos de madres y de las promotoras comunitarias.

Puede que los grupos de apoyo informales sean más capaces que los servicios de salud formales de ofrecer la ayuda personal y frecuente que las madres necesitan para aumentar su confianza y superar las dificultades. Posiblemente, una combinación de apoyo día a día en la comunidad, respaldado por una atención más especializada en los servicios de salud cuando sea necesario, podría ser más eficaz que cualquiera de ellos por separado. (pag.84)

Se comprueba con esto que la idea de combinar el apoyo informal, como pueden ser los grupos de apoyo a la lactancia, con el apoyo formal proveniente de los profesionales sanitarios especializados en lactancia como matronas, consultores de lactancia, pediatras o médicos de familia, puede ser una actividad novedosa, eficaz y efectiva en términos de promoción y protección de la lactancia materna, tal y como resumimos en la gráfica I.
Tal vez, en base a lo anteriormente citado, la OMS, el Fondo Internacional de Emergencia de las Naciones Unidas para la Infancia (UNICEF) y la Iniciativa para la Humanización de la Asistencia al Nacimiento y la Lactancia (IHAN), publican dentro de los "Siete Pasos para una Feliz Lactancia Natural”, en su Manual para la acreditación de Centros de Salud IHAN (2014):

- Paso 2: Capacitar a los trabajadores para que puedan poner en práctica la normativa de lactancia.

- Paso 6: Proporcionar una atmósfera de acogida a las madres y lactantes.

- Paso 7: Disponer de un taller de lactancia y fomentar la formación y el contacto con grupos y recursos de apoyo a la lactancia en la comunidad.

Como requisitos imprescindibles para obtener dicho galardón. Comprobando una vez más la importancia de combinar el apoyo formal e informal).

El apoyo formal, entendiendo por éste, como cualquier profesional sanitario capaz de detectar, derivar o tratar adecuadamente, cualquier problema relacionado con la lactancia, proporciona una fuente de información

\section{Gráfico I}

Beneficios de la combinación del apoyo formal e informal.

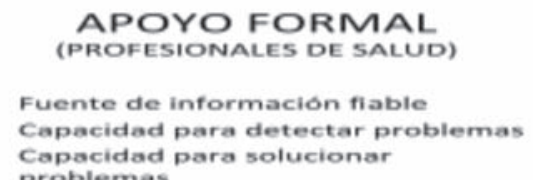

APOYO FORMAL

(PROFESIONALES DE SALUD)

Capacidad para solucionar problemas
APOYO INFORMAL

(GRUPOS DE APOYO)

Accesibilidad

Posibilidad de involucrar a la familia

Ambiente seguro, amigable, distendido, flexible y cercano.

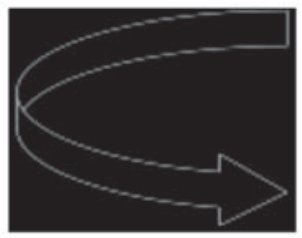

APOYO EFICAZ

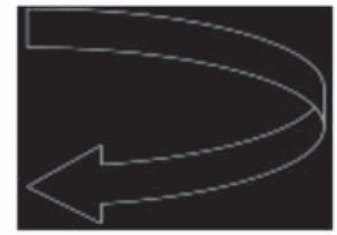

Fuente: Gráfico de elaboración propia 
fiable a las familias de niños lactantes, necesaria para superar las dificultades que puedas aparecer durante esa etapa. En cambio, encontramos en muchas ocasiones, que a los profesionales de salud, les es difícil brindar un seguimiento adecuado, proporcionando servicios no siempre accesibles o cercanos; es por esto que las madres pueden ser reacias a buscar ayuda en el sistema formal de salud cuando aparecen problemas o dificultades con la lactancia (OMS, 1998). Las redes de apoyo informales, como los grupos y recursos de apoyo a la lactancia en la comunidad, aportan accesibilidad, un ambiente distendido, seguro, flexible y amigable, que hacen que las madres y familias de lactantes se sientan más cómodas a la hora de consultar sus problemas sobre lactancia; también permiten involucrar a la familia inmediata de la madre, como los compañeros, abuelas o amigas, que tanta influencia tienen sobre la decisión de lactar (Álvarez, 2013; López, Molina, Martínez, Frutos y Molina, 2012). Numerosos estudios (Hoddinott \& Pill,1999; Lavender, McFadden \& Baker, 2006; McFadden \& Tooler, 2006; Scott \& Mostyn, 2003) concluyen que las experiencias y percepciones derivadas del apoyo informal, tales como grupos de apoyo a la lactancia o amigos y familiares, tienen una fuerte influencia en la intención de lactar y en la permanencia de ésta (NCT, 2014).

Además de los factores protectores de la lactancia materna que acabamos de comentar, no podemos pasar por alto la importancia de la empatía dentro del apoyo formal e informal como requisito imprescindible para la consejería en lactancia materna (OMS y UNICEF, 1993; Simões, Soares, Duarte, Bracarense y Cortes, 2015). Nogales (2012) define la empatía como "la vivencia de la experiencias de sujetos ajenos, la vivencia de experiencias de otros. Vivencia de experiencias de otros que abren en uno, horizontes distintos al que es propiamente personal", y pone de manifiesto en su estudio, la necesidad e importancia de su aplicación para la enfermería en el contexto familiar.

Parece que en base a lo anteriormente expuesto, queda claro que la promoción, protección y apoyo a la lactancia materna se compone de varios factores que en conjunto resultan mucho más efectivos que por separado. La iniciativa del Baby Café es un claro ejemplo de combinación de apoyo a la lactancia formal e informal; pero para poder entender éste fenómeno, es necesario conocer más a fondo el concepto del Baby Café, por esta razón pasamos a desarrollamos a continuación su concepto, objetivos y evolución:

\section{El Baby Café}

El Baby Café es un servicio internacional de apoyo a la lactancia que combina los beneficios de un ambiente distendido e informal propio de un grupo de apoyo a la lactancia, pero a la vez, liderado por profesionales en lactancia, capaces de ayudar de manera profesional, accesible y eficaz a las madres que lo necesiten.

Tal y como aparece en el Informe Anual del Baby Café 2005-2006 (The Baby Café Charitable Trust, 2006), los objetivos generales que pretende la iniciativa son:

1) Promover la salud física y psicológica de las madres y los niños a través de la capacitación y educación en las técnicas sobre lactancia materna.

2) Fomentar la educación acerca de los beneficios para la salud de la lactancia materna tanto inmediatos como a largo plazo en la sociedad en general y sobre todo en aquellas personas interesadas en el cuidado de los niños. 
3) Mejorar la formación del personal voluntario que trabaja en esta área mediante la provisión de capacitación pertinente.

Y a nivel específico (Baby Café Local, 2013):

- Proveer un modelo de apoyo social a la lactancia en un ambiente cómodo y cercano.

- Proporcionar un servicio universal, accesible a todos los niveles de la sociedad, en especial a los grupos más desfavorecidos o marginales.

- Procurar un servicio profesional capaz de ofrecer información fiable y dar apoyo a la lactancia, de manera accesible y cercana. Siendo capaz de detectar problemas relacionados con la lactancia y tratarlos o derivarlos cuando sea necesario.

- Respetar y mantener el estándar de calidad propuestos por la organización.

- Ayudar a que más mujeres lacten, contribuyendo a que superen sus problemas de lactancia de manera oportuna y eficaz. Favoreciendo la lactancia materna para que ésta sea una experiencia positiva para todas ellas y apoyándoles para que sean capaces de lactar hasta donde se lo propongan.

En líneas generales, se persigue que las mujeres tengan una experiencia positiva con su lactancia, fomentando la cultura de la lactancia materna, y aumentando con ello la incidencia y permanencia de ésta.

\section{Nacimiento y evolución del Baby Café}

Por los motivos anteriormente mencionados y con la intención de implantar como parte del plan de UNICEF para la acreditación de la IHAN, se crea en 2000 por primera vez el concepto del Baby Café por dos consultoras internacionales de lactancia, Catherine Pardoe y Juli Williams (The Baby Café Charitable Trust, 2015). El primer Baby Café se fundó en West Sussex (Inglaterra), como parte del Departamento de Iniciativa de Alimentación Infantil Saludable del Sistema Nacional Inglés de Salud (NHS Trust). Pronto, éste modelo fue creciendo en popularidad llegando a incluirse dentro del Protocolo de Buenas Prácticas e Innovación en Lactancia Materna del NHS (Department of Health, 2004).

En diferentes partes de Inglaterra se empezó a solicitar la creación de dicho modelo como parte de los servicios de promoción a la lactancia materna del Sistema Nacional de Salud. Fue entonces cuando se desarrolló una guía donde se especificaba paso a paso cómo solicitar, crear y evaluar un centro Baby Café (Baby Café, 2012).

Gracias a la gran aceptación que esta iniciativa obtuvo, se decidió internacionalizar el concepto del Baby Café, registrando la marca y el logo de Baby Café. De este modo, cualquier centro que quisiese acreditarse como tal, tendría que pagar una cuota anual que le permitiese acceder a la estructura nacional de apoyo, así como asegurar el asesoramiento y la supervisión del centro garantizando cumplir con los requisitos de calidad requeridos por la organización. Las 12 normas de calidad exigidas por la organización son (Baby Café Local, 2013):

1. Respetar la marca “The Baby Café”. Los centros acreditados deberán usar el mismo nombre y logo registrado por la organización.

2. Personal cualificado. La persona responsable de solicitar la acreditación deberá poseer como mínimo una titulación sanitaria equivalente al Grupo 6 (visitador sanitario, enfermera, matrona o consultor internacional de lactancia; todos ellos con una experiencia mínima requerida).

3. Trabajo multidisciplinar. Los centros Baby Café deberán involucrar y contar con 
la colaboración de distintos profesionales de salud así como con voluntarios y grupos de apoyo a la lactancia.

4. Ambiente acogedor. Los centros acreditados proporcionarán un ambiente seguro, cálido y hospitalario en el que se ofrecerá bebida y comida para atraer a las mujeres regularmente (apoyo informal). Igualmente se asegurará espacio y tiempo suficiente para atender madres con problemas en lactancia (apoyo formal).

5. Modelo de apoyo social. El modelo de Baby Café asegurará un apoyo formal, por parte de los profesionales de salud o consultores de lactancia, que permitirá identificar madres y niños con necesidades especiales tanto físicas como mentales, respondiendo correctamente a sus requerimientos bio-psico-sociales. Así mismo se asegurará un trato amable y cercano a aquellas que tengan problemas sociales o emocionales.

6. Promover y apoyar la lactancia. El Baby Café acogerá a mujeres en periodo prenatal y postnatal, animando a que éstas continúen lactando exclusivamente más de 6-8 semanas, usando el modelo de refuerzo positivo. La mayoría de casos de destete no son planificados, el $80 \%$ de las mujeres que dejan de lactar durante las primeras seis semanas de vida del bebé lo hicieron antes de lo planeado y más de tres cuartas partes de las madres hubieran preferido seguir lactando durante más tiempo (NCT, 2014).

7. Atención a toda la comunidad. Cualquier mujer, provenga del sector de la comunidad que provenga, deberá de sentirse motivada para acceder al centro, recibiendo siempre información y apoyo apropiado.

8. Servicio accesible. El acceso al centro debe de garantizar unos mínimos. Se deben de cumplir al menos tres de los seis requisitos que se plantean a continuación: un lugar para aparcar los carritos, acceso al centro por medio de autobús, cerca de otros servicios de salud o tiendas, buena ubicación en la que haya acceso al un parking asequible por las usuarias, capacidad por parte de los trabajadores para hablar varios idiomas o instrumentos que faciliten la comunicación con mujeres que tengan limitaciones con el idioma.

9. Capacidad para derivar correctamente. Los profesionales que trabajen en el Baby Café deberán ser capaces de identificar correctamente los problemas de lactancia y ayudar a solventarlos o derivarlos a otro especialista si lo requieren.

10. Fuente de información de alta calidad. Los centros contarán con información sobre lactancia fiable y de calidad, de fácil comprensión y accesible para toda la familia. Tales como posters, folletos, o soportes audiovisuales. Se proporcionará también información sobre otros servicios de apoyo a la lactancia.

11. Revisiones periódicas y de mejora. La organización del Baby Café se reúne periódicamente para hacer revisiones sobre sus servicios, reflexionar sobre el trabajo realizado, abordar propuestas de mejora y planes de actuación.

12. Proporcionar datos fiables. Cada 31 de Enero se recogen y analizan todos los datos solicitados para cada centro y éstos se estudian junto con el Sistema Inglés de Estadística. Así mismo, se publica un trabajo anual en el que se exponen y analizan dichos datos.

En 2005 la iniciativa del Baby Café se convierte en "The Baby Café Charitable Trust”, consiguiendo así una estructura más estable y sólida. Un año más tarde se publica el Manual del Baby Café, en el que se proporciona información detallada sobre cómo desarrollar un Centro Baby Café con éxito y se pone de ma- 
nifiesto la importancia de controlar el cumplimiento de las doce normas anteriormente mencionadas y asegurar la calidad mínima exigida para cada centro. El objetivo principal de este control es asegurar un apoyo a la lactancia continuo, accesible y de calidad para toda la sociedad, garantizando así el número creciente de centros y madres que acuden a éstos (The Baby Café Charitable Trust, 2015). Finalmente en 2010 "The Baby Café Charitable Trust" se fusiona con el NCT (National Childbirth Trust), la mayor organización inglesa sin ánimo de lucro que da apoyo a las familias en el periodo prenatal y postnatal (NCT, 2014), permaneciendo esta unión hasta día de hoy.

El desarrollo del concepto del Baby Café, como iniciativa novedosa de apoyo formal e informal a la lactancia materna, ha tenido un crecimiento exponencial como se puede comprobar en la Tabla I. El primer centro se abrió en el 2000, y en 2013 ya habían un total de 155 centros acreditados en todo el mundo; pero esta cifra tan solo representa los centros que mantienen la acreditación a esa fecha, en cambio, si contamos los 165 centros que no han podido mantener la acreditación o los que han cerrado a lo largo de esos años, nos encontraríamos con una cifra de 320 Baby Cafés abiertos entre el 2000 y 2013 a nivel internacional. Inicialmente el crecimiento de esta iniciativa fue principalmente por Reino Unido, pero rápidamente empezó a desarrollarse por todo el mundo. A 31 de diciembre de 2013 habían 108 Baby Cafés en Inglaterra, 41 en Estados Unidos, 4 en México, 1 en Nueva Zelanda y 1 en Singapur (Baby Café Local, 2013). La influencia de los Baby Cafés es significativa, o por lo menos abarca a un número importante de mujeres. Se calcula que solo en los Baby Cafés de Inglaterra durante el año 2013 pasaron más de diez mil mujeres de las cuales, más de una cuarta parte acudieron al centro seis veces o más (Baby Café Local, 2013), si esto lo aplicamos al resto de centros y a lo largo de los años que ésta iniciativa lleva funcionando, las cifras serían considerables.

\section{MATERIAL Y MÉTODO}

Para dar respuesta a los objetivos planteados en el estudio, se ha abordado una meto-

Tabla I

Evolución del número total de Baby Cafés de 2001 a 2013.

(Baby Café Local, 2013; The Baby Café Charitable Trust, 2006)

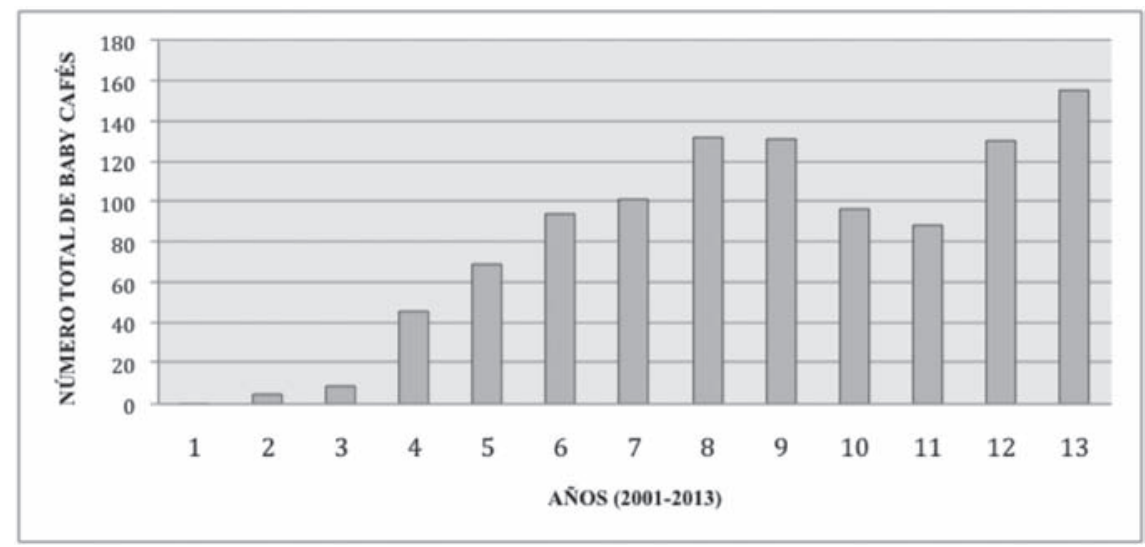

Tabla de elaboración propia a partir de los documentos anteriormente mencionados 
dología cualitativa, que como la define Taylor y Bogdan (1987), se trata de una investigación que produce datos descriptivos: las propias palabras de las personas, habladas o escritas y la conducta observable, permiten profundizar en la teoría fenomenológica de manera intuitiva y en base a la experiencia; permitiendo reflexionar sobre las acciones realizadas en una determinada situación. El Baby Café de Singapur ha sido el principal fenómeno a explorar en este estudio, siendo el diario de campo el instrumento utilizado para poder llevarlo a cabo.

El estudio se ha desarrollado en el distrito 10 de Singapur o distrito Central, más concretamente, en el único centro acreditado como Baby Café de Singapur. Las participantes del estudio han sido las usuarias del Baby Café de Singapur, que han acudido al centro con sus bebés durante el mes de marzo de 2015 y que habiendo sido previamente informadas del proyecto han dado su consentimiento para poder realizarlo. La investigación se ha elaborado bajo el firme compromiso de respetar tanto las normas éticas que rigen los estudios científicos, como el anonimato de los participantes de este estudio, siguiendo la Ley Orgánica de Protección de Datos de Carácter Personal.

Dentro de las limitaciones del estudio hay que tener en cuenta que al haber informado a las usuarias sobre el proyecto de estudio y habiendo pedido previamente su consentimiento para éste, puede que la técnica de observación haya ejercido una presión que haya disminuido o bloqueado la espontaneidad en algunas participantes, pero como afirman Taylor y Bogdan (1987), la investigación cualitativa es sensible a los posibles efectos debido a la presencia del investigador, pero a su vez es necesaria para comprender a las personas dentro de su propio marco de referencia. Es por ello, que teniendo en cuenta la naturaleza de la investigación cualitativa, consideramos adecuada la técnica.

\section{Experiencia en el Baby Café de Singapur: diario de campo}

El diario de campo se ha desarrollado en cuatro sesiones de observación, de las cuales, tres han sido observaciones relacionadas con el contexto y la población a estudiar y una última, en las que hemos intervenido como profesionales.

\section{DESCRIPCIÓN}

Observación 1: Contexto de ocurrencia (2 de marzo de 2015).

Objetivo: Describir el contexto en el que se desarrolla el Baby Café de Singapur.

Anotaciones: Dentro del un centro comercial, en la tercera planta, hay un centro de atención prenatal y postnatal en el que trabajan diferentes profesionales relacionadas con el embarazo y crianza. Así podemos encontrar matronas, enfermeras, visitadoras sanitarias (health visitor), consultoras internacionales de lactancia o instructoras de yoga y pilates pre y post natal. Algunas de las actividades que se ofertan en el centro son, educación prenatal, clases de primeros auxilios, introducción a los sólidos, incorporación laboral y lactancia materna, consulta del niño sano, consulta de lactancia, consulta de la matrona, visita domiciliaria, yoga, pilates, masaje del bebé y el Baby Café entre otras. El Baby Café se organiza semanalmente, los lunes de 2 a 4 de la tarde. Se invita a todas las mamás o futuras mamás, así como a los familiares, que acuden al centro por otros motivos y también se anuncia en la página web del centro. La sala donde se desarrolla la actividad es bastante 
amplia y luminosa, con cómodos sillones con cojines a todo alrededor. También hay dos soportes cambiadores para los bebés. Hay una mesa en un lateral en donde hay por lo general galletas o pasteles con dispensadores de café, tee y agua. En el suelo hay mantitas de colorines para los bebés, el suelo está todo enmoquetado, y solo se puede acceder sin calzado a la sala. En las paredes hay imágenes de bebés y madres dando el pecho, así como carteles que hacen alusión a los beneficios, la técnica o los principales problemas y soluciones sobre lactancia. Se puede encontrar a la entrada numerosos contactos de otros recursos de apoyo a la lactancia y diferentes profesionales a los que pueden acudir las usuarias del centro. En la recepción del centro hay productos relacionados con la lactancia y crianza que se pueden comprar, como pañuelos porta bebés, sacaleches, cojines de lactancia, etc. Además de la sala en donde se desarrolla el Baby Café hay otra sala anexa más pequeña, en la que se llevan a cabo otras actividades como clases o consultas al mismo tiempo que transcurre el Baby Café.

Observación 2: Relaciones y situaciones de los sujetos (9 de marzo de 2015).

Objetivo: Acercarse a la población a estudiar: las usuarias del Baby Café de Singapur.

Anotaciones: La mayoría de mujeres que acuden con sus bebés al Baby Café suelen ser madres que están dando el pecho o que lo combinan con leche de fórmula, también acuden, aunque en menor número, madres que no dan el pecho, embarazadas o familiares de éstas. La edad de los bebés también varía mucho, pero por lo general suelen venir bebés de entre 1 semana y 6 meses, aunque también se pueden encontrar niños mayores de un año o hermanos de éstos. El número de usuarias que acuden al Baby café suele ser numeroso, aun- que en periodo vacacional se suele notar un descenso importante de mujeres, por lo general los grupos suelen oscilar de 10 a 20 mujeres y sus respectivos bebés. La actividad del Baby Café está liderada por dos profesionales que trabajan en el centro, que suelen ser matronas y/o consultoras internacionales de lactancia. En la recepción hay dos trabajadoras más que hacen labores administrativas y que atienden a las usuarias que quieran comprar algún producto o apuntarse a cualquier otra actividad que oferta el centro. El perfil de las usuarias suele coincidir con mujeres expatriadas, de diferentes nacionalidades, sobre todo europeas y chinas, siendo la comunidad más numerosa, la inglesa. Las mujeres locales también acuden a esta actividad aunque en menor proporción. El idioma que se habla es el inglés, pero en algunas ocasiones acuden mujeres con limitaciones en el idioma, con las que se trabaja más intensivamente para salvar dicha limitación. Los profesionales que trabajan en el Baby Café suelen hablar varios idiomas.

\section{Imagen I}

\section{Imágenes del Baby Café de Singapur}

(Marzo, 2015).

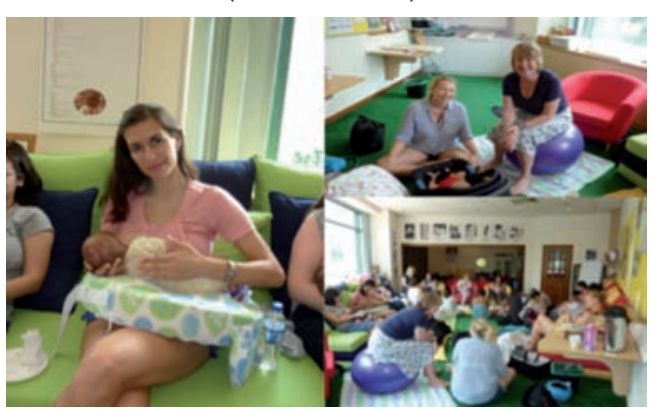

Fuente: Mother and Child, Singapur, Marzo del 2015

Observación 3: Correlaciones y situaciones.

Objetivo: Observar cuidadosamente qué problemas o consultas se dan en el Baby Café (16 de marzo de 2015).

Anotaciones: Las madres que acuden al 
centro, inicialmente acuden para consultar su problema de lactancia con algún profesional destinado a tal efecto, pero después de probar por primera vez la actividad, suelen repetir con mucha frecuencia ya que terminan haciendo amistad con otras madres, puesto que se trata de una reunión informal y distendida, es por ello que además de servirles de apoyo, también le sirve de entretenimiento y actividad social con niños. Las usuarias van acercándose a las dos trabajadoras que lideran la actividad y le van preguntando sus dudas o consultas sobre lactancia y crianza de manera informal, en ocasiones, entre las propias usuarias resuelven sus dudas, sirviéndose de la experiencia de otras madres que han pasado por la mima situación que ellas. Las madres se suelen encontrar relajadas y cómodas para consultar cualquier duda. Las consultas más frecuentes son problemas de agarre o enganche del bebé al pecho, cansancio o problemas con el sueño del bebé, grietas en el pezón, cómo y cuándo incorporar los sólidos, recomendaciones antes de incorporarse a trabajar y rechazo del pecho por parte del bebé. Casi todas las madres van buscando en esta actividad un apoyo social a su situación, ya que en muchas ocasiones se sienten solas o incomprendidas.

Observación 4: Observación y participación.

Objetivo: Participar como matrona en el Baby Café (23 de marzo de 2015).

Anotaciones: El trabajo con madres y bebés, es un trabajo muy gratificante pero a la vez muy dedicado, las usuarias del Baby Café suelen ser madres que buscan un apoyo que no encuentran en la sociedad, lo que conlleva a que en muchas ocasiones se sientan solas o incomprendidas como hemos mencionado anteriormente; es por ello que la empatía y la comunicación cercana y accesible son requi- sitos imprescindibles para trabajar con estas mujeres. Hay consultas que son bastante sencillas de resolver, pero en otras ocasiones nos vemos obligados a derivar a las usuarias a otros especialistas que colaboran con el centro como pediatras, médicos de familia, especialistas en frenillos, quiroprácticos o ginecólogos. El ambiente que se respira en el Baby Café es amable, relajado y seguro. Las consultas se resuelven sobre la marcha mientras conversamos de manera informal.

Testimonio de una de las usuarias del Baby Café de Singapur:

"I've been attending the Baby Café at Mother \& Child from my baby's second week of age. At that time motherhood was totally new to me and it felt great to be able to meet with other mums in similar situation and to get great support and advice from the available midwifes there. The Baby Café was recommended to me by a friend towards the end of my pregnancy but I didn't give it much thought at the time. However, a few days after my baby was born I had many questions and felt quite isolated, so I managed to get over any initial shyness and fear of going out with a newborn, and there has been no looking back.

I try to attend the Baby Cafe every week. Not only it gives me a great opportunity to spend time with other mums, exchange ideas, and get my baby to meet other babies and spend some time in a stimulating environment. I also get all the time I need with a midwife, usually my Spanish compatriot Isabel, to ask any questions and clear up any doubts about feeding, baby behaviour, sleeping issues and generally getting practical tips to make each day of my new motherhood chapter that little bit easier.

We had some serious issues in our early breastfeeding days, and attending the Baby Cafe weekly, allowed me to correct latching proble- 
ms, have great support and hear from other mums who had succeeded in breastfeeding their babies. It is not unusual for me to come to the Baby Cafe with a list of questions, as I'm confident that I will get great answers and help.

I would strongly recommend to any new (and not-so-new) mums to join us every Monday. The atmosphere is positive and friendly, the setting is comfortable with lots of comfy cushions for mummy and baby, and there is always a yummy cake or delicious homemade cookies! Come join us at the Baby Cafe!"

"He estado asistiendo al Baby Café en Mother and Child desde que mi bebé tenía dos semanas. En aquel momento la maternidad era totalmente nueva para mí y me sentó genial poder reunirme con otras madres en la misma situación que yo y conseguir un gran apoyo $y$ asesoramiento por parte de las matronas disponibles allí. Una amiga me recomendó el Baby Café hacia el final de mi embarazo, pero no le di mucha importancia en aquél momento. Sin embargo, pocos días después del nacimiento de mi bebé tenía muchas preguntas y me sentí bastante aislada, así que me las arreglé para salvar la timidez inicial y el miedo a salir con un recién nacido, y lo hice, no había vuelta atrás.

Intento ir al Baby Café cada semana. No sólo es una gran oportunidad para pasar tiempo con otras madres, intercambiar ideas, y hacer que mi bebé conozca otros niños y pasar algún tiempo en un ambiente estimulante. También tengo todo el tiempo que necesito con la matrona, por lo general mi compatriota española Isabel, de hacer preguntas y aclarar cualquier duda acerca de la alimentación, el comportamiento del bebé, problemas para dormir y en general conseguir consejos prácticos para hacer que cada día de mi nuevo capítulo de la maternidad sea un poco más fácil.
Hemos tenido algunos problemas serios en nuestros principios con la lactancia materna y asistir a la Baby Café semanalmente, me permitió corregir problemas de enganche, tener un gran apoyo y escuchar a otras madres que habian logrado amamantar a sus bebés. No es raro en mí ir al Baby Café con una lista de preguntas, ya que estoy segura de que voy a obtener grandes respuestas y ayuda.

Recomiendo encarecidamente a todas las nuevas (y no tan nuevas) madres a unirse a nosotros todos los lunes. El ambiente es positivo $y$ amable, el lugar es confortable, con un montón de cojines cómodos para mamás y bebés, y siempre hay deliciosas tartas o galletas caseras! Ven y únete a nosotros en el Baby Café! "

Traducción personal.

\section{DISCUSIÓN}

Como hemos comentado en apartado de introducción, parece que queda claro que la combinación del apoyo formal e informal es muy efectivo en términos de promoción y protección de la lactancia materna. Un ambiente cercano, accesible, relajado y empático, propio del apoyo informal procedente de las redes o grupos de apoyo a la lactancia, unido a un apoyo formal, como son los profesionales sanitarios especializados en lactancia, es la clave para acceder e interferir de manera positiva en la duración y permanencia de la lactancia materna.

Nuestra experiencia como profesional especializado en lactancia en el Baby Café de Singapur, coincide con lo que la evidencia científica avala en cuanto a la efectividad de éste tipo de servicios para la comunidad. Por lo general, las usuarias del Baby Café hablan muy bien de la iniciativa y la recomiendan muy a menudo; tal vez sea por eso que la mayoría de mujeres que llegan por primera 
vez al centro, sea por medio de la recomendación de algún amigo, familiar o profesional (Baby Café Local, 2013).

Por todos los motivos anteriormente expuestos, recomendamos que iniciativas como la del Baby Café, se impulsen y promuevan con más fuerza a nivel internacional, bien por medio de su difusión y desarrollo a través de organismos públicos o privados de salud, o bien por el fomento de la investigación de éste tipo de fenómenos.

\section{CONCLUSIONES}

A través de éste estudio, hemos profundizado en el concepto del Baby Café, llegando a la conclusión de que éste tipo de iniciativas son muy beneficiosas para la sociedad en la que vivimos, en la que los bajos índices de lactancia suponen un problema de salud mundial. Como hemos comprobado en el estado de la cuestión, la lactancia materna es beneficiosa no sólo para la salud del lactante, también lo es para las familias, el medo ambiente y la sociedad en general; es por ello que cada vez se hacen más necesarias, medidas de promoción protección y apoyo a la lactancia materna que contribuyan a solucionar dicho problema.

La evolución del Baby Café ha sido exponencial, su crecimiento e internacionalización se deben, en gran parte, al éxito de éste tipo de modelos de apoyo a la lactancia materna. No suponen un gran coste económico para la sociedad y en cambio mejoran la calidad del sistema de salud, enriquece la percepción que las mujeres tiene sobre sus lactancias y contribuyendo a mejorar la permanencia e incidencia de la lactancia materna en la comunidad.

Mediante el diario de campo hemos tenido la oportunidad de aproximarnos al fenómeno del Baby Café de Singapur, viendo más de cerca cómo se desarrolla el día a día de éste servicio. El ambiente que se respira es familiar y cercano, las usuarias suelen volver en numerosas ocasiones, lo que nos sugiere que es una iniciativa que funciona y que cumple su principal objetivo, que es ayudar y apoyar a las madres durante sus lactancias. El testimonio de una de las usuarias ratifica todo lo anteriormente expuesto y pone de manifiesto el alto grado de satisfacción percibida por ésta al contar con los servicios del Baby Café de Singapur.

Con este estudio queda clara la importancia y necesidad que los profesionales sanitarios especializados en lactancia, en combinación con el servicio del Baby Café, juegan para la sociedad; aun así, queda mucho por hacer en cuanto a investigación sobre éste tipo de iniciativas de apoyo a la lactancia; es por ello que animamos a que se realicen más estudios que avalen el verdadero impacto que el Baby Café tiene sobre la sociedad, con el fin último de promover proteger y apoyar a la lactancia materna de forma unánime.

\section{BIBLIOGRAFÍA}

- Álvarez Zendejas, P. M. (2013). Proyecto Terminal Profesional: "Propuesta de intervención para promover una práctica correcta de la lactancia materna exclusiva en adolescentes embarazadas de Santo Tomás Ajusco”. (Maestría en Salud Pública Área de Concentración: Epidemiología para obteneción del grado de maestría en Salud Pública). Instituto Nacional de Salud Pública. Escuela de Salud Pública de México. Recuperado el 15 de enero de 2015 de http://www.inspvirtual.mx/CentroDocumentacion/cwisBancoPF/SPT--DownloadFile. php? Id $=560$

- Baby Café. (2012). Supplementary Information Sheets. Baby Café National Co-ordinators. September 2012. Recuperado el 24 de marzo de 2015 de http://www.google. com.sg/url? sa $=\mathrm{t} \& \mathrm{rct}=\mathrm{j} \& \mathrm{q}=\& \mathrm{esrc}=\mathrm{s} \&$ source $=\mathrm{web} \& \mathrm{~cd}=$ 2\&ved=0CCEQFjAB\&url=http\%3A\%2F\%2Fthebabyca 
fe.org\%2Findex.php\%3Foption\%3Dcom_rubberdoc\% 26view\%3Ddoc\%26id\%3D153\%26format\%3Draw\&ei= NsAQVdXwIpe3uQS8gYHIDg\&usg=AFQjCNHWEiei eNYQulj35Ee0mfEtlHyM5Q\&bvm=bv.89184060,d.c2E

- Baby Café Local. (2013). Report on Baby Café Services during 2013. Recuperado el 24 de marzo de 2015 de http://www.nct.org.uk/sites/default/files/related_documents/Baby\%20Cafe\%202013\%20Annual\%20Report\%202014\%20External\%20use_0.pdf

- Baño Piñero, I., Canteras Jordana, M., Carrillo García, C., López Araez, A. \& Martínez Roche, M. E. (2015). Desarrollo y validación de un instrumento diseñado para medir el impacto de las redes de apoyo a la lactancia materna. Nutr Hosp. 31(4), 1525-32

- Department of Health. (2004). Good practice and innovation in breastfeeding. Recuperado el 19 de enero de 2015 de http://webarchive.nationalarchives.gov.uk/+/www. dh.gov.uk/en/Publicationsandstatistics/Publications/ PublicationsPolicyAndGuidance/DH_4097202

- García Méndez, J. A. (2010). Eficacia diferencial de los programas de apoyo a madres con intención de lactar sobre la exclusividad y duración de la lactancia materna: Un estudio meta-analítico. (Tesis Doctoral). Universidad de Murcia. Murcia.

- Hernández Aguilar, M. T. \& Aguayo Maldonado, J. (2005). La lactancia materna: Cómo promover y apoyar la lactancia materna en la práctica pediátrica. Recomendaciones del Comité de Lactancia de la AEP. An Pediatr. 63(4), 340-56.

- Hoddinott, P. \& Pill, R. (1999). Qualitative study of decisions about infant feeding among women in the east end of London. BMJ. 318, 30-4.

- Lavender, T., Mc Fadden, C. \& Baker, L. (2006). Breastfeeding and family life. Matern.Child Nutr. 2(3), 145-55.

- López Marín, R., Molina Rodríguez, A., Martínez Roche, M., Frutos Molina, D. \& Molina Rodríguez, T. (2012). Figura del padre en relación a la crianza: pasado, presente y futuro. Cultura De Los Cuidados. 16(32), 12-7. doi:http://dx.doi.org/10.7184/cuid.2012.32.02

- Mc Fadden, A. \& Toole, G. (2006). Exploring women's views of breastfeeding: a focus group study within an area with high levels of socio- economic deprivation.
Matern.Child Nutr.2(3), 156-68.

- NCT. (2014). Baby Feeding Policy 2014. DRAFT for discussion. Recuperado el 24 de marzo de 2015 de http://www.nct.org.uk/sites/default/files/related_documents/2014\%20Baby $\% 20$ Feeding $\% 20$ policy $\% 20$ $\% 282 \% 29 . p d f$

- Nogales Espert, A. (2012). La empatía según Edith Stein y sus aplicaciones en enfermería en el contexto familiar. Cultura De Los Cuidados. 12(24), 119-33. Recuperado de http://culturacuidados.ua.es/enfermeria/article/ view/302/603

- Organización Mundial de la Salud (OMS). (2015). Lactancia materna. Salud de la madre, el recién nacido, del niño y del adolescente. Recuperado el 16 de febrero de 2015, de http://www.who.int/maternal_child_adolescent/topics/newborn/nutrition/breastfeeding/es/\#

- OMS. (1998). Prueba Científica de los Diez Pasos Hacia una Feliz Lactancia Natural. División de Salud y Desarrollo del Niño. Ginebra. Recuperado el 9 de noviembre de 2014 de http://whqlibdoc.who.int/hq/1998/WHO_ CHD_98.9_spa.pdf?ua=1

- OMS \& UNICEF. (1993). Curso de Capacitación Manual del Participante. Consejería en Lactancia Materna. Recuperado el 3 de marzo de 2015 de http://www.unicef.org/ argentina/spanish/Consejeria_en_Lactancia_Materna. pdf

- OMS, UNICEF \& IHAN. (2014). Estrategia Centros de Salud IHAN. Revisada, actualizada y ampliada para la atención integral en los centros de salud. Manual para la acreditación IHAN-España. 2014. Recuperado el 19 de febrero de 2015 de http://www.ihan.es/docs/documentacion-acreditacion/centros_salud/Manual_para_la_ acreditacion_IHAN_en_AP.pdf

- Scott, J. A. \& Mostyn, T. (2003). Women's experiences of breastfeeding in a bottle-feeding culture. J Hum Lact. 19(3), 270-7.

- Siles González, J., Solano Ruiz, M. \& Cibanal, J. (2012). El origen fenomenológico del "cuidado" y la importancia del concepto de tiempo en la historia de la enfermería. Cultura De Los Cuidados, 12(21), 19-27. Recuperado de http://culturacuidados.ua.es/enfermeria/article/ view/270/539 


\section{Cultura de las Cuidados}

- Simões, A., Soares, H., Duarte, J., Bracarense, C. \& Cortes, R. (2015). La humanización en el proceso de formación académica de los profesionales de la salud. Cultura De Los Cuidados. 18(40), 72-81. doi:http://dx.doi. org/10.7184/cuid.2014.40.10

- Taylor, S. J. Bogdan, R. (1987). Introducción a los métodos cualitativos de investigación. La búsqueda de significados. Ediciones Paidós Ibérica. S. A. Barcelona.

- The Baby Café Charitable Trust. (2006). ANNUAL REPORT and ACCOUNTS 2005 2006. Including information from the National Statistics and Evaluation 2005.
Recuperado el 23 de marzo de 2015 de http://www.google.com.sg/url? sa $=t \& r c t=j \& q=\& e s r c=s \&$ source $=$ web \& $\mathrm{cd}=2 \& v e d=0 \mathrm{CCEQFjAB} \& u r l=h t t p \% 3 \mathrm{~A} \% 2 \mathrm{~F} \% 2 \mathrm{Fwww}$. thebabycafe.org\%2Findex.php\%3Foption\%3Dcom_rub berdoc\%26view\%3Ddoc\%26id\%3D16\%26format\%3Dr aw\&ei=_b0QVdPkAo_buQTzwoHQBg\&usg=AFQjCN Hk1bR37mtpsgRMfdAA9MPElycIJw\&bvm=bv. 891840 60, d.c2E

- The Baby Café Charitable Trust. (2015). The Baby Café. Recuperado el 19 de enero de 2015 de http://www.thebabycafe.org

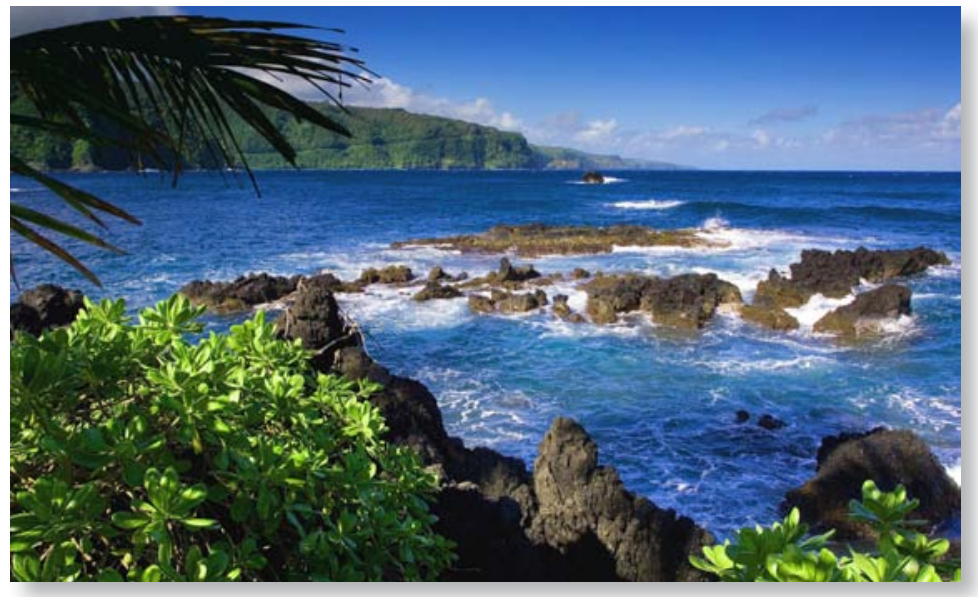




\title{
Camino Soria
}

\author{
Soria way \\ Soria Caminho
}

Francisco Herrera-Rodríguez

Catedrático de Escuela Universitaria. Facultad de Enfermería y Fisioterapia (Universidad de Cádiz)

Cómo citar este relato en edición digital: Herrera Rodríguez, F. (2015). Camino Soria. Cultura de los Cuidados (Edición digital), 19(43). Disponible en:< http://dx.doi.org/10.14198/cuid.2015.43.04>

Correspondencia: Francisco Herrera-Rodríguez. Facultad de Enfermería y Fisioterapia. Avda. Ana de Viya, 52. 11009-Cádiz. Correo electronico: francisco.herrera@uca.

Recibido: 11/05/2015; Aceptado: 14/07/2015

\section{ABSTRACT}

Josep Pla taught us that life in all its dimensions fit in a bus, so the traveler looks at the trees in the way, but also the suffering and joyful hearts that accompany it. The stories he sees and hears are overwhelming, like Maria Zambrano said about Galdos' characters, except that here on the bus the traveler feels the devastation and the glory of life in the raw.

Keywords: Loneliness, heartbreak, alcoholism, drugaddiction.

\section{RESUMO}

Josep Pla nos ensinou que a vida em todas as suasdimensões se encaixamemumônibus, de modo que os ro viagemolhar para as árvores do caminho, mas também o sofrimento e corações alegres que o acompanham. As histórias que vêem e ouvem sãoesmagadoras, como Maria Zambrano dos personagensem Galdos, exceto que aqui no ônibus o viajante sente a devastaçãoeaglória de matéria-vida disse.

Palavras chave: Solidão, desgosto, alcoolismo, toxicodependência.

\section{RESUMEN}

Josep Pla nos enseñó que la vida en todas sus dimensiones cabe en un autobús, por eso el viajero mira a los árboles del camino, pero también a los corazones dolientes y alegres que le acompañan. Las historias que ve y escucha son arrolladoras, como decía María Zambrano de los personajes de Galdós, salvo que aquí en el autobús el viajero siente la devastación y la gloria de la vida en carne viva.

Palabras clave: Soledad, desamor, alcoholismo, drogadicción.

El autobús paró y se subieron varios viajeros, entre ellos una mujer con el pelo arruinado, la falda muy corta y penumbra de alcohol en la mirada. Se sentó cerca de mí y sacó el móvil tembloroso. Sola en su abismo empezó a leer en voz alta los mensajes que había recibido sabe Dios cuando. Al rato exclamó: «iEste! ¡Este es el que más me gusta!». Y leyó con voz rota: "Siempre supiste amarrarme con una mirada, con un beso o cogiéndome de la mano. Nadie me ha querido como tú. Me regalaste en Soria la noche más bonita de mi vida». Se calló, exhaló una bocanada de aire agrio, y con la serenidad de los triunfadores, con la seguridad de haber ganado la partida de su vida dijo: "iQué cabrón! Esto por mis muertos se lo mando a la Bego, para que vea que el mierda este me ha querido más que a ella». El autobús paró y se bajó como pudo dando tumbos. Los huesos dolían solo de mirarla. Caminaba en dirección a la noche, tecleando temblorosamente en su móvil. La perdí de vista y el autobús arrancó, y no sé por qué pensé en los olmos heridos de Soria, que reverdecen cada primavera, no se sabe si por desamor o por costumbre. 


\title{
Dos islas, una frontera, un mestizaje: Una metáfora sobre la comunicación y el cuidado
}

\author{
Two islands, one border, one mestizaje: \\ A metaphor for communication and care
}

\author{
Duas ilhas, border, mestiçagem: \\ Uma metáfora para a comunicação e cuidado \\ Juan Carlos Delgado Antolín
}

Enfermero, Antropólogo. Enfermero de Atención Primaria C. S. de Griñón, Madrid. Profesor externo de la Universidad Rey Juan Carlos, Madrid

Cómo citar este artículo en edición digital: Delgado Antolín, J.C. (2015). Dos islas, una frontera, un mestizaje: Una metáfora sobre la comunicación y el cuidado. Cultura de los Cuidados (Edición digital), 19(43). Disponible en: $<$ http://dx.doi. org/10.14198/cuid.2015.43.05>

Correspondencia: C/ Villamanín $318^{\circ} \mathrm{F} 28011$ Madrid.

Correo electronico: jcdantolin@gmail.com

Recibido: 09/06/2015; Aceptado: 12/09/2015

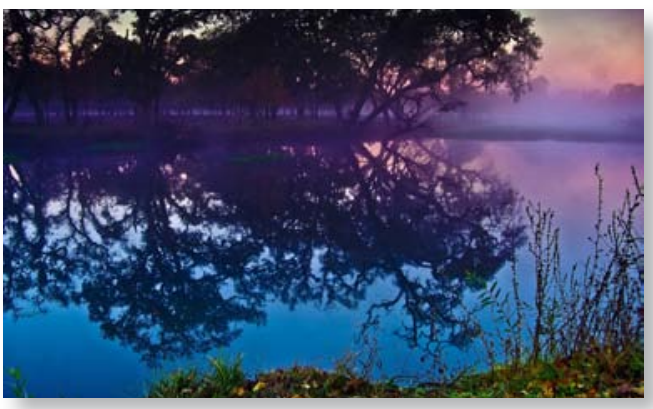

ABSTRACT

It is an opinion, a personal reflection metaphorically, on the evolution of the nursing process, based on the System Caregiver Ratio Dorothea Orem. As a care process from the initial ratio of distance, approaching two personalities can go two evaluative own visions and converge on a common vision and hybridized with a single purpose, caring for the person. The tool to use is communication.

Keywords: care, communication, health relationship, values.

\section{RESUMO}

É uma opinião, uma reflexão pessoal metaforicamente, sobre a evolução do processo de enfermagem, com base na Relação Sistema Cuidador de Dorothea Orem. Como um processo de cuidado a partir da relação inicial de distância, aproximando-se duas personalidades podem ir duas próprias visões de avaliação e convergem para uma visão híbrida comum e um objetivo, cuidar da pessoa. A ferramenta a ser usada é a comunicação.

Palavras-chave: Cuidado, Comunicação, relacionamento saúde, valores.

\section{RESUMEN}

Es un artículo de opinión, una reflexión personal en forma metafórica, sobre la evolución del proceso de enfermería, basándome en los Sistema de Relación Cuidadora de Dorothea Orem. Como en un proceso de cuidado desde la relación inicial de lejanía, pueden irse acercándose dos personalidades, dos visiones valorativas propias y confluir en una visión común híbrida y con un único fin, el cuidado de la persona. La herramienta a emplear es la comunicación.

Palabras claves: Cuidado, comunicación, relación sanitaria, valores. 
Cuando hablamos del cuidado profesional casi siempre lo hacemos de un modo conceptual, intentando explicar sus características, sus conceptos básicos de desarrollo, la historia de sus orígenes, su situación actual, la influencia del componente femenino en su ejercicio, etc., es decir, hablamos del cuidado desde un punto de vista teórico y explicativo de su realidad o de una parcela de su realidad. Pero el cuidado de los seres humanos, todo tipo de cuidado y especialmente el cuidado profesional, siempre se da dentro de una relación, una relación interpersonal y donde como poco deben existir dos personas, un dador y un receptor de cuidados. Normalmente, los profesionales de enfermería son los encargados de proporcionar y establecer esos cuidados y las personas con necesidades alteradas, reales o potenciales, los reciben. Bien, pues partiendo de este hecho aparentemente simple, se puede establecer toda una relación que a medida que crece, se complica y se va haciendo más compleja. La maestra Dorothea Orem hablaba (Donobue Eben, Nation, Marriner, y Nordermeyer, 1989: 104) de tres sistemas en la relación cuidadora: Sistemas de Enfermería totalmente compensatorios, la enfermera debe compensar la incapacidad total de los pacientes para el autocuidado. Sistemas parcialmente compensatorios, la enfermera compensa ciertos déficit en el autocuidado. Sistemas de apoyo-educativo, la enfermera enseña y fomenta el autocuidado en el paciente. El objetivo de la Enfermería es avanzar en estos sistemas lo más posible y si las circunstancias nos lo permiten, debemos llegar al último sistema en la relación cuidadora, es decir, al sistema que proporciona la mayor autonomía e independencia a la persona cuidada, mediante el empoderamiento y la autosuficiencia, pues el objetivo fundamental es proporcionar el máximo sistema de autocuidado y autogobierno a la persona, que ha pasado por un proceso de necesidades alteradas y que la ha incapacitado para su pleno desarrollo.

El título de esta reflexión "Dos islas, una frontera, un mestizaje: Una metáfora sobre la comunicación y el cuidado" es fruto de lo que pretende ser una evolución desde una relación totalmente dependiente hasta una relación de apoyo-educativo, donde se pretende y se quiere potenciar un horizonte de máxima independencia.

En los Sistemas totalmente compensatorios, al principio se establecerá una relación entre dos personas ajenas. Tan sólo les une una relación profesional de incapacidad y de complejidad en la labor cuidadora, me explicaré: Una persona que hasta ese momento era capaz de ejercer el autocuidado y este se encontraba instaurado dentro de su vida común, de su cotidianeidad, se encuentra incapaz de seguir autocuidándose, pues el hecho normal $y$ cotidiano, se ha convertido en un hecho excepcional y complejo que necesita de la acción y de la ejecución de una persona experta, de una enfermera. Esta necesidad alterada pone en contacto a dos personas, dos islas, que sintiéndose próximas están separadas. Cada una maneja y conoce una corporeidad propia y diferente de la otra, una al ser profesional, ha podido explorar más en otras corporeidades, en otros comportamientos, en otras necesidades, pero la persona a cuidar es una isla, incluso una isla virgen a esta nueva etapa de la dependencia. Cada una conoce su terreno, pero todavía no comparten nada en común. La relación comienza y los objetivos parecen comunes, de hecho deben ser comunes, el bien de la persona cuidada. En un principio cada una tiene unas ideas de cómo debe ser la relación y unos valores en los que debe moverse y llevar 
a cabo esa relación. Pronto empiezan a comunicarse, hay puentes de unión, trasportes de intercambios. El acercamiento entre las dos islas es progresivo y se puede decir que con el tiempo, llegan casi a unirse. Si han fijado y delimitado bien la finalidad de la relación, el cuidado de la persona con las necesidades alteradas, y se han ido limando las continuas asperezas que surgen en toda relación, un sentimiento de acercamiento y de proximidad se puede poner de manifiesto en la relación cuidadora. Pero dos personas, dos islas no pueden unirse en una sola, siempre se conservan rasgos de identidad propios, pues existen fronteras.

Con el tiempo y la comunicación las personas pueden conocerse, reunirse y transformar esas dos islas en las que comenzaron su relación en un archipiélago, pero la línea de separación será una frontera. Esas líneas imaginarias es lo que tienen, que separan, ponen límites. Al fin y al cabo son dos personas, dos identidades propias que conviven y en este caso poseen una finalidad común. Pero a las vez las fronteras lo mismo que sirven para separar, son puntos de unión, de aproximación. Todos los terrenos fronterizos nos hablan de la proximidad del otro. Otro diferente a mí, pero próximo, vecino y por lo tanto cercano. Con el que me tengo que entender, con el que tengo que llegar a acuerdos y cuando este en su lado de la frontera, nuestra relación se regirá por las normas de su lado, pero cuando estemos en mi lado, las normas serán las mías. Las fronteras por tanto separan y aproximan, pues muchas veces, cuando pasamos una frontera estamos donde realmente queríamos ir.

Así cuando pasamos de un Sistema totalmente compensatorio a un Sistema parcialmente compensatorio, estamos en un terreno completamente fronterizo, pues somos dos en

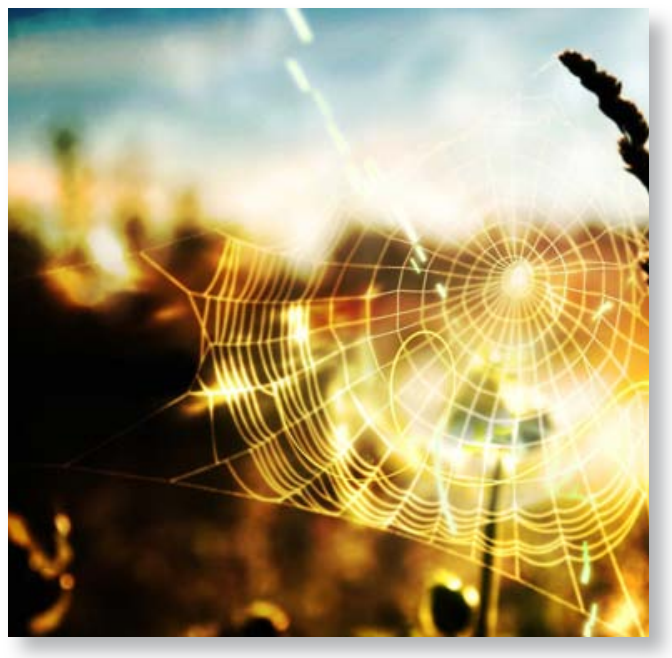

uno. Nos situamos a ambos lados de la frontera según la necesidad a tratar, según la actividad a desarrollar en el cuidado. Cuando se va compensando el sistema, el desarrollo del cuidado y la actividad lo realizará, según la complejidad y la destreza, una parte u otra de la frontera. Parte del cuidado será autocuidado y parte del cuidado seguirá siendo "heterocuidado", es decir, dependiente de otra persona. El cuidado seguirá avanzando hacia la independencia, pero en un terreno aún incierto. La aproximación de las islas se ha producido, pero cada una tiene su competencia claramente definida.

Por último, llegamos al último Sistema al apoyo-ayuda. Las islas son independientes, fronterizas y ahora llega el momento de crear una cultura mestiza, al fin y al cabo cada vez parece más seguro que el homo sapiens moderno es un mestizaje del ADN de varias especies (homo sapiens, homo neanderthalensis, denisovanos y posiblemente homo erectus) (Meyer, et al., 2014; Nieves, 2013). Una cultura mestiza en ese terreno incierto donde nos encontramos, donde las normas de unos y de otros sean respetadas. Donde desde el diálogo y la escucha activa mantenida, se lleguen a acuerdos. En el sistema de apoyo se establece 
un mestizaje donde los cuidados ya proporcionados por el propio paciente son asesorados y potenciados por la enfermera, pero con los valores del paciente y la matización de los valores del profesional como experto en la materia que se trata. La hibridación producida entre los valores de uno y otro, nos llevará a obtener el respeto por parte de ambos. Sólo en el mestizaje se llega a una plena integración de la interculturalidad. Sólo las personas mestizas son interculturales y eligen en cada momento lo mejor de las dos culturas y las potencian de una manera integrada, participando de lo mejor de cada una en cada momento, en cada lugar y en cada circunstancia. Pues se han desprendido de los prejuicios de cada lado para establecer un nuevo estatus criollo de integración.

La interculturalidad es el paso previo a la transculturalidad, como un orden totalmente independiente de las creencias culturales sesgadas y separadoras entre las personas. Cuando uno se siente intercultural y comienza a entender que su modo de ser, de pensar, de obrar, puede ser bueno para él, pero no tiene que ser el mejor para otro, y capta la capacidad de mejora que tienen otras ideas y otras culturas y que esas ideas y valores le pueden servir también a él, estamos entrando en la interculturalidad. En la interculturalidad los valores, las ideas, los hechos culturales se funden y se va creando poco a poco un híbrido, un mestizo con aportaciones de uno y otro lado. Sólo en ese momento se está comenzando a avanzar hacia el cuidado transcultural y se es capaz de ser un cuidador sin islas, sin fronteras y con un claro sentido de mezcla. Habrá superado la isla como separación, la frontera como proximidad y el mestizaje como integración.

Por supuesto, que este viaje virtual a través de la insularidad se puede dar en los tres

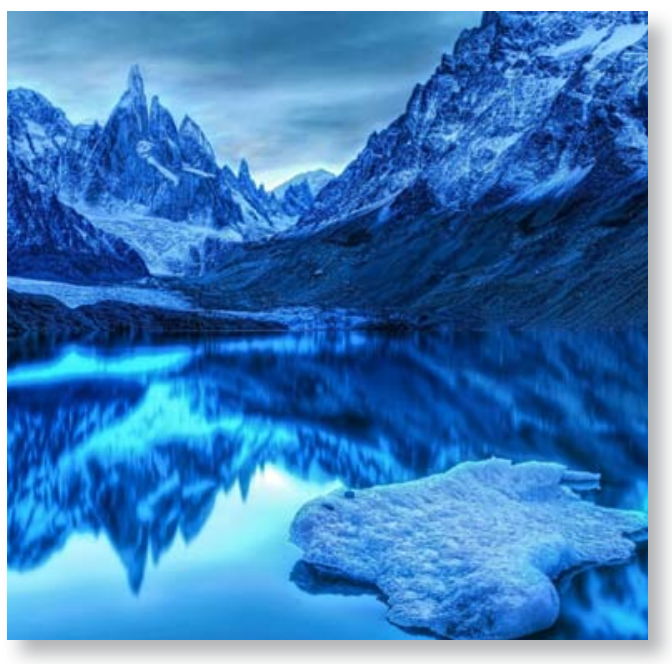

sistemas y que a veces, en cada uno de ellos no pasamos de ser islas y de evitar la aproximación por si acaso, por el qué dirán o por si las moscas. Aunque en las etapas iniciales de un sistema totalmente compensatorio no se pueda ejercer ciertas cotas de autocuidado, se puede llegar a ejercer un cuidado individual con el conocimiento y el mestizaje de los valores integrados entre el profesional y la persona cuidada. Es decir, que el "islamiento", las fronteras y el mestizaje dependerán más de nosotros, de ambos, que de la situación física y de dependencia que se dé en la realidad.

Si en el mundo de los valores y su influencia a la hora de ejercer el cuidado debemos avanzar hacia la interculturalidad y hacia una cierta transculturalidad, en toda relación humana también se puede profundizar y que llegue a tener un efecto y un componente transpersonal.

La relación transpersonal, la podríamos definir como una relación que traspasa el plano netamente personal y va más allá, estableciéndose una relación mayor, más significativa y con un mayor compromiso. Es una relación que se da entre personas y que muchas veces su producto transciende la pura relación comunicativa para producir un efecto complejo 
y completo, donde se ponen de manifiesto una relación que abarca todos los planos entre las personas que intervienen en la relación. Ese nivel implica una conexión donde los deseos y las necesidades alteradas de una de las partes, son percibidas de una forma especial por la otra parte, la que proporciona los cuidados, transcendiendo su conexión el plano de la comunicación hablada o gestual.

La comunicación sigue siendo una de las herramientas más eficaces que poseemos las enfermeras, y la comunicación no se compone sólo de lenguaje verbal, también la compone el lenguaje no verbal y el contacto, y por supuesto debe ser seguida de una buena y autentica deliberación por ambas partes. Estamos acostumbrados a defender nuestras ideas como las auténticas, como las verdaderas, como las más valiosas y hablamos pero no escuchamos, decimos pero no oímos y a lo mejor los otros tienen razón, pues sus circunstancias, sus ámbitos y sus contextos son diferentes a los míos y por tanto para ellos sus ideas son más valiosas.
Debemos hacer un ejercicio de humildad e intentar pensar que a lo mejor yo estoy equivocado y ellos pueden tener razón. Aunque sea por un solo instante. Luego podemos volver a nuestra auténtica y valiosa verdad.

Fin de la metáfora.

\section{BIBLIOGRAFÍA}

- Donobue Eben, J., Nation, M. J., Marriner, A., Nordermeyer, S. B., (1989). Dorotehea E. Orem: Teoría del déficit de auto-cuidado en Enfermería. En A. Marriner (Eds), Modelos y teorías de Enfermería. Barcelona: Ediciones Rol.

- Meyer, M., Fu, Q., Aximu-Petri, A., Glocke, I., Nickel, B., Arsuaga, J.L., Martínez,... y E., Pääbo, S. (2014). Amitochondrial genome sequence of a hominin from Sima de los Huesos. Nature, 505 (7483), 403-406.

- Nieves, J. M. (2013). Los humanos éramos cuatro especies que se apareamos entre sí. El Blog ciencia y tecnología ABC, Madrid (18-12-2013). Recuperado de http:// abcblogs.abc.es/nieves/public/post/los-humanos-eramos-cuatro-especies-que-se-aparearon-entre-si-16196. asp/ 


\title{
Un día de Hambre
}

\author{
A Day of Hunger \\ Um Dia da Fome \\ Javier Fernández Álvarez \\ Diplomado Universitario en Enfermería. Hospital de Begoña. Cooperante con Fundación Pablo Horstmann \\ Cómo citar este artículo en edición digital: Fernández Álvarez, J. (2015). Un día de Hambre. Cultura de los Cuidados (Edición \\ digital), 19(43). Disponible en:< http://dx.doi.org/10.14198/cuid.2015.43.06> \\ Correspondencia: C/Acacia $n^{\circ} 52^{\circ}$ Dch. Gijón. \\ Correo electrónico: jfernandez_alvarez@hotmail.com \\ Recibido: 09/06/2015; Aceptado: 12/09/2015
}

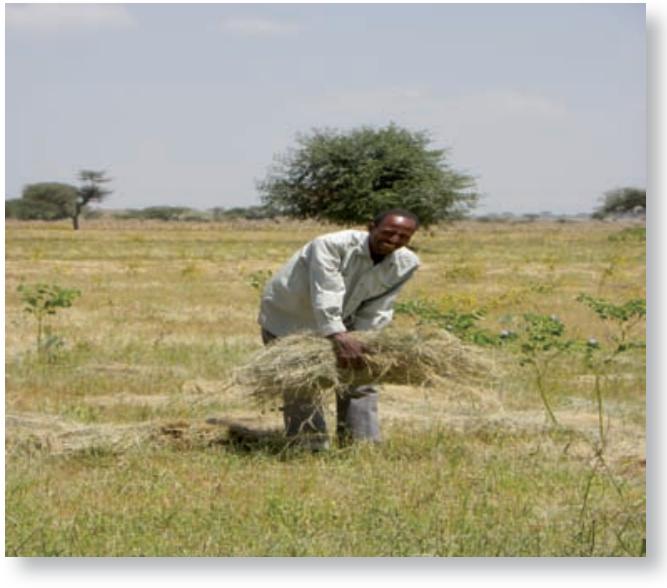

Imagen 1 Padre en su huerta

\section{ABSTRACT}

My experience as a volunteer in Africa made me reflect on the importance of the death of a child and look for different situations and cultures. In European society, we assume that parents should outlive their children and who would die for their children. In Ethiopia where families can not afford to make a minimum contribution of food needed, mothers come in such bad shape that they are unable to give breastfeeding, and people are accustomed to the early years are the most critical, the most difficult, as they are accustomed to losing in those years to his brothers, sons, grandsons, nephews and friends.

Keywords: Transcultural nursing; experiences; cooperation.

\section{RESUMO}

Minha experiência como voluntário na África me fez refletir sobre a importância da morte de uma criança e olhar para diferentes situações e culturas. $\mathrm{Na}$ sociedade europeia, assumimos que os pais devem sobreviver a seus filhos e que morreria por seus filhos. $\mathrm{Na}$ Etiópia, onde as famílias não têm condições de fazer uma contribuição mínima de alimentos necessária, as mães vêm em tão má forma que eles são incapazes de dar a amamentação, e as pessoas estão acostumadas aos primeiros anos são os mais críticos, o mais difícil, já que eles estão acostumados a perder naqueles anos a seus irmãos, filhos, netos, sobrinhos e amigos.

Palavras-chave: Enfermagem transcultural; experiências; cooperação.

\section{RESUMEN}

Mi vivencia en África como cooperante me hizo reflexionar sobre la importancia de la muerte de un hijo y la mirada desde diferentes situaciones y culturas. En la sociedad europea, suponemos que los progenitores deben sobrevivir a sus hijos y que darían la vida por sus hijos. En Etiopía donde familias no tienen dinero suficiente para asegurarse un aporte mínimo de los alimentos necesarios, las madres vienen en tan malas condiciones que son incapaces de dar la lactancia, y las personas están acostumbradas a que los primeros años 
son los más críticos, los más difíciles, en que están acostumbrados a perder en esos años a sus hermanos, hijos, nietos, sobrinos o amigos.

Palabras clave: Enfermería transcultural; experiencias; cooperación.

Eran las seis de la mañana en Meki (Etiopía), un pueblo en medio de una carretera, un pueblo de paso, donde los camioneros paran como mucho a degustar los platos típicos en cualquiera de los bares dispuestos en la carretera principal, un pueblo escondido bajo el polvo en el viento, un pueblo de chabolas de barro en el Centro de África. Estaba sentado con la espalda apoyada contra la pared de la casa de voluntarios, los pájaros alzaban el vuelo desde los árboles. En más de una ocasión había visto como algún pobre despistado, que se apresuraba en su despertar, se daba de bruces contra el edificio. El cielo del amanecer anaranjado con tonos rojizos, suplantaba poco a poco el azul oscuro brillante, salpicado de estrellas fugaces, a las que les pedía siempre el deseo de no tener que irme de Meki.

Las siete de la mañana, me acerqué a la entrada, como era previsible las mamás hacían cola, esperaban a que se abriese la puerta $y$ pasar, para tener número. Muchas habían caminado varias horas para llegar, para llegar primero, para no quedarse sin sitio y poder volver en el mismo día a su hogar lo antes posible, donde posiblemente el resto de sus hijos y su marido esperasen a que ella llegase para hacer la comida para lavar la ropa, para atender a la familia, que en parte se habría pasado el día trabajando bajo el sol y en parte se habría quedado en casa ocupándose de sus hermanos esperando a que su mamá volviese.

Abrimos y comienzan los llantos, uno tras otro, no importa lo tranquilo que estuviese todo, solo es necesario que uno de ellos empiece a llorar y todos parecen aprender el gesto mas rápido que el de al lado. Sentados sobre las piernas de sus mamás intentando digerir la pasta densa que les ofrecemos, ante sus miradas dudosas que intentan comprender y entender que eso será bueno para su hijo.

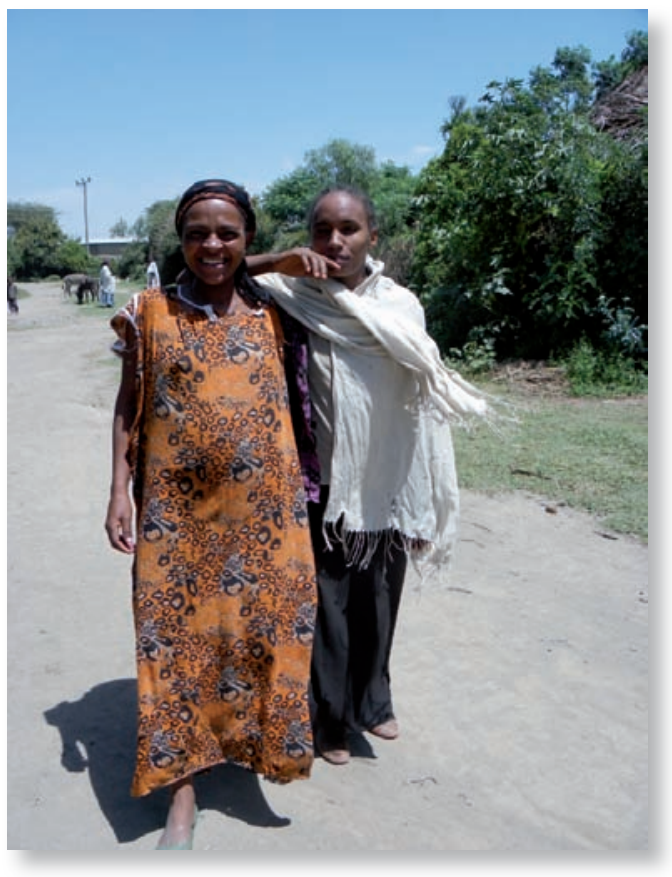

Imagen 2 Madres de Meki

Los niños mal nutridos llegan cansados, débiles, sin fuerza, y reservan su energía para llorar desconsoladamente; lloran y no saben por qué lloran, pero apenas tienen lágrimas. Tienen el pelo y la piel envejecida, color cuero viejo, sin brillo, arrugada, frágiles y delgados, hinchados por el líquido que el organismo no sabe manejar, con los ojos saltones, suplicando atención.

Acojo a la primera madre y su hijo y le explico que vamos a hacer una prueba simple, pero muy importante, algo que nos permite saber si vamos a poder controlar al niño o si por el contrario lo tenemos que trasladar a un hospital especializado. Se lava las manos mientras yo sostengo a su niño, que la persigue con la mirada, que no deja observarla y que llora 
ante la situación de no encontrarse seguro cerca de ella. Pasamos a la sala, donde, sentadas ya con sus niños otras tres madres le dan la bienvenida. Se sienta y pone a su hijo en su regazo. Le explico que el niño debe estar sentado, que el niño debe sentir cariño, y que cuando coma no se le debe forzar, taparle la nariz o echarle la cabeza para atrás, hasta que el guerrero, decida tragar el preparado. Le digo que no debe enfadarse que su hijo está muy enfermo, le digo que no debe gritarle, que no lo zarandee, que no le obligue, que sea paciente. Son cosas que resultan obvias pero cuando uno pierde la paciencia desaparece también la obviedad.

Le facilité un preparado con aspecto de una densa pasta con sabor a cacahuete salado $y$ dulce. A veces llegan con tan poca fuerza que son incapaces de pasar por su garganta la pasta, que se adhiere a las paredes provocándoles finalmente el vómito, en esos casos se diluye con un poco de agua. Es un preparado que los centros reciben gratis, y que tristemente a veces cae en un mercado negro donde la gente lo vende, generalmente a jóvenes que quieren ponerse fuertes y han decidido tomarlo para ganar peso, no tendría mayor importancia, si no fuese porque sabes que cada uno de esos paquetitos de pasta de cacahuete densa es para un niño que realmente lo necesita, niños que están en el borde entre la vida y ... la otra vida ¿quizás?

Poco a poco a los niños se les fuerza lentamente a que ingieran cierta cantidad, dependiendo del peso y poco a poco. Algunos ya acostumbrados, puede ser que no sea la primera vez que tienen que seguir este tratamiento, lo devoran bien a gusto, otros, que ya han perdido incluso las ganas de comer, luchan contra su madre en cada trago para que sea el último. No pueden comer muy rápido, no pueden estar agitados, porque entonces de seguro acabaran vomitándolo todo.
En el transcurso del día observo que dos de los niños apenas han comido nada, luchan y se niegan, lloran y vomitan, los otros dos pasan la prueba tranquilamente. A las madres de los que han comido les damos varios paquetes de pasta de cacahuete hasta el próximo control y se les dice que tienen que traer los sobres vacíos, para evitar que al salir los venda por unas monedas en ese mercado negro de pasta de cacahuete. A los dos que no han comido se les explica que es necesario ir al hospital y se les da dinero para ir al centro. Se incide en que es muy importante que vayan al hospital ese mismo día, para comenzar lo antes posible con el tratamiento, porque su hijo esta muy enfermo.

Comenzamos a preparalo todo y mientras realizamos los trámites, una de las madres se acerca y nos dice que no va a ir al hospital, que no puede, que se va a su casa. Insistimos mucho, pero parece inútil, le explicamos y le decimos con palabras, cada vez más duras, que su hijo se muere. Llama a su marido para buscar aprobación y no la encuentra pero tras nuestra insistencia cede, parece darse cuenta de que es la última oportunidad para su hijo, acepta y les damos el dinero a las dos mamas y se van.

Al cabo de una hora, una de las mamás vuelve desconsolada. Nos relata que la indecisa ha decido finalmente no ir pues centrarse en un hijo puede suponer descuidar al resto. Dejar de lado los trabajos de la huerta para ir al hospital durante dos semanas podría estropear la cosecha que dará de comer al resto de tu familia durante todo el próximo año. Así pues, desanda el camino para decirnos que no se atreve a ir sola, que no sabe cómo tiene que llegar hasta el otro hospital y tiene miedo. Vuelve buscando respuesta a tantas incertidumbres... Le doy escrita la dirección y le explico cómo tiene que llegar, qué autobuses tiene que coger, 
todo muy despacio, con ternura pero emponderándola. Veo salir a la madre y antes de atravesar la puerta metálica, mira una última vez hacia atrás. Ahora depende de ella llegar y conseguir lo mejor para su hijo. La responsabilidad y el cansancio la abruman pero decide seguir adelante.

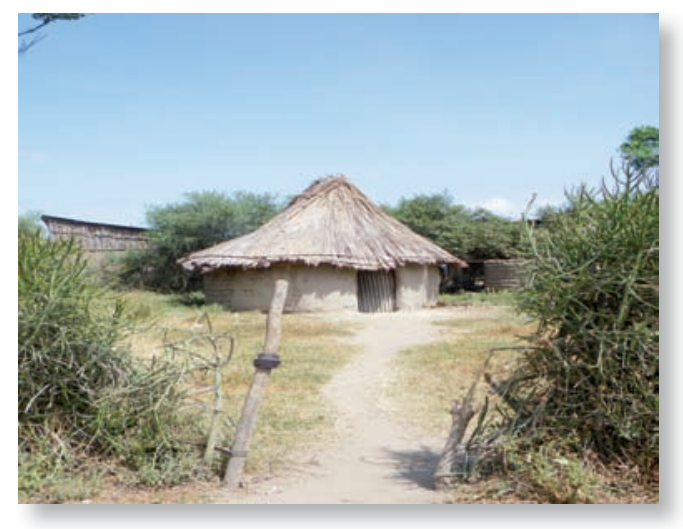

Imagen 3 Casa típica en Meki

\section{AGRADECIMIENTOS.}

A Ana Sendagorta, por su decisión y su alegría por su fuerza que nos inunda. A Jorge y Mar por su compresión y por acogernos en su casa. A los niños del orfanato por la ilusión de una oportunidad. A Carmen Chamizo por su paciencia y su compañía, por ayudarnos a encontrar nuestro camino. 


\section{Historia}

\section{Primeras intervenciones higiénico - sanitarias en el ámbito escolar: el caso de Navarra}

Early sanitary and hygienic measures in schools: the case of Navarre

Primeiras intervenções higiênico - sanitárias no âmbito escolar: o caso de Navarra

Rebeca Ema Maté1, Maider Ema Maté2.

${ }^{1}$ Diplomada en Enfermería por la Universidad de Navarra. Enfermera en el Servicio Navarro de Salud, Osasunbidea. ${ }^{2}$ Diplomada en Enfermería por la Universidad de Navarra. Enfermera en el Hospital Dr. José Molina Orosa. Lanzarote. Servicio Canario de Salud.

Cómo citar este artículo en edición digital: Ema Maté. R. y Ema Maté, M. (2015). Primeras intervenciones higiénico - sanitarias en el ámbito escolar: el caso de Navarra. Cultura de los Cuidados (Edición digital), 19(43). Disponible en: $<$ http://dx.doi. org/10.14198/cuid.2015.43.07>

Correspondencia: C/Juslarrocha 24-4ºD. C.P. 31014 Pamplona.

Correo electronico: remamat2002@yahoo.es

Recibido: 13/07/2015; Aceptado: 12/10/2015

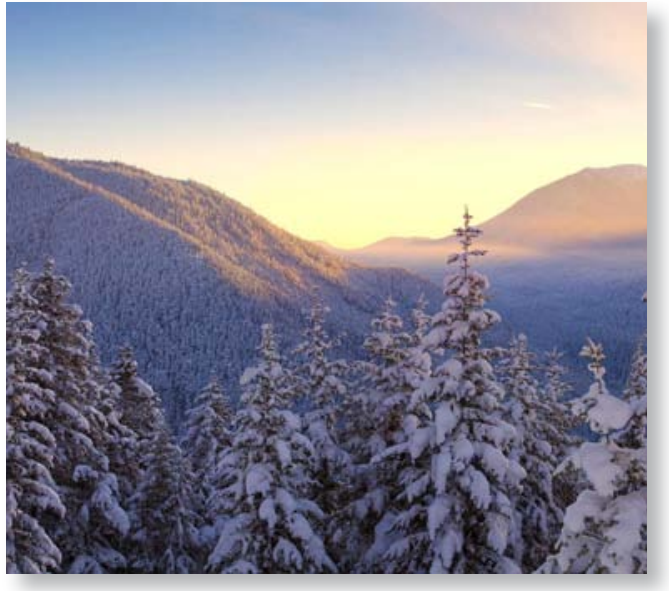

\section{ABSTRACT}

The appearance of the hygienist movement in the mid-nineteenth century, social and educational changes linked to the schooling process that took place in this century and the scientific study of childhood, developed at the turn of the century period, led to a growing concern for school hygiene.

This article intends to describe the first sanitary and hygienic measures taken by both municipal authorities as by health and education authorities, on school population of Navarre at the time of a public system establishment of primary education. As in most local governments throughout $\mathrm{Na}$ varre Restoration, including Pamplona, the attention to the supply of primary education was dependent on hardship and limitations. The situation was even worse, with regard to hygienic-educational field by a shortage of institutions designed to relieve the poor health of schoolchildren in disadvantaged social classes. The first test for municipal authorities, as well as faculty and medical corps were cholera pandemics of 1855 and 1885. These and other epidemics had consequences that, as well as support and control, performed the first steps for the creation, years later, of the health-school inspection.

Keywords: School Hygiene, health education, infectious diseases, Pamplona nineteenth century. 


\section{RESUMO}

Com o aparecimento do movimento higienista, em meados do século XIX, as mudanças sociais e educativas ligadas ao processo de escolarização que tiveram lugar neste século e o estudo científico da infância, desenvolvido no período de entre séculos, propiciaram uma preocupação crescente pela higiene escolar.

Este artigo pretende descrever as primeiras atuações higiênico - sanitárias, tanto das autoridades municipais como das sanitárias e educativas, sobre a população escolar de Navarra no momento de implantação de um sistema público de instrução primária. Como na maioria dos municípios navarros ao longo da Reabilitação, incluído o de Pamplona, a atenção à provisão de educação primária estava sujeita a privações e limitações. A situação era, inclusive pior, no relativo ao âmbito higiênico-pedagógico pela escassez de instituições orientadas a paliar a deficiente saúde dos escolares das classes sociais mais desfavorecidas.

O primeiro desafio para as autoridades municipais, assim como para os docentes e sanitários, foram as pandemias de cólera-morbo de 1855 e 1885. As repercusões que tiveram estas e outras epidemias, assim como as contribuições e o controle realizado, foram os primeiros passos para a criação, anos mais tarde, da inspeção sanitária escolar.

Palavras-chaves: Higiene escolar, educação para a saúde, doenças infecciosas, Pamplona século XIX.

\section{RESUMEN}

La aparición del movimiento higienista a mediados del siglo XIX, los cambios sociales y educativos ligados al proceso de escolarización que tuvieron lugar en dicho siglo, y el estudio científico de la infancia, desarrollado en el período de entresiglos, propiciaron una preocupación creciente por la higiene escolar.

Este artículo pretende describir las primeras actuaciones higiénico - sanitarias, tanto de las autoridades municipales como de las sanitarias y educativas, sobre la población escolar de Navarra en el momento de implantación de un sistema público de instrucción primaria. Como en la mayoría de municipios navarros a lo largo de la Restauración, incluido el de Pamplona, la atención a la provisión de educación primaria estaba sujeta a estrecheces y limitaciones. La situación era, incluso peor, en lo relativo al ámbito higiénico-pedagógico por la escasez de instituciones orientadas a paliar la deficiente salud de los escolares de las clases sociales menos favorecidas.

La primera prueba de fuego para las autoridades municipales, así como para el profesorado y el cuerpo médico, fueron las pandemias de cólera morbo de 1855 y 1885 . Las repercusiones que tuvieron éstas y otras epidemias, así como las aportaciones y el control realizado, fueron los primeros pasos para la creación, años más tarde, de la inspección médico - escolar.

Palabras clave: Higiene escolar, educación para la salud, enfermedades infecciosas, Pamplona siglo XIX.

\section{INTRODUCCIÓN}

El siglo XIX representa, entre otras cosas, el inicio del higienismo como forma de entender la vida en el conjunto de la sociedad.

En Europa, el desarrollo de sociedades cada vez más urbanas, provocó profundas consecuencias económicas y políticas, además de otras de carácter social. Los movimientos migratorios hacia núcleos urbanos, cada vez más extensos, que crecían con escasas o nulas infraestructuras urbanísticas y sanitarias, 
la insalubridad de muchos barrios, la falta de depuración del agua de consumo y las limitaciones de las viviendas, que favorecían el hacinamiento, contribuyeron a la aparición de múltiples enfermedades de tipo infeccioso. Si a todo ello añadimos la mala alimentación, unida en muchos casos a la pobreza, consecuencia de la grave crisis económica de fin de siglo, ya tenemos el marco propicio que va a contribuir a una toma de conciencia, cada vez mayor, sobre el problema de la higiene y la salud (López Núñez, 1992).

De esta manera, surge en toda Europa un movimiento en defensa de la higiene promoviendo medidas higiénico-sanitarias para luchar de manera eficaz contra las múltiples enfermedades contagiosas, producidas por las malas condiciones de vida erradicando los focos infecciosos (Terrón, 2000).

Esta preocupación por la sanidad y el higienismo escolar surge de la conjunción de tres factores primordiales:

En primer lugar, la importancia dada al higienismo en la escuela era una consecuencia del cambio en la nueva percepción de la infancia. La infancia había adquirido interés y se empezaba a considerar como una etapa de la vida con especificidad propia y esencial para el desarrollo individual y social. Fueron quedando atrás, poco a poco, las prácticas degradantes, la indolencia, cuando no la crueldad con la que hasta el siglo XIX se había venido tratando a los niños (Robertson, 1982).

En segundo lugar, es evidente que el interés de los diferentes Estados no estaba puesto exclusivamente en cuestiones de pura humanidad, más bien se trataba de una apuesta de la burguesía gobernante por lograr una sociedad próspera y segura para lo cual era necesario el logro de una clase trabajadora vigorosa y de unos futuros ciudadanos sanos, capaces de ser más productivos para el desarrollo económico de la nación y con una mayor preparación física para la defensa militar de la nación.

Por último, las autoridades nacionales $y$ también las locales y sanitarias, habían llegado al convencimiento de que la escuela, por la asistencia obligatoria, era el lugar privilegiado para desarrollar todo tipo de actividades de carácter higienista; desde las propiamente instructivas o divulgativas hasta las punitivas, pasando por aquellas de carácter preventivo.

En este artículo nos vamos a circunscribir al nacimiento de la preocupación por estos temas en relación con el control de las enfermedades contagiosas en Navarra desde finales del siglo XIX hasta los primeros años del siglo.

\section{MATERIAL Y MÉTODOS}

Este trabajo corresponde a una investigación archivística y por tanto, las fuentes documentales manuscritas constituyen la base de la misma. Se ha llevado a cabo un estudio histórico-documental en el Archivo Municipal de Pamplona durante el año 2014. Entre los diversos tipos de documentación manejada, se encuentran, en primer lugar, los Libros de Actas de la Junta Local de Sanidad. En segundo lugar, hemos consultado los diversos expedientes originados por instituciones $y$ organismos diversos, que van desde el propio Ayuntamiento hasta la Junta Provincial de Instrucción Pública de Navarra. La revisión de la documentación ha llevado a cabo desde un punto de vista histórico, social y sanitario. Hemos tratado de adoptar un método genérico y flexible que se adaptase a una situación muy concreta dentro de un marco regional. El método utilizado es una reflexión sintética desde la óptica de los cuidados de la salud y la dialéctica entre profesionales sanitarios, educadores y políticos. 
El procedimiento a seguir ha consistido en recopilar documentación publicada desde el año 1855 (primera epidemia de cólera) hasta finales del siglo XIX. Si tenemos en cuenta que dicha documentación tiene distintas procedencias hemos podido estudiar la información proporcionada para luego contrastarla. Posteriormente hemos procedido al análisis hermeneútico de toda la información recolectada. Por último, hemos utilizado técnicas cuantitativas en la medida que los datos obtenidos de las fuentes nos lo han permitido.

En cuanto a la bibliografía utilizada, además del catálogo de los fondos bibliográficos de la Universidad Pública de Navarra, se ha consultado también en la biblioteca general de Navarra lo que ha permitido una necesaria contextualización del tema, sobre aspectos sanitarios, históricos y/o educativos relacionados con Navarra. El conjunto de todas las fuentes primarias y secundarias han contribuido a guiar la investigación y a elaborar un análisis interpretativo de toda la información. En cualquier caso, han servido para esclarecer y comparar los datos ofrecidos.

\section{CRECIMIENTO VEGETATIVO, POBLA- CIÓN INFANTIL Y EPIDEMIAS}

La mayoría de autores coinciden en considerar como población escolar aquella que estaba obligada a acudir a la escuela según la legislación contemplada en cada momento. Ahora bien, el Reglamento de Instrucción Primaria Elemental de 1838 señalaba en su artículo doce que para ser admitidos en la escuela los niños debían tener por regla general, de seis a trece años. Mientras que la Ley Moyano de 1857, en el artículo séptimo, ordenaría la obligatoriedad desde los seis años hasta los nueve.

Por otra parte, Navarra mantenía vigente su legislación educativa, en tanto en cuanto no se opusiera a lo dictaminado por la Ley de Fueros de 1841. La Ley XLI de las Cortes de Navarra de los años 1780 y 1781 ordenaba “...que como de nada sirva el tener buenos Maestros, si no hay concurso de niños en las Escuelas y en esto consista el mayor daño: Que de aquí adelante en todos los Pueblos donde huviere (sic) Maestro, y Escuela abierta, deban todos los Niños concurrir desde la edad de cinco años cumplidos, hasta la de doce, también cumplidos.... Consecuentemente, el Plan y Reglamento General para las escuelas de Primeras Letras del Reino de Navarra de 1831 que la Junta Superior de Primera Educación elaboró, recoge esta norma y la incorpora al artículo 65: "Estando obligados por Ley a asistir a las escuelas todos los niños de este Reino desde la edad de 5 años, hasta los doce cumplidos, cuidaran sus padres o tutores de presentarlos en ellas con la debida puntualidad" (Legajo, 6a, no 46 bis).

Así pues, teniendo en cuenta todo lo anterior, se han efectuado los cálculos que vienen a continuación sobre la población comprendida entre los tres y los seis años, por una parte, $y$ desde los seis hasta los doce años, por otra. El límite inferior de los tres años se ha fijado en función de la existencia -desde 1842- de una escuela de párvulos que admitía niños con edades comprendidas entre los dos años y medio y los seis, además de constatar la asistencia a numerosas escuelas privadas y públicas de niños menores de seis años. Por otra parte, el límite superior de los doce años viene a ser el más considerado por la generalidad de autores, además de concordar con la mayoría de los datos aportados por los maestros a las estadísticas solicitadas por la Junta Provincial o Local.

Las fuentes básicas utilizadas para la realización de los Cuadros 1 y 2 han sido los censos de población de los años 1877 y 1887 y los padrones municipales correspondientes a los 
años 1857 y 1860 . No se han podido utilizar los censos de estos dos últimos años, ya que los criterios seguidos para su realización en cuanto a intervalos de edad no es coincidente con el de los censos 1877 y 1887.

En cualquier caso, ha sido necesario realizar el cálculo de los intervalos de los cuadros a partir de las cifras ofrecidas. La falta de datos generales sobre la población infantil en los padrones municipales de los años $1857 \mathrm{y}$ 1860 nos ha obligado a realizar un minucioso recuento calle por calle de los niños comprendidos en las edades ya señaladas. Es posible, por otra parte, que exista un pequeño margen de error en las cifras ofrecidas, debido fundamentalmente a la elaboración del propio padrón o a la ilegibilidad de algunas de las cifras, que sin embargo no creemos que modifiquen sustancialmente las conclusiones que podamos extraer. Como ya es sabido, los intervalos de edad ofrecidos por censos y padrones no coinciden exactamente entre sí, por lo que se impone hablar de población infantil estimada.

Una vez hechas las necesarias precisiones metodológicas y con las cautelas propias que requiere la visión general derivada de los datos así obtenidos, podemos realizar algunas observaciones que llaman la atención al analizar las cifras de los Cuadros 1 y 2.

Si consideramos el grupo de edad entre tres y seis años, se observa que en el periodo analizado se produjo un aumento total de 553 niños, lo que supone un $60^{\prime} 7 \%$, que en los pri- meros años (1857-1860) llegó a ser negativo, es decir, un decrecimiento del 4'7\%. Estas cifras nos permiten afirmar que de 1857 a 1877 las necesidades de escolarización de los niños entre tres y seis años se mantuvieron estables, para aumentar de forma considerable en el último periodo intercensal, como se puede apreciar en el Cuadro 1. Vemos pues que las demandas de escolarización para los párvulos -tres a seis años- en 1887, podrían haber tenido un aumento importante, aunque no tanto como el de la edad escolar propiamente dicha.

Entre 1857-1860, el ritmo de incremento en el tramo de edad escolar -seis a doce años- es irrelevante, el 4'4\% frente a los dos periodos siguientes (1860-1877 y 1877-1887), en los que el aumento es del 22\% y 49'5\%, respectivamente. A lo largo de estos treinta años, el incremento en cifras absolutas es de 2.116, lo que representa un aumento del 80'5\%. Esto, en principio, nos hace pensar en un fuerte aumento de la demanda de plazas escolares durante el último cuarto del siglo XIX.

En relación al sexo, el número de niños durante el último periodo intercensal (18771887) crece once puntos porcentuales más que el de las niñas (véase Cuadro 2). Mientras que el número de niñas en edad escolar aumentaba en un $44 \%$, el de niños lo hacía en un 55'6\%, lo que nos puede indicar una demanda mayor de escolarización masculina frente a la femenina, si atendemos exclusivamente a la variable de crecimiento de población en edad escolar.

\section{CUADRO 1. POBLACIÓN INFANTL PAMPLONESA ESTIMADA (1857-1887)}

\begin{tabular}{|c|c|c|c|}
\hline AÑO & DE 3 A 6 AÑOS & DE 6 A 12 AÑOS & TOTAL \\
\hline $\mathbf{1 8 5 7}$ & 911 & 1.716 & 2.627 \\
\hline $\mathbf{1 8 6 0}$ & 868 & 1.792 & 2.660 \\
\hline $\mathbf{1 8 7 7}$ & 972 & 2.193 & 3.165 \\
\hline $\mathbf{1 8 8 7}$ & 1.464 & 3.279 & 4.743 \\
\hline
\end{tabular}


CUADRO 2. POBLACIÓN INFANTIL PAMPLONESA (1877-1887)

\begin{tabular}{|l|c|c|c|c|c|c|c|}
\cline { 2 - 8 } \multicolumn{1}{c|}{} & \multicolumn{3}{c|}{ DE 3 A 6 AÑOS } & \multicolumn{4}{c|}{ DE 6 A 12 AÑOS } \\
\hline AÑO & Niños & Niñas & Total & Niños & Niñas & Total & TOTAL \\
\hline $\mathbf{1 8 7 7}$ & 453 & 519 & 972 & 1.040 & 1.153 & 2.193 & 3.165 \\
\hline $\mathbf{1 8 8 7}$ & 714 & 750 & 1.464 & 1.619 & 1.660 & 3.279 & 4.743 \\
\hline
\end{tabular}

CONTROL DE LAS ENFERMEDADES INFECCIOSAS EN LAS ESCUELAS

Los ayuntamientos de Navarra debían velar por la salubridad y la higiene de la población, implantando las medidas higiénicas más adecuadas en cada momento. El Ayuntamiento de Pamplona contaba al respecto con unas nuevas ordenanzas municipales desde abril de 1899, las cuales habían sido sometidas al examen de la Diputación y de la Comisión de Asuntos Médicos de la Junta Provincial de Sanidad.

Las primeras intervenciones públicas en relación con problemas higiénico - sanitarios en el medio escolar en Navarra, de las que tenemos noticia documentada, hacen referencia a las epidemias de cólera morbo asiático de 1855 y 1885.

Las epidemias afectaron de manera desigual al conjunto de la población. Sin embargo, del total de afectados por la enfermedad en Pamplona desde el 25 de agosto hasta el 10 de septiembre de 1855 -meses en los que la enfermedad cobra mayor virulencia-, solamente el $12^{\prime} 84 \%$ eran niños/as. Mientras que los fallecidos por su causa fueron el $16^{\prime} 4 \%$ de niños, frente al 54\% de mujeres y al 29'3\% de hombres. Los datos recogidos del Hospital de Coléricos que instaló el Ayuntamiento confirman la misma tendencia; tanto los niños ingresados (de 1 a 10 años) como los fallecidos superaban escasamente la cifra del $4 \%$.

De los 861 muertos a causa de la enfermedad, el conjunto de los niños fallecidos en edad escolar solamente habría supuesto el 0’84\% de la población total de la ciudad. Los cálculos están realizados sobre el número total de habitantes de la ciudad (16.827) (Padrón Municipal 1855).

Por otra parte, en 1855 no fue considerablemente mayor el número total de niños fallecidos que en años inmediatamente posteriores, tal y como podemos comprobar en el cuadro 3 si bien es preciso señalar que los escasos datos obtenidos en las cuatro parroquias de la ciudad no nos permiten establecer una relación precisa, fundamentalmente por la falta de obituarios de párvulos de estas fechas en dos de las parroquias (San Lorenzo y San Juan Bautista).

En segundo lugar, durante el periodo que duró la epidemia, la mortalidad general aumentó; los cadáveres eran conducidos directamente desde las casas al cementerio público según una orden del Gobernador de la provincia. En tales circunstancias, muchos padres no daban parte de la muerte de los niños a los párrocos correspondientes, por lo que es muy probable que falten las partidas de algunos párvulos y que por tanto las anotaciones tengan considerables descuidos.

Del análisis de los datos obtenidos y de todo lo hasta aquí expuesto, podemos deducir que, frente a lo que en principio pudiera suponerse, las epidemias de cólera no incidieron de forma especial en la población en edad escolar; bien al contrario parece ser el grupo de edad menos afectado. Por tanto, las invasiones de cólera de 1855 y 1885 no entorpecieron el proceso escolarizador más que en la medida en que una epidemia de estas características 
CUADRO 3. PÁRVULOS FALLECIDOS EN LAS PARROQUIAS DE PAMPLONA (1855-1858)

\begin{tabular}{|l|c|c|c|c|c|c|c|c|c|c|c|c|}
\multicolumn{1}{c|}{} & \multicolumn{3}{c|}{ S. NICOLÁS } & \multicolumn{3}{c|}{ S. SATURNINO } & \multicolumn{3}{c|}{ S. LORENZO } & \multicolumn{3}{|c|}{ S. JUAN } \\
\hline $\mathbf{A} \tilde{\mathbf{N O}}$ & $\mathbf{V}^{*}$ & $\mathbf{H}^{*}$ & $\mathbf{T}^{*}$ & $\mathbf{V}$ & $\mathbf{H}$ & $\mathbf{T}$ & $\mathbf{V}$ & $\mathbf{H}$ & $\mathbf{T}$ & $\mathbf{V}$ & $\mathbf{H}$ & T \\
\hline $\mathbf{1 8 5 5}$ & 48 & 31 & 79 & 42 & 30 & 72 & - & - & - & - & - & - \\
\hline $\mathbf{1 8 5 6}$ & 38 & 33 & 71 & 16 & 18 & 34 & - & - & - & - & - & - \\
\hline $\mathbf{1 8 5 7}$ & 31 & 36 & 67 & 40 & 48 & 88 & - & - & - & - & - & - \\
\hline $\mathbf{1 8 5 8}$ & 42 & 29 & 71 & - & - & - & - & - & - & - & - & -
\end{tabular}

* V.- Varones. H.- Hembras. T.- Total.

alteró el conjunto de la vida ciudadana de la pequeña capital.

No obstante lo anteriormente dicho, las autoridades, por medio del Gobernador Civil, de la Junta Provincial de Sanidad y las Juntas Locales de Instrucción Pública, trataban de poner diversos remedios que evitasen la propagación de la epidemia, dictando severas medidas sanitarias. Las autoridades sanitarias y municipales ordenaron el blanqueo de habitaciones, desinfección de alcantarillas y limpieza de bajeras y letrinas (Arazuri, 1967).

En el ámbito escolar ya se venían adoptando algunas medidas preventivas encaminadas a evitar el contagio en las aulas desde años anteriores, tal es el caso de la circular del Gobernador, que el 11 de agosto de 1884 ordena el cierre de todas las escuelas públicas de la provincia durante el mes de agosto, para que, aprovechando su clausura, se desinfecten y blanqueen, limpiando sus alrededores. En cuanto a las escuelas privadas, solamente debían cerrarse en caso de que las Juntas Locales considerasen que no reunían las condiciones higiénicas y pedagógicas adecuadas (B.O.N. $\mathrm{n}^{\circ}$ 17, 11, agosto, 1884). Estas medidas contribuyeron a paliar en gran medida los efectos mortíferos de la enfermedad sobre la población escolar. El mismo año de la epidemia, la Junta Provincial de Sanidad publica en el Boletín Oficial de Navarra las medidas que se deberán adoptar en las escuelas públicas (B.O.N. $n^{\circ}$ 17, 17, Julio, 1885):

“...teniendo en cuenta las malas condiciones higiénicas y pedagógicas de la presente estación canicular acuerda: 1.- La supresión de las clases por la tarde desde su publicación y hasta todo el mes de Agosto. 2.- En aquellos pueblos donde las salas de clase no reúnan las condiciones de salubridad, se suspenden las clases totalmente. Los maestros podrán ausentarse de la localidad ya para tomar los Baños ya para asuntos particulares".

En septiembre, y a pesar de haber remitido la epidemia de forma considerable, el Gobernador de la provincia ordena en una circular (B.O.N. no 33, 16, Septiembre, 1885) que: "1.En todos aquellos pueblos que hayan sido invadidos por la epidemia colérica continuaran cerradas las escuelas. $2^{\circ}$.- En todos los demás pueblos que no han sido invadidos, y en aquellos en que a pesar de haberlo sido se ha cantado el Te Deum en acción de gracias por haber desaparecido la epidemia, se restablecerán las clases por la mañana y tarde en todos los días lectivos, desde el siguiente en que sea recibido el Boletín oficial con la presente circular".

Continuaba la circular advirtiendo a los maestros para que tuvieran especial cuidado en la limpieza e higiene de las salas de clase, exhortándoles a ser más escrupulosos que en otras épocas “...en las revistas de aseo y lim- 
pieza que a sus discípulos diariamente pasan, con el fin de que todos estén perfectamente limpios y aseados" (B.O.N. no 33, 16, Septiembre, 1885). En el mes de octubre, el Ayuntamiento de Pamplona, en oficios dirigidos a los directores de los centros escolares, autoriza la apertura de todas las escuelas de la ciudad (Legajo 29 - 4).

Las enfermedades causantes de mayor mortalidad entre los escolares de Pamplona en el último tercio del siglo XIX fueron las infecciosas; el alza de los precios en los productos básicos y la consecuente aparición del hambre, unida al clima extremado y variable de la ciudad contribuían a agravar las condiciones de vida de las clases sociales más desfavorecidas, en cuyos miembros se ensañaban las enfermedades y en última instancia la muerte. Según Cipriano Monzón, Pamplona se distinguía de otras poblaciones en lo que a defunciones infantiles se refiere, “...en el gran exceso de mortalidad por tuberculosis; en el exceso de fallecidos por enfermedades del aparato respiratorio sobre las del aparato digestivo" (Monzón, 1903). A su juicio la causa estaba en un déficit de aire no sólo en las viviendas por las malas condiciones para la ventilación, sino en el mismo recinto urbano a causa de las condiciones climáticas de Pamplona. Sin embargo, otras enfermedades infecciosas como la temible tuberculosis no eran patrimonio exclusivo de los pamploneses. En España, en 1900, hubo 36.566 defunciones producidas por tuberculosis, lo que suponía el doble de víctimas que entre todas las demás enfermedades infecciosas juntas (Dirección General del Instituto Geográfico y Estadístico 1901).

Otra de estas enfermedades, la viruela, fue bastante pertinaz, sobre todo en la última década del siglo, obligando a cerrar las escuelas públicas de la ciudad en el verano de 1891
(Libro de actas de la J.L.I.P. 3, sept. 1891). En 1896, la Junta Local de Instrucción procede a la clausura de la escuela pública de la calle $\mathrm{Ma}$ yor dos veces en un corto periodo de tiempo “...por causa de la viruela" (Libro de actas de la J.L. de Sanidad 18, enero 1896). Junto al cierre de escuelas se procedía a la fumigación de los retretes y de las aulas blanqueándolas “... mezclando a la cal una disolución de bicloruro de mercurio al dos por mil y arrojar al suelo serrín humedecido con ácido fénico para preparar el barrido" (Libro de actas de la J.L. de Sanidad 20, oct. 1896). Por otra parte, se había enviado al practicante de la Beneficencia domiciliaria a que vacunara por cuenta del municipio a los niños que no lo estuvieran. Este tipo de iniciativas todavía despertaban recelos en algunas familias lo que obligó a la expulsión de dos niños de las escuelas públicas de Calderería cuyos padres se habían negado a que fueran vacunados.

Por otra parte, la deseable alianza del médico y del maestro para esta tarea no siempre fue fácil como veremos a continuación.

En enero de 1896, la Junta Local de Sanidad acordó dirigirse a los maestros “.... a fin de que inspeccionaran cuidadosamente a los alumnos, debiendo en el momento que dejara de concurrir alguno de ellos a las aulas, avisar a sus padres, que no serían admitidos nuevamente a ellas si, habiendo padecido alguna enfermedad contagiosa, no presentaran el certificado facultativo correspondiente en que se hiciera constar que había desaparecido el peligro de contagio para los demás alumnos" (Libro de actas de la J.L. de Sanidad 18 enero 1896). Pero las epidemias de viruela no sólo traían consigo consecuencias nefastas para la población escolar, sino que también acarreaban perjuicios a maestros que tenían instaladas sus escuelas privadas en barrios ex- 
tramuros como el de la Rochapea. En 1899, el maestro Florencio Yoldi recibe la orden de cerrar su escuela al producirse un caso de viruela en la casa donde tenía establecida la misma con el consiguiente perjuicio económico. Ante estos hechos se dirige al Ayuntamiento para que éste le conceda, provisionalmente y mientras durase la epidemia en la casa que ocupaba, un local para instalar su escuela en la antigua fábrica del gas propiedad del Ayuntamiento, “...pues de no ser así y en el supuesto de que la enfermedad variolosa(sic) se propague en la casa y fuere largo el periodo de vacaciones, además de los perjuicios que en ese tiempo se irrogarían al exponente; podría darse el caso de que los niños pudientes o de pago que hoy concurren se fueran a otras escuelas de la población y esto sería lo más doloroso y la ruina del que suscribe" (Legajo 46B/46C - 60).

Otra de las enfermedades epidémicas habituales de la infancia era el sarampión. Ya en diciembre de 1896 se tiene noticia de varios casos en la capital por lo que la Junta Local de Sanidad aconsejaba “...se observara mucha vigilancia en las escuelas para evitar que los niños que estuvieran enfermos acudieran a ellas y que volvieran a las aulas sin certificado del facultativo los que hubieran pasado el sarampión"(Libro de actas de la J.L. de Sanidad 16 de dic. 1896). En mayo de 1901, el alcalde dirige un oficio a todos los maestros de las escuelas públicas y colegios particulares y al Dr. Antonio Gayarre, decano de la Beneficencia Municipal con motivo de la epidemia de sarampión. En dicho oficio se hacía constar lo siguiente: “...el artículo 182 de las ordenanzas de policía urbana de esta capital dispone que los directores de colegios y escuelas no admitirán en sus clases a los alumnos que no estén vacunados ni a los que tengan en la cabeza enfermedades repugnantes a la vista o que hayan padecido o padezcan enfermedades infecciosas como sarampión, viruela, escarlatina, difteria, tifoidea, etc., hasta no haber transcurrido dos meses después de haber pasado la enfermedad" (Legajo 63). En carta enviada a la maestra de párvulos Joaquina Ezcurra se recrimina su actitud por haber admitido, sin haber transcurrido el plazo, a algunos niños que habían padecido el sarampión.

Otras de las enfermedades que causaron alta mortalidad infantil eran las afecciones relacionadas con el aparato respiratorio que en 1891 causaron la muerte de 184 niños. Estas enfermedades se propagaban con facilidad ya que según el Dr. Agustín Lazcano en Pamplona "Respiramos un aire infeccionado, como es natural supuesta la considerable densidad de población en un perímetro tan reducido" (Lazcano, 1903). No es de extrañar que, sobre todo, en los meses de invierno, se recomendara a los maestros que no elevaran demasiado la temperatura de las salas de clase “... a fin de no viciar demasiado la atmósfera, y para evitar el cambio brusco que de otro modo experimentarían los alumnos al salir a las calles, y las fatales consecuencias que esto podría originar a la salud de los mismos, que carecen por su edad del necesario conocimiento para tomar las debidas precauciones al cambiar la temperatura" (Libro de actas de la J.L.I.P. 28, oct. 1896).

\section{CONCLUSIONES}

A través de esta breve aportación, hemos tratado de poner de relieve algunos aspectos en torno a las primeras intervenciones higiénico - sanitarias por parte, tanto de las autoridades sanitarias como de las educativas, en torno a la población escolar de Navarra. Podemos afirmar que las primeras epidemias de cólera morbo, durante la segunda mitad del siglo XIX, contra lo que pudiera parecer, no afecta $\neg$ ron 
de manera especial a la población en edad escolar por lo que el proceso escolarizador no se vio alterado de manera signifi $\neg$ cativa.

En segundo lugar, hemos comprobado que la decidida intervención, a través de las primeras actuaciones higiénicas, de carácter preventivo de las autoridades y de los profesionales sanitarios y educativos en las escuelas, fueron esenciales para controlar no sólo de las epidemias de cólera sino también de otras enfermedades infecciosas como el sarampión, viruela, escarlatina, difteria y tifus. Se evitó su mayor propagación gracias a las normas que se prescribieron así como a la colaboración de los maestros que las llevaron a cabo consiguiendo de esta manera disminuir la mortalidad infantil y elevar el nivel sanitario de los escolares y por consiguiente del conjunto de la población..

Estas primeras intervenciones sirvieron de pauta y constituyeron el germen para la creación primero de la inspección municipal de Sanidad y posteriormente de la inspección médico - escolar.

\section{FUENTES}

- Archivo parroquial de San Saturnino. 20 Libro de párvulos $n^{\circ} 155$.

- Archivo parroquial de San Nicolás. 1 Libro de párvulos difuntos $n^{\circ} 88$.

- Archivo Municipal de Pamplona. Actas de la Junta Local de Instrucción Primaria. Libro 2º (1878-1896).

- Archivo Municipal de Pamplona. Sección de Enseñanza Pública. Legajos 29, 46B/46C y 63.

- Archivo Municipal de Pamplona. Sección Padrón municipal. Años 1855, 1860 y 1880: Legajos 110 a 120. Libros de Actas de la Junta Local de Sanidad. Legajos 9 y 10.

- Boletín Oficial de Navarra. (1847-1900). Archivo General de Navarra. Sección Instrucción Pública. Legajo $6^{\circ}$, no 46 bis. Pamplona.

- Dirección General del Instituto Geográfico y Estadístico (1901). Movimiento anual de la población de España.
Año 1900. Segunda parte. Defunciones clasificadas por edades y por causas de mortalidad. Madrid: Ministerio de Instrucción Pública.

- Lazcano, A. (1903). Higiene y salubridad públicas en Pamplona. Pamplona: Imp. de Juan Sanz.

- Masip Budesca, E. (1926). Higiene escolar. Madrid: Imp. Municipal.

- Monzón, C. (1903). Mortalidad infantil en Pamplona. Pamplona: Tipografía Católica.

- Redondo, E. (1912). La inspección médica en las escuelas. El Liberal, 11.842: 2.

- Tolosa Latour, M. (1897). Un problema de Higiene escolar. Madrid: Imp. de los Hijos de M. G. Hernández.

\section{BIBLIOGRAFÍA}

- Anaut Bravo, S. (2001). Luces y sombras de una ciudad. Los límites del reformismo social y del higienismo en Pamplona. Pamplona: Ayuntamiento de Pamplona-Universidad Pública de Navarra.

- Arazuri, J. J. (1967). Pamplona antaño. Pamplona: Edit. Gómez.

- Beltrán Aguirre, J. L., Iriarte Amigot, N. (1991). Recopilación de la legislación sanitaria de Navarra. Pamplona: Gobierno de Navarra.

- Cohen Amselem, A. (1996). La mortalidad de los niños. En Borrás, J. Ma ., Historia de la infancia en la España contemporánea (1834-1936) (PP.185-188). Madrid: Ministerio de Trabajo y Asuntos Sociales-Fundación Germán Sánchez Ruipérez.

-Del Pozo Andrés, Ma. M. (2000). Salud, higiene y educación desarrollo de la inspección médico-escolar en Madrid (1900-1931). Áreas, 20, 95-119.

- Esplugues, J. X., Robles, E. (1997). Higiene i salubritat en els municipis valencians. En Seminari de Estudis sobre la Ciencia. (13-16). Valencia: Trobades.

- Fernández Soria, J. M. y Mayordomo Pérez, A. (1984). Perspectiva histórica de la protección a la infancia en España. Historia de la Educación. Revista Interuniversitaria, 3, 191-214.

- Gómez Redondo, R. (1992). La mortalidad infantil española en el siglo XX. Madrid: Siglo XXI.

- López García, G. (1968). Asistencia Médica: Navarra. En 


\section{Cultura de las Cuidados}

Temas de cultura popular, 14. Pamplona: Diputación Foral de Navarra.

- López Núñez, A. (1992). Los inicios de la protección social a la infancia en España. Madrid: CEPE.

- Robertson, P. (1982). El hogar como nido: la infancia de la clase media en la Europa del siglo XIX. En De Mause, LL. Historia de la infancia.(pp.444-471). Madrid: Alianza.

- Ruiz Rodrigo, C., Palacio Lis, I. (1999). Higienismo, educación ambiental y previsión escolar. Antecedentes y prácticas de educación social en España (1900-1936).
Valencia: Universitat de València.

- San Martín, H. (1989). Salud pública y medicina preventiva. Barcelona: Masson.

- Siles, J. (2011). Historia de la enfermería. Madrid: DAE.

- Terrón Bañuelos, A. (2000). La higiene escolar: un campo de conocimiento disputado. Áreas 20, 73-94.

- Viñao Frago, A. (2000). Higiene, salud y educación en su perspectiva histórica. Áreas 20, 9-24.

- Viñes Rueda, J.J. (1997). La sanidad en Navarra 19261996. En Anales del Sistema Sanitario de Navarra.20. Pamplona: Gobierno de Navarra.

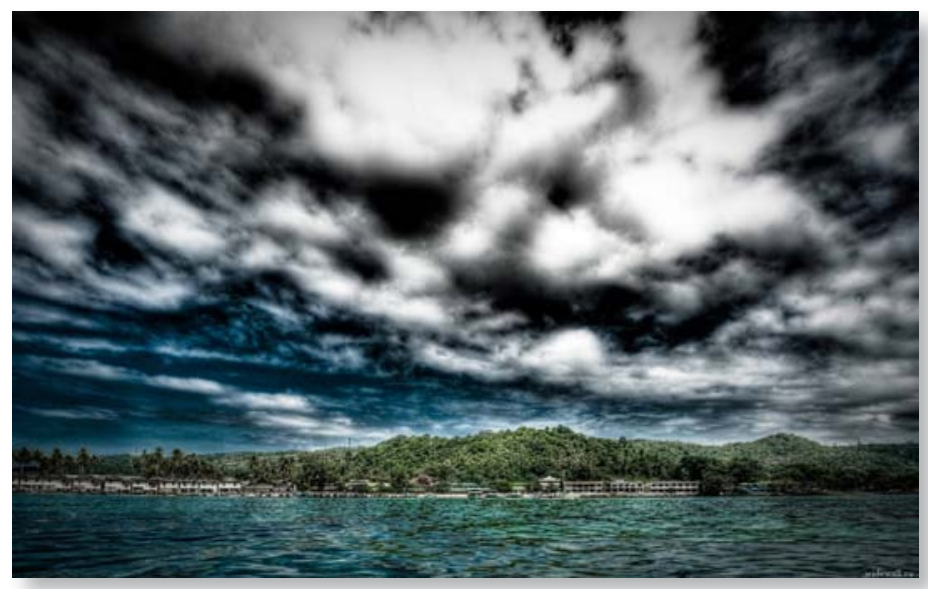




\title{
Las campañas de vacunación contra la poliomielitis en Jerez de la Frontera (1963-1965)
}

Vaccination campaigns against polio in Jerez de la Frontera

(1963-1965)

\section{As campanhas de vacinação contra a poliomielite em Jerez de la Frontera (1963-1965)}

\author{
Francisco Herrera-Rodríguez \\ Catedrático de Escuela Universitaria. Facultad de Enfermería y Fisioterapia (Universidad de Cádiz) \\ "Trabajo realizado en el marco del proyecto HAR2012-39655-C04-03 del MINECO"
}

Cómo citar este artículo en edición digital: Herrera Rodríguez, F. (2015). Las campañas de vacunación contra la poliomielitis en Jerez de la Frontera (1963-1965). Cultura de los Cuidados (Edición digital), 19(43). Disponible en:< http://dx.doi. org/10.14198/cuid.2015.43.08>

Correspondencia:FranciscoHerrera-Rodríguez.FacultaddeEnfermeríayFisioterapia.Avda.AnadeViya,52.11009-Cádiz. Correo electrónico: francisco.herrera@uca.es

Recibido: 09/06/2015; Aceptado: 11/10/2015

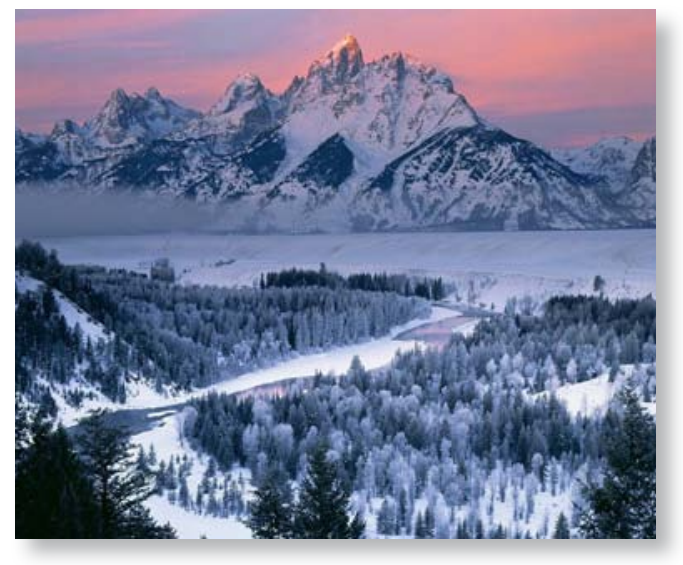

ABSTRACT

The aim of this article is to study the two phases of the poliomyelitis' vaccination campaign in the years 1963 and 1964, with the Sabin oral vaccine, in the city of Jerez de la Frontera (Cádiz). We also expound some data about the vaccination campaign in 1965 against polio, diphtheria, whooping cough and tetanus in the same city. We have used, in our study, original documents sources from Municipal Archives of Jerez, other archives and libraries of the province, as well as local, regional and national press, which have pro- vided us some information on the mentioned vaccination campaigns.

Key words: Polio Vaccination Campaign, Vaccination, Diphtheria, Pertussis, Whooping Cough, Tetanus, XX Century, Preventive Medicine, Sanitary Policy, Jerez de la Frontera, Cádiz, Spain.

\section{RESUMO}

Neste artigo temos que definir o objetivo de estudar as duas fases da campanha de vacinação contra a poliomielite em 1963 e 1964, com a vacina oral Sabin, na cidade de Jerez de la Frontera (Cádiz). Os dados também expor a campanha de vacinação contra a poliomielite em 1965, a difteria, coqueluche e tétano naquela cidade. Nós utilizado em nosso estudo fontes documentais originais Jerez Arquivos Municipais e outros arquivos e bibliotecas da província, bem como da imprensa local, regional e nacional, que nós fornecemos informações sobre as campanhas de vacinação que motivaram nossa pesquisa.

Palavras-chave: campanha de vacinação da Poliomielite, a vacinação, a difteria, co- 
queluche, tétano, Jerez de la Frontera, Cádiz, século XX, Medicina Preventiva, A política de Sáude, Jerez de la Frontera, Cádiz, Espanha.

\section{RESUMEN}

En el presente artículo nos hemos planteado como objetivo estudiar las dos fases de la campaña de vacunación contra la poliomielitis de los años 1963 y 1964, con la vacuna oral Sabin, en la ciudad de Jerez de la Frontera (Cádiz). Asimismo exponemos datos de la campaña de vacunación del año 1965 contra la poliomielitis, la difteria, la tos ferina y el tétanos en la referida ciudad. Hemos utilizado en nuestro estudio fuentes documentales originales del Archivo Municipal de Jerez y de otros archivos y bibliotecas de la provincia, así como prensa local, regional y nacional, que nos ofrecen información sobre las campañas de vacunación que han motivado nuestra investigación.

Palabras clave: Poliomielitis, Campaña de vacunación, Vacunación, Difteria, Tos ferina, Tétanos, Siglo XX, Medicina Preventiva, Política Sanitaria, Jerez de la Frontera, Cádiz, España.

A mis padres que en las fechas que estudia este trabajo se preocuparon de que no me faltara ninguna vacuna, tampoco la de la polio, la del terrón de azúcar.

\section{INTRODUCCIÓN}

El problema de la polioliomielitis en España ha concitado en los últimos años el interés de diversos investigadores, entre los que podemos citar a Águila Maturana (2000 y 2002), Muñoz Singi (2007); Tuells (2008), Rodríguez-Sánchez y Seco-Calvo (2009), Báguena Cervellera (2000 y 2009), Martínez Pérez (2009a y 2000b), Rodríguez-Sánchez (2010, 2012, 2013, 2014, 2015, etc.), Porras Gallo (2014), Porras Gallo et al. (2012 y 2013), Ba- llester y Porras (2009 y 2012), Nájera (2006 y 2013), Herrera (2006, 2011, 2012 y 2015), etc. Una atención especial se está dispensando en algunas de estas investigaciones a la lucha contra la enfermedad durante el franquismo, período sobre el que Ayarzagüena Sanz (2013) ha realizado una excelente síntesis del marco político, económico, social y cultural. Incluso el 2 de julio de 2013, el Ministerio de Sanidad, Servicios Sociales e Igualdad (con el título "Celebración del 50 aniversario de la instauración de las campañas de vacunación antipoliomielitis en España"), organizó un homenaje a la figura del médico e investigador Florencio Pérez Gallardo, figura crucial en la lucha contra la poliomielitis en los años cincuenta y sesenta. En este acto intervinieron Ferrán Martínez Navarro, Eduardo Fernández-Cruz Pérez, Luis Valenciano Clavel, Rafael Nájera Morrondo, Gloria Trallero Masso, Odorina Tello Anchuela, Francisco Salmerón García, Aurora Limia Sánchez y Jesús Pérez. En ese mismo año la Revista Española de Salud Pública publicó en sus páginas el trabajo clásico de Florencio Pérez Gallardo, Luis Valenciano Clavel y Jesús Gabriel y Galán: "Resultados de la campaña nacional de vacunación antipoliomielítica por vía oral en España (Estudio virológico y epidemiológico)"; estudio al que haremos alusión en este trabajo y también muy particularmente a la figura del médico de San Fernando (Cádiz), Florencio Pérez Gallardo (1917-2006) (Nájera, 2006a; Nájera, 2006b; Rey Calero, 2006; Domingo y Contreras, 2006).

No es de extrañar que la poliomielitis en la España de Franco preocupe a los investigadores, aunque evidentemente la enfermedad tiene una huella histórica que no podemos sintetizar en estas páginas. Ateniéndonos solo a España, a finales del siglo XIX y en las pri- 
meras décadas del siglo XX, debemos subrayar la excelente revisión realizada por Porras Gallo (2014). En la España franquista, pues, preocupó la morbilidad y la mortalidad que generaba esta enfermedad (figura 1), y desde la década de los cincuenta y de los sesenta toda la problemática de la vacunación, primero con la llamada vacuna Salk y posteriormente con la vacuna de Sabin. Aunque, como es sabido, uno de los puntos de debate que sostienen en la actualidad los investigadores es el de si las campañas de vacunación llegaron tardíamente o no a nuestro país, y por tanto se podrían haber reducido más tempranamente las cifras de morbilidad y de mortalidad por la poliomielitis, incluso a finales de los cincuenta el Jefe provincial de Sanidad de Cádiz planteó la escasa difusión en la provincia gaditana de la vacuna Salk (Aristoy-Santos, 1959).

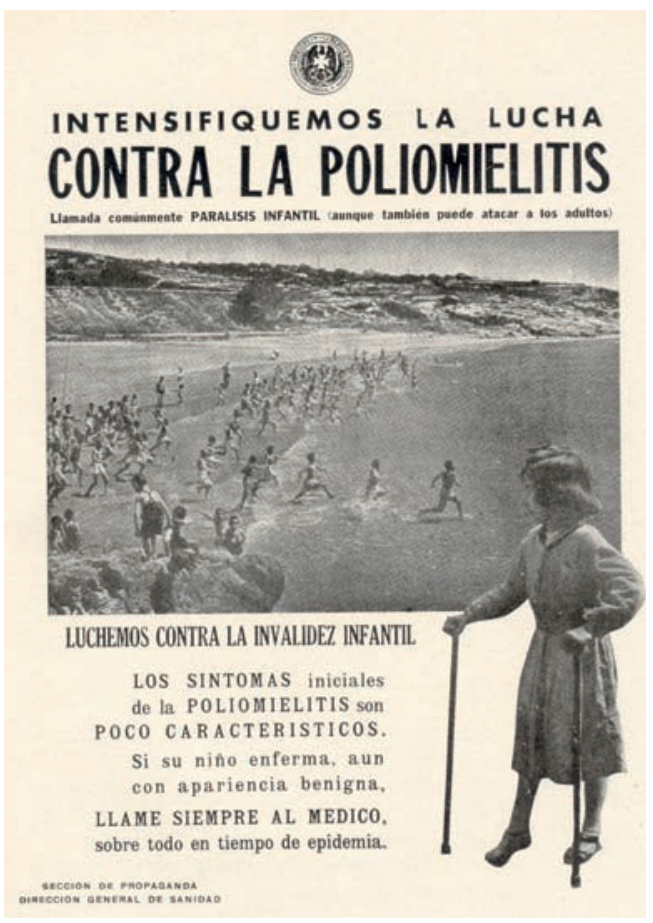

Figura 1: Cartel de la Dirección General de Sanidad para la lucha contra la poliomielitis. Fuente: González Rodríguez (1953).
El objetivo, pues, de nuestro trabajo es estudiar la organización de la campaña de vacunación contra la poliomielitis, con la vacuna oral Sabin, que se llevó a cabo en 1963 y 1964, en Jerez de la Frontera (Cádiz), en el contexto claro está de la campaña nacional; pero también nos proponemos comprobar si tuvo continuidad la vacunación contra la poliomielitis en Jerez en la siguiente campaña del año 1965.

Pero antes de exponer los resultados se impone que en esta introducción realicemos una breve reflexión sobre dos cuestiones concretas: en primer lugar una breve síntesis sobre la utilización de las vacunas de Salk y de Sabin contra la poliomielitis y en segundo lugar unos apuntes sobre la situación planteada por esta enfermedad en España y en la provincia de Cádiz en la década de los cincuenta y de los sesenta.

\section{Las vacunas de Salk y de Sabin}

En la historia de la investigación de la poliomielitis es de obligado cumplimiento resaltar la labor de muchos investigadores que desde la clínica o el laboratorio han contribuido a su mejor conocimiento y a paliar las graves secuelas que deja en las personas esta enfermedad (Herrera, 2011 y 2015). En este artículo tan solo recordaremos a Jonas Edward Salk (19141995) y Albert Bruce Sabin (1906-1993), investigadores que pusieron las bases para la lucha contra la poliomielitis con sus respectivas vacunas. El primero de ellos, Salk, a mediados de los años cincuenta aplicó la "vacuna inactiva$d a$ ", que se administraba intramuscularmente, mientras que la de Sabin era una "vacuna atenuada" que comenzó a suministrarse por vía oral a los niños con un terrón de azúcar a partir del año 1957. Sin los trabajos de estos investigadores no se podría haber puesto en marcha la vacunación masiva de la población. Aunque también se debe recordar que en EE.UU., entre 
1934 y 1935, Brodie y Kolmer, desarrollaron las primeras vacunas. Una contenía el virus inactivado y la otra el virus atenuado. Pero su administración produjo efectos adversos provocando casos graves de alergias, parálisis y muertes (León Rega y Echevarría, 2005). También cabe recordar los trabajos de Hilary Koprowski (1916-2013) que, junto con Jervis, planificó su ensayo en una residencia de niños con graves problemas mentales de Letchworth Village (Nájera, 2013b). No cabe duda de que la historia de la poliomielitis merece también una reflexión sobre el cumplimiento o no de los aspectos éticos en la experimentación en humanos.

Es importante apuntar que entre los años 1959 y 1963 se comenzó a utilizar la vacuna Salk en España, en niños que abarcaban la edad de cinco meses a los ocho años, concretamente en tres dosis, con un mes de intervalo, pero todo ello "con una baja cobertura de vacunación" (Pachón del Amo, 2004). Aunque también se debe precisar que la vacuna Salk estuvo disponible en España desde 1955, pero utilizándose de forma muy limitada en el ámbito de la medicina privada y no en campañas de vacunación propiciadas por las autoridades sanitarias "pese a la importante epidemia que sufría el país desde finales de los años 40". Se ha estimado que la decisión de combatir la epidemia de poliomielitis mediante campañas de vacunación promovidas y financiadas por los poderes públicos se tomó de forma muy tardía; si se hubiese utilizado activamente la vacuna de Salk desde el año 1956 "se hubieran evitado más de 12.000 casos de poliomielitis paralítica y más de 1.600 muertes por esta causa" (León Rega y Echevarria, 2005). También se ha apuntado el año 1957 como el de la introducción de la vacuna Salk: "La vacuna Salk introducida en 1957 se hace de forma individual, no asumi- da por la Seguridad Social y, aunque por una Orden del Ministerio de Trabajo (27.12.62) se ampliaba y se hacía gratuita, no tuvo ninguna influencia en la evolución de la enfermedad que, como ya hemos visto, desde 1957 a 1963, son los años de máxima incidencia" (Nájera, 2013a). Otros autores señalan que las campañas con Vacuna Salk se iniciaron en 1958 y que fueron llevadas a cabo por la Dirección General de Sanidad, fundamentalmente a través de las jefaturas provinciales $y$, si en éstas se consideraba oportuno, por los médicos titulares municipales (Rodríguez-Sánchez, 2010).

Nosotros hemos podido documentar vacunaciones con la vacuna Salk, en Cádiz capital, en los meses de febrero, marzo y abril de 1959, en la segunda mitad de 1960 y de 1961 a 1963, aunque no descartamos que se llegara a administrar en la provincia en 1958, sobre todo si tenemos en cuenta las palabras de Francisco Aristoy, jefe provincial de Sanidad, que transcribimos más adelante en este artículo. En 1961 se ofrece noticia en la prensa de una nota de la alcaldía de Cádiz en la cual se informa que en el primer semestre solo se había producido un caso de poliomielitis en la ciudad, mientras que en 1960 en el mismo periodo de tiempo se habían producido ocho casos, siempre en niños que no estaban vacunados. La alcaldía destaca la eficacia de la vacuna y se lamenta de que todavía existan en Cádiz padres que consideran peligrosa la vacunación (DC, 25-VI-1961). Llama la atención también que en algunas semanas de los meses de agosto y septiembre de 1963, en el municipio de Cadiz, no se administran las vacunas Salk contra la polio (aunque sí contra la difteria, la viruela y la fiebre tifoidea) por encontrarse la enfermera, "Julia", "enferma" o de "vacaciones". Y en lo que se refiere a la vacuna Sabin comprobamos que en Cádiz capital existen partes en los que 
consta que fue administrada a finales de 1963 y en 1964. Hay que apuntar que la información ofrecida la hemos obtenido de los partes emitidos por el Jefe local de Sanidad (Ayuntamiento de Cádiz) al Jefe provincial de Sanidad (Caja 3.831, AMC).

Centremos ahora nuestros comentarios en la vacuna de Sabin. En 1953, Sabin consiguió "las primeras cepas atenuadas útiles y en 1955 las administró a 80 voluntarios" (León y Echevarría, 2005). Entre 1954 y 1959 se administraron vacunas atenuadas a unas 350.000 personas (Singapur, Checoslovaquia, la URSS, los EE.UU., Holanda y Méjico). En 1959, la OMS asumió la coordinación de los estudios y en 1960 el comité de expertos en poliomielitis de esta institución emitió un informe en el que se recomendaba abiertamente el uso masivo de las vacunas atenuadas en los países que sufrían epidemias de poliomielitis y en los que la identificación de los grupos particularmente vulnerables no plantease ningún problema. Recuérdese, por ejemplo, que en ese mismo año fueron vacunadas 75 millones de personas con la vacuna Sabin en la URSS (León y Echevarría, 2005). Algunos autores señalan que Albert Bruce Sabin, entre 1961 y 1963, desarrolló las vacunas orales de la polio monovalente y trivalente (Fernández-Cruz y Rodríguez Sainz, 2013).

Es a partir de 1963, "siguiendo la experiencia de otros países", cuando se implantó en España la vacuna atenuada de Sabin, pero previamente a la primera campaña masiva de vacunación, se realizaron "una serie de estudios con el fin de conocer mejor el patrón epidemiológico de la enfermedad y poder adaptar la administración de la vacuna a nuestra situación real: estudio epidemiológico de los casos notificados de la poliomielitis; estudio de aislamiento de poliovirus en heces de niños sanos; y estudio serológico de detección de anticuerpos" (Pachón del Amo, 2004). Posteriormente, antes de la campaña nacional, se realizó una campaña piloto en las provincias de Lugo y León, a la que han dedicado un extenso y documentado estudio Rodríguez-Sánchez y Seco-Calvo (2009). Estos autores señalan que en el año 1963 se realizaron vacunaciones contra la polio con la vacuna Salk y con la vacuna oral de Sabin, circunstancia que también hemos podido comprobar en lo que se refiere al municipio de Cádiz (Cajas 3.831 y 3.834, AMC). La campaña con vacuna Salk fue puesta en marcha por el Seguro Obligatorio de Enfermedad (SOE) y la Dirección General de Sanidad promovió la experiencia piloto con vacuna oral Sabin. Según apuntan Rodríguez-Sánchez y Seco-Calvo, esto se planteó así por la pugna que sostenían ambos organismos por controlar la Medicina Preventiva en España. Motivo por el que la Dirección General de Sanidad anticipó su campaña de vacunación mediante "un ensayo de una novedosa vacuna trivalente oral en la provincia de León, aspectos que fueron ocultados a la población". La campaña piloto se llevó a cabo en las provincias de Lugo y León "en un clima de enfrentamiento entre los responsables nacionales y locales de la Dirección General de Sanidad y del Seguro Obligatorio de Enfermedad que saturaron la prensa de réplicas y contrarréplicas, convertidas en confuso mensaje para una población ajena al auténtico mensaje del debate". Asimismo los autores citados consideran que no fue un "ensayo meramente administrativo", debiéndose tener en cuenta que las vacunas fueron diferentes, "no sólo en los laboratorios, sino también en su composición: en tanto que León vacunaba en sus dos fases con vacuna trivalente (tipo I, II y III en la misma) y en dos grupos con diferentes concentraciones; en Lugo se vacunó en la primera 
fase con monovalente tipo I y en la segunda con bivalente II y III" (Rodríguez-Sánchez y Seco Calvo, 2009). Estos autores sostienen, pues, que la campaña piloto fue concebida como ensayo de la nueva vacuna trivalente y no como un mero ensayo administrativo. En cambio, Florencio Pérez Gallardo y cols., en su clásico artículo, reeditado en 2013, por la Revista Española de Salud Pública, señalaron que "para adquirir experiencia propia en el manejo de la vacuna y en la manera de llevar a cabo su distribución en las mejores condiciones, se efectuó en la primavera de 1963 una Campaña piloto de vacunación en las provincias de León y Lugo..." (Pérez Gallardo, Valenciano Clavel y Gabriel y Galán, 2013) (Pachón del Amo, 2004). José Tuells (2010), apoyándose en Nájera, Llácer y Valenciano (1975), ha señalado "el éxito de la campaña piloto contra la poliomielitis (19631964)". Y también ha sido calificada la campaña de 1963-1964 de "éxito indiscutible" (Nájera, 2013a). Controvertido tema que tan solo planteamos aquí, que será motivo con toda seguridad de nuevas investigaciones y debates en el futuro, remitimos en este aspecto a los trabajos que tiene en marcha Rodríguez Sánchez.

Aunque, en estas líneas introductorias, no podemos dejar de mencionar otras cuestiones que creemos tienen interés, recogidas del periódico ABC-M del día 2 de abril de 1958. Por ejemplo, el citado periódico dedica casi una página a la ayuda económica para la de investigación concedida a Florencio Pérez Gallardo (figura 2), por el Consejo del Patronato de la Fundación de Juan March. Pérez Gallardo en esos momentos era jefe de la Sección de Virus de la Escuela Nacional de Sanidad y estaba en posesión de un historial científico considerable ya que trabajó en el Instituto de Higiene de Varsovia y en los Laboratorios de la Fundación Rockefeller de Nueva York, además de haber descubierto, en colaboración con el doctor Cla- vero, la cepa E de Rickettsia prowazeki, y haber investigado sobre la fiebre "Q" y las vacunas contra la gripe y la rabia, sin olvidarnos de que era miembro de la Organización Mundial de la Salud. De todo esto da cuenta el periódico, pero también que la dotación económica ascendía a la cantidad de medio millón de pesetas y que el tema específico de la investigación que se debía desarrollar en el plazo de dos años era el siguiente: "Estudios de epidemiología y profilaxis de la poliomielitis en España. Desarrollo de las técnicas de aislamiento del virus y de preparación de vacunas en la parálisis infantil”. Sobre los estudios de seroprevalencia de Pérez Gallardo puede consultarse con provecho el trabajo de Ballester y Porras (2009).

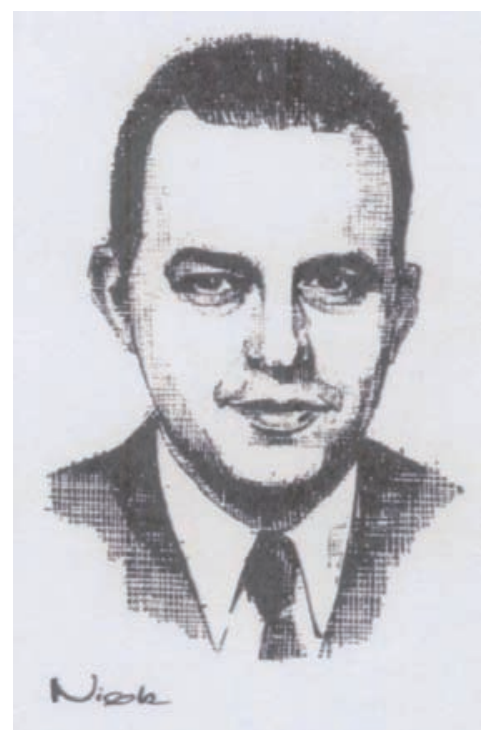

Figura 2: Florencio Pérez Gallardo (1917-2006). Fuente: Fundación Juan March. Ayudas de investigación (1957-1962).

El motivo por el que se concede esta ayuda se explica de la siguiente manera:

"Otra de las razones que justifican la concesión de la Ayuda de Investigación, es la situación que se ha creado en muchos países con motivo del descubrimiento, en los últimos años, de diversas vacunas contra la poliomielitis y su empleo masivo en unos casos (vacuna muer- 
ta tipo Salk) y en plano experimental en otros (vacunas vivas de los doctores Cox, Koprowski y Sabin). Resulta, pues, fundamental tener un conocimiento exacto de la situación epidemiológica de la poliomielitis en España, para lo que se necesita hacer un estudio serológico de la población (...). España debe prepararse con la debida cautela en el ritmo de adquisición de experiencia técnica para producir la vacuna antipoliomielítica que sea más conveniente. Así no dependeríamos de las regulaciones de exportación de los escasos países que la producen ni de las circunstancias comerciales".

Como se puede apreciar en los argumentos se utilizan factores científicos, pero también de tipo económico. El doctor Pérez Gallardo, pues, recibe esta ayuda para sus investigaciones en 1958, año especialmente duro en cuanto a la morbilidad y la mortalidad generada por la poliomielitis (véanse más adelante las tablas 1 y 2). Recuérdese que en el referido año se producen 2.079 casos de poliomielitis y 325 defunciones. Pero esta es una cuestión en la que profundizamos en el siguiente apartado de nuestra introducción. La ayuda económica a Pérez Gallardo, para las investigaciones sobre la poliomielitis, por parte de la Fundación Juan March, indican una preocupación latente de que el problema de esta enfermedad debía ser abordado de forma inminente porque la situación era acuciante. En 1953, la Asociación Europea contra la Poliomielitis señalaba "que sería prematuro formular una opinión sobre el valor y las posibilidades de la vacunación contra la poliomielitis en el estado actual de las investigaciones". Por este motivo "la Asociación recomienda que los países miembro deberían llevar a cabo, en los límites de sus recursos, ensayos científicos y bien controlados de estos métodos". En el V Simposio de esta Asociación (Madrid, 1958) se presentaron los informes de catorce países sobre el estado de vacunación, y no solo
España, también Francia, "estaban claramente rezagados, con bajos o prácticamente inexistentes niveles de vacunados" (Porras, Báguena, Ballester y de las Heras, 2012).

La poliomielitis en España y en la provincia de Cádiz en la década de los cincuenta y de los sesenta.

En España la situación se complicó en la década de los cincuenta, tan solo hay que repasar las cifras de morbilidad que presentó la enfermedad desde el año 1958 a 1962 (tablas 1 y 2).

\begin{tabular}{|c|c|}
\hline $\begin{array}{l}\text { ANOS } \\
(1950-1962)\end{array}$ & $\begin{array}{l}\text { MORBILIDAD } \\
\text { (Casos por } 100.000 \\
\text { habitantes) }\end{array}$ \\
\hline 1950 & 5,73 \\
\hline 1951 & 1,92 \\
\hline 1952 & 5,56 \\
\hline 1953 & 3,27 \\
\hline 1954 & 3,01 \\
\hline 1955 & 3,74 \\
\hline 1956 & 4,30 \\
\hline 1957 & 3,12 \\
\hline 1958 & 7,00 \\
\hline 1959 & 7,12 \\
\hline 1960 & 5,28 \\
\hline 1961 & 5,84 \\
\hline 1962 & 5,40 \\
\hline
\end{tabular}

Tabla 1. Poliomielitis. Tasas anuales de morbilidad por cien mil habitantes en España (1950-1962). Fuente: Cruz Hernández, 1972, tomo $2^{\circ}$, p. 1.555

Efectivamente, en España, como han señalado León y Echevarría (2005), "las epidemias más severas ocurrieron entre 1950 y 1963. Entre los años 1930 y 1950 se produjeron 400 casos anuales como media. Después esta cifra fue aumentando 
progresivamente hasta 1963, alcanzando los 1.500 casos anuales de media" (tabla 2).

\begin{tabular}{|c|c|c|}
\hline $\begin{array}{c}\text { ANOS } \\
(1949-1967)\end{array}$ & $\begin{array}{c}\text { NUMERO DE } \\
\text { CASOS }\end{array}$ & DEFUNCIONES \\
\hline 1949 & 522 & 104 \\
\hline 1950 & 1.597 & 127 \\
\hline 1951 & 541 & 118 \\
\hline$\overline{1952}$ & 1.576 & 165 \\
\hline 1953 & 935 & 121 \\
\hline 1954 & 867 & 117 \\
\hline 1955 & 1.085 & 117 \\
\hline 1956 & 1.258 & 158 \\
\hline 1957 & 919 & 151 \\
\hline 1958 & 2.079 & 325 \\
\hline 1959 & 2.130 & 328 \\
\hline 1960 & 1.632 & 208 \\
\hline 1961 & 1.778 & 218 \\
\hline 1962 & 1.853 & 192 \\
\hline 1963 & 1.959 & 210 \\
\hline 1964 & 193 & 43 \\
\hline 1965 & 70 & 34 \\
\hline 1966 & 308 & 37 \\
\hline 1967 & 362 & 34 \\
\hline
\end{tabular}

Tabla 2. Poliomielitis en España. Casos y defunciones (19491967). Fuente: Datos tomados de León y Echevarría (2005), que a su vez utilizan los de Nájera y cols. (1975).

Recuérdese, por ejemplo, que en el conjunto de la provincia de Cádiz, entre los años 1951 y 1953, fallecen por la poliomielitis aguda 21 personas, de las cuales 16 corresponden a hombres y 5 a mujeres. De estas 21 defunciones, 6 se producen en Cádiz capital (Reseña estadística de la provincia de Cádiz, 1957). En cuanto a la mortalidad, entre 1958 y 1975, la poliomielitis aguda en la provincia acaba con la vida de 123 personas (70 hombres y 53 mujeres), siendo especialmente duros en cuanto al número de defunciones los años 1958, 1959, 1960, 1962, 1963 y 1971 (tabla 3). Y en lo que se refiere a los casos presentados en la provincia de Cádiz, entre 1957 y 1971, tan solo hay que revisar la tabla 4 para comprender la situación que comentamos.

\begin{tabular}{|c|c|c|c|}
\hline $\begin{array}{c}\text { AÑos } \\
\text { (1958-1975) }\end{array}$ & $\begin{array}{c}\text { NÚMERO DE } \\
\text { DEFUNCIONES } \\
\text { POR } \\
\text { POLIOMIELITIS } \\
\text { AGUDA EN LA } \\
\text { PROVINCIA DE } \\
\text { CÁDIZ } \\
\text { (HOMBRES) } \\
\text { (1958-1975) } \\
\end{array}$ & $\begin{array}{c}\text { NÚMERO DE } \\
\text { DEFUNCIONES } \\
\text { POR } \\
\text { POLIOMIELITIS } \\
\text { AGUDA EN LA } \\
\text { PROVINCIA DE } \\
\text { CÁDIZ } \\
\text { (MUJERES) } \\
\text { (1958-1975) }\end{array}$ & $\begin{array}{c}\text { TOTAL DE } \\
\text { DEFUNCIONES } \\
\text { POR } \\
\text { POLIOMIELITIS } \\
\text { AGUDA EN LA } \\
\text { PROVINCIA DE } \\
\text { CÁDIZ } \\
(1958-1975)\end{array}$ \\
\hline 1958 & 18 & 9 & 27 \\
\hline 1959 & 5 & 4 & 9 \\
\hline 1960 & 22 & 16 & 38 \\
\hline 1961 & 4 & 1 & 5 \\
\hline 1962 & 8 & 6 & 14 \\
\hline 1963 & 5 & 5 & 10 \\
\hline 1964 & 1 & 1 & 2 \\
\hline 1965 & 0 & 2 & 2 \\
\hline 1966 & 2 & 1 & 3 \\
\hline 1967 & 0 & 1 & 1 \\
\hline 1968 & 2 & 0 & 2 \\
\hline 1969 & 0 & 1 & 1 \\
\hline 1970 & 0 & 0 & 0 \\
\hline 1971 & 2 & 5 & 7 \\
\hline 1972 & 0 & 0 & 0 \\
\hline 1973 & 0 & 0 & 0 \\
\hline 1974 & 0 & 0 & 0 \\
\hline 1975 & 1 & 1 & 2 \\
\hline TOTAL & 70 & 53 & 123 \\
\hline
\end{tabular}

Tabla 3: Defunciones en la provincia de Cádiz por poliomielitis aguda (hombres, mujeres y total) (1958-1975). Elaboración propia, 2015. Fuente: INE: Libros del Movimiento Natural de la Población de España (1958-1975).

\begin{tabular}{|c|c|}
\hline $\begin{array}{c}\text { PROVINCIA } \\
\text { DE CÁDIZ } \\
\text { (1957-1971) }\end{array}$ & $\begin{array}{c}\text { MORBILIDAD } \\
\text { (Casos por } \\
\mathbf{1 0 0 . 0 0 0} \\
\text { habitantes) }\end{array}$ \\
\hline $\mathbf{1 9 5 7}$ & 13,43 \\
\hline $\mathbf{1 9 5 8}$ & 26,21 \\
\hline $\mathbf{1 9 5 9}$ & 8,15 \\
\hline $\mathbf{1 9 6 0}$ & 35,2 \\
\hline $\mathbf{1 9 6 1}$ & 6,50 \\
\hline $\mathbf{1 9 6 2}$ & 14,46 \\
\hline $\mathbf{1 9 6 3}$ & 11,90 \\
\hline $\mathbf{1 9 6 4}$ & 0,23 \\
\hline $\mathbf{1 9 6 5}$ & 0,22 \\
\hline $\mathbf{1 9 6 6}$ & 3,40 \\
\hline $\mathbf{1 9 6 7}$ & 0,77 \\
\hline $\mathbf{1 9 6 8}$ & 0,76 \\
\hline $\mathbf{1 9 6 9}$ & 2,97 \\
\hline $\mathbf{1 9 7 0}$ & 1,25 \\
\hline $\mathbf{1 9 7 1}$ & 3,72 \\
\hline & \\
\hline & \\
\hline & \\
\hline
\end{tabular}

Tabla 4: Poliomielitis. Tasas anuales de morbilidad por cien mil habitantes en la provincia de Cádiz (1957-1971). Fuente: Revista de Sanidad e Higiene Pública. Elaborada y cedida para este trabajo por Juan Antonio Rodríguez Sánchez. 
En cambio, el periódico ABC en 1958 considera que la situación en torno a esta enfermedad no es preocupante en España, cierto es que cuando esto se escribe es en el mes de abril y quedan muchos meses para que concluya el año, pero hay que tener en cuenta que las cifras de 1957 eran también muy preocupantes: 919 casos y 151 defunciones (tabla 2) y en lo que se refiere a la provincia de Cádiz, en el año 1958, la poliomielitis se cobra la vida de 27 personas (tabla 3) y presenta una tasa de morbilidad de 26,21 casos por cien mil habitantes (tabla 4). Por eso merece la pena rescatar el siguiente párrafo del periódico, con el cual parece que se quita importancia a lo que está sucediendo (ABC-M, 2-IV-1958):

"El problema de la poliomielitis en España es actualmente de reducida intensidad. Sin embargo, hay que contar con que la endemia adquiera con el tiempo una mayor importancia, ya que, por excepción, esta infección aumenta al mejorar las condiciones de vida".

El mismo periódico, en enero de 1959, con motivo de un extenso artículo titulado "La sanidad de España ante la V Reunión Nacional de Sanitarios", reconoce la gravedad de la situación con respecto a la poliomielitis en nuestro país (ABC-M, 23-I-1959):

"La poliomielitis ofrece estas novedades: hasta fines de noviembre de 1958 el número de casos declarados oficialmente ha sido de 1.857. Extendida por todo el país no respetó ninguna provincia. La cifra es mayor que la calculada como promedio anual en el último decenio y es también superior a la más alta registrada en cualquiera de los años del mismo (...). Las provincias más afectadas han sido las de Cádiz, Sevilla y Lugo. Sin embargo, la cifra sigue sin constituir un problema de la importancia que ha adquirido en los Estados Unidos e Inglaterra, por ejemplo".
En el referido artículo también se hace mención de las dificultades existentes para obtener la vacuna, "toda de importación", motivo por el que la Escuela Nacional de Sanidad trabaja en la investigación para disponer de la vacuna antipoliomielítica en España; sin duda, en esta nota de prensa, se están refiriendo a las investigaciones lideradas por Florencio Pérez Gallardo, que como hemos visto fueron dotadas con medio millón de pesetas por la Fundación Juan March.

Pero de todo lo referido nos quedamos con un dato; en el año 1958, la provincia de Cádiz, junto con las de Sevilla y Lugo, es señalada como una de las más afectadas por la poliomielitis. Esta cuestión merece algunos comentarios fraguados desde una perspectiva local.

La situación en la provincia de Cádiz era complicada (tablas 3 y 4), y así lo manifestó Francisco Aristoy Santos, jefe provincial de Sanidad en Cádiz y profesor de Microbiología en la Facultad de Medicina, en la comunicación que presentó en 1958 en la V Reunión Nacional de Sanitarios que se celebró en Madrid. Nada menos que 878 casos de poliomielitis se registraron durante una década en el Instituto de Sanidad de Cádiz, apuntando también que se debe tener en cuenta que la campaña de vacunación estuvo "limitada a las poblaciones afectadas en las que se mantiene la endemia que son las situadas alrededor de las bahías de Cádiz y Algeciras" (Aristoy-Santos, 1959). Aristoy incluso se lamenta sobre la campaña de vacunación en la provincia gaditana de la siguiente manera:

"El ideal hubiera sido hacer una vacunación gratuita, en gran escala, en esta zona en que la Polio es endemoepidémica, y principalmente entre las clases de más débil economía, que son las más afectadas por la enfermedad, pero no dispusimos de ninguna subvención, si bien la 
Dirección General de Sanidad, preocupada por el problema, envió 130 dosis gratuitas para vacunar a los niños de la Línea de la Concepción".

Y prosigue Aristoy con algunos datos que subrayan aún más lo exigua que fue la vacunación en la provincia gaditana a finales de los años cincuenta:

"Además de la vacunación practicada en nuestros servicios del Instituto con la vacuna enviada por la Dirección General de Sanidad, al precio de 200 pesetas las tres dosis, algunos Ayuntamientos, la Diputación y varias entidades industriales la han llevado a efecto con carácter gratuito en determinados establecimientos benéficos y entre los hijos de sus empleados. Podemos calcular que, entre las controladas por nosotros y las practicadas libremente, suman un total de 6.295 vacunaciones".

Francisco Aristoy expuso con mucha claridad como estaba la situación en la provincia gaditana a finales de los años cincuenta y el panorama como hemos podido ver era de preocupación, y en cierta manera también el epidemiólogo manifestaba su impotencia ante la escasez de recursos y medios para combatir a la poliomielitis. Aristoy se mantuvo en su puesto de Jefe provincial de Sanidad de Cádiz hasta mayo de 1963 en que como apunta Diario de Cádiz, por jubilación, entregó su cargo a José Manuel Pérez Álvarez (DC 9 y 19-V1963).

\section{LA ORGANIZACIÓN DE LAS CAMPAÑAS DE VACUNACIÓN CONTRA LA POLIO EN JEREZ DE LA FRONTERA (1963-1964 y 1965)}

En 1963 se implantó en España la vacunación contra la poliomielitis con la vacuna atenuada de Sabin (VPO). La campaña fue gratuita y se centró en la vacunación de niños de dos meses a siete años. Como es sabido la campaña se desarrolló en dos fases, administrándose dos dosis de vacuna (Pachón del Amo, 2004):

“...en la primera fase (finales de 1963) con vacuna VPO monovalente de poliovirus 1 ( $m V P O)$ y la segunda (principios de 1964) con vacuna VPO trivalente de poliovirus 1, 2 y 3 (tVPO), alcanzándose una cobertura del 95\% en la primera fase y del $98 \%$ en la segunda, lo que provoca un descenso brusco de la incidencia de la enfermedad desde una media de 1.900 casos notificados en el periodo prevacunal a 195 casos en 1964".

En la primera fase de la campaña nacional se empleó, como hemos indicado, virus polio tipo 1 y fueron vacunados 4.400 .000 niños, es decir el 95\% de la población de entre dos meses y siete años. En la segunda fase la vacuna fue trivalente con los tipos 1,2 y 3 y cubrió a 4.680.000 niños, lo que representó el 98,8\% (Pérez Gallardo, Valenciano y Gabriel y Galán, 2013).

En lo que se refiere al Boletín Oficial de la Provincia de Cádiz, en los números de 9 de enero y 19 de febrero de 1963, se encuentran normativas reguladoras de la campaña de vacunación antipoliomelítica masiva durante los meses de enero a junio de 1963, en las que se puede comprobar la dicotomía existente en la vacunación (vacuna Salk) entre el Seguro Obligatorio de Enfermedad y la Dirección General de Sanidad, aspecto en el que no profundizamos porque ya lo han hecho otros autores (Rodríguez-Sánchez y Seco Calvo, 2009). En cambio nos sorprende que el Boletín Oficial de la Provincia de Cádiz no recoja normativas explícitas en lo referido a la campaña nacional de vacunación con la vacuna Sabin, que se llevó a cabo en dos fases a finales de 1963 y principios de 1964, más adelante concretaremos estas fechas.

Hemos podido comprobar, como ya hemos comentado, en lo que se refiere a Cádiz capital, que desde enero de 1963, en los partes de va- 
cunación semanales emitidos por el Jefe local de Sanidad (Ayuntamiento de Cádiz) al Jefe provincial de Sanidad, se hace constar durante todo el año vacunación contra la poliomielitis, con la vacuna inactivada de Salk (VPI), hasta el 23 de noviembre en que ya no constan vacunaciones contra la poliomielitis; aunque en las semanas del 7 al 14 y del 15 al 21 de diciembre constan en esos partes 120 vacunaciones por vía oral. Datos que consideramos incompletos y que evidentemente no reflejan la totalidad de las vacunaciones llevadas a cabo en Cádiz capital porque probablemente se consignarían los registros de vacunación en otros documentos que no hemos podido localizar (Caja 3.831, AMC). Aunque no es el objetivo de nuestro trabajo estudiar los pormenores de la Campaña de vacunación antipolio en Cádiz capital, podemos apuntar que la Jefatura provincial de Sanidad puso en marcha la segunda fase de la Campaña el lunes 30 de marzo de 1964, el mismo día que en Jerez de la Frontera, y que en la capital de la provincia se establecieron los siguientes Centros de vacunación, información que hemos recogido en el Archivo Municipal de Jerez de la Frontera (Legajo 1.929, expediente 36.654, AMJ):

- Escuela Padre Villoslada (Carretera Industrial).

- Guardería Infantil de Puertas de Tierra.

- Guardería de Nuestra Señora de Sonsoles (calle Brasil).

- Casa de Socorro de los Caballeros Hospitalarios (calle Benjumeda).

- Escuela Barriada de Puntales.

- Jefatura provincial de Sanidad (Olivillo).

- Casa de Socorro (Plaza de Toros).

- Colegio de la Viña (lugar en que la vacunación se hará el día 31).

Centrémonos ya en Jerez de la Frontera, importante localidad de la provincia de Cádiz, que en 1960 superaba los 130.000 habitantes (Capel Sáez, 1971; Caro Cancela, 1999). En 1963 las superficies de viñedos eran 2.518 hectáreas (Cabral Chamorro, 1990). Este dato nos puede llevar a deducir que la situación en la ciudad, en su conjunto, era próspera y boyante, pero había núcleos de población sumidos en la pobreza. La localización de un expediente con documentación de la Junta Municipal de Beneficencia de 1962-1963, refiere que en este último año se incluye en la "pobreza legal", y por tanto con derecho a la "asistencia médico-farmacéutica gratuita”, a 3.513 familias, sumando un total de 9.062 beneficiarios (Legajo 1.929, Expediente 36.653, AMJ). Es cierto que el período 1950-1985 ha sido el de mayor prosperidad para los vinos de Jerez; pero también hay que recordar la huelga de los viticultores de abril de 1962, reivindicando mejoras salariales, y la de 1964 que se prolongó casi dos meses. En los años sesenta muchos trabajadores españoles tuvieron que emigrar, también jerezanos, a diferentes países de Europa y a otras regiones de España; no olvidemos tampoco que Jerez se ha caracterizado por un reparto muy desigual de las riquezas (Ruiz Mata, 2010). Entre 1963 y 1965, años que abarca nuestro estudio, encontramos que se suceden dos alcaldes en la ciudad: Tomás García Figueras, hombre leal al Régimen y militar especialista en temas norteafricanos, y Miguel Primo de Rivera, sobrino del fundador de Falange. En esos años Jerez tenía problemas con las viviendas, la inmigración interior desde los núcleos rurales cercanos y la escolarización de los niños, tanto es así que Primo de Rivera reconoce que la falta de vivienda y de plazas escolares son dos gravísimos problemas que entorpecen el despegue de Jerez. El problema de la vivienda era acuciante por el estado insalubre y antihigiénico de los pisos del casco histórico, llegando la situación al "hacinamiento, el suburbio y el chabolismo a 
niveles alarmantes". Y no menos grave era el problema educativo, con cerca de 8.000 niños que no recibían enseñanza primaria por falta de escuelas (Caro Cancela, 1999).

Este es, pues, el contexto general en que se va a llevar a cabo en Jerez de la Frontera la campaña de vacunación que es motivo de nuestro estudio. Una campaña que como hemos dicho tuvo dos fases; concretamente, en Jerez, la primera fase abarcó del 25 de noviembre al 3 de diciembre de 1963, y la segunda fase del 30 de marzo al 8 de abril de 1864 (Legajo 1.929, Expediente 36.654, AMJ). Avisamos de que en la portada del citado expediente existe un error en las fechas de la segunda fase de la campaña; error, que se corrige estudiando la documentación que contiene. Precisamente esta documentación del archivo jerezano nos permite plantear cómo se organizó en la ciudad la campaña con la vacuna oral de Sabin en las dos fases que hemos indicado.

\subsection{La primera fase de la vacunación ( 25 de noviembre al 3 de diciembre de 1963)}

El 15 de noviembre de 1963, el Gobernador Civil de la provincia de Cádiz, Santiago Guillén Moreno, le remite una carta al Alcalde de Jerez de la Frontera, comunicándole que el Ministerio de la Gobernación, a través de la Dirección General de Sanidad, ha emprendido la tarea de conseguir en la segunda quincena de noviembre y en el mes de diciembre llevar a cabo una campaña nacional antipoliomielítica "de alcance muy superior a las que hasta ahora se han realizado". Especifica también que la vacuna que se va a administrar es la vacuna Sabin, por vía oral, "con la que será posible no solo obtener la inmunidad de todos los niños vacunados sino, de forma especial, la erradicación de la enfermedad de nuestra Patria". La carta del Gobernador al Alcalde jerezano aclara que la administración de la primera dosis (tipo I de la vacuna) incluye a los niños de dos meses a siete años de edad. Entre los argumentos de Guillén Moreno destaca la necesidad de crear conciencia en la población de que desaparezca esta enfermedad de España ya "que produce un promedio de 200 muertos y de 2.000 inválidos cada año, con los consiguientes daños físicos, morales y económicos". Por todo ello, el objetivo al que se aspira es acercarse al 100\% de los niños vacunados, insistiendo en que la vacunación se debe llevar a cabo con absoluta independencia de que los niños sean o no vecinos de Jerez de la Frontera. Guillén Moreno anuncia al Alcalde de Jerez que próximamente recibirá unas fichas u "hojas individuales" para registrar los datos de los niños. Para realizar la tarea de cumplimentar las fichas se demanda la colaboración desinteresada de los parientes de los niños, de los maestros, de las divulgadoras rurales, afiliadas a la Sección Femenina, sacerdotes, o cualquier persona idónea que se ofrezca para ello, "siempre que escriba en forma bien legible". Entre los datos que se deben consignar en la ficha destacan los siguientes: provincia, localidad, nombre y apellidos del niño, sexo, edad, número cartilla "S.O.E" (si es beneficiario del mismo), lugar de nacimiento, domicilio habitual, y si el niño ha recibido inyecciones de vacuna contra la poliomielitis, "a pesar de lo cual debe tomar ahora la vacuna por vía bucal". Asimismo se debe anotar la organización que lo vacunó: Sanidad Nacional, "S.O.E." (Seguro Obrero de Enfermedad) u "Otros”, apuntando en la casilla correspondiente el número de inyecciones de vacuna que haya recibido el niño. Esta ficha debe guardarla una persona responsable, pariente o no, quien la entregará al equipo de vacunación en el momento de presentarse el niño para ser vacunado. Guillén Moreno insiste en que, durante la distribución de estas hojas o fichas, debe aprovecharse para que todos los padres de familias o encargados sean 
informados de la Campaña, "de su carácter gratuito y de sus evidentes ventajas, destacando la responsabilidad moral en que incurrirán quienes no vacunen a sus hijos, dejándoles expuestos a contraer tan grave enfermedad" (Legajo 1.929, expediente 36.654, AMJ).

El 20 de noviembre de 1963, el Jefe provincial de Sanidad da instrucciones al Jefe local de Sanidad de Jerez de la Frontera, indicándole que el comienzo de la campaña es el día 25 de noviembre a las nueve de la mañana, solicitando además la colaboración en la misma de los médicos de Asistencia Pública Domiciliaria y de los médicos libres, así como de los alguaciles y de la guardia civil en los caseríos para reparto y cumplimentación de las fichas, impresos que se podían recoger en el Negociado de Beneficencia y Sanidad del Ayuntamiento jerezano. Entre las instrucciones que el Jefe provincial de Sanidad indica al Jefe local de Sanidad destaca también la necesidad de buscar locales para la vacunación, que sean céntricos y que estén bien comunicados, y que tengan puerta de entrada y de salida para facilitar la circulación fluida y evitar los retrasos en la vacunación.

El 22 de noviembre el alcalde de Jerez, Tomás García Figueras, convocó con carácter urgente, en el salón de las Casas Consistoriales, a los maestros de las Escuelas Nacionales y Privadas, así como representaciones de los organismos colaboradores, de las alcaldías rurales y de las entidades locales menores, que debían enviar a un representante a la reunión. Se procedió, en el transcurso de la organización de la Campaña, a realizar un inventario de las escuelas, anotándose el nombre del director, dirección de la misma y los grados que se impartían, todo ello con la finalidad de localizar al mayor número de niños a efectos de que recibieran la vacuna oral Sabin.
El Alcalde, en esos días, también envió una carta a los directores de Radio Jerez y del periódico La Voz del Sur, para que se le diera la mayor difusión a la campaña. Precisamente este periódico nos ha proporcionado información sobre la organización y el desarrollo de la misma. La Voz del Sur, en su edición del día 22 de noviembre de 1963, publicó dos noticias relacionadas con la vacunación que se iba a llevar a cabo. La primera titulada "Campaña Nacional Antipolio", de carácter divulgativo, señala que esta campaña comienza en la provincia de Cádiz, y en otras provincias españolas, el lunes 25 de noviembre, siguiendo posteriormente con otro grupo de provincias el día 2, concluyendo el 9 de diciembre en Madrid y Barcelona. Se señala que la campaña es completamente gratuita y que su objetivo es "establecer una barrera contundente contra la enfermedad (...) de manera que cada núcleo de población importante, en el plazo de unos días, tenga vacunados más del noventa por ciento de los niños de las edades comprendidas en la campaña...". Se apunta también que en realidad la campaña comenzó el 14 de mayo en las provincias de León y de Lugo donde "no hubo incidente, ni se ha producido una sola reacción, quedando plenamente demostrado que la vacuna con virus vivo, tipo Sabin es totalmente inofensiva". Con este artículo en el periódico se trata de divulgar la campaña en Jerez y de tranquilizar a la población sobre cualquier suspicacia que se pudiera tener sobre la vacuna. Pero ese mismo día, en la sección del periódico "Jerez, cada día", se da noticia de la convocatoria en la Alcaldía de todos los maestros de escuelas nacionales y privadas para recibir instrucciones. Y se precisa que la Delegación Provincial de Sanidad, a través del delegado en Jerez, Antonio Berengena del Rey, comunica que la vacunación de forma intensiva se llevará 
a cabo entre los días 25 al 27 de noviembre por "un equipo médico desplazado desde Madrid". El día 23 en la misma sección del periódico se da noticia de que se han habilitado las guarderías y hogares de la Sección Femenina para la campaña. En cuanto a las fichas quedarán en poder de las familias de los niños, que la presentarán en el centro de vacunación cumplimentadas, por ellos mismos o con la ayuda de los maestros. Los días 25, 26 y 27 se desplazarán a Jerez "los equipos médicos designados por la Jefatura Provincial de Sanidad”. Asimismo se aclara que la vacuna "por vía bucal deben tomarla también los niños ya vacunados o que estén vacunándose por inyecciones con vacuna Salk. La protección que confiere la vacuna Sabin es más duradera; en todo caso completa los efectos de aquella”. Y, por último, se señala en el periódico que los días señalados y en horario de 10 a 14 horas y de 16 a 20 horas se llevarán a cabo las vacunaciones en los siguientes lugares de la ciudad de Jerez:

- Hogar de "José Antonio" (calle Zaragoza, 40).

- Guardería Infantil “San Carlos” (calle Lealas, frente al cine).

- Hogar Azul (Calle Vicario, entrada por Ronda Muleros).

- Centro Comarcal de Higiene (calle Cristal, 1 y 3$)$.

Aunque el día 26 de noviembre, el delegado de Beneficencia, comunicó en un escrito que se realizarían las vacunaciones "para mayor facilidad”, además de en los lugares referidos, en los siguientes: Escuela Unitaria de Niñas (Parroquia de la Vid), Casa de Socorro (calle Arcos) y Guardería Infantil (Barriada Federico Mayo).

Pero también había que realizar las vacunaciones, y esto era más complejo, en la campiña jerezana. El Delegado de Beneficencia señaló los días y los centros en que vacunarían los equipos de la Jefatura provincial de Sanidad:

- Jueves, 28 de noviembre: Guadalcacín del Caudillo, Colonia de Caulina, Estella del Marqués, La Guareña, Barca de la Florida, San Isidro del Guadalete, El Torno, Torrecera y José Antonio.

- Viernes, 29 de noviembre: San José del Valle, El Mimbral y Tempul.

- Sábado, 30 de noviembre: Desde la Escuela de la Jarda se desplazarán los equipos a los núcleos urbanos más poblados, y también en el Charco de los Hurones.

- Lunes, 2 de diciembre: El Torno, en la carretera de Medina, La Ina, Fuente Rey, Mesas de Asta y El Majuelo.

- Martes, 3 de diciembre: Santos Inocentes (carretera de Sevilla), La Parra, El Portal, Alcántara y Nueva Jarilla.

- Miércoles, 4 de diciembre (último día de vacunación): Las Tablas.

Los resultados de la primera fase de la campaña no tardan en comunicarse, tanto a través de carta del Jefe de Negociado de Beneficencia o a través de la propia prensa. En la referida carta, fechada en Jerez el 4 de diciembre de 1963, se consigna que en total la campaña ha durado siete días, desde el 25 de noviembre al día 3 de diciembre, estableciéndose los centros de vacunación, pero también "puestos secundarios" en toda la campiña, "incluidas Barriadas rurales y Entidades Locales Menores". De manera, que según los datos oficiales, en Jerez de la Frontera y su término, "ha sido un éxito rotundo, pasando de 22.000 el número de niños vacunados, cuando los cálculos que de Madrid traían los equipos cifraban, 12.500 vacunaciones en número alzado".

El día 4 de diciembre, el Alcalde, Tomás García Figueras, también comunica el éxito y señala la colaboración desinteresada de padres, tutores, religiosos, maestros, directores 
de grupos y encargados de escuelas nacionales y privadas, así como de Auxilio Social, Sección Femenina, Alcaldes de Barriadas Rurales y Entidades Locales Menores, no olvidándose de la prensa y de la radio local. El alcalde también señala la cifra de más de 22.000 niños vacunados. Pero en su carta, en un comunicado a la prensa y a la radio, señala un matiz que creemos interesante consignar para conocer mejor los detalles de organización de la primera fase de la campaña de vacunación en Jerez:

"Como la inclemencia del tiempo de estos últimos días, ha podido dar lugar a que algunos niños se hayan quedado sin vacunar, pueden hacerlo en la Barriada Rural de San José del Valle, La Barca de la Florida y en el Centro Comarcal de Higiene, calle Cristal 1 y 3, donde el equipo de la Jefatura Provincial de Sanidad ha dejado dosis suficientes para ello".

Como se puede comprobar fue grande el esfuerzo realizado en pocos días para llegar a todos los puntos del término municipal de Jerez de la Frontera. Y muchas las personas que participaron. Al finalizar la primera fase de la campaña, el Jefe provincial de Sanidad de Cádiz escribe al Alcalde de Jerez, el día 11 de diciembre de 1963, agradeciendo su colaboración y la del doctor don Antonio Berengena, Jefe local de Sanidad, corroborando también el éxito "de la Campaña en la Provincia y en Jerez". Añadiendo el Jefe provincial de Sanidad: "Igualmente me complace manifestar a V.E. que en el Resúmen que esta Jefatura prepara para enviar a la Dirección General de Sanidad, hará especial mención de la diligencia y eficacia del Excmo. Ayuntamiento de Jerez de la Frontera" (Legajo 1.929, expediente 36.654, AMJ).

\subsection{La segunda fase de la campaña de vacu- nación (30 de marzo al 8 de abril de 1964)}

El Alcalde de Jerez de la Frontera, en el mes de marzo de 1964, recibió un telegrama del
Gobernador Civil anunciándole el comienzo inmediato de la segunda fase de la Campaña Nacional de Vacunación Antipoliomielítica, "debiendo esa Alcaldía prestar máxima colaboración a Jefatura Provincial de Sanidad y dispondrá que Policía Municipal preste servicios de mantenimientos, orden en todos los puestos de vacunación. Acúseme recibo".

El periódico $\mathrm{La} \mathrm{Voz} \mathrm{del} \mathrm{Sur,} \mathrm{del} \mathrm{día} 27$ de marzo de 1964, en su sección "Jerez, cada día", anuncia que la segunda fase de la campaña nacional contra la poliomielitis se iniciará el lunes 30 de marzo. Recuérdese que en esta ocasión se hizo con VPO trivalente de poliovirus 1, 2 y 3 (Pachón del Amo, 2004), e igualmente en niños con edades comprendidas entre los dos meses y los siete años. Se insiste en el periódico, en la edición del día 7 de abril, que "ningún niño debe quedarse sin vacunar". En esta ocasión visitó Jerez el Jefe provincial de Sanidad, acompañado del doctor Aljama, jefe del equipo móvil de vacunación antipolio que actúa en la ciudad. El mismo periódico, el día 8 de abril, anuncia que es el último día de vacunación, habiéndose vacunado hasta ese momento en la ciudad 12.433 niños, de los cuales 7.043 recibieron la vacuna en un solo día. Se insiste por parte de las autoridades, a través de la prensa y de la radio, con el objetivo de incentivar la campaña de vacunación, en el hecho "que desde que se administró la dosis anterior no se ha producido ni un solo caso de poliomielitis en la provincia entre los niños vacunados".

En esta segunda fase se cuenta con la experiencia de la primera y observamos que se repiten algunos aspectos. La organización de la campaña está en manos de las jefaturas provincial y local de Sanidad, y por supuesto de la Alcadía. De hecho la primera autoridad municipal, a través de una carta a los medios de comunicación, recordó que tanto los padres o parientes de los niños, como los maestros, las 
afiliadas a la Sección Femenina, los religiosos o cualquier persona idónea debían prestar su colaboración desinteresada, rellenando las fichas que se facilitaban en el Negociado de Beneficencia de la Secretaría Municipal. Como se puede apreciar, en buena medida, se repiten los esquemas de la organización de la primera fase de la Campaña.

La campaña de vacunación en la población de Jerez se llevó a cabo en los días señalados, en horarios de 9 a 13 horas y de 16 a 19 horas, utilizándose los mismos centros que hemos citado ya para la primera fase, añadiéndose a estos el local de la Cruz Roja (calle 18 de julio no 17). Y en lo que se refiere al término municipal, que por su dispersión ofrecía una mayor dificultad, se organizó de manera análoga a la fase anterior. Señalamos a continuación los días y sitios en que fueron vacunados los niños en estos lugares, que fueron divulgados a la población a través del periódico "La Voz del Sur" y suponemos que también a través de la radio local (Legajo 1.929, expediente 36.654, AMJ):

- Lunes, 30 de marzo: Estella del Marqués, Guadalcacín del Caudillo, Nueva Jarilla y Alcántara.

- Martes, 31 de marzo: La Guareña, San Isidro del Guadalete, Barca de la Florida, El Torno, Torrecera, José Antonio, Venta de San Miguel y San José del Valle.

- Jueves, 2 de abril: El Torno y carretera de Medina, Fuente del Rey, El Majuelo, Mesas de Asta, Los Santos Inocentes, El Portal y Las Tablas.

Estos son los días estipulados en principio para vacunar en esos puntos del término municipal jerezano, pero en documentación complementaria se puede comprobar que el día 2 abril vacunaron en Las Abiertas, Albadalejo, Barca de la Florida y Las Cuevas; el día 3, en Charco de los Hurones, Guadalcacín y Casa Blanca; el día 4, en Nueva Jarilla, Mendosilla, Parrilla, Portal y Quinientas; el día 6, en Romerales, Romero, San Isidro de Guadalete y San José del Valle, y el día 7, en Tabajete, Torno y Torrecera (Legajo 1.929, expediente 36.654, AMJ).

Una vez finalizada la segunda fase de la Campaña, la Alcaldía de Jerez, con fecha de 13 de abril, comunicó que en el Centro Comarcal de Higiene (calle Cristal 1 y 3), en horas de 10 a 12 de la mañana, se seguiría administrando la segunda dosis a los niños con edades comprendidas entre los dos meses y los siete años, "que por cualquier causa hayan dejado de tomarlas o que no se encuentren vacunados ni en su primera dosis, cuyo plazo terminará improrrogablemente el próximo sábado día 18 de los corrientes" (Legajo 1.929, expediente 36.654, AMJ).

La documentación consultada en el Archivo Municipal de Jerez de la Frontera contiene información numérica de las vacunaciones realizadas en la ciudad y en la campiña, en la segunda fase (marzo-abril de 1964), en la cual se especifica las localidades y los niños vacunados. Según nuestros cálculos, a partir de la citada documentación, se vacunaron en esta segunda fase de la Campaña unos 24.000 niños (Legajo 1.929, expediente 36.654, AMJ). Recuérdese que en la primera fase de la Campaña (noviembre-diciembre de 1963) apuntamos la cifra de 22.000 .

Como hemos podido apreciar la Campaña de vacunación contra la polio en Jerez de la Frontera (1963-1964), en sus dos fases, fue llevada a cabo con orden y con instrucciones precisas; como en el resto del país, al ser una campaña organizada por la Dirección General de Sanidad, tuvo su apoyo fundamental en las jefaturas provinciales y en las jefaturas locales de Sanidad, en este caso concreto en las de Cádiz y Jerez, respectivamente. Se aprecia a través 
de la documentación burocrática del municipio jerezano y de la prensa de la localidad que fueron días intensos y de mucho trabajo por parte del personal sanitario y municipal, pero también para otros colectivos como los maestros, incluso voluntarios, que ya hemos señalado. Hay aspectos sobre los que no hemos localizado documentación específica; por ejemplo, sobre la forma en que se hizo el transporte de las vacunas por los equipos móviles y sobre su conservación y mantenimiento en buen estado. Sobre este particular Florencio Pérez Gallardo ofrece información en la memoria de la campaña (Rodríguez Sánchez, 2010).

1.3. Notas sobre la campaña de vacunación contra la polio y otras enfermedades en Jerez de la Frontera (1965)

Con lo apuntado podríamos dar por con-cluido nuestro estudio sobre las dos fases de la Campaña de 1963 y 1964 en Jerez de la Fron-tera. Pero también nos planteamos en esta in-vestigación la necesidad de localizar documen-tación que permita comprobar si este trabajo intenso contra la enfermedad, realizado en los años apuntados, tuvo continuidad en Jerez de la Frontera, al menos, en el año 1965. Y en esta línea hemos procedido a la búsqueda de los ci-tados documentos, acompañándonos la fortuna al localizar un expediente que nos permite rea-lizar un esbozo de lo acontecido en el referido año (Legajo 1.929, expediente 36.659, AMJ). En 1965 se puso en marcha en Jerez de la Frontera, la "Campaña Nacional de Vacuna-ción Antipolio, Difteria, Tosferina y Tétanos", y se realizó en dos fases, segúnconsta en el expe-diente consultado: la primera, del 22 de febre-ro al 11 de marzo, y la segunda del 5 al 10 de abril (Legajo 1.929, expediente 36.659, AMJ). Parece que en esta ocasión, la experiencia de la campaña del año anterior, hace que el Jefe provincial de Sanidad escriba, el día 8 de ene- ro, al Alcalde de Jerez solicitando se entregue al Director del Centro Comarcal de Higiene de la ciudad un censo infantil, "toda vez que en dicho Centro será montado un puesto de vacunación, atendido directamente por el personal adscrito al mismo". En otra carta de la misma fecha informa al Alcalde sobre el comienzo de la citada campaña, que en esta ocasión, como hemos indicado, será contra la difteria, la tos ferina, el tétanos y la poliomielitis. La campaña se llevará a cabo entre los días 22 de febrero y el 11 de marzo. Será gratuita y los niños "sujetos" a la misma serán los mayores de tres meses y menores de tres años para la difteria, la tos ferina y el tétanos, y para la poliomielitis por vía oral "los comprendidos en las mismas edades que no hayan sido anteriormente vacunados por la vacuna Sabin...”. En cuanto a los encargados de administrarlas, en los casos de "agrupaciones humanas con médico titular", se encargarán los médicos de la Asistencia Pública Domiciliaria (APD), con la supervisión del Jefe local de Sanidad, y auxiliados por los practicantes y las comadronas de APD y hospitales municipales y Casas de Socorro. En los casos de "agrupaciones humanas sin médico titular distantes más de tres kilómetros del casco urbano" serán vacunados por los médicos, practicantes y comadronas de APD o "por equipo de esta jefatura”. Se emplearán para la vacunación cuatro horas diarias (dos por la mañana y dos por la tarde), y el número de locales serán los que estime oportuno el Alcalde. Se anuncia como fecha de administración de la segunda dosis a partir del día 5 de abril. Para todo ello es crucial que el Ayuntamiento tenga disponible un censo infantil antes del día 1 de febrero con los "niños nacidos en 1962, 1963 y 1964, residentes en el término municipal", expresando en el mismo los nombres y apellidos, domicilios, fechas de nacimiento y "dejando espacio en blanco 
para poder señalar si se vacunan de la tripe o de polio" (Legajo 1.929, expediente 36.659, AMJ). Una vez realizados los cálculos para el censo desde la Secretaría del Ayuntamiento se apunta "12.000 niños las sumas de los 3 años". Se calcula que "unos 4.000 niños por año".

Nuevamente el Alcalde anuncia, con fecha de 13 de enero, que para esta campaña se requerirá la colaboración de la Sección Femenina, de Acción Católica, de los maestros y de personal voluntario. En esos días los alcaldes pedáneos o de barrios de El Torno, Guadalcacín, Torrecera, Nueva Jarilla, El Portal, etc., comunican de forma aproximada el número de niños nacidos en los años requeridos y los locales disponibles para la vacunación. El día 23 de enero, el Presidente de la Comisión de Beneficencia y Sanidad recibe una carta del Laboratorio Municipal de Higiene de Jerez, en la que se comunica que se ha recibido un telegrama del Jefe provincial de Sanidad para que se suspenda la vacunación antivariólica en niños mayores de tres meses y menores de tres años "hasta nueva orden". Esta medida la aclararemos en este trabajo más adelante.

El Alcalde, el Teniente de Alcalde de Beneficencia y Sanidad, y el Jefe local de Sanidad se reúnen el día 20 de enero para estudiar el em- plazamiento de los locales para llevar a cabo la vacunación. En febrero de 1965, Miguel Primo de Rivera y Urquijo, Alcalde de Jerez, y Joaquín Albuín Gómez, Delegado de Beneficencia y Sanidad, firman un Bando en el que comunican a la población los Centros donde se administrarán las vacunaciones (figura 3).

En el Bando también se hace constar los días y lugares en que se realizarán las vacunaciones en la campiña jerezana. En otro Bando, también del mes de febrero, se establecen los turnos de los médicos y de los practicantes que deberán administrarlas, no constan en este documento nombres de matronas para realizar esta labor, aunque sí se insta a una practicante, la Srta. Martín de Castro, junto con otros compañeros, a que no pierdan el contacto con la Jefatura local de Sanidad por si fueran necesarios sus servicios. No citaremos los nombres de los profesionales, médicos y practicantes, para no alargar en demasía este artículo, pero sí debemos consignar que, por ejemplo, Luis Encina González, Decano del Cuerpo de Médicos de APD, tenía programada su labor de vacunación en la Barriada de la Asunción.

El 29 de enero, el Jefe provincial de Sanidad escribe nuevamente al Alcalde de Jerez y realiza unas precisiones que consideramos interesante

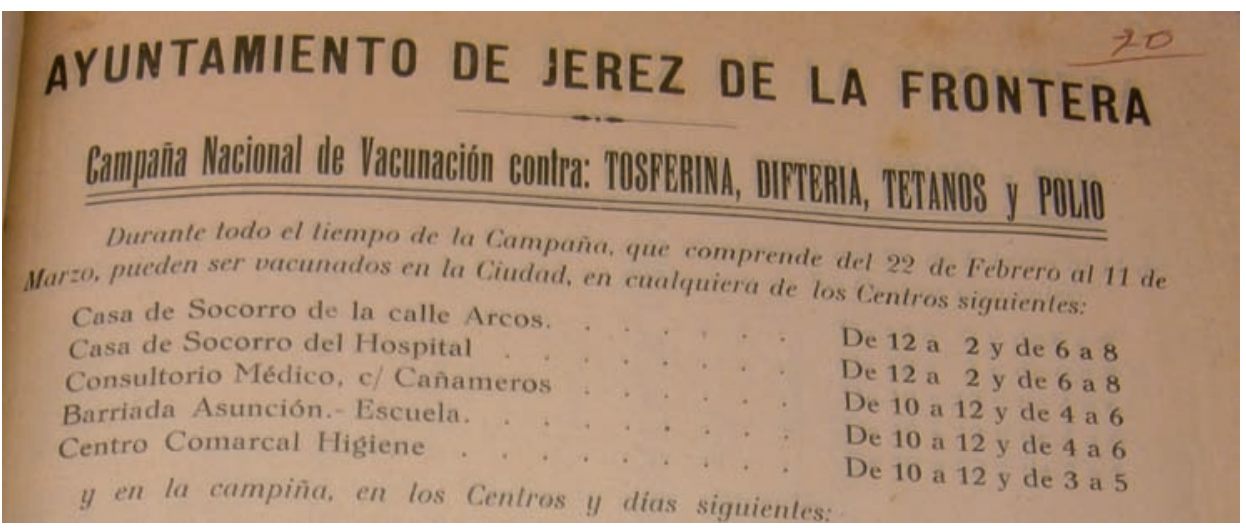

Figura 3: Fragmento del Bando firmado en febrero de 1965 por el Alcalde de Jerez, Miguel Primo de Rivera y Urquijo, en el cual constan los centros para la campaña de vacunación en la ciudad de Jerez. Fuente: (Legajo 1.929, expediente 36.659, AMJ). 
apuntar; por ejemplo, se corrobora que la edad de los niños que van a recibir la "vacuna triple" deben ser "niños mayores de 3 meses y menores de 3 años", y con respecto a la vacuna Sabin encontramos mayor precisión que en el anterior apunte que hemos realizado, en lo que se refiere a esta campaña de 1965: "A los mayores de 3 meses y menores de un año". Se insiste que en cada puesto de vacunación deberá haber un médico y un practicante, comadrona o enfermera, "todos ellos de los servicios oficiales o titulares aunque no se debe prescindir de la colaboración desinteresada que ofrezca cualquier otro profesional sanitario". En este sentido, como hemos apuntado ya, hemos visto que fueron asignados a los puestos de vacunación médicos y practicantes, pero no hemos observado la participación de comadronas o enfermeras. Otra cuestión más plantea el Jefe provincial de Sanidad: el Alcalde debe comunicar a la Jefatura provincial de Sanidad las neveras, tanto oficiales como particulares (siempre que le ofrezcan las debidas garantías), en que pueden guardarse las vacunas para realizar con eficacia la Campaña en Jerez. El día 2 de febrero, el Teniente de Alcalde, Delegado de Beneficencia y Sanidad, detalla al Jefe provincial de Sanidad, los lugares en que se encuentran las neveras donde pueden conservarse las vacunas:

- En la ciudad de Jerez: Las neveras del Hospital Municipal de Santa Isabel ("muy amplia”), del Laboratorio Municipal de Higiene y del Centro Comarcal de Higiene.

- En la campiña jerezana: En la Barca de la Florida (las neveras de los domicilios particulares del médico y del Secretario del Ayuntamiento, y la nevera del "Bar Bolilla”). En San José del Valle (la nevera del domicilio particular del médico y "además existen en esta Barriada dos bares con frigorifico").
En cuanto a la administración de la vacuna triple se hará en inyección intramuscular de 0,5 centímetros cúbicos en región glútea, previa desinfección con "alcohol yodado", mientras que la vacuna Sabin se administrará "en forma igual que la campaña anterior". Como ejemplo apuntamos la relación del material que se recibió en el puesto de vacunación de la Barca de la Florida, en febrero de 1965: 2 jeringas de 3 centímetros cúbicos; 432 dosis de vacuna trivalente; 150 dosis de vacuna antipolio; 50 cucharillas; dos litros de alcohol yodado; 1 kilogramo de algodón hidrófilo; 150 terrones de azúcar; 2 cajas de aguas (24 agujas); 500 fichas individuales y 5 hojas de relación nominal.

En esta campaña también se utilizó Radio Jerez y el periódico La Voz del Sur para divulgar los comunicados del Alcalde o de otras autoridades municipales y sanitarias, sobre este particular se pueden consultar los periódicos de los días 9, 11, y 16 de febrero, que insisten por ejemplo en la gratuidad de la campaña. El día 23, la prensa jerezana aclara las edades para las vacunaciones de los niños, que ya hemos consignado anteriormente, pero también matiza lo siguiente: "En cuanto a los mayores de estas edades pueden también vacunarse, pero corriendo de su cuenta la adquisición de las vacunas, ya existentes en las farmacias". Igualmente se apuntan algunas cuestiones apelando a la responsabilidad de los padres: la existencia de casos de muerte en España "en niños no vacunados por abandono de sus padres, pese a la obligatoriedad por orden ministerial del año 1943, por cuanto a la difteria se refiere". Y se inserta una pequeña nota en la prensa de ese día referida a la poliomielitis: "Ya no debe volver a España la poliomielitis. Vacunad a los niños que antes no recibieron la vacuna Sabin y contribuiréis al bienestar de la infancia”. 
En La Voz del Sur, de 24 de febrero, se publicó un amplio artículo del Dr. Gimeno de Sande titulado "Campaña Nacional de Vacunación contra la difteria, tosferina, tétanos y poliomielitis”. Destaca una frase de este artículo:

"Nosotros también confiamos más en la persuasión y en la elevación del nivel cultural sanitario, que en la obligatoriedad, y buen ejemplo ha sido el rotundo éxito en la pasada campaña contra la Poliomielitis al vacunarse prácticamente el 100 por 100 de los niños, a cuyo éxito tanto contribuyó una Campaña de Propaganda bien llevada por la Televisión, Radiodifusión y Prensa".

El citado periódico, los días 28 de febrero y 3 de marzo, insiste en la obligatoriedad de la vacunación, también en que a finales del mes de febrero se han vacunado en España "más de medio millón de niños" en los cinco primeros días de la Campaña. En lo que se refiere a Jerez de la Frontera, el periódico anuncia una prórroga los días 9, 11 y 14 de marzo para la aplicación de la vacunación, "por el mal tiempo de los últimos días".

El día 12 de marzo, La Voz del Sur realiza un balance de la primera fase de la Campaña de vacunación de 1965, subrayando que está a punto de finalizar y que el número de vacunados mayores de tres meses y menores de tres años en España es de 1.176.331, destacando que "409.365 menores de un año, han recibido además la vacuna Sabin contra la poliomielitis, lo que representa un 70 por 100 de los comprendidos en aquellas edades". Y se insiste además en que aún quedan días para que termine la Campaña. En lo que se refiere a Jerez de la Frontera podemos ofrecer datos estadísticos de las vacunaciones efectuadas entre los días 22 de febrero y 11 de marzo de 1965, a partir de un documento en el que no consta membrete ni firma (tabla 5).

\begin{tabular}{|c|c|c|}
\hline DÍA Y MES & $\begin{array}{c}\text { "TRIVALENTE" } \\
(\mathbf{s i c})\end{array}$ & ANTIPOLIO \\
\hline 22 febrero & 203 & 76 \\
\hline 23 febrero & 326 & 126 \\
\hline 24 febrero & 578 & 216 \\
\hline 25 febrero & 627 & 303 \\
\hline 26 febrero & 329 & 132 \\
\hline 27 febrero & 343 & 116 \\
\hline 1 marzo & 129 & 40 \\
\hline 2 marzo & 412 & 133 \\
\hline 3 marzo & 586 & 199 \\
\hline 4 marzo & 304 & 99 \\
\hline 5 marzo & 402 & 132 \\
\hline 6 marzo & 184 & 70 \\
\hline 8 marzo & 377 & 137 \\
\hline 9 marzo & 427 & 161 \\
\hline 10 marzo & 224 & 28 \\
\hline 11 marzo & 354 & 112 \\
\hline TOTAL & $\mathbf{5 . 8 0 5}$ & $\mathbf{2 . 0 8 0}$ \\
\hline
\end{tabular}

Tabla 5: Número de vacunaciones de "trivalente" (sic) y antipolio en Jerez de la Frontera (22 de febrero al 11 de marzo de 1965). Obsérvese que el funcionario que elaboró este documento escribe "trivalente" cuando debía referirse a la "triple" (Difteria, tétanos y tos ferina). Fuente: Legajo 1.929, Expediente 36.659. Campaña de vacunación antipolio, difteria, tos ferina y tétanos, 1965 (AMJ).

Los días 27, 29 de marzo y 2 de abril, La Voz del Sur, incluye Bandos del Alcalde, Primo de Rivera, y noticias anunciando que la segunda fase de la Campaña se llevará a cabo entre los días 5 y 14 de abril. Podemos apuntar que en el Centro de Vacunación de la Casa de Socorro de la calle Arcos, entre el 22 de febrero y el 18 de abril de 1965, ambos inclusive, se administraron 2.272 vacunas de la "triple" y 711 de la polio (Legajo 1.929, Expediente 36.659, AMJ). Datos que solo ofrecen una panorámica parcial de las vacunaciones efectuadas en Jerez de la Frontera en ese periodo de tiempo, ya que no incluye las estadísticas de otros centros de vacunación.

Conviene precisar también algunos aspectos subrayados por el Jefe provincial de Sanidad de Cádiz, en su extenso comunicado del día 29 de enero de 1965 al Alcalde de Jerez; el primero de ellos es que el haber padecido la 
tos ferina no constituye contraindicación alguna para esta vacunación y que la vacuna triple solo está contraindicada en los niños que padezcan procesos febriles, eczema, piodermitis generalizadas, lesiones cerebrales o convulsiones, y en los casos en que los niños estén sometidos a tratamiento con corticosteroides. En cuanto a la poliomielitis debemos subrayar un aspecto que ha llamado nuestra atención del escrito del Jefe provincial de Sanidad (Legajo 1.929, expediente 36.659, AMJ):

"Los niños menores de un año y mayores de tres meses cuyos padres rehúsen que les sea administrada la vacuna triple quedarán excluidos de la administración de la vacuna SABIN hecho que conviene sea recogido en los bandos y propaganda”.

No hemos podido aclarar, en lo que se refiere a la vacuna Sabin, si en Jerez de la Frontera se utilizó la elaborada por el Laboratorio Pfizer, o la del Laboratorio Wellcome o la del Laboratorio Ibys. En cambio, en el Archivo Municipal de Cádiz hemos encontrado un prospecto de Laboratorio Ibys con el nombre comercial de "Virusvacuna antipoliomielítica oral. Tipo Sabin” (Caja 3.834, AMC). Este laboratorio presentaba diversos envases: monovalente (tipo I), bivalente (tipos 2 y 3 ) y trivalente (tipos 1, 2 y 3 ). Se aclara en el prospecto que la vacuna puede conservarse por los menos seis meses entre $2^{\circ}$ y $10^{\circ}$, aunque puede ser expuesta excepcionalmente durante cortos periodos de tiempo a $25^{\circ} \mathrm{C}$. Se apunta también que esta vacuna "no produce reacción (...) y que no hay contraindicaciones en su uso, excepto en las infecciones agudas y en las diarreas (porque pueden ser debidas a un enterovirus que interferiría la vacunación". Asimismo se "aconseja dejar un intervalo de 21 días antes de realizar otras vacunaciones con virus vivos, tales como la vacunación antivariólica y la antiamarílica.
Sin embargo, la vacuna antipoliomielítica por vía oral se puede administrar simultáneamente con vacuna antitetánica, antidiftérica y antipertusis, con garantía y efectividad”. Estas matizaciones pueden hacernos entender el motivo por el que el Jefe provincial de Sanidad de Cádiz envió a Jerez de la Frontera un comunicado suspendiendo la vacunación antiavariólica en los niños mayores de tres meses y menores de tres años "hasta nueva orden".

\section{EPÍLOGO}

En la década de los cuarenta, cincuenta y sesenta existió una gran preocupación en España, en muchas familias, por la gravedad creciente de la poliomielitis, tanto en lo referido a la morbilidad como a la mortalidad. Tan solo hay que estudiar la tabla 2 que ofrece datos de los años 1949 a 1967, además de a los autores citados a lo largo del texto, para comprender que era un problema de salud pública al que había que poner remedio. Un remedio que llegó en forma de vacuna, primero la de Jonas Edward Salk y después la de Albert Bruce Sabin, sobre las cuales hemos precisado a lo largo del trabajo su utilización y sus diferencias.

No cabe duda de que la campaña de vacunación de finales de 1963 y principio de 1964, en España, supuso un antes y un después en la lucha contra la enfermedad; muchos profesionales (médicos, practicantes y enfermeras), así como voluntarios, participaron para que la vacuna Sabin llegara a los niños españoles, aspecto que hay que subrayar. Desde el punto de vista de la investigación y puesta en marcha de la campaña, debe destacarse la labor del médico gaditano Florencio Pérez Gallardo, que también tuvo una participación notable en la campaña piloto llevada a cabo previamente en las ciudades de León y Lugo, que como hemos visto en este trabajo ha sido estudiada en 
profundidad y de forma crítica por RodríguezSánchez y Seco Calvo (2009).

La referida campaña piloto, y la propia campaña nacional de vacunación contra la poliomielitis puesta en marcha en 1963 y 1964, incluso las campañas posteriores llevadas a cabo en los años sesenta, requieren de más trabajos monográficos para conocer pormenores que quizás en la actualidad solo están esbozados, para ello hay que seguir insistiendo en el estudio de las fuentes manuscritas e impresas, pero también de las fuentes orales, y en esta línea vienen trabajando con solvencia varios investigadores en nuestro país, algunos de los cuales han quedado referenciado en la bibliografía de este artículo.

Ateniéndonos a la campaña de vacunación contra la poliomielitis de 1963 y 1964, en sus dos fases, se debe considerar que se pusieron en marcha cincuenta equipos móviles. García Orcoyen señaló, en noviembre de 1963, que con esta campaña se aspira "fundamentalmente a la erradicación de la enfermedad, como ya se ha conseguido con la viruela y el paludismo". El director del Centro Nacional de Virus, Florencio Pérez Gallardo, al presentar a los medios la primera fase de la campaña manifestó "que se había trabajado intensamente para conseguir que los equipos de vacunación alcancen a todos los municipios y lugares españoles". Entre los recursos humanos señaló el médico gaditano que se contaba para llevar a cabo la campaña con más de 150 médicos especializados, acompañados cada uno por dos o tres enfermeras, afiliadas a la Sección Femenina o colaboradoras, que "se distribuirán por todo el país para administrar la vacuna; con ellos cooperarán los nueve mil médicos titulares y la clase médica en general". En la presentación de la campaña se subrayó la necesidad de la colaboración por parte de los padres, maestros, directores de colegios y de orfelinatos (ABC-M, 15-XI1963), hecho que hemos podido comprobar en nuestro estudio de la campaña de vacunación en Jerez de la Frontera. Así, pues, en 1963, la Dirección General de Sanidad inició la primera de sus grandes campañas nacionales y en unos meses "se vacunaron a 4.631.154 niños mayores de dos meses y menores de ocho años (sic)". Lo que tuvo como consecuencia el descenso de la morbilidad que ya hemos indicado para los años 1964 y 1965 (ABC-S, 20-XII-1967). Recuérdese que en la primera fase de la campaña nacional fueron vacunados 4.400 .000 niños (95\% de la población) y en la segunda a 4.680 .000 (98\%) (Pérez Gallardo, Valenciano Clavel, Gabriel y Galán, 2013).

En la prensa se señaló con insistencia que no debía quedar ni un niño sin vacunar, mayores de dos meses y menores de siete años, además se destacó lo fácil de su administración al ser una vacuna oral que se dispensaba con un terrón de azúcar o con una cucharadita de agua o jarabe, de esta forma tan sencilla "quedan totalmente vacunados y en su intestino no se reproducirán jamás los poliovirus paralizantes $y$, por consiguiente, se rompe la cadena de propagación de los virus de la poliomielitis, desapareciendo el peligro de transmisión y el de padecer esta terrible enfermedad, que en muchas ocasiones producía la muerte del niño o lo dejaba deforme o incapacitado para toda la vida" (ABC-S, 29-III-1964).

Ya hemos expuesto en este artículo la preocupación, en cuanto a la morbilidad y a las escasas vacunaciones contra la poliomielitis que se estaban llevando a cabo en la provincia de Cádiz en la década de los cincuenta, sobre todo a partir de los escritos del Jefe provincial de Sanidad Francisco Aristoy; pero también Manuel Cruz Hernández, catedrático de Pediatría de la Facultad de Medicina de 
Cádiz, mostró su inquietud en un trabajo titulado "Consideraciones sobre las formas graves de poliomielitis en el último brote epidémico de Cádiz", apuntando que desde julio de 1957 a primeros de agosto de 1958, en los servicios de Pediatría y en el dispensario de la Jefatura provincial de Sanidad, fueron asistidos 104 enfermos, de los cuales 26 padecían "formas graves". El propio Cruz Hernández, en los años sesenta, debido a que la situación era preocupante (tablas 3 y 4), consiguió que la Diputación Provincial pusiera en marcha para la asistencia rehabilitadora y médica de los niños con poliomielitis, incluido el pulmón de acero, el "Centro San Acacio" (Herrera, 2012).

Juan del Rey Calero, actualmente miembro de la Real Academia Nacional de Medicina, que vivió el problema de la poliomielitis en los años sesenta, concedió una entrevista a Diario de Cádiz, en la que manifestó que en la citada década Cádiz tenía la mayor tasa de niños con poliomielitis, "casi 150 afectados de los 2.200 que existían en España". Rey Calero subraya el esfuerzo que se hizo en 1963 porque en algunas poblaciones de la provincia de Cádiz en los Ayuntamientos no existían las listas con los niños del pueblo y en los colegios había un porcentaje alto de absentismo, sobre todo en los barrios marginales, "por lo que era complicado localizar a los pequenos para vacunarlos". Rey Calero apunta que "conseguimos vacunar a todos los niños, con una cobertura superior al 95\%" (DC, 19-XI-2001). Unas cifras para la provincia de Cádiz que vienen a ser coincidentes con las apuntadas para el conjunto del país por Pérez Gallardo, Valenciano Clavel y Gabriel y Galán (2013).

Hay que tener en cuenta que después de la campaña de vacunación de 1963-1964 el número de casos de poliomielitis en España, según las cifras oficiales, se redujeron de 1.959, en el año 1963, a 193 en 1964 y a 70 en 1965 (tabla 2) (figura 4); aunque en los años 1966 y 1967 se vuel- ve producir un incremento a 308 y 362 casos respectivamente, circunstancia que motiva que algunos investigadores estén tratando de aclarar de qué manera se desarrollaron las campañas a lo largo de todo el segundo quinquenio de la década de los sesenta, intentando comprender si hubo relajación en las campañas de vacunación o si se incurrieron en defectos en su organización que habrían motivado que quedaran niños sin vacunar (Rodríguez Sánchez, 2014). Hecho que en otros contextos históricos y en otras circunstancias ha ocurrido en nuestro país, con respecto a la viruela, por ejemplo en el primer tercio del siglo XX (Herrera, 1990 y 2007; Sáinz Otero, 2007). En este aspecto compartimos la opinión de Rafael Nájera (2013a), que califica la campaña de vacunación con la vacuna Sabin (1963-1964):

"(de)...éxito indiscutible que debería haber dado paso a la eliminación en un corto período de tiempo, pero que, al relajarse la lucha contra la enfermedad, vacunación y vigilancia, permitió un repunte que arrastró la presencia de la polio en España durante 23 años. La cifra de 62 casos de 1965 no se va a mejorar hasta 1976 con 41 casos".

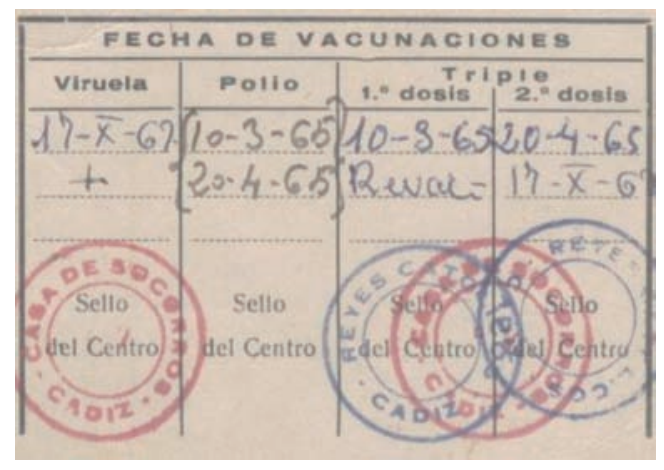

Figura 4: Detalle de una ficha de los servicios sanitarios del Ayuntamiento de Cádiz, en la que omitimos los datos personales del niño. Constan las vacunaciones recibidas contra la polio y la "triple" (1965), además de la vacuna de la viruela. Fuente: Archivo personal de F.H.R. 
En este trabajo hemos estudiado monográficamente la campaña de vacunación contra la poliomielitis de 1963 y 1964, en sus dos fases y con la vacuna Sabin, en Jerez de la Frontera; pero también hemos procurado localizar fuentes documentales que nos permitan comprender si en esta importante ciudad de la provincia de Cádiz hubo continuidad o no en la vacunación contra la enfermedad en el año 1965. En lo que se refiere a este año se ha subrayado como peculiaridad específica de la misma, que en España y también en Jerez de la Frontera se vacunó contra la poliomielitis, con la vacuna Sabin, pero también se incorporó a la campaña la vacunación contra la difteria, el tétanos y la tos ferina (DPT). En esta campaña, en lo que se refiere al conjunto del país, se alcanzó una cobertura de vacunación del 70\% y en lo que se refiere a la poliomielitis se observa que también hubo un descenso en la morbilidad (Pachón del Amo, 2004) (tabla 2). Todo lo cual indica que durante los años 1963 a 1965 se realizó un esfuerzo notable en la lucha contra la poliomielitis en España y también en Jerez de la Frontera, tanto en su núcleo urbano como en la campiña, tarea coordinada desde la Jefatura provincial de Sanidad de Cádiz que se apoyó en la Jefatura local de Sanidad, en las autoridades municipales, en los médicos, practicantes y enfermeras, en los maestros y en personas voluntarias de la localidad jerezana, que colaboraron también en la cumplimentación de las fichas, elaboradas para consignar los datos de los niños vacunados contra la poliomielitis, en la campaña de 1963-1964, pero también en la de 1965 en que la vacunación se llevó a cabo contra esta enfermedad, pero también como hemos indicado contra la difteria, la tos ferina y el tétanos.

A pesar de todo ello llama la atención, como hemos indicado, que en el conjunto del país se pasara de los 70 casos de poliomielitis del año
1965 a los 308 del año 1966 y a los 362 de 1967 (tabla 2); en lo que se refiere a la provincia de Cádiz se deben subrayar de forma significativa las 7 defunciones que se producen en el año 1971 (tabla 3) y el indicador de la morbilidad que en 1966 es de 3,4 y en 1969 de 2,97, mientras que en 1971 asciende a 3,72 (tabla 4).

No cabe duda de que éste y otros aspectos sobre la enfermedad requieren de un mayor número de investigaciones para conocer en plenitud los problemas que acontecieron, y para ello como hemos indicado hay que seguir recurriendo a las fuentes documentales de los archivos, pero también a las fuentes orales para conocer en su justa medida como se llevaron a cabo las campañas de vacunación, la vigilancia y en su conjunto la lucha contra la enfermedad (Rodríguez Sánchez, 2009, 2010, 2013b y 2014; Nájera, 2013a).

\section{AGRADECIMIENTOS:}

Agradezco al profesor Juan Antonio Rodríguez Sánchez, de la Universidad de Salamanca (uno de los mayores expertos en el estudio de la historia de la poliomielitis en España), sus comentarios, sugerencias y generosidad al proporcionarme bibliografía y datos estadísticos. Asimismo su estímulo para que llevara a término este modesto trabajo.

\section{FUENTES Y ARCHIVOS}

- Archivo Municipal de Jerez de la Frontera (AMJ):

- Legajo 1929. Expediente 36.653 (Beneficencia. Distribución sanitaria).

- Legajo 1929. Expediente 36.654 (Campaña de vacunación antipoliomielítica) (1963-1964).

- Legajo 1929. Expediente 36,659 (Beneficencia y Sanidad. Campaña de vacunación amtipoliomielítica, difteria, tos ferina y tétanos (1965).

- Periódico "La Voz del Sur" (Recortes de prensa localizados en Legajo 1929, expediente 36.654). Citamos a continuación los días y páginas consultados de este periódico: 22 de noviembre de 1963, pp. 3-4; 23 de noviembre de 
1963, p. 5; 27 de marzo de 1964, p. 6; 7 de abril de 1964, p. $5 ; 8$ de abril de 1964 , p. 5.

- Periódico "La Voz del Sur" (Recortes de prensa localizados en Legajo 1929, expediente 36.659). Citamos a continuación los días y páginas consultados de este periódico: 9 de febrero de 1965, p. 4; 11 de febrero de 1965, p. 5; 16 de febrero de 1965, p. 5; 23 de febrero de 1965, p. 4; 24 de febrero de 1965, p. 63; 28 de febrero de 1965, p. 4; 3 de marzo de 1965, p. 7; 12 de marzo de 1965, p. 3.

- Archivo Municipal de Cádiz (AMC):

- Caja 3.831. Partes estadísticos semanales. Estadística sanitaria 1956-1973. Contiene partes emitidos por el Jefe local de Sanidad (Ayuntamiento de Cádiz) Jefe provincial de Sanidad (Instituto provincial de Sanidad. Paseo de las Delicias, Olivillo, Cádiz).

- Caja 3.834. Beneficencia y Sanidad. Expediente y documentación “varia” de vacunaciones (1950-1964).

- Boletín Oficial de la Provincia de Cádiz (BOPC): 9 de enero de 1963 (No7): Orden de 27 diciembre de 1962 sobre la campaña de vacunación antipoliomielítca masiva durante los meses de enero a junio de 1963, p. 1; 19 de febrero de 1963 ( $\mathrm{N}^{\circ} 42$ ): Orden de 26 de enero de 1963 por la que se dictan normas en cuanto a las obligaciones y facultades de la Dirección General de Sanidad en materia de medicina preventiva (vacunación antipoliomielítica),p. 1.

- Biblioteca José Celestino Mutis (Cádiz):

- Se han consultado los siguientes números de Diario de Cádiz (DC): Diario de Cádiz: 25 de junio de 1961; 13 de septiembre de 1963, p. 6; 9 de mayo de 1963, p. 3; 19 de mayo de 1963, p. 3; 22 de mayo de 1963, p. 1; 19 de noviembre de 2001, p. 12.

- Instituto Nacional de Estadística:

- Libros del Movimiento Natural de la Población de España (1958-1975).

- Hemeroteca digital:

- Se ha consultado el periódico ABC de Madrid (ABC-M) y ABC de Sevilla (ABC-S):

- ABC-M, 2 de abril de 1958, edición de la mañana, p. 26. Disponible en: http://hemeroteca.abc.es/nav/Navigate.exe/hemeroteca/madrid/abc/1958/04/02/026.html (Consultado el 26 de julio de 2015).
- ABC-M, 23 de enero de 1959, edición de la mañana, pp. 31-32. Disponible en: http://hemeroteca.abc.es/nav/ Navigate.exe/hemeroteca/madrid/abc/1959/01/23.html (Consultado el 26 de julio de 2015).

- ABC-M, 15 de noviembre de 1963. Edición de la mañana, p. 60. Disponible en: http://hemeroteca.abc.es/nav/ Navigate.exe/hemeroteca/madrid/abc/1963/11/15/060. html (Consultado el 31 de julio de 2015).

- ABC-S, 29 de marzo de 1964. Edición de Andalucía, p. 95. Disponible en: http://hemeroteca.sevilla.abc.es/nav/Navigate.exe/hemeroteca/sevilla/abc.sevilla/1964/03/29/095. html (Consultado el 31 de julio de 2015).

- ABC-S, 20 de diciembre de 1967. Edición de Andalucía, p. 34. Disponible en: http://hemeroteca.sevilla.abc.es/nav/Navigate.exe/hemeroteca/sevilla/abc.sevilla/1967/12/20/034. html (Consultado el 31 de julio de 2015).

\section{BIBLIOGRAFÍA}

- Aguila Maturana, A. (2000). El debate médico en torno a la Rehabilitación en España (1949-1969). Tesis doctoral. Facultad de Medicina. Madrid: Universidad Complutense.

- Aguila Maturana, A., Álvarez Badillo, J.C., Miangolarra Page, L.P., Rodríguez Rodríguez, L.P. (2002). Influencia de las epidemias de poliomielitis sobre la rehabilitación en España (1949-1969). Rehabilitación (Madr), 36, 4249.

- Aristoy-Santos, F. (1959). Notas sobre la poliomielitis en Cádiz (Campaña de Vacunación)”. En Libro de Actas de la V Reunión Nacional de Sanitarios (pp.20-24). Madrid. - Ayarzagüena Sanz, M. (2013). El marco político, económico, social y cultural de España (1939-1975). En M.I. Porras-Gallo, et al (Coords.), El drama de la polio. Un problema social y familiar en la España franquista, (pp. 32-47). Madrid: Los libros de la Catarata,

- Báguena Cervellera, Mª.J. (2004). Saberes y prácticas en torno a la polio en la medicina valenciana (1900-1950). En J. Martínez Pérez, et al (Coords.), La medicina ante el nuevo milenio: una perspectiva histórica, (pp.949-962). Cuenca: Editorial de la Universidad de Castilla-La Mancha.

- Báguena Cervellera, Ma .J. (2009). Estudios epidemio- 
lógicos y virológicos sobre la poliomielitis en Valencia (1959-1969). Asclepio. Revista de Historia de la Medicina $y$ de la Ciencia, 1, 39-54.

- Ballester, R. y Porras, M.I. (2009). El significado histórico de las encuestas de seroprevalencia como tecnología de laboratorio aplicada a las campañas de inmunización. El caso de la poliomielitis en España. Asclepio. Revista de Historia de la Medicina y de la Ciencia, 1, 55-80.

- Ballester, R. y Porras, Ma.I. (2012). La lucha europea contra la presencia epidémica de la poliomielitis: una reflexión histórica. Dynamis, 2, 273-285.

- Cabral Chamorro, A. (1990). Una aproximación a la crisis de la vid y del vino en el marco de Jerez: el caso de Trebujena. Agricultura y Sociedad, 57, 241-260.

- Capel Sáez, H. (1971). La Red urbana española: 19501960. Tesis doctoral. Departamento de Geografía. Barcelona: Universidad de Barcelona. Disponible en: ¡Error!Referencia de hipervínculo no válida. (Consultado el 26 de julio de 2015).

- Caro Cancela, D. (1999). Jerez Contemporáneo (siglos XIX y XX). En D. Caro Cancela (Coord.), El Jerez moderno y contemporáneo (pp.195-438). Cádiz: Servicio de Publicaciones de la Diputación Provincial de Cádiz.

- Celebración del 50 aniversario de la instauración de la campaña de vacunación antipoliomielitis en España. Homenaje al Dr. D. Florencio Pérez Gallardo (2013). Revista Española de Salud Pública, 87,5. Disponible en http://scielo.isciii.es/scielo.php?script=sci_ issuetoc\&pid $=1135-572720130005 \& \operatorname{lng}=$ pt\&nrm $=$ iso (Consultado el 8 de agosto de 2015).

- Cruz-Hernández, M. (1959). Consideraciones sobre las formas graves de poliomielitis en el último brote epidémico de Cádiz. Farmaes, 57-73.

- Cruz-Hernández, M. (1972). Pediatría y Puericultura. Barcelona: Editorial Romargraf.

- Domingo Fernández, C.J. y Contreras Carrasco, G. (2006). Los tiempos del piloto. Anales de la Real Academia Nacional de Medicina, CXXIII, 4, 747-757.

- Fernández-Cruz, E., Rodríguez-Sáinz, C. (2013). Inmunología de la poliomielitis: vacunas, problemas para la prevención/erradicación e intervenciones de futuro. Revista Española de Salud Pública, 87, 443-454
- Ferrán Martínez Navarro, J. (2013). Los estudios epidemiológicos sobre la poliomielitis en España antes de la vacunación. Revista Española de Salud Pública, 5, 429441.

- Fundación Juan March. Ayudas de investigación (19571962). Disponible en: http://recursos.march.es/web/ prensa/anales/1956-1962/8-Ayudas-de-investigacion. pdf (Consultado el 26 de julio de 2015).

- González Rodríguez, P. (1953). Aspectos epidemiológico y social de la poliomielitis. La parálisis infantil en España (folleto para médicos). Madrid: Dirección General de Sanidad.

- Herrera-Rodríguez, F. (1990). Enrique Alcina Quesada (1879-1943) y su visión de la enfermera durante la Guerra Civil española. En Libro de Actas del Primer Encuentro Interdisciplinar de Estudios de la Mujer (tomo I, 433-441), Granada.

- Herrera-Rodríguez, F. (2006). Antonio Orozco Acuaviva: un médico humanista en la Academia Hispanoamericana. Cádiz: Real Academia Hispanoamericana de Ciencias, Artes y Letras de Cádiz..

- Herrera-Rodríguez, F. (2007). La obra sanitaria de Leonardo Rodrigo Lavín (1867-1950). Cádiz: Fundación Provincial de Cultura (Diputación de Cádiz).

- Herrera-Rodríguez, F. (2011). Un viaje a Newark en busca de la polio. Cultura de los Cuidados, 31, 30-40.

- Herrera-Rodríguez, F. (2012) Polio y Rehabilitación en la obra de Antonio Orozco Acuaviva. Llull, 76, 339-340.

- Herrera-Rodríguez, F. (2015). Una revisión de Pedro Rodrigo Sabalette sobre la poliomielitis (1948). Cultura de los Cuidados, 41, 56-70.

- León Rega, P., Echevarría Mayo, J.M. (2005). La poliomielitis y el síndrome post-polio; una breve revisión. Disponible en http://www.postpoliomexico.org/PolioPostPolioBreveResumen.html (Consultado el 26 de julio de 2015). - Martínez-Perez, J. (2009a). Presentación: La poliomielitis como modelo para el estudio de la enfermedad en perspectiva histórica. Asclepio. Revista de Historia de la Medicina y de la Ciencia, 1, 7-21.

- Martínez-Pérez, J. (2009b). Consolidando el modelo médico de discapacidad: sobre la poliomielitis y la constitución de la traumatología y ortopedia como especialidad 
en España (1930-1950). Asclepio. Revista de Historia de la Medicina y de la Ciencia, 1, 117-142.

- Muñoz Singi, G. (2007). La poliomielitis en la prensa salmantina (1954-1967. Tesis doctoral dirigida por el Dr. Juan A. Rodríguez Sánchez. Salamanca: Universidad de Salamanca.

- Nájera, E. y otros (1975). Análisis epidemiológico de la situación actual de la poliomielitis en España. Revista de Sanidad e Higiene Pública, 49, 953-1.025.

- Nájera, R. (2006a). Florencio Pérez Gallardo (19172006). Revista Española de Salud Pública, 80, 605-608.

- Nájera, R. (2006b). Recuerdos de una vida. Anales de la Real Academia Nacional de Medicina, CXXIII, 4, 759776.

- Nájera, R. (2013a). La eliminación de la Poliomielitis en España. Virología, 3, 33-37. Disponible en: http:// sevirologia.es/media/uploads/ultimo_numero_revista_ sev/06historia.pdf (Consultado el 3 de agosto de 2015).

- Nájera, R. (2013b). Hilary Koprowski (1916-2013). Virología, 3, 33-37. Disponible en: http://sevirologia.es/ media/uploads/ultimo_numero_revista_sev/06historia. pdf (Consultado el 3 de agosto de 2015).

- Pachón del Amo, I. (2004). Historia del programa de vacunación en España. En C. Amela, (Coord.), Epidemiología de las enfermedades incluidas en un programa de vacunación (pp.9-16). Madrid: Sociedad Española de Epidemiología y Emisa.

- Pérez Gallardo, F., Valenciano Clavel, L., Gabriel y Galán, J. (2013). Resultados de la campaña Nacional de Vacunación Antipoliomelítica por vía oral en España (Estudio virológico y epidemiológico). Revista Española de Salud Pública, 87, 523-540.

- Porras-Gallo, M.I., Báguena, M.J., Ballester, R., De las Heras, J. (2012). La Asociación Europea contra la Poliomielitis y los programas europeos de vacunación. Dynamis, 32, 287-310.

- Porras-Gallo, M.I., Ayarzagüena Sanz, M., Heras Sarlord de las, J., Báguena Cervellera, Ma J. (coords.) (2013). El drama de la polio. Un problema social y familia en la España franquista. Madrid: Los Libros de la Catarata.

- Porras-Gallo, M.I. (2014) La poliomielitis en la España franquista: educar e reeducar. Educar em Revista Curi- tiva, 54, 71-95.

- Reseña Estadística de la provincia de Cádiz (1957). Presidencia del Gobierno. INE, Madrid.

- Rey Calero, J. Florencio Pérez Gallardo in memoriam. Anales de la Real Academia Nacional de Medicina, CXXIII, 4,739-746.

- Rodríguez-Sánchez, J.A. y Seco-Calvo, J. (2009). Las campañas de vacunación contra la poliomielitis en España en 1963. Asclepio. Revista de Historia de la Medicina y de la Ciencia, 1: 81-116.

- Rodríguez-Sánchez, J.A. (2010). Responsabilidades nao assumidas: a poliomielite na Espanha (1954-1967). En D. Raimundo do Nascimento (coord.), A história da poliomielite. Garamondn (pp.195-224). Río de Janeiro.

- Rodríguez-Sánchez, J.A. (2012). Las secuelas sociales de la polio: el inicio del movimiento asociativo en España (1957-1975). Dynamis, 2, 391-414.

- Rodríguez-Sánchez, J.A. (2013). Poliomielitis y movimiento antivacunacionista en España (1955-1963). En Actas I Congreso de Historia Contemporánea, IHC (pp.145-159). Lisboa-Coimbra.

- Rodríguez-Sánchez, J.A. (2013b). Del control a la erradicación: salud pública y atención primaria en la lucha contra la polio en España (1963-1988). Ponencia presentada en Seminario Política, Salud y Enfermedad en España: entre el desarrollismo y la transición. Alicante: Museo Arqueológico Provincial de Alicante, 12-13 de diciembre.

- Rodríguez-Sánchez, J.A. (2014). De las campañas de vacunación al calendario vacunal: el Programa Nacional de Vacinaçao portugués y las Campañas Nacionales de Vacunación Antipoliomielítica en España (1963-1967). En R. Campos Marín et al. (Coords.), Medicina y Poder Político. Sociedad Española de Historia de la Medicina (pp.203-210). Madrid: Universidad Complutense.

- Rodríguez-Sánchez, J.A. (2015). An Introduccion (Guest Editor). En Poliomyelitis after Poliomyelitis: Light and shadow of the erradication. Higyiea Internationalis an interdiscinary Journal for the history of Public Health, 1, 7-31.

- Ruiz Mata, J. (2010). Breve Historia de Jerez de la Frontera. Tierra de Nadie Editores, Jerez de la Frontera. 


\section{ᄃultura de las Cuidados}

- Sáinz-Otero, A. (2007). La mortalidad en Cádiz (19231939). Tesis doctoral. Cádiz: Facultad de Medicina Universidad de Cádiz.

- Tuells, J. (2008). Los testimonios de los expertos y su participación en las primeras campañas de vacunación an- tipoliomielíticas en España. En: T. Ortiz et al (Coords.), La experiencia de enfermar en perspectiva histórica (pp.321-324). Granada: Universidad de Granada.

- Tuells, J. (2010). El frágil inicio de la cadena de frío vacunal en España. Gaceta Sanitaria, 24, 354-357.

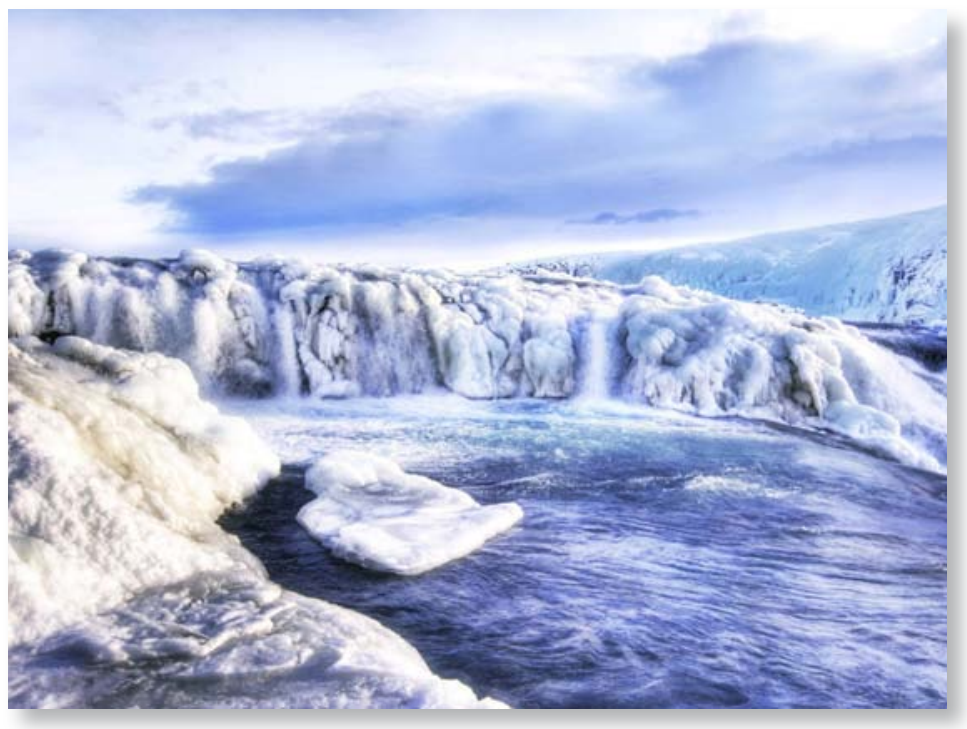




\section{El cuidado de enfermería y su evolución histórica: una revisión integrativa}

\section{Nursing care and historical evolution: an integrative review \\ O cuidado de enfermagem e sua evolução histórica: uma revisão integrativa}

Camila Neumaier Alves ${ }^{1}$, Ana Cândida Lopes Corrêa ${ }^{2}$, Marilu Correa Soares ${ }^{3}$, Sonia Maria Könzgen Meincke

${ }^{1}$ Enfermeira, Mestre, Doutoranda, Programa de Pós-Graduação em Enfermagem, Universidade Federal de Pelotas. E-mail: camilaenfer@gmail.com

${ }^{2}$ Enfermeira, Mestre, Doutoranda, Programa de Pós-Graduação em Enfermagem, Universidade Federal de Pelotas. E-mail: analopescorrea@hotmail.com

${ }^{3}$ Enfermeira Obstetra, Doutora, Professora do Curso de Enfermagem da Universidade Federal de Pelotas. E-mail:enfmari@uol.com.br

${ }^{4}$ Enfermeira, Doutora, Professora do Curso de Enfermagem da Universidade Federal de Pelotas. E-mail: meinckesmk@gmail.com

Cómo citar este artículo en edición digital: Neumaier Alves, C., Lopes Corrêa, A.C., Correa Soares, M. y Könzgen Meincke, S.M. ${ }^{a}$. (2015). O cuidado de enfermagem e sua evolução histórica: uma revisão integrativa. Cultura de los Cuidados (Edición digital), 19(43). Disponible en: <http://dx.doi.org/10.14198/cuid.2015.43.09>

Correspondencia: Camila Neumaier Alves. Rua Gomes Carneiro, no 01, Sala 201. Pelotas (Rio Grande do Sul/Brasil). Correo electrónico: camilaenfer@gmail.com

Recibido: 14/07/2015; Aceptado:14/10/2015

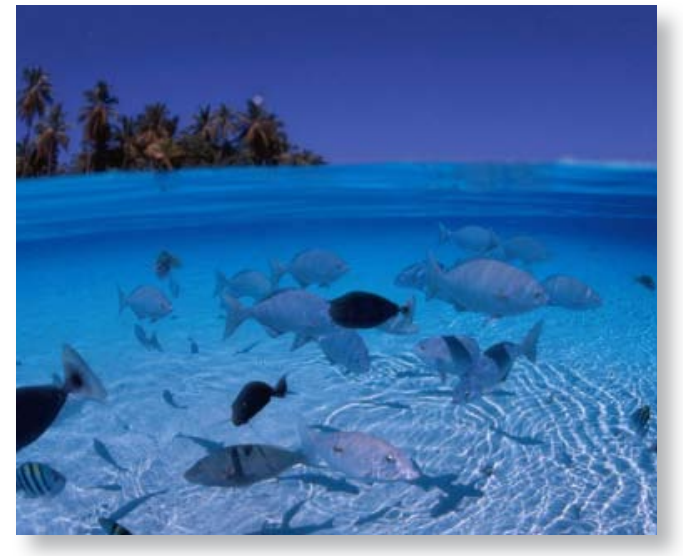

ABSTRACT

The aim is to identify the publications available in the literature about the history of nursing in the field of care provided by nurses. The method used included the integrative literature review, which is one of evidence-based practice resources. The search was conducted in August 2014, in the Virtual Library of Health. Were included articles that presented in titles or ab- stracts references to the history of nursing or the nursing care. Were excluded articles unrelated to the subject studied. For identification of the results it was decided to make a descriptive analysis of the publications and grouping of topics. It was found that the productions focus their writings on the contributions of Florence, religion and other for nursing. Moreover, prevailed discussions about the evolution of nursing through the ages and the history of care. It is understood that these findings are fundamental to locate the nurse in its history, since the nursing remains in progress and we are all actors in this art.

Keywords: Nursing; History of Nursing; Nursing Care.

\section{RESUMEN}

El objetivo es identificar las publicaciones disponibles en la literatura sobre la historia de la enfermería en el ámbito de la atención pres- 
tada por los enfermeros. El método utilizado incluyó la revisión integradora de la literatura, que es uno de los recursos de la práctica basada en la evidencia. La búsqueda se realizó en agosto de 2014, en la Biblioteca Virtual de Salud. Fueran incluídos artículos que presentan en títulos o resúmenes referencias a la historia de la enfermería o la atención de enfermería. Se excluyeron los artículos no relacionados con el tema estudiado. Para la identificación de los resultados se decidió realizar un análisis descriptivo de las publicaciones y agrupación de los temas. Se encontró que las producciones centran sus escritos sobre las contribuciones de Florence, la religión y otros para la enfermería. Por otra parte, se impuso discusiones acerca de la evolución de la enfermería a través de los siglos y la historia de la atención. Se entiende que estos resultados son fundamentales para localizar el enfermero en su historia, ya que la enfermería sigue en curso y somos todos actores de esta arte.

Palabras clave: Enfermería; Historia de la enfermeira; Cuidados de Enfermería.

\section{RESUMO}

Objetiva-se identificar as publicações disponíveis na literatura acerca da história da enfermagem, no campo dos cuidados realizados por enfermeiros. O método utilizado compreendeu a revisão integrativa da literatura, que é um dos recursos da prática baseada em evidências. A busca foi realizada em agosto de 2014, na Biblioteca Virtual da Saúde. Incluíram-se artigos que apresentaram nos títulos ou resumos referências à história da enfermagem ou aos cuidados de enfermagem. Excluíram-se artigos não relacionados à temática estudada. Para identificação dos resultados optou-se por fazer uma análise descritiva das publicações e agrupamento dos temas. Identificou-se que as produções centram suas escritas nas contribuições de Florence, da religião e de outros povos para a enfermagem. Ademais, prevaleceram discussões acerca da evolução da enfermagem através dos tempos e a história dos cuidados. Compreende-se que estes achados são fundamentais para situar o enfermeiro em sua trajetória, uma vez que a enfermagem permanece em evolução e somos todos atores nesta arte.

Palavras chave: Enfermagem; História da Enfermagem; Cuidados de Enfermagem.

\section{INTRODUÇÃO}

Cuidar é uma atitude de ocupação, preocupação, responsabilização e afeto com o outro (Boff, 1999). Cuidar envolve um olhar integral ao ser humano, desde suas necessidades até o contexto cultural ao qual se insere, considerando que cada um possui seus valores, crenças, saberes e práticas de cuidados. Logo, cuidar é valorizar o ser humano na sua totalidade, é um cuidado feito com compaixão, interesse e com carinho, no qual o ser humano é olhado, escutado e sentido (Waldow, 2004).

Historicamente o cuidado era realizado por pessoas, na maioria das vezes mulheres, que ajudavam outras e atendiam suas necessidades. Os cuidados eram voltados para as crianças, as gestantes, o fogo, a caça, as plantas e as colheitas (Collière, 1989). Assim, cuidar passou a ser entendido como ajudar a viver e as mulheres desempenhavam papel fundamental no cuidado ao outro, sendo vistas como alguém que cuida.

Com o passar dos anos a mão de obra especializada foi requisitada para executar as ações de cuidado, e assim as mulheres que cuidavam passaram a serem reconhecidas como enfermeiras (Collière, 1989). Foi então com as ações de Florence Nightingale que a 
enfermagem passou a sistematizar o cuidado. Florence valorizava a arte por meio das ações de enfermagem, enfatizando conceitos de cuidado à saúde. Além destes aspectos, ressaltava a importância do cuidado amoroso e honesto, de forma que as enfermeiras, além do conhecimento científico, necessitavam de um elevado padrão moral e de criatividade (Stamm, 2002).

Entretanto, a necessidade de mão de obra especializada e o crescimento de profissionais na área da saúde influenciaram para que o cuidado fosse realizado de forma isolada e nas dimensões do corpo que necessitavam de tratamento, dando força ao modelo biomédico de cuidado, o qual estimula os profissionais da saúde a aderirem ao comportamento cartesiano (Barros, 2002).

Stamm (2002), ao tratar sobre a evolução do cuidado de enfermagem, cita alguns autores que foram determinantes nesse processo, como Boff, Leininger, Waldow e Watson. Para ela, os trabalhos desses autores chamaram atenção dos demais enfermeiros e trabalhadores da saúde para a dominação que estavam sofrendo pelo modelo biomédico, fazendo com que refletissem acerca da sua atuação e de novas concepções de cuidado na enfermagem.

Desta maneira, o cuidado de enfermagem passa a ser percebido como uma atitude essencial à vida. Que envolve amor, solidariedade, expressando um "saber-fazer" embasado na ciência e na ética, direcionado às necessidades do indivíduo, da família e da comunidade (Vale, Pagliuca, 2011).

A partir desta contextualização, entende-se que conhecer a história dos cuidados de enfermagem torna-se fundamental para integrar e contextualizar o enfermeiro na sua história e na arte de fazer a enfermagem. Corrobora estudo ao destacar que a valorização da evolução histórica da enfermagem permite conhecer como esta profissão foi se desenvolvendo ao longo dos anos e seu caminho para formar uma disciplina (Siles, 2010). Para tanto objetiva-se identificar as publicações disponíveis na literatura acerca da história da enfermagem, no campo dos cuidados realizados por enfermeiros.

\section{MÉTODO}

O presente estudo apresenta como método um dos recursos da prática baseada em evidências, a revisão integrativa da literatura, que vem permitir investigar o tema em questão. Fundamentou-se este estudo em publicações que detalham e validam esse método de pesquisa (Ursi, 2005; Ursi, Galvão, 2006; Mendes, Silveira, Galvão, 2008).

A revisão integrativa é um modelo que tem por finalidade reunir e sintetizar resultados de pesquisas sobre um determinado tema, possibilitando apontar lacunas no conhecimento e a síntese de múltiplos estudos publicados, permitindo conclusões gerais a respeito de um tema particular, ou uma aérea de estudo (Mendes, Silveira, Galvão, 2008).

Para a elaboração da presente revisão integrativa percorreu-se as etapas propostas por Mendes, Silveira e Galvão (2008), a saber: estabelecimento da questão de pesquisa; estabelecimento de critérios de inclusão e exclusão de artigos; categorização dos estudos; avaliação dos estudos; interpretação dos resultados; e a síntese do conhecimento. Desta maneira, para guiar a pesquisa, formulou-se a seguinte questão: como a história dos cuidados de enfermagem vem sendo discutida nas produções científicas?

A seleção dos artigos foi realizada por meio de uma busca na Biblioteca Virtual da Saúde (BVS). Assim, procurou-se ampliar as possibilidades da pesquisa. Os critérios de inclusão foram artigos que apresentassem nos títulos ou 
resumos referências à história da enfermagem ou aos cuidados de enfermagem; nos idiomas inglês, espanhol ou português. Os critérios de exclusão foram artigos que não se relacionassem a temática estudada e/ou não respondessem à pergunta de pesquisa.

Para iniciar a busca localizou-se o descritor "história da enfermagem"; após filtrou-se no campo assunto principal "cuidados de enfermagem"; na opção por limites definiu-se "humano"; no campo idioma selecionaram-se "inglês", "espanhol" e "português"; e no tipo de documento "artigo". Ressalta-se que não se estipulou o marco inicial por ano a fim de possibilitar maior abrangência na busca.

A busca foi realizada em agosto de 2014, e a partir desta encontrou-se um total de 69 publicações. Para realizar a captação dos conhecimentos produzidos nas publicações utilizou-se um quadro sinóptico proposto por Ursi e Galvão (2006), adaptado para este estudo, que contempla os seguintes aspectos: referência da pesquisa; intervenção estudada (objetivo); resultados e recomendações e/ou conclusões. A apresentação dos resultados e discussão dos dados obtidos será feita de forma descritiva, para possibilitar ao leitor que verifique a possibilidade de aplicar os resultados encontrados.

\section{RESULTADOS}

Os 69 estudos encontrados referem-se aos cuidados de enfermagem; destes 26 estavam indexados em Medical Literature Analysis and Retrieval System Online (MEDLINE), 25 no Índice Bibliográfico Espanhol de Ciências da Saúde (IBECS) e 18 na Literatura Latino-Americana e do Caribe em Ciências da Saúde (LILACS); 28 estavam na língua inglesa, 24 em espanhol e 18 em português. Após a seleção das produções e sua organização, realizou-se a leitura dos títulos e resumos a fim de enqua- drá-los na temática quanto à intervenção estudada. Sendo assim, após a leitura e exclusão dos artigos que não se enquadravam na temática de pesquisa e não respondiam à pergunta norteadora, foram selecionados 24 artigos.

Após esta etapa, realizou-se nova leitura destes artigos para delimitação dos resultados encontrados, dos quais foram excluídos mais nove, que tratavam da história da enfermagem em outros focos de estudo, que não os cuidados de enfermagem. A partir destas considerações, apresenta-se a seguir uma tabela demonstrativa dos 15 artigos selecionados (Tabela 1).

\section{DISCUSSÃO}

Os dados apresentados demonstram que a temática do cuidado na história da enfermagem vem sendo trabalhada em diferentes óticas, sendo as preponderantes relacionadas a influência de Florence Nightingale às ações de enfermagem e o surgimento da enfermagem em diversas sociedades e culturas. Destaca-se um significativo número de artigos publicados no ano de 2013 e a prevalência de publicações na Revista Cultura de los cuidados, da Espanha, com seis artigos. No Brasil, a revista com maior número de publicações foi a Escola Anna Nery Revista de Enfermagem com três artigos.

Para melhor visualização dos dados optou-se por realizar uma aproximação das temáticas trabalhadas nos artigos e apresentá-los em três categorias analíticas distintas, sobre a história dos cuidados de enfermagem em uma perspectiva geral; a história na Espanha; e a história no Brasil.

\section{História dos cuidados de enfermagem: uma perspectiva geral}

Santiago (2009) apresenta em seu texto a enfermagem como um exercício de práticas de cuidado, as quais são necessárias para a conser- 
vação da vida. Trata que no começo de tudo, os cuidados eram realizados por ações intuitivas, e que, na maioria das vezes, por mulheres que não tinham preparação ou conhecimentos específicos. Das mulheres era a responsabilidade de cuidar da família, da reprodução e da gestão das condições domésticas.

Para essa mesma autora o cuidado é inato na mulher e na mãe que, amorosamente, cuida de seu filho. Na enfermagem essa ideia prevalece, uma vez que as enfermeiras inseridas em diferentes contextos atuam de acordo com as orientações religiosas, sob a organização social e os valores de cada época. Para ser enfermeira era necessário possuir motivação religiosa, com doses de sacrifício, obediência, humildade e desprendimento dos bens materiais.

Segundo Santiago (2009), os enfermeiros são imprescindíveis na estrutura social, uma vez que contribuem na proteção, prevenção e melhorias da saúde e qualidades da saúde. Para Siles (2010), a profissionalização da enfermeira como protetora e cuidadora amorosa vem das concepções sociais de que a mulher tem deveres maternos e religiosos, sendo as responsáveis pelos cuidados com a família.

Coelho e Fonseca (2005) resgatam a construção histórica do cuidado, o qual existe desde que há vida humana. No transcorrer dos tempos, o cuidado se organizou do nascimento à morte, havendo uma intrínseca relação entre mulheres e cuidado. Para estes autores as mulheres podem ter adquirido um comportamento devido à maternidade, na qual elas cuidam do recém-nascido e do seu desenvolvimento, de outras mulheres na puberdade, gestação e parto, de adultos, idosos e moribundos, estando, assim, presentes em todo o ciclo vital dos seres humanos.

Neste interim, estudo de Siles e Solano (2011) destaca que os sentimentos relaciona- dos à maternidade fundamentavam as bases dos cuidados e motivava a função dos cuidadores nesta história da criação da enfermagem profissional. Para eles o papel que a mulher desempenhava dentro da família e da sociedade conferiu grande influência na base histórica da enfermagem.

O estudo de Padilha e Mancia (2005) ao investigar os ensinamentos da enfermagem e a influência sofrida pelas irmãs de caridade destaca que esta influência ainda existe de forma direta nos ensinamentos de amor e fraternidade, nos ditos acerca da valorização do ambiente e da divisão social do trabalho. Em vista disso, eles consideram enganoso atribuir somente às ideias de Florence o movimento para criação e desenvolvimento da enfermagem, uma vez que houve a influência religiosa nesse processo.

Nesta perspectiva, o estudo de Alves, Moreira e Junior (2005) trata da solidariedade franciscana como fundamento para a Enfermagem, em que o cuidado prestado por São Francisco é alicerçado na essência do ser humano, com ideia de solidariedade. A enfermagem é uma profissão de ajuda ao ser humano em suas necessidades biológicas, psicológicas e sociais, que partilha das ideias de São Francisco, o que perdura até os dias atuais. Segundo o estudo, o legado de Francisco de Assis para a Enfermagem é um exemplo de atenção ao ser humano, que transcende a assistência ao corpo debilitado, ampliando para a tríade corpo-mente-espírito.

Concernente a esta perspectiva, quando o profissional médico percebeu que o hospital compunha um campo de saber e consequente poder, ele passou a assumir este espaço e, passivamente, as irmãs de caridade o cederam. Entretanto, Florence com seus conhecimentos e a crença de que a enfermagem poderia 
ser uma profissão reconhecida e exercida por mulheres, propõe a retomada desse espaço. Assim, esta configuração de espaços no ambiente hospitalar consolidou os fundamentos que serviram de base para a atual prática de enfermagem, ainda priorizando os ideais de fraternidade e altruísmo (Padilha, Mancia, 2005).

Os feitos e escritos de Florence influenciaram diversas áreas além da enfermagem, como a estatística, administração em saúde, saúde pública, fisioterapia e espiritualidade. Ressalta-se que seus escritos são passíveis de adaptação nos mais variados cenários de cuidado, influenciando na experiência de ser enfermeira (Frello, Carraro, 2013). Da mesma forma, estudo que discute a identidade da enfermagem destaca que Florence teve grande importância na história desta profissão, e que seus ditos e ações contribuíram para a obtenção do reconhecimento da enfermagem pela sociedade (Siles, 2005).

Porto, Neto e Magalhães (2013) discorrem sobre a vivência do cuidado através dos tempos, representada pela imagem de Pietá (obra de Michelangelo que se traduz como símbolo para a enfermagem por sua imagem de ajuda, solicitude e humanidade). Para tanto, os autores adotaram a representação de cuidado de Ricouer, que prezava o respeito, a estima, a solicitude e o reconhecimento do valor humano como condições de realização da humanidade. Os autores entendem que a escultura de Pietá, pode representar um signo do cuidado, no processo de construção da imagem da Enfermeira.

Zuñiga, Morales e Gonzáles (2013), em seu trabalho retomam a história da enfermagem através dos tempos, quando eram responsáveis pela institucionalização do cuidado, com rotinas, horários, organização do espaço e tempo.
Segundo os mesmos autores, o processo histórico do cuidado vem caracterizando a identidade da enfermagem, que tem por objetivo manter o bem estar e a sobrevivência daqueles que necessitam.

A origem do trabalho do enfermeiro provém de complexas situações individuais e inerentes a cada ser humano. Por esta razão, torna-se importante considerar e conhecer o ser humano em sua completude, uma vez que este não está mais atrelado ao biológico, permeando a necessidade de aprofundar-se na gênese do ser humano para adequar seus cuidados ao contexto histórico (Arias, Riera,2013). Corroboram Zuñiga, Morales e Gonzáles (2013) ao destacarem a importância de o enfermeiro não esquecer que existe uma relação estreita com o sujeito de seu cuidado, uma vez que é preciso ter em vista que cada um está imerso em um contexto sociocultural e possui suas próprias práticas de cuidado.

Entende-se ser preciso resgatar os sentidos do cuidar, defendendo-se um cuidar pensado, sentido e exercido de forma contextualizada, que integra o singular, o particular e o estrutural, sedimentados na valorização das condições objetivas e subjetivas de quem é cuidado e de quem cuida (Coelho, Fonseca, 2005).

\section{História dos cuidados de enfermagem: tem- pos espanhóis}

Borredá et al (2012) abordam em seu trabalho uma reflexão sobre a história da enfermagem, suas raízes e valores atuais centrando-os na enfermagem moderna espanhola. Tratam da biografia de F. Nightingale e de F. Rubio e suas ações no campo da enfermagem. Destacam que há um paralelo entre Florence e Rubio, uma vez que seus estudos são similares no que tange às medidas sanitárias. O que pode ter influenciado a enfermagem na Espa- 
nha. Segundo Mestre et al (2013) a contribuição de enfermeiras com a saúde na Espanha iniciou nos anos 20 por meio de cuidado às famílias em seus domicílios, ensinando higiene, economia doméstica e cuidados de saúde infantil.

No texto de Garcia (2013) enfocam-se os manuais da Cruz Vermelha destinados a ensinar o cuidado de enfermagem para enfrentar a gripe no ano de 1918. Segundo este autor a Cruz Vermelha inspirou-se nos ditos de Florence Nightingale e foi fundamental para a saúde pública espanhola. Assim, os manuais avaliados compõem ensinamentos sobre a clínica, as técnicas de cuidado, puericultura, saúde materno-infantil, além de introduzir a história e organização da instituição. Nestes manuais, a enfermeira era encarregada dos cuidados aos feridos da guerra, subordinada às ordens médicas, além de realizar a higiene dos pacientes, a observação do ambiente e o controle de infecção.

Cadaya e Fernandes (2012) traçam uma evolução acerca da transição ocorrida, na Espanha, de atendente sanitário para enfermeiro diplomado. Essa evolução modificou a orientação dos cuidados integrais dispensados ao indivíduo, ampliou as funções do enfermeiro no âmbito assistencial, docente, gestor e investigador, o que proporcionou ampliar os conhecimentos científicos da própria disciplina. Há destaque no texto, no que se refere a evolução ocasionada por essa mudança, a forma de pensar do enfermeiro (holística), a forma de atuar (autonomia) e a forma de comunicação (plano de cuidados).

História dos cuidados de enfermagem: tempos brasileiros

Neto e Fugencio (2010) fazem um apanhado histórico da enfermagem no Brasil, em que destacam que no período de 1500 a 1822 o Brasil foi colônia de Portugal e, por isso, a enfermagem estava subjugada aos modelos portugueses. Nesse mesmo tempo, em 1741 a enfermagem era entendida como a aplicação de medicamentos ou tratamentos sob a prescrição de médicos.

Visualiza-se que até meados do século XIX, a enfermagem brasileira e a portuguesa caminhavam juntas, uma vez que eram influenciadas pela igreja, fundamentadas na imagem de vocação e caridade. As práticas de enfermagem, no início do século XX, no Brasil, eram desenvolvidas por pessoas leigas, irmãs de caridade e pessoas com treinamento ministrado por médicos ligados a diversas instituições hospitalares (Abrão et al, 2010).

Nascimento, Lima e Tyrrell (2003) abordam o desenvolvimento da enfermagem em Salvador, dando destaque para as unidades sanitárias. Segundo os autores o exercício da enfermagem teve início com as ações ligadas à saúde pública, com atuação dirigida ao controle e prevenção de problemas de saúde. Fazem uma ressalva que o atendimento a mulheres, por meio da consulta pré-natal, foi uma das primeiras atividades a serem desenvolvidas e se mantém até a atualidade na cidade de Salvador.

Abrão et al (2010), em seu estudo, analisam a influência da cultura germânica nos primórdios da enfermagem, na cidade de Recife em 1924, onde identificaram que a atuação das enfermeiras se dava pela dedicação e abnegação aos enfermos. Segundo as autoras um dos eventos que influenciou o campo da saúde daquela época foi a criação de um Hospital Modelo e a vinda de enfermeiras alemãs para Pernambuco.

Com estes acontecimentos se iniciou a organização das atividades de Enfermagem na 
cidade do Recife, as quais possuíam conhecimento sobre tecnologia, ciência e serviços médicos. Provavelmente, as enfermeiras alemãs que exerceram a enfermagem puderam contribuir para a ciência, a partir das práticas e condutas utilizadas, deixando a área hospitalar com uma enfermagem mais bem preparada (Abrão et al, 2010).

\section{CONSIDERAÇÕES FINAIS}

Revisitar a história dos cuidados de enfermagem permitiu identificar que são muitos os olhares lançados sobre essa temática. $\mathrm{Na}$ ocasião desta revisão de literatura os achados permitem refletir acerca da evolução dos cuidados, iniciados pelas irmãs de caridade e a visão além do seu tempo de Florence Nightingale. Pode-se conceber a participação de alemães, portugueses e religiosos no traçado da história da enfermagem, com destaque especial para as sociedades espanholas e brasileiras.
Nas produções analisadas, imprime-se o entendimento de que a enfermagem está em constante evolução, permeada por uma diversidade de profissionais de variadas culturas e conhecimentos. Em vista desse aspecto, é importante considerar a historicidade de nossa profissão e buscar conhecer as fontes de inspiração para que a enfermagem continue a exercer sua arte com excelência.

Destaca-se que a enfermagem apresenta um papel fundamental no cuidado ao ser humano, uma vez que ela permeia a compreensão dos contextos sociais aos quais os indivíduos se relacionam, sendo cada um único em sua forma. Entender a singularidade do ser cuidado e trabalhar para que a arte de fazer e ser enfermeiro perdure em nossas ações é fundamental para que a enfermagem continue evoluindo e seja cada vez mais reconhecida como ciência e disciplina do saber.

Tabela 1. Identificação das publicações selecionadas

\begin{tabular}{|c|c|c|}
\hline Identificação do artigo & Objetivos & Resultados \\
\hline $\begin{array}{l}\text { Nascimento E.R., Lima L.L.G., Tyrrell } \\
\text { M.A.R. O desenvolvimento da enfer- } \\
\text { magem e a inserção social das mu- } \\
\text { lheres. Rev. baiana enferm;18(1/2): } \\
\text { 11-18, jan.-ago. } 2003 \text {. }\end{array}$ & $\begin{array}{l}\text { Abordar aspectos do desenvolvi- } \\
\text { mento da enfermagem em unidades } \\
\text { sanitárias da Rede Básica Salvador e } \\
\text { sua contribuição para a crescente in- } \\
\text { serção social das mulheres. }\end{array}$ & $\begin{array}{l}\text { O exercício da enfermagem teve } \\
\text { início com as ações ligadas à saúde } \\
\text { pública, com atuação dirigida ao } \\
\text { controle e prevenção de problemas } \\
\text { de saúde. }\end{array}$ \\
\hline $\begin{array}{l}\text { Coelho E.A.C., Fonseca, R.M.G.S. } \\
\text { Pensando o cuidado na relação } \\
\text { dialética entre sujeitos sociais. Rev } \\
\text { Bras Enferm;58(2): 214-217, mar.- } \\
\text {-abr. } 2005 \text {. }\end{array}$ & $\begin{array}{l}\text { Busca oferecer subsídios teóricos } \\
\text { para a compreensão do cuidado em } \\
\text { saúde, valorizando-se a interação } \\
\text { entre as dimensões constitutivas de } \\
\text { sujeitos coletivos. }\end{array}$ & $\begin{array}{l}\text { Faz-se o resgate da construção his- } \\
\text { tórica do cuidado. Enfatiza-se a } \\
\text { contribuição de estudos da atuali- } \\
\text { dade na redefinição do cuidar com } \\
\text { ênfase na indissociabilidade entre } \\
\text { as dimensões expressivas e instru- } \\
\text { mentais. }\end{array}$ \\
\hline $\begin{array}{l}\text { Alves A.P.C., Moreira F.A.S., Silva } \\
\text { Júnior O.C. Cuidado e solidarie- }\end{array}$ & $\begin{array}{l}\text { Identificar as concepções de soli- } \\
\text { dariedade desenvolvidas por São }\end{array}$ & $\begin{array}{l}\text { O cuidado prestado por São Fran- } \\
\text { cisco, alicerçado na essência do ser }\end{array}$ \\
\hline
\end{tabular}




\begin{tabular}{|c|c|c|}
\hline $\begin{array}{l}\text { dade: São Francisco de Assis e a } \\
\text { enfermagem. Esc. Anna Nery Rev. } \\
\text { Enferm;9(2): 176-182, ago. } 2005 \text {. }\end{array}$ & $\begin{array}{l}\text { Francisco, correlacionar essas con- } \\
\text { cepções com o cuidado e analisar } \\
\text { a dimensão de sua obra como um } \\
\text { elemento inspirador para a enfer- } \\
\text { magem. }\end{array}$ & $\begin{array}{l}\text { humano, e sedimentado em todo } \\
\text { o movimento franciscano, confir- } \\
\text { ma a ideia da solidariedade como } \\
\text { fundamento para o cuidado e para } \\
\text { a Enfermagem. As contribuições do } \\
\text { personagem ultrapassaram as fron- } \\
\text { teiras da Idade Média e perduram } \\
\text { até os dias atuais. }\end{array}$ \\
\hline $\begin{array}{l}\text { Padilha M.I.C.S., Mancia J.R. Flo- } \\
\text { rence Nightingale e as irmãs de } \\
\text { caridade: revisitando a história. Rev } \\
\text { Bras Enferm;58(6): 723-726, nov.- } \\
\text {-dez. } 2005 \text {. }\end{array}$ & $\begin{array}{l}\text { Refletir acerca dos elos entre a prá- } \\
\text { tica de enfermagem e a influência } \\
\text { recebida das associações religiosas. }\end{array}$ & $\begin{array}{l}\text { A enfermagem profissional erigida } \\
\text { por Florence Nightingale sofreu in- } \\
\text { fluência direta dos ensinamentos de } \\
\text { amor e fraternidade. }\end{array}$ \\
\hline $\begin{array}{l}\text { Santiago M.A.M.. Pasado, presente } \\
\text { y futuro de la Enfermería: una apti- } \\
\text { tud constante. Rev. adm. sanit. siglo } \\
\text { xxi; } 7(2) \text { : } 243-260 \text {, abr.-jun. } 2009\end{array}$ & $\begin{array}{l}\text { Refletir sobre a importância de co- } \\
\text { nhecer a evolução histórica dos cui- } \\
\text { dados de cada cultura. }\end{array}$ & $\begin{array}{l}\text { Destaca-se que uma atitude cons- } \\
\text { tante ao longo dos tempos tem sido } \\
\text { o encontro com o outro. O outro } \\
\text { que é sujeito dos cuidados de enfer- } \\
\text { magem e a razão de suas ações. }\end{array}$ \\
\hline $\begin{array}{l}\text { Cristo Neto D.V., Fulgêncio I. Pos- } \\
\text { tilla Religiosa e a arte de enfermei- } \\
\text { ros: a primeira obra em português } \\
\text { para o ensino de enfermagem no } \\
\text { século XVIII. REME rev. min. } \\
\text { enferm;14(1): 119-122, jan.-mar. } \\
2010 \text {. }\end{array}$ & $\begin{array}{l}\text { Resgata-se a primeira obra escrita } \\
\text { em português com ensinamentos } \\
\text { para a realização dos cuidados de } \\
\text { enfermagem - a Postilla Religiosa e } \\
\text { a Arte de Enfermeiros, escrita por } \\
\text { Padre Frei Diogo Santiago em } 1741 .\end{array}$ & $\begin{array}{l}\text { Os preceitos exibidos permanecem } \\
\text { presentes nos códigos de ética e dis- } \\
\text { ciplinas do ensino da enfermagem } \\
\text { mais moderno. Pontos estes que } \\
\text { comprovam tratar-se da enferma- } \\
\text { gem como arte do cuidado e ciência } \\
\text { mais antiga do que aparenta ser. }\end{array}$ \\
\hline $\begin{array}{l}\text { Abrão F.M.S., Oliveira R.C., Freitas } \\
\text { N.S., Costa N.F.C.G., Sales V.M.B. } \\
\text { Influência germânica nos primór- } \\
\text { dios da enfermagem profissional } \\
\text { na cidade do Recife, Pernambuco } \\
\text { (1924-1927). Esc. Anna Nery Rev. } \\
\text { Enferm;14(2): 275-283, abr.-jun. } \\
2010 \text {. }\end{array}$ & $\begin{array}{l}\text { Análise da influência germânica no } \\
\text { campo da saúde nos primórdios da } \\
\text { enfermagem profissional na cidade } \\
\text { do Recife, Pernambuco. }\end{array}$ & $\begin{array}{l}\text { A influência se dá nos primórdios } \\
\text { da enfermagem profissional pelo } \\
\text { reconhecimento da atuação das } \\
\text { enfermeiras pela dedicação e abne- } \\
\text { gação aos enfermos no trabalho que } \\
\text { desenvolviam. }\end{array}$ \\
\hline $\begin{array}{l}\text { Cadaya N.M., Fernández M.L.F. } \\
\text { El rol enfermero. Cambios más sig- } \\
\text { nificativos entre ayudante técnico }\end{array}$ & $\begin{array}{l}\text { Identificar a evolução do papel do } \\
\text { enfermeiro, na Espanha, durante a } \\
\text { transição de ajudante técnico-sani- }\end{array}$ & $\begin{array}{l}\text { Apresenta a mudança do papel do } \\
\text { enfermeiro, que modificou sua } \\
\text { orientação com relação à admi- }\end{array}$ \\
\hline
\end{tabular}




\begin{tabular}{|c|c|c|}
\hline $\begin{array}{l}\text { sanitario y diplomado universitario } \\
\text { en Enfermería. Cult. cuid;16(33): } \\
\text { 22-29, mayo-ago. } 2012 \text {. }\end{array}$ & tário a diplomado em enfermagem. & $\begin{array}{l}\text { nistração dos cuidados integrais } \\
\text { do indivíduo, expandindo as suas } \\
\text { funções. }\end{array}$ \\
\hline $\begin{array}{l}\text { Santainés B.E., Faus G.F., Camaño } \\
\text { P.R., Sarturi F. ção Florence Ni- } \\
\text { ghtingale y Federico Rubio: refor- } \\
\text { madores de la Enfermería moderna } \\
\text { española. Cult. cuid; 16(33): 43-49, } \\
\text { mayo-ago. } 2012 \text {. }\end{array}$ & $\begin{array}{l}\text { Estabelecer um paralelo entre a } \\
\text { vida de Florence Nightingale e Fre- } \\
\text { derico Rubio; e identificar a reper- } \\
\text { cussão de Florence na enfermagem } \\
\text { moderna espanhola. }\end{array}$ & $\begin{array}{l}\text { Os dados obtidos apresentam si- } \\
\text { milaridades nos planos de estudo } \\
\text { e nas medidas sanitárias relacio- } \\
\text { nadas à saúde pública, que podem } \\
\text { significar que houve influência de } \\
\text { Florence sobre Rubio e suas ações } \\
\text { na Espanha. }\end{array}$ \\
\hline $\begin{array}{l}\text { Frello A.T., Carraro T.E. Contribui- } \\
\text { ções de Florence Nightingale: uma } \\
\text { revisão integrativa da literatura. } \\
\text { Esc. Anna Nery Rev. Enferm;17(3): } \\
\text { 573-579. } 2013\end{array}$ & $\begin{array}{l}\text { Identificar a contribuição dos feitos } \\
\text { e escritos de Florence Nightinga- } \\
\text { le nos artigos publicados entre os } \\
\text { anos de } 2004 \text { e } 2011 \text {, na percepção } \\
\text { de seus autores. }\end{array}$ & $\begin{array}{l}\text { Conclui-se que seus feitos e escritos } \\
\text { influenciaram diversas áreas além } \\
\text { da enfermagem, a exemplo da es- } \\
\text { tatística, administração em saúde, } \\
\text { saúde pública, fisioterapia e espiri- } \\
\text { tualidade. }\end{array}$ \\
\hline $\begin{array}{l}\text { Porto F., Neto M., Goulart M.S. } \\
\text { Pietá: a representação imagética do } \\
\text { cuidado. Cult. cuid;17(37): 13-21, } \\
\text { sept.-dic. } 2013 \text {. }\end{array}$ & $\begin{array}{l}\text { Reflexão sobre a vivência do cuida- } \\
\text { do através do tempo pelas noções } \\
\text { de cuidado e tempo do filósofo Paul } \\
\text { Ricoeur. }\end{array}$ & $\begin{array}{l}\text { A narrativa na linguagem imagé- } \\
\text { tica da escultura Pietá é uma das } \\
\text { possibilidades da representação da } \\
\text { experiência do cuidado. Funda- } \\
\text { mentou a compreensão histórica de } \\
\text { quem encomendou e a materializou } \\
\text { a obra que ao longo do tempo vem } \\
\text { representando para a Enfermagem } \\
\text { como um signo do cuidado. }\end{array}$ \\
\hline $\begin{array}{l}\text { Zúñiga B.J., Morales A.R.H., Gon- } \\
\text { zález A.B. La historia de enferme- } \\
\text { ría: trascendencia del fenómeno } \\
\text { cuidado y su relación con el tiempo. } \\
\text { Cult. cuid;17(36): 11-18, mayo-ago. } \\
2013 \text {. }\end{array}$ & $\begin{array}{l}\text { Analisar de forma hermenêutica a } \\
\text { relação entre cuidado e tempo e sua } \\
\text { importância histórico-filosófica. }\end{array}$ & $\begin{array}{l}\text { Identifica um paradoxo no trabalho } \\
\text { da enfermagem, onde estão seguin- } \\
\text { do horários, rotinas e atividades; o } \\
\text { que torna impossível a prestação } \\
\text { de cuidados com o tempo necessá- } \\
\text { rio para realizar o atendimento de } \\
\text { forma satisfatória, com qualidade e } \\
\text { incentivar o processo de construção } \\
\text { da enfermagem. }\end{array}$ \\
\hline $\begin{array}{l}\text { Arias J.M., Riera J.R.M. } \\
\text { El ser humano y la génesis del tra- }\end{array}$ & $\begin{array}{l}\text { Descrever a origem do trabalho do } \\
\text { enfermeiro e sua relação com o ser }\end{array}$ & $\begin{array}{l}\text { Considera-se ser importante co- } \\
\text { nhecer a complexidade que abrange }\end{array}$ \\
\hline
\end{tabular}




\begin{tabular}{|c|c|c|}
\hline $\begin{array}{l}\text { bajo enfermero comunitario. Cult. } \\
\text { cuid;17(36): 59-65, may-ago. } 2013 .\end{array}$ & humano de acordo com sua cultura. & $\begin{array}{l}\text { o ser humano, que vai além do bio- } \\
\text { lógico. Destaca-se que o enfermeiro } \\
\text { necessita relacionar-se com os ou- } \\
\text { tros, a fim de gerar uma rede que } \\
\text { não habite só aspectos fisiológicos, } \\
\text { mas sim abarquem o contexto biop- } \\
\text { sicossocial. }\end{array}$ \\
\hline $\begin{array}{l}\text { Mestre J.B., García C.C., Sánchez } \\
\text { M.E.G., Paramio P.G., López E.M.T. } \\
\text { Género y profesión en la evolución } \\
\text { histórica de la Enfermería Comuni- } \\
\text { taria en España. Enferm. clín;23(6): } \\
\text { 284-289, dic. } 2013 \text {. }\end{array}$ & $\begin{array}{l}\text { Os antecedentes históricos da ques- } \\
\text { tão de gênero, na Espanha, na me- } \\
\text { dida em que se pode ajudar a enten- } \\
\text { der muitos problemas e deficiências } \\
\text { que a enfermagem comunitária se- } \\
\text { gue mostrando na atualidade. }\end{array}$ & $\begin{array}{l}\text { A contribuição de enfermeiras com } \\
\text { a saúde na Espanha iniciou nos } \\
\text { anos } 20 \text { por meio de cuidado às fa- } \\
\text { mílias em seus domicílios, ensinan- } \\
\text { do higiene, economia doméstica e } \\
\text { cuidados de saúde infantil. }\end{array}$ \\
\hline $\begin{array}{l}\text { Alberto G.G. Los manuales de for- } \\
\text { mación de la Cruz Roja durante la } \\
\text { epidemia de gripe de 1918-1919. } \\
\text { Cult. cuid;17(36): 19-28, mayo-ago. } \\
\text { 2013. }\end{array}$ & $\begin{array}{l}\text { Analisar os manuais de formação } \\
\text { da Cruz Vermelha para identificar } \\
\text { em que momento pode-se situar a } \\
\text { introdução de conteúdos relaciona- } \\
\text { dos à saúde pública. }\end{array}$ & $\begin{array}{l}\text { A Cruz Vermelha contribuiu sobre- } \\
\text { maneira para a enfermagem na saú- } \\
\text { de pública espanhola, devido a sua } \\
\text { atuação na guerra e na epidemia da } \\
\text { gripe. }\end{array}$ \\
\hline
\end{tabular}

\section{REFERÊNCIAS}

- Abrão, F.M.S. et al. (2010). Influência germânica nos primórdios da enfermagem profissional na cidade do Recife, Pernambuco (1924-1927). Escola Anna Nery Revista de Enfermagem, 2(14),275-283.

- Alberto, G.G. (2013). Los manuales de formación de la Cruz Roja durante la epidemia de gripe de 1918-1919. Cultura de los Cuidos, 17(36),19-28.

- Alves, A.P.C., Moreira, F.A.S., Silva Júnior, O.C. (2005). Cuidado e solidariedade: São Francisco de Assis e a enfermagem. Escola Anna Nery Revista Enfermagem, 9(2),176-182.

- Arias, J.M., Riera J.R.M. (2013). El ser humano y la génesis del trabajo enfermero comunitario. Cultura de los Cuidados, 17(36),59-65.

- Boff, L. (1999). Saber cuidar: ética do humano, compaixão pela terra. Brasil, Editora Vozes.

- Barros, J.A.C. (2002). Pensando o processo saúde doença: a que responde o Modelo biomédico? Revista Saúde e Sociedade, 11(1),67-84.
- Cadaya, N.M., Fernández, M.L.F. (2012). El rol enfermero. Cambios más significativos entre ayudante técnico sanitario y diplomado universitario en Enfermería. Cultura de los Cuidados, 16(33),22-29.

- Coelho, E.A.C., Fonseca, R.M.G.S. (2005). Pensando o cuidado na relação dialética entre sujeitos sociais. Revista Brasileira de Enfermagem, 58(2),214-217.

- Collière, M.F. (1989). Promover a vida: da prática da mulher de virtude aos cuidados de enfermagem. Coimbra, Editora Ledil.

- Cristo Neto, D.V., Fulgêncio, I. (2010). Postilla Religiosa e a arte de enfermeiros: a primeira obra em português para o ensino de enfermagem no século XVIII. REME Revista Mineira de Enfermagem, 14(1),119-122.

- Frello, A.T., Carraro, T.E. (2013). Contribuições de Florence Nightingale: uma revisão integrativa da literatura. Escola Anna Nery Revista de Enfermagem, 17(3),573-579.

- Mendes, K.D.S., Silveira, R.C.C.P., Galvão, C.M. (2008). Revisão integrativa: método de pesquisa para incorporação de evidências na saúde e na enfermagem. Texto 
Contexto Enfermagem, 17(4),758-764.

- Mestre, J.B. et al. (2013). Género y profesión en la evolución histórica de la Enfermería Comunitaria en España. Enfermagem Clínica, 23(6),284-289.

- Nascimento, E.R., Lima, L.L.G., Tyrrell, M.A.R. (2003). O desenvolvimento da enfermagem e a inserção social das mulheres. Revista Baiana de Enfermagem, 18(1/2),11-18.

- Padilha, M.I.C.S., Mancia, J.R. (2005). Florence Nightingale e as irmãs de caridade: revisitando a história. Revista Brasileira de Enfermagem, 58(6),723-726.

- Porto, F., Neto, M., Goulart, M.S. (2013). Pietá: a representação imagética do cuidado. Cultura de los Cuidados, 17(37),13-21.

- Santainés, B.E. et al. (2012). Florence Nightingale y Federico Rubio: reformadores de la Enfermería moderna española. Cultura de los Cuidados, 16(33),43-49.

- Santiago, M.A.M. (2009). Pasado, presente y futuro de la Enfermería: una aptitud constante. Revista de Administración Sanitária Siglo XXI, 7(2),243-260.

- Stamm, M. (2002). Evolução do cuidado na enfermagem até o cuidado transdimensional: uma revisão de literatura. Ciência Cuidado e Saúde, 2(1),293-298.

Siles, J. G. (2005). La eterna guerra de la identidad enfermera: un enfoque dialéctico y deconstruccionista. Index de Enfermería, 50. Recuperado de http://www.index-f.com/indexenfermeria/50revista/5196.php

- Siles, J. G. (2010). Los cuidados de enfermería en el marco de la historia social y la historia cultural. Em C. González y F. Martínez (Eds.) La transformación de la enfermería. Nuevas miradas para la historia (pp.219250). Granada: Comares.

- Siles, J. y Solano M.C.. (2011). A história cultural e a estética dos cuidados de enfermagem. Rev. Latino-Am. Enfermagem. 19(5),1-10.

- Ursi E.S., Galvão C.M. (2008). Prevenção de pele no perioperatório: revisão integrativa da literatura. Revista Latino Americana de Enfermagem, 14(1),124-131.

- Ursi E.S. (2005). Prevenção de pele no perioperatório: revisão integrativa da literatura. (Dissertação). Universidade de São Paulo, São Paulo.

- Vale, E.V., Pagliuca, L.M. (2011). Construção de um con- ceito de cuidado de enfermagem: contribuição para o ensino de graduação. Revista Brasileira de Enfermagem, 64(1),106-113.

- Waldow, V.R. (2004). Os fundamentos filosóficos do cuidar. In V.R. Waldow (Ed.) O cuidado na saúde. Brasil: Editora Vozes.

- Zúñiga, B.J., Morales, A.R.H. y González, A.B. (2013). La historia de enfermería: trascendencia del fenómeno cuidado y su relación con el tiempo. Cultura de los Cuidados, 17(36),11-18. 


\section{Cultura de los cuidados: el debate entre historia y enfermería pre-profesional en las acuarelas de Jean-Baptiste Debret (1816-1831)}

Culture of care: the debate between history and pre-profissional nursing in watercolors of Jean-Baptiste Debret (1816-1831)

Cultura dos cuidados: o debate entre história e enfermagem pré-profissinal nas aquarelas de Jean-Baptiste Debret (1816-1831)

Paulo Fernando de Souza Campos

Doutor em História com Pesquisa de Pós-Doutorado em História da Enfermagem pela Escola de Enfermagem da Universidade de São Paulo - EE/USP/FAPESP. Professor do Programa de Pós-Graduação Interdisciplinar em Ciências Humanas da Universidade de Santo Amaro - UNISA.

Cómo citar este artículo en edición digital: Campos, P. F. S. (2015). Cultura dos cuidados: o debate entre história e enfermagem pré-profissinal nas aquarelas de Jean-Baptiste Debret (1816-1831)

Cultura de los Cuidados (Edición digital), 19(43). Disponible en: $<$ http://dx.doi.org/10.14198/cuid.2015.43.10>

Correspondencia: Rua Isabel Schmidt, 349, Santo Amaro, São Paulo, Brasil. CEP 04743-030.

Correo electrónico: pfcampos@unisa.br

Recibido: 07/07/2015; Aceptado: 5/11/2015

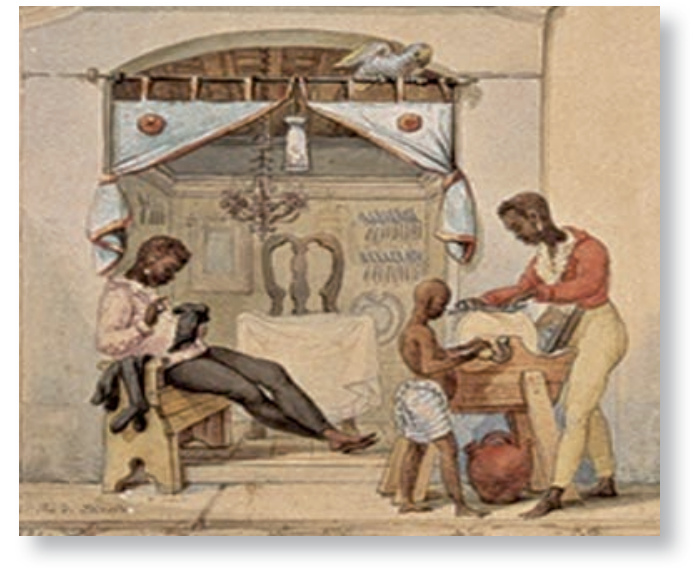

ABSTRACT

To identify practices to care for and cure performed by black men and women, the study evokes the historical context marked by the transfer of the Portuguese Crown (1808-1820) to Brazil, social space meant as conducive to the development of diseases. Legacy pictorial records of the work of Jean-Baptiste Debret, preserved in the Museum Castro Maya, Rio de Janeiro, were used as the source and the results are social places of care and its performers as well as the links between History and History of Pre-Professional Brazilian Nursing in their oblique relations with the culture of care.

Keywords: Culture Care; Cultural History; Pre-Professional Nursing; Negros

\section{RESUMEN}

La identificación de las prácticas de cuidar y curar realizadas por hombres y mujeres negros, permitio el estudio del contexto histórico marcado por la transferencia de la Corona Portuguesa (1808-1820) para Brasil, espacio social significado como propicio para el desarrollo de enfermedades. El registros pictóricos legados de la obra de Jean-Baptiste Debret, conservados en el Museo Castro Maya, Rio de Janeiro, fueron utilizados como fuentes de la investigación y los resultados apresentan lugares sociales de atención a la salud y sus executores, así como los vínculos entre Historia e Historia de la Enfermería Pre-Profesional brasileña en sus relaciones oblicuas con la cultura del cuidados. 
Palavras-Clave: Cultura de los Cuidados; Historia Cultural; Enfermería Pré-Profesional; Negros.

\section{RESUMO}

Ao identificar práticas de cuidar e curar realizadas por homens e mulheres negros, o estudo evoca o contexto histórico marcado pela transferência da Coroa Portuguesa (18081820) para o Brasil, espaço social significado como propício para o desenvolvimento de doenças. Os registros pictóricos legados da obra de Jean-Baptiste Debret, preservados nos Museus Castro Maya, Rio de Janeiro, foram usados como fonte e os resultados apresentam lugares sociais do cuidado e seus executores, bem como os nexos entre História e História da Enfermagem Pré-profissional brasileira em suas relações oblíquas com a cultura dos cuidados.

Palavras-Chave: Cultura dos Cuidados; História Cultural; Enfermagem Pré-Profissional; Negros.

\section{INTRODUÇÃO}

No início do século XIX, com a instalação da família real portuguesa na Colônia brasileira, escolas de medicina são fundadas no Brasil. $\mathrm{O}$ fato se mostra decisivo para a adoção de uma nova representação de saúde em um ambiente físico e social cujo clima, alimentação, costumes e paisagens, além de diametralmente opostos aos do mundo europeu, caracterizavam o local como propício para o desenvolvimento de doenças. Assim, os cuidados com a saúde deveriam atingir a camada melhor posicionada economicamente da população, que valorizava a prática da medicina acadêmica, de origem predominantemente portuguesa e claramente influenciada por valores positivis- tas. Entretanto, práticas populares executadas por homens e mulheres negros constituíam a possiblidade de cuidado e cura mais acessível e que surtia melhores resultados (Malerba, 2000; Abreu, 2007).

Mesmo com a progressiva afirmação da Medicina, práticas culturais e antropológicas de cuidado e cura não deixaram de ter importância social uma vez que continuavam a serem utilizadas não somente por quem não dispunha de condições financeiras para pagar consultas médicas, mas pela desconfiança da competência de médicos portugueses na manutenção da vida e diminuição de sofrimentos (Ribeiro, 1997). A existência simultânea das duas possibilidades de saberes sobre os corpos doentes proporcionou uma realidade diversa de práticas de cuidado e cura, cujo alcance se constata nos dias atuais, em vivências que se interpõem à perspectiva dominante, bem como na constante busca pela compreensão de sua historicidade (Figueiredo, 2002).

Nesse sentido, a História, compreendida não mais como narrativa linear e evolutiva dos acontecimentos, redimensionou fatos considerados incontestes ao desdobrar o passado conhecido e seus impactos na vida das pessoas. As novas perspectivas recuperaram autores relegados pela historiografia dominante e multiplicaram estudos históricos fundados na interdisciplinaridade, cujas abordagens provocaram o encontro de saberes distintos, correlatos ou não, mas com interesses convergentes. Os resultados permitiram reconhecer novos objetos, problemas e novas abordagens na interpretação do tempo histórico, assumido não mais como pronto e acabado, mas como processo, assim, em constante transformação e movimento (Le Goff, 1990).

Temas considerados menores, marginais ou evocados da vida cotidiana, a partir de fon- 
tes não oficiais, mas provenientes de acervos desprestigiados ofereciam aos 'novos' historiadores a possibilidade de uma escrita diametralmente oposta ao que vigorava no século XIX como legitima e científica. Interessados nas práticas cotidianas e experiências de homens e mulheres comuns, estudos históricos ampliaram o diálogo interdisciplinar e avançaram nos domínios da História como, neste caso, as abordagens propostas pela antropologia médica, cultura dos cuidados e história da enfermagem pré-profissional, as quais se associam ao debate da história cultural, praticada de acordo com Peter Burke (1992) há mais de duzentos anos na Alemanha (Kulturgeschichte). Portanto, não se trata de algo novo.

A associação entre campos disciplinares como avaliou Clifford Geertz, antropólogo norte-americano que inspirou historiadores culturais, implica pensar o “[...] padrão historicamente transmitido, de significados incorporados em símbolos, um sistema de concepções herdadas, expressas em formas simbólicas, por meio das quais os homens se comunicam, perpetuam e desenvolvem seu conhecimento e suas atitudes acerca da vida" (Geertz, 1989, p.89). O intuito dos estudos que emergem dessa matriz teórico-metodológica é reiterar a presença de redes de valores que se internalizam e são reproduzidos por indivíduos e coletividades como naturais ou correlatos de verdade, quando invariavelmente é produzida para a manutenção de ideologias e mentalidades dominantes.

A perspectiva permite considerar que concepções de saúde e doença como de cura e cuidado são construções sociais, logo, permeadas por intencionalidades datadas e caracterizadas por contextos históricos específicos, dos quais emergem interesses políticos, institucionais, econômicos, sociais e de gênero. Suas repre- sentações se alteram no tempo e explicam a existência da realidade humana, porém, assumidas na forma de conceitos universais, ditos positivos ou estabelecidos por critérios rigidamente propostos, minimizam a contribuição das ciências humanas como balizadora dos processos, mesmo os técnicos.

Ocorre que na História o estabelecimento de conceitos não se dá como definição imutável ou sem interesses de grupos que se interpõem e atribuem significados às práticas sociais (Chartier, 1991). O diálogo necessário, mas pouco estabelecido, impede o reconhecimento de mudanças, reconfigurações, impactos e permanências nas esferas de atuação historicamente constituídas - no caso, dos enfermeiros - por desprestigio ou desconsideração de campos disciplinares compreendidos em oposição ou menores na escala utilizada como referência. Ainda que estudiosos da história da enfermagem pré-profissional, norte-americanos e europeus, reconheçam relações de interdependências entre os campos disciplinares, no Brasil, interdisciplinaridade e uso de corpus teórico-metodológico diverso do oficial constituem-se enquanto espaços em aberto para a produção de um conhecimento ainda a ser explorado (Donahue, 1996; Soares, 1997; Siles-Gonzales, 1999; Viterbo, 2012).

A reconfiguração da escrita da História possibilitou o desprendimento de determinismos impostos por datações rígidas, oficializadas por modelos demarcadores de uma história linear e progressiva, vale dizer, os estudos históricos avançaram nas diferentes temporalidades. No caso específico, tal procedimento permite reconhecer nas práticas de cuidar e curar exercidas no Brasil Colônia a identificação de permanências, transformações e rupturas de interesses comuns, isto é, tanto para historiadores, quanto para enfermeiros. Neste 
sentido, o presente artigo investiga práticas de cuidar e curar anteriores a profissionalização do cuidado, considerando-as nos domínios das ações executadas por agentes não profissionais, portanto, analisando-as como parte do processo histórico, cultural e antropológico do cuidar e curar no Brasil.

Partindo desses pressupostos, a pesquisa ora apresentada utilizou como corpus as aquarelas de Jean-Baptiste Debret pintadas durante sua permanência no Brasil (1816-1831). Cabe destacar que o uso da fonte imagética, por se inscrever no campo do imaginário, encontrou resistência entre historiadores, pois parecia não informar o real, mas "[...] uma fissura entre real e imaginário (ilusório, quimera, sonho), colocando dessa maneira obstáculos ao uso dessa fonte pelo historiador uma vez que o seu ofício definia-se em torno do acontecido e não de elaborações que se inscreviam no campo das representações" (Silva, 1996, p.43).

Ressalta-se, entretanto, que não se trata de uma reflexão sobre a arte, dos elementos artísticos e das técnicas de pintura, tampouco, das problemáticas que envolvem a história dos viajantes, mas da identificação de práticas de cuidar e curar exercidas no Brasil Colônia, seus executores e locais nos quais foram retratados. Do mesmo modo, o tratamento ao tema possibilita criticar o uso da História como metodologia, o que invariavelmente desqualifica ou ignora diferentes dimensões históricas, no caso, a dimensão pré-profissional da arte e ciência do cuidado, modernamente identificada como Enfermagem.

As aquarelas utilizadas foram intituladas por Jean-Baptiste Debret como Boutique de Barbier, Les Barbiers Ambulants e Laguna vue de L'Hôpital, pintadas entre 1821 e 1828, cujos originais encontram-se preservados nos Museus Raymundo Ottoni de Castro Maya/
IBRAM/MinC, Rio de Janeiro, que mantém a Coleção Brasiliana. As análises foram empreendidas a partir de pressupostos da História Cultural como os que contemplam a complexidade do tempo histórico, a diversidade das práticas e representações inscritas no cotidiano e as pessoas comuns como fundamento teórico-metodológico para a construção da narrativa histórica.

\section{Negros como cuidadores: as raízes do cuidado no Brasil}

Base da sociedade colonial brasileira, a escravidão de africanos serviu como modelo para o constructo de sociabilidades ascendentes em um sistema social forjado na violência, característica do longo período Colonial que recobre a politica escravocrata no Brasil. Durante quatro séculos de história oficial as mentalidades existentes significavam os negros a partir da escravidão. Ser negro no Brasil implicava naturalmente ser escravo, constituindo-se como condição inexorável, pois ainda que libertos ou alforriados eram desclassificados moral, social e fisicamente (Schwarcz, 1993).

Mesmo considerando a existência de enriquecimento, a maioria negra foi discriminada, posta à margem da sociedade colonial. Suas experiências - explícitas ou subterrâneas - foram desconsideradas pela historiografia. A dupla exclusão, entretanto, não impedia resistências e participações cotidianas na vida colonial, mas ao contrário, como revelou a história social produzida no Brasil na década de 1980. Os estudos históricos derivados reconfiguraram o cotidiano das populações negras e destituíram a hegemonia de modelos teórico-metodológicos que os representavam como escravo-coisa ou mercadoria, significando-os como ignorantes, desajustados e doentes. A historiografia brasileira (Chalhoub, 1996; Or- 
tiz, 1994) desmontou representações anteriores ao desvelar os negros em experiências, não raro, que os anunciavam em condições de luta e sobrevivência criativas. A historiografia rompia com as análises esquemáticas fundadas em lógicas dissonantes.

O movimento transatlântico da Cora Portuguesa para o Brasil (1808-1820), promovido pela fuga da Família Real das tropas de Napoleão Bonaparte (1769-1821), implicou a interferência significativa de regras de comportamento e valores novos trazidos pela Cora, entre os quais, os que atingiam práticas cotidianas de cuidado, tratamento, cura de doenças e moléstias físicas e mentais. Raramente mencionados, personagens anônimos, os cuidadores pré-profissionais do Brasil colonial foram sufocados por uma escrita estanque sobre a história da enfermagem brasileira. Negros eram cuidadores em potencial no longo período que recobre a sociedade colonial brasileira.

A transferência da Metrópole para a Colônia acarretou profunda alteração na rotina dos diversos grupos sociais da cidade do Rio de Janeiro. Aproximadamente 15 mil pessoas desembarcaram em seus portos e, nesse processo, não somente mudanças políticas e econômicas resultaram de tal empreendimento, mas alterações culturais, que impactaram nas formas de sobrevivência dos homens e mulheres reinóis, brancos e negros. Três classes sociais foram formadas na Corte com pouca possibilidade de mudança. Em primeiro plano os membros da Corte, seguidos da elite fluminense formada por comerciantes abastados, na base da sociedade colonial a população predominante negra e escravizada. Desse processo emerge uma complexa rede de interdependências, que permeia o novo arranjo social e no qual se constatava a necessidade de estabelecimentos de laços sociais para o alcance de variados in- teresses como afirma Jurandir Malerba (2002), entre os quais o cuidado, a cura.

$\mathrm{Na}$ esteira das mudanças, práticas dedicadas ao cuidado do corpo enfermo realizadas secularmente permaneceram efetivas na sociedade brasileira. Entre as mulheres negras existiam as que se tornavam reconhecidas e requisitadas por suas habilidades como parteiras, amas-de-leite, benzedeiras, mães pretas (Souza Campos, 2008). Inseridas em uma sociedade patriarcal e escravocrata, a eventual capacidade de intervir positivamente ante um sofrimento físico - ou espiritual - conferia aos que detinham tal conhecimento posição de destaque social, de considerável vantagem em um mundo fundado na submissão, mas também na resistência. Ainda assim, conflitos gerados pelo medo de contágio de moléstias, que supostamente albergavam corpos negros, ampliavam os rigores. As recusas atingiam principalmente mulheres que atuavam da porta para dentro, no interior das casas coloniais, constantemente vigiadas (Mott, 1991; Graham, 1992).

O debate torna-se procedente se avaliado em relação à formação de uma nova história da enfermagem. A presença negra no cuidado desvela um dos traços marcantes da sociedade colonial brasileira, qual seja, “[...] a lenta mas constante proximidade com as famílias dos senhores [...] Coube às babás e mas de leite, cuidadosamente escolhidas entre as famílias negras, promover essa proximidade, ao serem encarregadas de cuidar dos filhos de seus senhores" (Ermakoff, 2004, p.98). O não reconhecimento da participação afrodescendente no processo histórico do cuidado no Brasil contribui para reafirmar imagens sociais perpetuadas, que os desqualificam.

As prerrogativas permitem considerar que sociabilidades fundadas na dualidade 
superior/inferior atingiram a orientação e o exercício profissional dos enfermeiros, cujos impactos reverberam educação, trabalho $e$ orientação profissional na medida em que atravessa o saber-fazer, pois interferi na assistência prestada e prejudica competências e habilidades inerentes ao exercício profissional como comunicação, relacionamento interpessoal, equidade, empatia, tolerância, poder de decisão, reflexão, problematização e transversalidade, temas pontuados nas diretrizes para formação superior em Enfermagem no Brasil (Brasil, 2001).

Um dos sentimentos gerados pode ser reconhecido como racismo, que sustenta a discriminação em relação a indivíduos considerados de outra raça/etnia. Não somente no Brasil, como em outros países, o racismo age como mecanismo utilizado por grupos considerados superiores, para justificar a dominação de uns sob outros com a finalidade de satisfazer interesses, hierarquizar relações e excluir o diferente/divergente (González, 1990). No caso brasileiro, as vicissitudes da escravidão são exemplares do processo danoso provocado pelo racismo.

A conduta, fortalecida pela noção de hereditariedade, inferioridade em relação ao branco, impunha uma representação desqualificadora aos afrodescendentes. Todavia, nas aquarelas de Jean-Baptiste Debret os negros são identificados em suas atuações no âmbito das práticas de cuidar, cuidado e cura. Como destacado, mulheres negras no Brasil Colônia agregavam em suas práticas cotidianas o trabalho de parteira, cuidadoras de idosos e crianças, sãos ou doentes, nutrindo-os não apenas no peito, mas produzindo seu alimento, cuidando de sua dieta e saúde (Souza Campos, 2008). Vale dizer, os negros aturam como precursores pré-profissionais da arte e ciência do cuidado no Brasil e a primazia da mulher negra não era diferente nas Américas como permite considerar a trajetória de Mary Seacole, reconhecida e condecorada na Inglaterra Vitoriana como Florence Negra por sua atuação na Batalha de Sebastopol durante a Guerra da Criméia (1856-1865). No caso brasileiro, antes da profissionalização, homens e mulheres negros assumiam as funções sociais que hoje são realizadas sistematicamente por enfermeiros.

\section{Cuidadores Negros nas Aquarelas de Jean- -Baptiste Debret}

As práticas de cuidar e curar expressas nas obras do pintor francês considerado um dos principais narradores da vida cotidiana colonial brasileira destacam seus executores. A produção legada da permanência do pintor no Brasil é avaliada um dos mais importantes registros da experiência dos negros durante a permanência da Corte nos trópicos. Estudiosos da técnica de pintura identificada como aquarela indicam que Debret antes de pintar desenhava esboços de aspectos específicos do que via nas cenas e personagens do cotidiano, isto é, de forma esparsa e isolada, cuja posterior justaposição resultava no quadro final. Seu método era a construção do todo pelo detalhe.

Jean-Baptiste Debret chegou ao Brasil em 26 de março de 1816 integrando a Missão Artística Francesa que fundou no Rio de Janeiro a Academia de Artes e Ofícios, definida por Júlio Bandeira (2006) como uma colônia de artistas bonapartistas no ostracismo. Na ocasião, o então professor de desenho e futuro diretor da Academia encontrava-se amargurado, solitário e exilado, sem expectativas e com problemas pessoais. A familiaridade com a pintura de cunho histórico e a pers- 
pectiva da mudança radical de sua condição motivou-lhe a ingressar na longa travessia do Atlântico e após dois meses de viagem chegou a Baía de Guanabara, na cidade do Rio de Janeiro, imagem que descreveu como uma das maravilhas do mundo. Ao se encantar pela profusão da paisagem: “[...] o aspecto de abundancia universal, a vegetação desconhecida, o colorido absolutamente novo para os olhos europeus o fizeram a desenhar quase que imediatamente [...]" afirma Ana Paola Baptista (2011, p. 10).

Jean-Baptiste Debret era membro de uma família de pintores e sua vida é marcada por sucessos nos salões europeus com pinturas históricas de cunho neoclássico, produtos de encomendas que recebia do governo napoleônico para obras celebratórias (Baptista, 2011). No Brasil, além da pintura histórica, Debret retratou a vida cotidiana na cidade do Rio de Janeiro e fora dela. Por esse motivo, sua obra é considerada um inventário enciclopédico da realidade brasileira à época.

Sintomaticamente, Jean-Baptiste Debret em sua obra apresenta homens negros identificados como barbeiros, sangradores, dentistas e outros cuidadores. De acordo com a historiografia consultada, não raro o trabalho dos cirurgiões - não havia mulheres no ofício - era compartilhado e indicado por médicos portugueses, que receitavam tratamentos dispensados por desconhecimento de determinados procedimentos ou pela eficácia dos mesmos. Conforme aponta Betânia Gonçalves Figueiredo (2002) os homens negros detinham o conhecimento de intervir no corpo ulcerado, nas pústulas, nas doenças da pele, no trato de membros quebrados como pernas e braços, na diminuição de dores, além de se ocuparem da higiene bucal, do cuidado dos dentes e das extrações, no trato dos cabelos e das unhas, além das rezas que aliviavam as dores da alma. Para tanto utilizavam ervas, sangrias, fumos, banhos e manipulavam instrumentos construídos para as finalidades propostas: cuidar e curar (Ribeiro, 1997; Betânia, 1999).

Dentre as aquarelas pintadas por Debret, expostas e publicadas no livro Viagens ao Sul do Brasil, três registros permitem considerar as práticas de cuidar e curar como ações exercidas por negros. A consideração reitera aspectos de interesse para a cultura dos cuidados e antropologia médica no Brasil, pois desvelam práticas e agentes do cuidado anteriores aos padrões estabelecidos como demarcadores para os processos históricos no campo da Enfermagem. O interesse se amplia com a constatação política de que na sociedade escravocrata o trabalho dedicado ao cuidado era executado por homens e mulheres negros, pois redimensiona a historicidade brasileira do saber considerado como o mais elegante das ciências modernas.

A profundidade das marcas deixadas pela escravidão no Brasil significava a população negra como destituída de organização ou conhecimento próprio e a historiografia os narrava a partir da inferioridade e depreciação de suas ações, mesmo após a abolição em 1888 . Deste modo, o estudo das aquarelas de Jean-Baptiste Debret é uma possibilidade de evidenciar práticas executadas por negros no âmbito do cuidado no século XIX, bem como a importância dessas ações para o desenvolvimento da sociedade brasileira e dos estudos históricos da enfermagem pré-profissional. A primazia de suas práticas, cujas ações incluíam a manutenção da higiene pessoal, alimentação, repouso, tratamento de doenças graves ou não, prevenção, acompanhamento e auxílio de pessoas enfermas como realização de pequenas cirurgias, partos e amputações de membros le- 
sionados, foram primordiais para a manutenção da saúde no Brasil. Ainda que o material documental utilizado apresente aspectos sutis, tais vestígios não são menos reveladores da memória histórica e antropológica do cuidado como permite considerar o paradigma indiciário fundado na investigação de pequenas pistas e sinais (Guinzburg, 1989).

Importantes para a vida em comum, a existência de cuidadores negros em uma sociedade escravocrata reverbera a proverbial desqualificação e ineficácia dos tratamentos executados por médicos portugueses (Ribeiro, 1997). A aquarela 1, identificada como Barbeiros ambulantes, remonta uma cena urbana, que mescla o encontro de pessoas, o comércio de rua e a chegada de navios no porto do Rio de Janeiro, assim, representa a Corte como um local de negociações constantes com o velho mundo e de fluxo interrupto de valores e pessoas.

A aquarela evidencia negros barbeiros pobres cuidando de outros negros também pobres. Nessa aquarela o autor retrata o cuidado como atividade aplicada a todos os residentes, permitindo supor a importância dos serviços prestados e a necessidade social de seus executores. Desse modo, desvela a complexidade da existência negra no Brasil, assim como suas resistências aos imperativos que os desqualificavam.

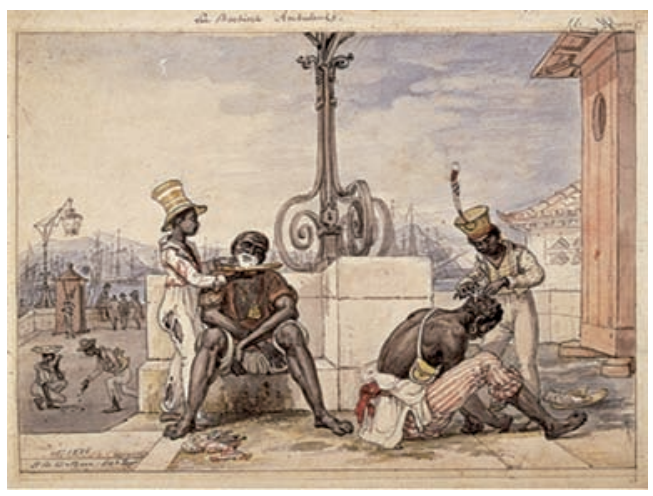

AQUERELA 1 - BARBEIROS AMBULANTES
Nessa aquarela, pintada em 1826, a condição social dos barbeiros é revelada nas vestimentas rotas, velhas e rasgadas. Ainda assim, o artista pontua a circularidade cultural vivida na Corte ao retratá-los com chapéus e outros adornos em bom estado de conservação, porém, de segunda mão, originalmente fabricados para outros fins e usos. Em contraste com as demais peças da indumentária, as quais se assemelham às roupas dos usuários, os chapéus são indicativos de uma rede social complexa, pois permitem considerar as sociabilidades entre os diferentes personagens que viveram a estadia da Corte no Brasil.

Os adornos sugerem trocas simbólicas alcançadas por esses cuidadores, ao mesmo tempo em que o oficio praticado em via pública e a céu aberto permite considerar a utilidade, importância e mobilidade desses homens na vida das pessoas ricas ou pobres. A aquarela indica ainda que a população pobre e trabalhadora necessitava e mantinha a higiene pessoal e o asseio, práticas reveladoras da cultura dos cuidados entre os negros e por eles preservadas, o que contribui para redimensionar interpretações unilaterais que os identificavam como sujos e disseminadores de doenças.

A aquarela 2, identificada como Loja de barbeiros, supostamente pintada anos antes, em 1821, retrata cuidadores na cidade do Rio de Janeiro em situações diametralmente opostas. Nessa aquarela o pintor amplia as considerações sobre a organização e divisão dos serviços de saúde para pobres e ricos, pois apresenta um estabelecimento público, comercial, destinado à cura e ao cuidado de pessoas enfermas. O estabelecimento retratado na aquarela desvela um local limpo, organizado, provido de instrumentos de corte e utensílios usados na preparação de remédios e intervenção do corpo doente. 


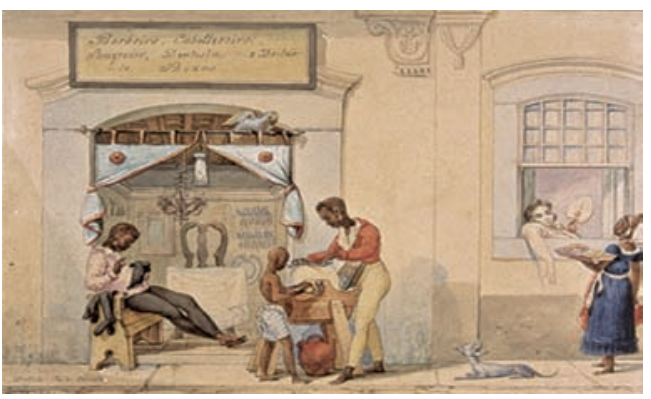

AQUERELA 2 - LOJA DE BARBEIROS

Nos dois casos, os negros figuram como cuidadores. Contudo, na aquarela 2, ao representar três homens negros em atividade de manutenção dos equipamentos - além de uma escrava de ganho e uma senhora branca - o pintor revela a existência de uma organização do trabalho, sugerindo a existência de equipe e hierarquia entre seus executores, além da existência de um espaço físico: a loja. A comparação entre a Loja de Barbeiros e Barbeiros Ambulantes evidencia tanto a distinção dos serviços prestados, quanto a participação efetiva de negros nas práticas de cuidado e cura no Brasil do século XIX, em diferentes condições de trabalho e identidades. A aproximação entre a loja de barbeiros e a casa de uma mulher branca, em cuja cena é retratada comprando produtos vendidos por uma escrava de ganho, permite supor que se tratava de um local da cidade habitado por pessoas abastadas, logo, que os negros não estavam alheios as diferenciações de classe, hierarquia social e outros distintivos, inclusive, internamente.

A obra de Debret desvela uma complexa participação de negros na vida social durante a permanência da Corte do Brasil. A aquarela 3, pintada em 1828 e intitulada Vista do hospital, Florianópolis, se destaca das demais por retratar a vida fora da cidade do Rio de Janeiro, mas a cidade de Desterro, então capital do Estado de Santa Catarina, região sul do Brasil. Nessa aquarela, Debret permite verificar o exercício do cuidado realizado por negros em um espaço hospitalar como confirmam alguns detalhes miniaturizados presentes na pintura, os quais revelam um doente sendo carregado em uma rede por dois negros e o que parece ser uma criança, que ampara um homem branco com uma das pernas enfaixada e usando muletas, elementos que permitem as considerações em pauta.

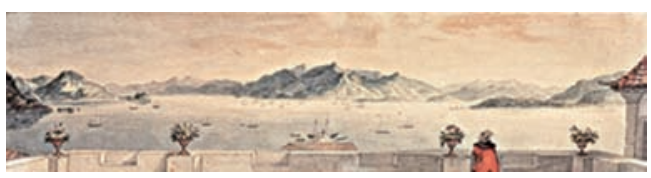

AQUERELA 3 - VISTA DO HOSPITAL, FLORIANÓPOLIS

Não obstante, as evidencias do cuidado nas obras de Debret revelam a existência de um legado cultural afrodescendente no âmbito da enfermagem pré-profissional brasileira. As aquarelas não somente destacam os negros em práticas de cuidar e curar, mas apontam para a fabricação de redes de sociabilidades complexas e diferenciadas, traduzidas pela antropologia médica e cultura dos cuidados como formas de cuidar e curar anteriores ao surgimento de escolas e da profissionalização ou do modelo vitoriano de formação. As aquarelas pintadas por Jean-Baptiste Debret comprovam a primazia das ações realizadas por homens e mulheres negros, cujas origens culturais remontam práticas ancestrais. Sua obra desvela a importância dos negros na vida social brasileira, sobretudo, redimensiona suas existências e representações na formação dessa mesma sociedade, sintomaticamente, como agentes na constituição da longa história da enfermagem pré-profissional no Brasil.

A forma de análise das práticas de cuidar e curar executadas por negros no contexto, por 
suas características próprias, implica considerar o debate em torno da formação histórico-cultural do cuidado no Brasil, vale dizer, em suas diferentes temporalidades e perspectivas históricas. O cotejamento das fontes com as referências possibilitou evidenciar a participação dos negros nesse processo, destacar as experiências do cuidado em sua dimensão pré-profissional, ou seja, consideradas não como produto da institucionalização de espaços de formação, mas como experiência exercida no processo histórico.

Os usos da História pela Enfermagem invariavelmente desconsideram ações anteriores aos marcos simbólicos instituídos por uma escrita linear que impõe uma historicidade única, unilateral. No caso específico, o surgimento de modelos profissionalizantes é considerado como marco para a historicidade, no caso brasileiro, construído no padrão dominante de ensino e formação profissional. Destarte, o estudo reitera que a História não é um método ou uma ferramenta de pesquisa e que se utilizada como metodologia, deixa de reconhecer no tempo contextos, agentes e práticas.

Ao partir de uma delimitação incompatível com a densidade da História e por destituí-la do debate teórico, estudos históricos oriundos da Enfermagem interpretam o tempo de suas ações a partir de maniqueísmos que fabricam histórias ilustres, sempre vencedoras. Ainda que destaquem as mulheres, estas são representadas no exercício do poder e pela via do discurso dominante, vinculadas às instituições de ensino, militares ou evocadas em postos de comando, cujas trajetórias são analisadas progressivamente, em oposição ao masculino, cujo gênero é avaliado subalternamente em relação a sua principal personagem: a enfermeira. $\mathrm{O}$ não reconhecimento da densidade histórica impede o desenvolvimento de po- tencialidades investigativas na medida em que restringe a historicidade das práticas de cuidar e curar a um recorte unidirecional e hermeticamente fechado.

\section{BIBLIOGRAFIA}

- Abreu, J. L. N. (2007). A Colônia enferma e a saúde dos povos: a medicina das 'luzes' e as informações sobre as enfermidades da América portuguesa. Hist. cienc. saudeManguinhos, 14(3), 761-778.

- Bandeira, J. (2006). Jean-Baptiste Debret: Caderno de viagem. Rio de Janeiro: Sextante Artes.

- Batista, A. P. (2011). Debret: Viagem ao Sul do Brasil. Rio de Janeiro: Memória Visual.

- Brasil. Resolução CNE/CES no 3, de 7 de novembro de 2001. Institui Diretrizes Curriculares Nacionais do Curso de Graduação em Enfermagem. Recuperado de: $<$ http://portal.mec.gov.br/cne/arquivos/pdf/CES03. pdf $>$.

- Bordieu, P. (1983). Sociologia. São Paulo: Ática.

- Burke, P. (1992). A Escrita da História. Novas perspectivas. São Paulo: Edunesp.

- Chalhoub, S. (1996). Cidade Febril. Cortiços e epidemias na corte imperial. São Paulo: Companhia das Letras.

- Chartier, R. (1991). O Mundo como Representação. Estudos Avançados, 5(11), 173-191.

- Debret, J-B. (2010). Viagem pitoresca e histórica ao Brasil. Belo Horizonte: Itatiaia.

- Donahue, P. (1996). Nursing, The Finest Art. An Illustrated History. St. Louis: Mosby.

- Ermakoff, G. (2204). O Negro na fotografia brasileira do século XIX. Rio de Janeiro: G. Ermajoff Casa Editorial.

- Freitas, M. V. de. (2012) Comadres e Matronas. Contributo para a História das Parteiras em Portugal (séculos XIII-XIX). Lisboa: Lusodidacta.

- Geertz, C. (1989). A Interpretação das Culturas. Rio de Janeiro: LTC.

- Ginzburg, C. (1989). Sinais. Raízes de um paradigma indiciário. En: Mitos, Emblemas e Sinais (pp. 143-180). São Paulo: Companhia das Letras.

- González, A. M. R. (1990). Estudios Médico-Sociales so- 
bre Marginalizados em la España del siglo XIX. Madrid: Ministerio de Sanidad y Consumo.

- Graham, S. (1992). Proteção e Obediência: Criadas e seus patrões no Rio de Janeiro (1860-1910). São Paulo: Companhia das Letras.

- Le goff, J. (1990). História Nova. São Paulo: Martins Fontes.

- Malerba, J. (2000). A corte no exílio: civilização e poder no Brasil às vésperas da independência (1808-1821). São Paulo: Companhia das Letras.

- Mott, M. L. de B. (1991). Submissão e resistência. São Paulo: Contexto.

- Ortiz, R. (1994) Cultura Brasileira \& Identidade Nacional. 5. ed. São Paulo: Brasiliense.

- Ribeiro, M. M. (1997). A ciência dos trópicos: a arte médica no Brasil do século XVIII. São Paulo: Hucitec.
- Schwarcz, L. M. (1993). O Espetáculo das Raças. Cientistas, instituições e questão racial no Brasil 1870-1930. São Paulo: Companhia das Letras.

- Siles Gonzáles, J. (2011). Historia de la Enfermería. Madrid: DAE-Paradigma.

- Silva, Z. L. da. (1990). Os Dilemas da Pesquisa: as fontes oficiais e a imagética. En Di Creddo, M. do C. S.; Alves, P. y C.R. Oliveira de. (Orgs.) Fontes Histórias (pp. 39-46). Assis: Programa de Pós-Graduação em História.

- Soares, M. I. (1997). Da Blusa de Brim à Touca Branca. Lisboa: Educa.

- Souza Campos, P. F. de. (2008) Los Negros y los Cuidados en las Familias de Brasil: una visión histórica e iconográfica. Cultura de los Cuidados - Revista de Enfermería y Humanidades, (24), 26-34.

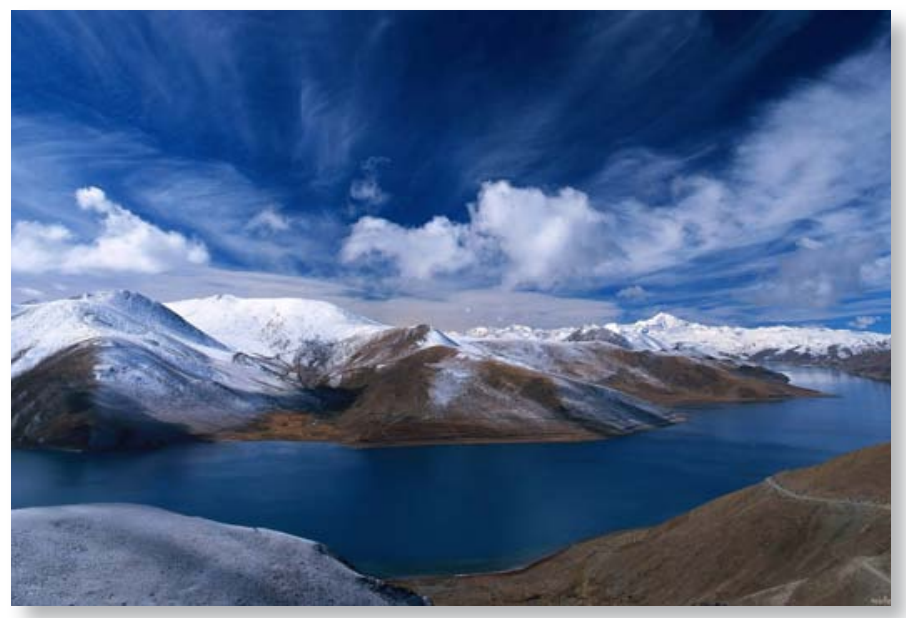




\section{Antropolog}

\section{Los cuidados paliativos y la muerte en los gitanos}

\section{Palliative care and death in the gypsy community}

\section{Os cuidados paliativos e morte nos ciganos}

Miguel Angel Badia Valera' ${ }^{1}$, Cristina Marcos Lezcanoํㅜ, María Jesús Aguarrón ${ }^{2}$

${ }^{1}$ Estudiante $4^{\circ}$ curso del Grado Enfermería Universidad Rovira i Virgili de Tarragona.

${ }^{2}$ Profesora Departamento de Enfermería Universidad Rovira i Virgili de Tarragona.

Cómo citar este artículo en edición digital: Badia Valera, A., Marcos Lezcano, C. y Aguarrón, Ma.J. (2015).

Los cuidados paliativos y la muerte en los gitanos. Cultura de los Cuidados (Edición digital), 19(43).

Disponible en: <http://dx.doi.org/10.14198/cuid.2015.43.11>

Correspondencia: Facultad de Enfermería. Campus de Cataluña. Avda. Cataluña, 35. 43002, Tarragona.

Correo electronico: badiavalera@hotmail.com

Recibido: 11/03//2015; Aceptado: 10/08/2015

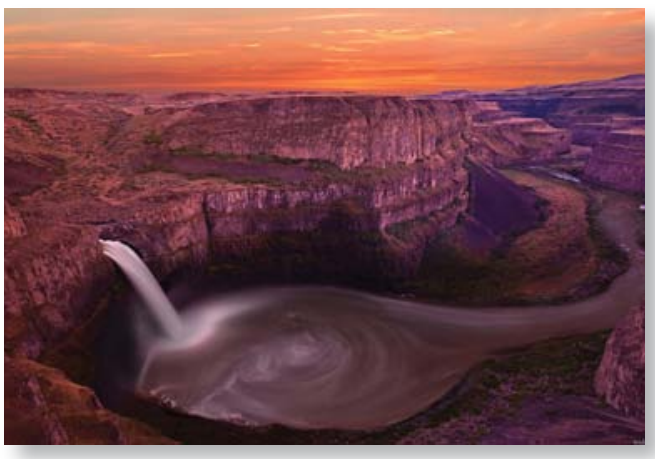

ABSTRACT

Introduction: The gipsy community is an important part in our society, which is distinguished by their own cultural elements. In the health world, the treatments, generally, do not attend to any cultural differences. The healthcare world is becoming more aware of the need to know and understand the cultural differences to conduct the most appropriate care, in our case, applying that to palliative care and death.

Aim: To know and understand the attitudes, traditions, and beliefs in the gipsy community, regarding palliative care and death.

Method: A bibliographical review is done to get to know the cultural characteristics of the community regarding the illness, the palliative care and the end of life. From that information, interviews are conducted in a focus group, as well as individually.

Results: After the study performed, some emerging categories are obtained, from which the bibliography is compared to the results from the interviews, providing a necessary information to the healthcare professionals, so that they can offer appropriate care to that ethnicity.

Keywords: gipsy, health\&illness, palliative care, death, grief.

\section{RESUMO}

Introdução: A comunidade cigana constitui uma parte importante da nossa sociedade, distinguindo-se pelos seus elementos culturais próprios. No mundo da saúde, geralmente, os tratamentos não se prendem com diferenças culturais. $\mathrm{O}$ mundo da saúde tem vindo a tornar-se cada vez mais conhecedor da necessidade de saber e perceber as diferenças culturais de modo a levar as cabo os tratamentos mais apropriados, no nosso caso em particular, aplicando-os aos cuidados paliativos e morte. 
Introdução: Saber e perceber as atitudes, tradições e crenças da comunidade cigana, no que toca aos cuidados paliativos e morte.

Objetivo: Saber e perceber as atitudes, tradições e crenças da comunidade cigana, no que toca aos cuidados paliativos e morte.

Método: Uma revisão bibliográfica é realizada com vista a conhecer as características culturais da comunidade, relativamente a doença, cuidados paliativos e ao fim da vida. Com base nessa informação, entrevistas são conduzidas num grupo de foco, bem como individualmente.

Resultados: Após realização do estudo, algumas categorias emergentes são obtidas, a partir das quais se compara a bibliografia com os resultados das entrevistas, proporcionando a informação necessária aos profissionais de saúde, a fim de poderem oferecer os cuidados apropriados a esta etnía.

Palavras-chave: cigano, saúde\&doença, cuidados paliativos, morte, luto.

\section{RESUMEN}

Introducción: La comunidad gitana es un pueblo importante en nuestra sociedad caracterizado por elementos culturales propios de sus individuos. En el mundo sanitario, los cuidados, en general, no atienden a diferencias culturales. Cada vez se es más consciente de la necesidad de conocer y comprender la variación cultural para poder así llevar a cabo unos cuidados apropiados, en este caso en relación a los cuidados paliativos y la muerte.

Objetivo: Conocer y comprender las actitudes, tradiciones y creencias en la población gitana ante los cuidados paliativos y la muerte.

Metodología: se realiza revisión bibliográfica para conocer las características culturales de la población en relación al acompañamiento en la enfermedad, paliativos y de final de la vida. A partir de dicha información se desarrollan entrevistas a un grupo focal y entrevistas personales.

Resultados y discusión: después del estudio realizado se obtienen unas categorías emergentes, de las cuales se ha podido comparar la bibliografía con las respuestas de los entrevistados, dando lugar a una información necesaria para los profesionales de la salud para poder ofrecer unos cuidados adecuados a dicha etnia.

Palabras clave: gitano, salud\&enfermedad, cuidados paliativos, muerte, duelo.

\section{INTRODUCCIÓN}

En la actualidad, los ciudadanos conocemos e integramos otras culturas a la propia, atendiendo a lo que se llama diversidad cultural, aunque siendo el pueblo gitano un grupo ubicado desde hace siglos en la península, las peculiaridades de su cultura en lo referente a la salud y enfermedad, no se tiene en cuenta a la hora de llevar a cabo, entre otros, la asistencia sanitaria.

En el mundo sanitario, no se atiende a diferencias culturales. Se proporcionan cuidados generales, sin tener en cuenta las necesidades espirituales, creencias y valores de otras culturas y religiones. Los profesionales de la salud cada vez somos más conscientes de la necesidad de conocer y comprender la variación cultural, para poder llevar a cabo unos cuidados apropiados a la cultura de las personas que cuidamos.

Es necesario destacar el papel de la enfermería transcultural, ya que esta es, en palabras de Madeleine Lenninger, un "área formal de estudio y trabajo centrado en el cuidado y basado en la cultura, creencias de la salud o enfermedad, valores y prácticas de las perso- 
nas, para ayudarlas a mantener o recuperar su salud, hacer frente a sus discapacidades o a su muerte" (Tarrés, 2001). Es decir, la enfermería transcultural la podríamos definir como el conjunto de actividades desempeñadas por profesionales determinados al cuidado, promoción, prevención o restablecimiento de la salud óptima tanto para la propia persona como para la sociedad. Dicho de otro modo, se encarga de dar un tipo de atenciones, que varía según los distintos significados de qué es cuidar, de los diversos tipos de prácticas y creencias que sobre la salud y la enfermedad tienen las personas que demandan o necesitan cuidados.

En la cultura gitana encontramos diferencias en la actuación de salud. En nuestra experiencia como estudiantes de enfermería hemos podido observar la falta de información para la actuación más adecuada, además del rechazo cultural que se realiza hacia las necesidades de este grupo. Este hecho ha conducido a investigar las costumbres y actitudes de la etnia gitana sobre la salud, enfermedad, los cuidados paliativos y la muerte, con el objetivo de conocer sus tradiciones y ritos culturales sobre estos temas con la finalidad de ofrecer una atención y unos cuidados que respeten e integren sus características culturales.

\section{METODOLOGÍA}

En primer lugar se realiza una búsqueda a través del metabuscador "scholar.google. es" y las bases de datos Cuiden, Cuidatge, Enfispo, utilizando las palabras clave "gitano", "enfermedad\&gitano", "muerte" y "cuidados paliativos", todos los artículos en español y no posteriores a 5 años de su publicación. Debido a la escueta información sobre el tema se amplía a 15 años la fecha de los documentos seleccionados, sin discriminación entre estudios cuantitativos y cualitativos, seleccionando un total de 34 artículos de interés para la revisión bibliográfica. 
lisis cualitativo de las mismas y a la búsqueda de categorías emergentes siendo estas: la percepción de la salud/enfermedad, la relación con el sistema sanitario, los cuidados paliativos, el acompañamiento, la muerte y el luto.

\section{La salud/enfermedad}

La salud, según la OMS, "es la condición de todo ser vivo que goza de un absoluto bienestar tanto a nivel físico como a nivel mental y social, es decir, el concepto de salud no solo da cuenta de la no aparición de enfermedades o afecciones sino que va más allá de eso".

En la cultura gitana la salud está vinculada con el estado de capacidad para poder desempeñar las actividades de la vida diaria. Por lo tanto estar sano, para la población gitana, se define como la condición de posibilidad para el desarrollo de dichas actividades. En las mujeres, dicha definición se basa en la posibilidad de hacer tareas como limpiar la casa, hacer la comida, así como cuidar de la familia. En el caso de los hombres, dichas actividades se relacionan con el trabajo fuera del hogar.

Al hablar del término enfermedad, diferenciada de la patología, se considera como un fenómeno cultural complejo en que los indicadores patológicos son transformados en signos sociales y relacionados simbólicamente con otras dimensiones de la vida social. La población gitana no la describe en términos médicos, sino que la considera como fortaleza del propio individuo. Cuando éste pierde la fuerza, debido a la edad o diferentes dolencias, ha de acudir al médico para resolver dicho padecimiento. Por el contrario, según la RAE, "la enfermedad es la alteración más o menos grave de la salud", por lo tanto se considera como un deterioro de la salud.

Nuestros informantes la definen como un estado en el que pueden realizar cualquier acto, la capacidad de poder llevar a cabo las actividades cuotidianas, además de la ausencia de enfermedad.

M: "La salud es vida, es estar bien para hacer cualquier cosa... Cuando no hay salud, estás enfermo. Depende de la gravedad, puedes estar mal y llegar a morir. [... ]La muerte es lo peor que te puede pasar".

\section{Relación con el sistema sanitario}

La relación con el sistema sanitario de la población gitana, según la bibliografía consultada, se basa en la tradición de los saberes del grupo o la posibilidad de acudir, como primer acceso sanitario a la farmacia, para restablecer su salud y poder llevar a cabo las actividades cotidianas. Si tras ello no se soluciona, se acude a la consulta médica, donde se espera del profesional efectividad, que la atención recibida sea rápida y que concluya con la solución al padecimiento. Una de las estrategias consiste en buscar segundas opiniones acudiendo a varios centros de salud, del sistema público y también a centros privados, para contrastar información (García, 2005).

$H$ : "A veces la enfermedad nos hace volver susceptibles a cualquier estimulo llegado por los demás familiares, amigos, enfermeros, etc... quiero decir que, cuando nos tratan con atención, creemos automáticamente que estamos mejor atendidos, de ahí la importancia de los cuidados".

En la población estudiada, sin embargo, el primer punto de acceso sanitario lo encontramos en el sistema privado o concertado ya que consideran que el público no atiende sus demandas de forma adecuada.

M: "Lo que pasa es claro, es que hay cosas que tienes que ir allí, a la segu- 
ridad social, pero normalmente, para cualquier "cosita", si puede ser privado, mejor. Es diferente, la atención, es muy diferente. Desde el recepcionista hasta que llegas al médico que te controla cualquier enfermedad que tengas. En cambio la seguridad social, estas colas... es que yo lo veo un poco engorroso".

G: "Cuando hay dinero, nosotros nos gusta más ir a médicos privados. Incluso nosotros mismos a los niños ya los apuntamos a privado. ¿Por qué? Porque nos gusta".

En relación con los profesionales sanitarios también existen diferencias en el trato, desde su punto de vista. La atención que reciben por parte de ellos, hacia el enfermo y los familiares o acompañantes, suele considerarse más óptima cuando influye el dinero en el servicio prestado, pero no niegan que generalizan en esta afirmación.

M: "Hay de todo en esta vida, no solo en la sanidad, sino en todos lados. Nosotros somos muy pesados en decir escucha enfermera, ¿porque pasa esto? ¿Y porque...? y ellas te dicen escucha no me toques más las narices y déjame estar. Hay gente muy profesional que te lo explica todo una vez, dos, tres...".

G: "Nosotros nos preocupamos mucho, somos de ésta manera, nos gusta preguntar, saber cómo está el enfermo, si esto va bien, si esto no va bien... somos muy sufridores. Nosotros cuando tenemos un enfermo padecemos mucho".

La falta de información y conocimiento por parte de los profesionales de la salud sobre otras culturas y tradiciones, además de prejuicios existentes, producen un atención inadecuada al paciente y la familia, sin tener en cuenta sus sentimientos.
H: "No se le podría llamar rechazo exactamente pero si mucha prudencia $y$ un poco de reparo al tratar al paciente gitano. Supongo que por falta de conocimiento hacia nuestra cultura".

J: "Tienes que pensar que esto siempre lo hemos visto. Es que si terminamos con estas pequeñas cosas, creo que el gitano se acabará”.

\section{Acompañamiento al enfermo y la familia}

El acompañamiento al enfermo hospitalizado y la familia se viven en comunidad. Los familiares acompañan a sus enfermos en todo momento, estén donde estén, ya que tienen que verificar su estado. De hecho el diagnóstico es una abstracción: si uno no lo ve, puede no ser verdad. Se basan en la vivencia de las cosas.

H: "Si lo consideramos muy importante poder acudir ya que para nosotros es nuestra forma de apoyar a la familia afectada, el hecho de interesarte por esa persona aunque a veces no sea familiar directo, crea un respeto y una atención que es muy considerada entre los gitanos".

Ante el posible ingreso de un miembro del grupo, sea cual sea el motivo, se hace presente toda la familia y persona allegadas, donde todos ofrecen apoyo, moralmente obligados a movilizarse, para proteger la vida de esta persona y sus necesidades.

G: "Nunca se queda nadie solo. El enfermo siempre tiene compañía, no lo dejamos solo".

En este punto, los sujetos entrevistados, coinciden con la bibliografía (García, 2005). La importancia de la familia $y$ las tradiciones en su cultura continua haciéndose presente. 
G: "Nosotros somos de esta manera y no podemos hacer más y... cambiarlo... es muy difícil [...] Nosotros somos más familiares".

M: "Somos así, nos han criado así, de esta manera, y también entiendo vuestra parte, que por vuestra parte lo podéis ver cómo, ¡viene la marabunta, vienen hasta aquí!".

A: "Sabemos que si solo se puede quedar uno o dos, pues es la hija o el hijo quien se queda acompañando. No hay ningún ritual ni nada. Aunque no seas familiar allegado tienes el compromiso como gitano, como persona que conoces, de ir a verlo, de estar un rato, de acompañarlo...”.

Existen prejuicios por parte de los "payos", (no gitanos), respondiendo a la recepción de un grupo de etnia gitana que llega a un hospital.

M: "Nosotros no somos más que vosotros, pero sípodrían tener un poco más de consideración, más que nada porque nos movemos en masas, y es un sentimiento diferente $y . .$. un poco adaptarse [...] pero también comprendo que no es normal estar allí más de 20 personas...”.

$G$ : "En los hospitales cuando ven gitanos, la verdad, pues a la gente le asusta. A ver, no nos comemos a nadie, pero claro somos de esta manera nosotros, somos muy familiares. Cuando un gitano está enfermo nos preocupamos".

Sus costumbres hacen que sea de obligada actuación la presencia de familiares para dar apoyo en todo lo necesario, aunque son conscientes de las normas e intentan aceptarlas modificando, en cierta forma, sus costumbres, por ejemplo, haciendo visitas correlativas o esperando fuera del hospital y no en la habitación.
M: "No nos comprenden porque nos movemos en masa. Si por ejemplo hay alguien ingresado, iremos toda la familia $y$, aunque no seamos familia, iremos allí para dar apoyo. Cuando los profesionales informan que todo ha salido bien, ya nos avisan de que nos podemos ir, $y$ eso hacemos, entonces nos vamos. Después ya son visitas correlativas. Primero unos, después otros, y otros... Pero pensamos que irnos en un momento así es como dar la espalda y eso no lo aceptamos. La conciencia no nos deja".

G: "No podemos hacer nada más, somos así de verdad. El no ir te sabe mal. Si es una persona que quieres te sabe mal el no ir".

\section{Los cuidados paliativos}

Haciendo hincapié en los cuidados paliativos en esta etnia, no se ha encontrado información bibliográfica.

Como ya se ha mencionado, la familia es un pilar fundamental en sus vidas. En la última etapa de la vida, se hace imprescindible cumplir con el deseo de vivir rodeado de sus allegados y en su hogar, siguiendo con la tradición.

En el caso de necesitar cubrir alteraciones en la salud y cuidados especializados, como cuidados paliativos, se suele hacer presente la figura de enfermería, contratada por ellos mismos, (coincidiendo con lo expuesto anteriormente, prefieren pagar servicios privados siempre que sea posible), o aprendiendo a realizar ellos mismos dichos cuidados necesarios para el enfermo. Éstos suelen llevarlos a cabo la mujer, la cuidadora principal en la familia durante generaciones:

$H$ : "La mujer asume los cuidados $y$ atenciones del paciente en ese mismo 
instante. Los cuidados, higiene, alimentación y, en algunos casos, trabajo, la mujer ha sido siempre el pilar más importante para el hogar, aunque es el hombre el que toma las decisiones importantes, eso no significa que el hombre no esté presente siempre, aunque en un papel más pasivo".

G: "Hemos tenido una enfermera con nosotros todo el día y si, la hemos tenido que pagar nosotros".

Dicen que los ancianos son su mayor legado y por tanto no son partidarios de hacer que los mayores vivan en una residencia o ingresen, siendo necesario, en un centro especializado como un centro sociosanitario:

G: "El abuelo para nosotros es lo mejor del mundo que tenemos, lo respetamos mucho, a toda la gente mayor. No nos gusta tampoco encerrarlos".

M: "No es una cosa ética que encerremos a los abuelos en una residencia".

En el caso de un paciente en estado terminal explican que también hacen que sus tradiciones se cumplan, llegando a pedir el alta del enfermo y llevándolo a su hogar para pasar sus últimos momentos con su familia y en su entorno:

G: "Cuando uno ha estado muy mal $y$ ha estado en el momento terminal nosotros mismos los sacamos y los llevamos a casa porque no nos gusta que estén allí. Si están en un hospital viene mucha gente y al hospital no nos dejan estar allí toda la noche y a nosotros no nos gusta, nos gusta tenerlos en casa, somos de esta manera. De hecho hay personas, donde la muerte es inminente, que se ha pedido el alta y los hemos sacado con el coche. Sales y vas hacia casa".

A: "Cuando una persona está termi- nal y el médico ya le ha visto, quieres llevártelo a casa, estar con la familia, estar allí lo que le queda de tiempo. Es eso lo que nos gustaría que pasara siempre".

\section{La muerte y el luto}

En relación a la muerte y el luto, se puede decir que cuando la enfermedad lleva inevitablemente a la muerte, la presencia del grupo se hace aún más fuerte. Al morir, el dolor se muestra de forma abierta y máxima sin tener en cuenta las normas de conducta sociales. No se permite que se practique la autopsia al cadáver ni que se le extraigan órganos, el hecho de preguntarlo resulta ofensivo. Se le guarda profundo respeto siendo el cuerpo algo sagrado para ellos. Se le entierra, nunca se le incinera.

G: "No, incineración los gitanos no. Para nosotros la muerte, dijéramos, es un respeto muy grande que tenemos nosotros con los difuntos y a aquel difunto nosotros no podemos quemarlo.

H: "Quemar es impensable... que a la persona que tanto has amado le hagan eso".

El período de duelo coincide con la información de los entrevistados, manteniéndose generalmente por mayor tiempo que en los "payos" y dependiendo de las costumbres de cada familia (FSG, 2007).

G: "Es algo que se lleva particularmente. Hay personas que están 5 meses, otros 3 meses, habrá personas que estarán un año, 2 años... La gente mayor lleva más tiempo el luto. Toda la vida dijéramos, si el que muere es el hombre, la gitana por costumbre ya no se lo quita nunca más. Toda la vida lleva luto, hasta que se muera y la entierras de negro".

La familia viste de negro, con pañuelos en el cuello o en la cabeza, no hace ningún tipo de 
actividad placentera, se detienen las actividades sociales o laborales. La familia se dedica a ayudar al difunto a dejar este mundo a través de la oración y del propio dolor. El momento de la separación física definitiva se vive de forma diferente según la cultura.

A: "La muerte en la cultura gitana es lo más fuerte que le puede pasar a una familia. Por muchos años que tenga, por mucha carrera que haya hecho aquella persona, es muy traumático para los familiares. Es muy fuerte, es lo peor que le puede pasar a una familia”.

La población estudiada narra que actualmente, las costumbres generacionales en relación al difunto se siguen llevando a cabo. Cuando un familiar muere, habitualmente, el velatorio se hace en casa ya que es el entorno más privado y referente para la familia.

M: "El velatorio es siempre en casa. Es poco habitual ir al tanatorio".

$H$ : "Bueno los gitanos prefieren velar al fallecido en casa, lo del cristal de separación que impide tocar por última vez a esa persona no lo llevan muy bien así que en la mayoría de casos se vela en casa".

La tradición hace que el luto sea muy presente en todos sus miembros, excepto en los niños. Actualmente no es tan estricto.

G: "Hay niños con 13 años que quizás se meterán luto, pero dijéramos que nosotros no les dejamos que lleven luto, porque un niño es un niño, tiene que jugar. Ahora si le sale de él, sí, pero tampoco le puedes decir que se lo meta. Ya sale de él. La mayoría con menos de 14 no lo llevan, cada uno tiene su cultura, tradición...".

Las ropas negras, la abstención de cualquier tipo de ocio, el tiempo de luto, ha cam- biado siendo hoy adaptado a los nuevos tiempos y dependiendo en todo momento del tipo de relación con el difunto. Es una forma de dar respeto al difunto y a toda la familia.

M: "Pero cada uno lo vive a su manera. Yo puedo escuchar la radio y pueden decir ¿cómo puede ser que escuche la radio? y yo no encontrarlo mal. Es el sentimiento que tengas hacia él".

$H$ : "Para los gitanos en general es una forma de guardar recuerdo, respeto, amor, honor $y$ a veces se hacen cosas realmente absurdas para los payos como no ver la tele, no entrar en los bares, ningún tipo de celebración, incluso no comer carne durante el luto esto como ya he dicho puede parecer absurdo pero para los gitanos si no haces esto no has honrado al fallecido. Y un detalle nunca puedes quitarte el luto por ti mismo siempre lo tiene que quitar el patriarca una persona mayor y respetada por el resto no sirve cualquiera".

Existen muchas leyes no escritas en la cultura gitana y en el caso de la muerte, en la gente mayor, más arraigadas a sus costumbres, se hace aún más patente. Las últimas voluntades de la persona muerta se llevan a término sin ninguna duda. Al muerto se le ha de enterrar en el cementerio, amortajado antes por sus familiares más próximos y llevando sus mejores ropas.

$H$ : "Al fallecido lo amortaja siempre la familia más cercana madre, padre, hijos, hermanos... es algo que tenemos que hacer nosotros".

A: "Si tu respetas a aquella persona guardas respeto por ella y ésta es nuestra manera”.

El cementerio es un sitio sagrado para los familiares, siendo el lugar donde pueden expresar sus emociones libremente. 
G: "A nosotros nos gusta mucho ir al cementerio, aunque pasen muchos años de que se mueran, nosotros casi siempre estamos allí, pase un mes, dos meses... vas allí al cementerio. Nosotros los tenemos como si fueran una reliquia, es decir, el nicho, el panteón... son espectaculares. Hay aquellas flores... esas cosas... [...]Les hablamos aunque no te oye nadie, pero son las costumbres que tenemos nosotros, las manías que tenemos, nos gusta mucho ir alli".

\section{CONCLUSIONES}

La asistencia sanitaria, en relación a los cuidados paliativos y la muerte en la cultura gitana, atendiendo a la diversidad cultural integrada en nuestra sociedad, se debería tener en cuenta para ofrecer una atención especializada y consecuente a las necesidades de este grupo.

Después de realizar las entrevistas a la población gitana, se ha podido conocer la cultura de los cuidados paliativos y la muerte en esta población. Esto permite conocer y entender las actitudes que este grupo presenta ante situaciones de enfermedad, cuidados paliativos o ante la muerte, interpretando sus palabras. Esto posibilita a realizar actuaciones sanitarias adecuadas a las necesidades de su cultura y evitar los estereotipos y prejuicios que a veces se tienen en relación a la cultura gitana, en gran parte por desconocimiento de ella, que se hace patente en la búsqueda bibliográfica previa.

La relación con el sistema sanitario no ha de depender del tipo de financiación del hospital donde se les atiende. Los profesionales de la salud tienen la obligación moral de atender a todos los pacientes por igual, siendo empáticos y conociendo sus costumbres, para poder ofrecer la mejor atención, respetando sus creencias y tradiciones siempre que sea posible.
El acompañamiento del enfermo hospitalizado se vive en comunidad. Los prejuicios que se tienen hacia la cultura gitana, como puede ser el bullicio, el miedo a posibles agresiones al personal sanitario, etcétera, hacen que exista un rechazo hacia ellos. La tradición hace que sea de obligado cumplimiento la presencia de la familia y allegados en el hospital, dando apoyo y conociendo el estado del enfermo. En estos tiempos son conocedores de las normas de los hospitales y modifican sus hábitos, evitando así incumplir dichas normas. Por lo tanto conociendo la importancia de la familia se tendría que ser flexible ante las normas, manteniendo los límites.

Cuando un paciente entra en estado terminal, la necesidad de vivir rodeado de sus allegados y en su hogar se hace más intensa, llegando incluso a pedir el alta del enfermo para vivir sus últimos momentos en su entorno. Esto puede llevarse a cabo con la imprescindible ayuda de enfermería. Dando la información necesaria, así como un entrenamiento de algún familiar, normalmente la mujer, cuidadora principal en el pueblo gitano, para asistir al enfermo en su casa.

Ante la muerte en un centro sanitario se debería poder concederles cumplir su tradición, velando a la persona durante un tiempo prudencial y haciéndose necesario amortajar al difunto por parte de los familiares más allegados. La incineración resulta ser un tema ofensivo para ellos.

Es necesario que enfermería se familiarice con las costumbres, rituales y cultura de las personas a las que cuidan. Solo de esta forma se podrá realizar unos cuidados holísticos que vayan más allá del aspecto físico de la enfermedad.

Todo lo anterior descrito, se puede tener en cuenta para realizar la atención a un paciente gitano. Es necesario el desarrollo de más inves- 
tigación sobre la cultura gitana desde el ámbito sanitario.

\section{BIBLIOGRAFÍA}

- Arranz, P., Toledo, N., Del Rincón, C., Sánchez, C., Albarracín, D. (2001). Protocolo de actuación para favorecer la comunicación entre paciente, familia y equipo sanitario en cuidados paliativos. Revista de psicología de la salud, 13 (2), 79-95.

- Asenjo, J. (2000). Diferencies en problemes de salut atesos en un centre d'atenció primaria entre gitanos i no gitanos. Butlleti de la societat catalana de medicina familiar i comunitaria. 18 (6), 205-209.

- Ayala, A. (2008). Actitudes y pautas de comportamiento de la población gitana de la Comunidad de Madrid en relación a su salud. Madrid: Instituto de salud pública de la Comunidad de Madrid y Universidad Complutense de Madrid.

- Benítez, M.A., Salinas, A., Asensio, A., Armas, J. (1999). Cuidados paliativos en atención primaria: opinión de los profesionales. Atención primaria, 23 (4), 187-191.

- Cabedo, V.R., Ortells, E., Baquero, L., Bosch, N., Montero A., Nácher, A., Sánchez-Peral, B., Tamborero, M.A. (2000). Como son y de que padecen los gitanos. Atención primaria, 26 (1), 21-25.

- Campos, B., Cardiel, B., García, A., Laparra, M., Del Pozo, J.M., Legal, I. (2005). Situación social y tendencias de cambio en la comunidad gitana. Pamplona: Departamento de trabajo social Gizarte Laneno Saila..

- Cepero, I., Fernández, F., Fernández, M.D., De La Flor, A., Lahoz, J., López, M.I., Martín, J., Moreno, E., Morillas, A., Santiago, J.A. (1998). Comunidad gitana. Junta de Andalucía. Sevilla: Consejería de Asuntos Sociales.

- Colell, R. (2008). Enfermería y cuidados paliativos. Lleida: Universitat Lleida. Corella, J.M., Mas, T. (1999). Enfermería y cuidados paliativos. Relación de ayuda. Enfermería integral. (50), XLIII-XLVI.

- Ferrer, F. (2003). El estado de salud del pueblo gitano en España. Una revisión de la bibliografía. Gaceta sanitaria. 17 (3), 2-8.

- Fundación Secretariado Gitano (2013). Discriminación y comunidad gitana. Informe anual, 111. Madrid: Fundación Secretariado Gitano.

- Fundación Secretariado Gitano (2007). Fundación Secretariado Gitano. Glosario. Disponible en: http://www. gitanos.org/servicios/prensa/glosario/terminos.html.

- García, C. (2005). Guía para la actuación con la comunidad gitana en los servicios sanitarios. Madrid: Fundación Secretariado gitano.

- Junta de Castilla y León-Consejería de Sanidad (2006). Salud y comunidad gitana: análisis de propuestas para la actuación. Madrid: Fundación Secretariado General Gitano.

- Márquez, M., Arenas, J., Feria, D.J., León, R., Barquero, A., Carrasco, M.C., Macías, A.C. (2000). A propósito de la muerte. Cultura de los cuidados, 4 (7 y 8), 181-186.

- Martínez, M.B., Monleón, M., Carretero, Y., García-Baquero, M.T. (2012). Enfermería en cuidados paliativos y al final de la vida. Barcelona: Elsevier, Ministerio de Sanidad y Consumo Centro de publicaciones (2001). Plan nacional de cuidados paliativos: Bases para su desarrollo. Disponible en: http://www.msssi.gob.es/organizacion/ sns/planCalidadSNS/pdf/excelencia/cuidadospaliativosdiabetes/CUIDADOS_PALIATIVOS/opsc_est7.pdf.pdf

- Palabra de gitano, episodio 7, El luto (2013) Madrid: Mediaset España.

- Ramírez, S. (2007). Entre calles estrechas: gitanos: prácticas y saberes médicos. Barcelona: Bellaterra.

- Reyero, F. (1998). De gitanos y médicos. Trabajo social y salud. (29), 87-97.

- Rubio, R.G. (1996). Mayores gitanos. Sesenta y más. (130), 6-11.

- Tarrés, S. (2001). El cuidado del “otro". Diversidad cultural y enfermería transcultural. Gaceta de antropología. 17, artículo 15. Disponible en: http://hdl.handle. net/10481/7475

- Tuset, M.G., Roca, A., Alamillo, P., Martorell, M.A. (2012). La salud y las creencias del pueblo gitano en Europa: revisión bibliografía. Cultura de los cuidados. 16, (34), 71-80.

- Valderrama, M.J. (2008). Al final de la vida... historias y narrativas de profesionales de cuidados paliativos. Barcelona: Icaria. 


\section{Experiencia de cooperación en Turkana (Kenia). Una mirada enfermera.}

\section{Experience of cooperation in Turkana (Kenya). A nurse look Experiência de cooperação em Turkana (Kenya). Um olhar enfermeira}

Andrés Climent Rubio ${ }^{1}$, José Ramón Martínez Riera ${ }^{2}$, Elena García Higón ${ }^{3}$

${ }^{1}$ Enfermero cooperante en Turkana (Kenia), Vocal de Cooperación Internacional y Relaciones Internacionales de la Asociación de Enfermería Comunitaria (AEC). Enfermero servicio de emergencias Ayuntamiento Teulada-Moraira (Alicante). asandres9@hotmail.com

${ }^{2}$ Enfermero. Presidente Asociación Enfermería Comunitaria (AEC). Profesor Titular Departamento Enfermería Comunitaria, Medicina Preventiva y Salud Pública e Historia de la Ciencia. Facultad Ciencias de la Salud. Universidad de Alicante.jr.martinez@ua.es

${ }^{3}$ Enfermera cooperante en Turkana (Kenia).egarciahigon@gmail.com

Cómo citar este artículo en edición digital: Climent Rubio, A., Martínez Riera, J.R. y García Higón, E. (2015). Experiencia de cooperación en Turkana (Kenia). Una mirada enfermera. Cultura de los Cuidados (Edición digital), 19(43). Disponible en: <http:// dx.doi.org/10.14198/cuid.2015.43.12>

Correspondencia: Servicio de emergencias Ayuntamiento Teulada-Moraira (Alicante).

Correo electrónico: asandres9@hotmail.com

Recibido: 11/03//2015; Aceptado: 10/08/2015

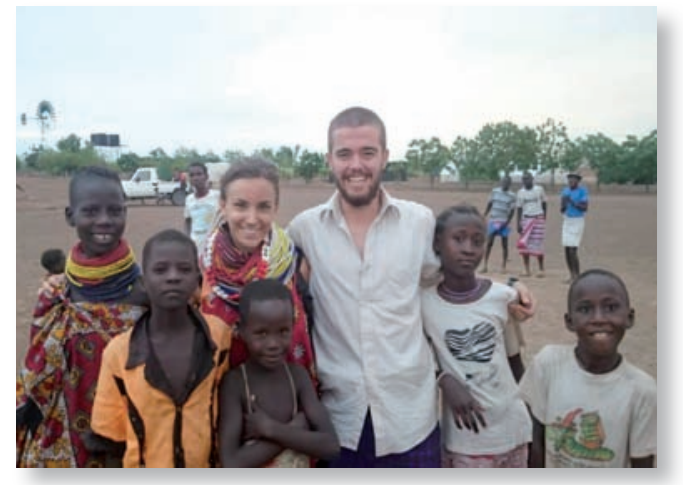

ABSTRACT

Speaking of international cooperation on many occasions we generate some associated with concepts far removed from what really is image.

What we will capture in this experience it is not intended to alarm or create scenarios manipulated or magnify poverty, lack of resources or human misery ... only pretend to be faithful to reality as far and near at the same time as we tell .

Two nurses and a professor at the University of Alicante (Spain) developed in Turkana (Kenya) a draft Community intervention in which public participation is central to its development. The main objective of the intervention is to identify major health needs and how people can respond to them independently and responsibly. The project is initiated by identifying community leaders through whom are involved in the community to begin the process of health education which responds to the health needs of the latter.

After almost a year of intervention have been achieved key objectives related to hygiene, nutrition and care during pregnancy and childbirth.

Keywords: International Cooperation, Community Intervention, Community Participation, Community Nursing.

\section{RESUMO}

Falando da cooperação internacional em muitas ocasiões que gerar algum associado com conceitos muito longe do que realmente é a imagem.

O que vamos capturar nesta experiência que não se destina a criar cenários de alarme 
ou manipuladas ou ampliar a pobreza, a falta de recursos ou a miséria humana ... só que fingir ser fiel à realidade como longe e de perto, ao mesmo tempo que nós dizemos.

Duas enfermeiras e um professor da Universidade de Alicante (Espanha) desenvolvido em Turkana (Kenya) um projecto de intervenção comunitária em que a participação pública é fundamental para o seu desenvolvimento. $\mathrm{O}$ principal objetivo da intervenção é identificar as principais necessidades de saúde e como as pessoas podem responder a eles de forma independente e responsável. O projeto é iniciado através da identificação de líderes comunitários através do qual estão envolvidos na comunidade para iniciar o processo de educação em saúde que responde às necessidades de saúde deste último.

Depois de quase um ano de intervenção foram alcançados objectivos fundamentais relacionados à higiene, nutrição e cuidados durante a gravidez eo parto.

Palavras-chave: Cooperação Internacional, Intervenção Comunitária, Participação Comunitária, Enfermagem Comunitária.

\section{RESUMEN}

Hablar de Cooperación internacional en muchas ocasiones nos genera cierta imagen asociada con conceptos muy alejados de lo que realmente es.

Lo que vamos a plasmar en esta experiencia no pretende alarmar, ni crear escenarios manipulados, ni magnificar la pobreza, la falta de recursos o la miseria humana... tan solo pretende ser fiel a una realidad tan lejana y cercana al mismo tiempo como la que narramos.

Dos enfermeros y un profesor de la Universidad de Alicante (España) desarrollan en Turkana (Kenia) un proyecto de intervención
Comunitaria en la que la participación de la población es el eje de su desarrollo. El principal objetivo de la intervención es la identificación de las principales necesidades de salud y la manera como la población puede responder a ellas de manera autónoma y responsable. El proyecto se inicia con la identificación de los líderes comunitarios a través de los cuales se interviene en la comunidad para iniciar el proceso de educación para la salud que de respuesta a las necesidades de salud de ésta.

Tras casi un año de intervención se han logrado objetivos clave relacionados con la higiene, la alimentación y la atención al embarazo y parto.

Palabras clave: Cooperación Internacional, Intervención Comunitaria, Participación Comunitaria, Enfermería Comunitaria.

\section{Cooperación, una mirada enfermera}

Hablar de Cooperación internacional en muchas ocasiones nos genera cierta imagen asociada con aventura, exploración de algo desconocido, ayuda pero sin saber bien qué tipo, idealismo, solidaridad puntual e incluso cierto morbo por acercarse a la penuria humana (2010, Delgado Caicedo, J. Barrera Castro, A.) (2004, Mazarrasa L, Montero M.J.).

También suele asociarse con proyectos internacionales de grandes ONGs con gran experiencia y muy organizadas.

Pero la Cooperación va mucho más allá de estos sentimientos, pensamientos o imaginaciones asociados a la ignorancia de lo que realmente significa, comporta y aporta. Y más allá, por supuesto de las intervenciones realizadas desde grandes proyectos, que siendo muy importantes, no representan la mayoría invisible de la Cooperación que se realiza (2009, de Almeida Souza, A.). 
Por lo tanto resulta necesario que se conozcan con detalle experiencias, en las que lo vivido va mucho más allá de cualquier imagen previa que nos hubiésemos o nos hubiesen trasladado. Que logren trasladar a la gran mayoría de quienes habitualmente nos situamos como meros espectadores de lo que se hace, vive y sufre de manera muy superflua, tamizada e incluso interesada a través de unos medios de comunicación interesados, mayoritariamente, en otras cuestiones más prosaicas, salvo catástrofe humanitaria que sirva para disparar sus cuotas de audiencia (2008, Casabona Martínez, I. Lillo Crespo, M. Mora Antón, MD. Cort Casabona, S.), (2012, Álvarez S.), (2010, Tassara C.).

Lo que vamos a plasmar en esta experiencia no pretende alarmar, ni crear escenarios manipulados, ni magnificar la pobreza, la falta de recursos o la miseria humana... tan solo pretende ser fiel a una realidad tan lejana $y$ cercana al mismo tiempo como la que narramos. No es nuestra intención tampoco generar lástima o falsa solidaridad. Creemos que es necesario que, huyendo de dramatismos, de eufemismos y de dogmatismos, sepamos contar con la realidad que merece lo que sucede, cómo sucede y dónde sucede y, además, que se haga desde la mirada enfermera de quienes estamos siendo actores voluntarios de esta experiencia de cooperación, enfermeros. Porque, sin duda, la mirada enfermera es intemporal en el sentido de que tiene su origen en la posibilidad humana de autocuidarse y se consolida en "mirada enfermera" en el momento en que se trasciende el instinto y se convierte en servicio. (2003, Alberdi, R.).

\section{África - Kenia - Turkana. La importancia del contexto.}

Para poder hacerse una idea real de la experiencia que vamos a compartir es funda- mental que conozcamos en contexto en el que se desarrolla (2007, Valtueña J.).

Kenia, con 39 millones de habitantes, tiene 47 distritos, cada uno de ellos con un gobierno semiautonómo respecto al gobierno central de Nairobi. La economía de Kenia es además la de mayor producto interno bruto de la región Este y Central de África, lo que resulta paradójico con la realidad de la región donde nos encontramos, el Distrito de Turkana. El Distrito de Turkana se encuentra al noroeste de Kenia en la región del Rift Valley, cuya capital es Lodwar. Su población, según el último censo de 2009, está contabilizada en 850.000 personas repartidas en los $77.000 \mathrm{~km} 2$ que abarca, incluyendo 95.000 refugiados ubicados en el campo de refugiados de Kakuma. El crecimiento anual es del 2,5\%. Hay 92 hombres por cada 100 mujeres, siendo la densidad de población de 11 habitantes por Km2. Pertenecen en su gran mayoría a la etnia Turkana, y su lengua es el Turkana.

La población Turkana se encuentra en una situación de pobreza extrema. Su economía es sumamente frágil, y las sequías periódicas son seguidas de hambrunas y muerte de los sectores de población más débiles -niños y ancianos-. Esta situación determina una esperanza de vida inferior a los 50 años sin contar la mortalidad infantil, que se sitúa en niños menores de 5 años en 170/1000 habitantes. El hambre es el mayor problema que afecta a los Turkana, junto con el aislamiento y la ausencia casi total de todo tipo de infraestructuras, desde carreteras a agua potable, sistema sanitario y medios de transporte.

Mayoritariamente, los Turkana son una etnia de pastores nómadas. Subsisten mediante el pastoreo nómada de cabras, camellos, burros y vacas. Se visten de sus pieles y se alimentan de su leche, sangre y carne, siendo utilizados, 
además, como medio de trueque. Los animales determinan la riqueza y la posición social y condicionan su modo de vida, ya que se desplazan por el distrito en función del acceso a pastos y agua a lo largo del año. Así, durante la época seca habitan las montañas, y en la época de lluvia se desplazan a las planicies.

La mayoría del pueblo Turkana mantiene su religión tradicional monoteísta. Su Dios (AKuj), está asociado con el cielo y es el creador de todas las cosas. A pesar de ello no tiene apenas influencia en sus vidas, y sólo se recurre a él en tiempos de necesidad. Existen médicosadivinos y brujas, cuyas funciones más importantes son predecir la victoria en las guerras, ayudar en la salud y remediar la esterilidad.

La diferenciación entre sexos es muy importante, y diferencian de manera muy clara las funciones de mujeres y hombres. Las mujeres se ocupan de las labores del hogar, cuidado de los hijos, recogida de agua desde los pozos, construcción de la vivienda en caso de nómadas y la mayoría de las tareas que se puedan llevar a cabo dentro de la unidad familiar. Los hombres son los encargados de ordenar las funciones de la mujer y los hijos y el pastoreo de la parte de ganado de la cual no se ocupan sus hijos varones.

A nivel educativo, las niñas y jóvenes se ven marginadas frente a los niños. La oposición a que acudan a la escuela primaria y secundaria parte de sus propias familias, para que así puedan ser casadas a una edad temprana. Solamente en los grandes núcleos de población las mujeres comienzan a desarrollar sus derechos sociales.

\section{Sistema de salud en Turkana}

El sistema de salud, es muy precario. Las enfermedades más frecuentes son la malaria, las enfermedades respiratorias y las infeccio- nes gastrointestinales. Se añaden otras enfermedades endémicas como la brucelosis, el quiste hidatídico o la madurelosis, así como la tuberculosis y el HIV/SIDA, sobre el cual no existen estadísticas fiables en Turkana, aunque supone ya el 33\% de la ocupación de las camas hospitalarias del hospital de Lodwar.

En todo el Distrito Turkana las infraestructuras sanitarias son mínimas. Existen solamente 990 camas hospitalarias repartidas en 5 hospitales, y 81 dispensarios y centros de salud, aunque es más que optimista pensar que todos ellos se encuentren en funcionamiento. La proporción personal sanitario/habitantes es de 1/80.000 en el mejor de los casos. Por lo tanto, el mayor problema de salud es la posibilidad real de acceso por parte de la población a algún centro de salud. Como reflejan las estadísticas gubernamentales publicadas en el Plan de Desarrollo del Distrito Turkana 2002-2008, la distancia promedio al lugar de atención sanitaria más cercano es de $50 \mathrm{Km}$. El hospital principal se encuentra en Lodwar, donde han florecido un buen número de consultas privadas, debido a los limitados servicios del hospital del gobierno.

La atención sanitaria por parte del Ministerio de Salud de Kenia en Turkana se limita a la atención de las poblaciones urbanas del distrito a través de dispensarios. Teniendo en cuenta que aproximadamente el $86 \%$ de la población en Turkana vive en el ámbito rural, la atención sanitaria de facto por parte del gobierno en Turkana es muy limitada. El resto, es llevado a cabo por la Diócesis Católica de Lodwar y por ONG's. Esta labor de suplencia en la atención sanitaria está plenamente aceptada por el Ministerio de Salud, el cual se coordina con las unidades de salud de la Diócesis de Lodwar para campañas en situaciones de epidemias o cuando equipos de especialis- 
tas visitan la zona (desde 2003 grupos de oftalmólogos españoles y desde 2004, grupos de cirujanos acuden a la zona cada año a operar durante 15 días). Asimismo, los dispensarios y centros de salud regentados por la Iglesia Católica informan mensualmente al Hospital central situado en Lodwar, de sus actividades y les remiten estadísticas sanitarias y epidemiológicas. Los dispensarios más alejados de la capital puestos en marcha por el gobierno y situados en los lugares más remotos se encuentran frecuentemente con la desaparición de los profesionales por periodos muy largos de tiempo sin dar respuesta a las necesidades del lugar. Para entender esta visión de la sanidad basta con leer los protocolos hospitalarios en los que se define una emergencia como una situación que puede esperar más de $8 \mathrm{~h}$, Urgencia como situación demorable a más de $24 \mathrm{~h}$ y enfermedad común como atención demorable a más de 7 días. Esto hace que se comprenda un poco mejor la visión de la enfermedad y de su gravedad (2010, Jerez C, García E, Saz M, Tamame M.), (2010, Serra R.)

También es importante describir los niveles de atención que existen en Kenia, que se pueden resumir en los siguientes niveles:

Nivel 1-Atención comunitaria y Comunity Health Worker (CHW)

Nivel 2- Dispensarios. Personal: 1 o 2 enfermeros uno de ellos es el gerente y 102 auxiliares.

Suelen encontrarse en lugares remotos con población muy dispersa y se asientan en poblados seminómadas estables.

Nivel 3- Centros de salud. Personal: 1 Clinical Officer (CO) con función asistencial y además es el gerente del centro, 1 o 2 Enfermeros, 1 o 2 auxiliares, 1 nutricionista, 1 trabajador social. Se encuentran en zonas más importantes con una población estable de envergadura (5000 habitantes)

Nivel 4- Hospitales primarios. Personal: Dependiendo de las dimensiones pero siempre 1 médico y varios $\mathrm{CO}$ o Enfermeros. El médico es el gerente.

Nivel 5- Hospital de referencia. Personal: Hospital que cuenta con unidades de cuidados especiales y con especialistas en diversas áreas médicas.

\section{Las enfermeras en Kenia. Compleja realidad.}

Dentro del sistema de salud de Kenia existen como ya hemos dicho Médicos, Clinical Officer y Enfermeros. La figura del médico queda relegada a grandes hospitales de nivel 5 y en escasas ocasiones a hospitales de nivel 4 llevando a cabo las funciones propias de un médico tal y como las conocemos en España. Los Clinical Officer se sitúan entre el enfermero y el médico y realiza actividades enfermeras y otras propias de la medicina. Podría ser descrito como un enfermero de práctica avanzada con capacidad diagnóstica y de prescripción.

Las Enfermeras, pueden ser generalistas y especialistas (Pediatria, UCI, Anestesia, Quirófano, Salud Mental, Familiar y Comunitaria y Matronas). Dependiendo de donde desempeñen su profesión las enfermeras, con independencia de ser especialistas o no, tienen más o menos competencias. La diferencia entre una enfermera general en Nairobi (capital del país) y una enfermera en Turkana, se centra en que la primera tiene funciones muy parecidas a las de una enfermera española, mientras que la enfermera rural como en Turkana tiene todo tipo de competencias llevando a cabo desde los cuidados más básicos hasta manejar el diagnóstico y tratamiento médico de enfermedades como la tuber- 
culosis (2011, Manjavacas J.), (2003, Palacios García A.L.).

La figura del clinical officer inexistente en nuestro país, no la conoemos dado que trabajan en áreas muy específicas y generalmente en grandes hospitales o grandes núcleos urbanos.

Dentro de esta compleja organización, es donde nos encontramos dos enfermeros españoles formando parte del equipo de salud de la diócesis de Lodwar prestando apoyo a los servicios sanitarios del gobierno, los cuales no son capaces de hacerse cargo de las demandas de salud de la zona donde trabajamos

\section{Las enfermeras en Turkana. Dura realidad.}

Con una visión ya más cercana al contexto en el que trabajamos, estamos en disposición de exponer la de un Enfermero de cooperación internacional en Kenia.

El trabajo en el Centro de Salud no dista mucho de la que se puede llevar a cabo en un Centro de Salud rural en España, con el único matiz de que el enfermero es el único profesional existente para prestar todo tipo de atención sanitaria. En base a ello, atiende la consulta de pacientes agudos (la mayoría de los usuarios); pacientes crónicos con patologías como epilepsia, tuberculosis, VIH; atención a la mujer embarazada; revisión del niño sano e inmunizaciones y todas las urgencias y emergencias que se generan tanto en el poblado como en toda nuestra área de actuación.

Otro aspecto a tener en cuenta es la gran carga de trabajo relacionada con la gestión y administración de recursos. Los recursos de los que se dispone son muy limitados y las posibilidades de obtener repuestos son complicadas o caras. Somos el único punto del proyecto que cuenta con vehículo propio para viajar a la capital donde se nos suministran los recursos. Los desplazamientos son muy costosos en carburante y tiempo dadas las pésimas condiciones de las infraestructuras viarias. El presupuesto, además, es muy limitado puesto que las subvenciones provienen exclusivamente de donaciones particulares y alguna subvención institucional.

Así pues, este fue el contexto y las competencias a las que nos enfrentábamos cuando llegamos. Hay que tener en cuenta que antes de nuestra llegada ya se estaba atendiendo a la población por parte de dos enfermeros españoles que trabajaron en el lugar durante dos años e iniciaron el proyecto. Sin embargo nuestra ilusión era poder desarrollar un proyecto amplio de intervención comunitaria más allá de la atención a la demanda y a la enfermedad que se venía realizando.

\section{Contextualización}

Antes de viajar por primera vez a Turkana el enfermero que iba a sustituir a los dos que llevaban dos años trabajando, autor 1, planteó al Profesor de la Universidad de Alicante Autor 2, la posibilidad de desarrollar un proyecto de intervención como los que había tenido ocasión de conocer en el transcurso de las clases de Intervención Comunitaria. El desconocimiento del contexto y de la situación real del lugar hicieron que en un primer momento se decidiera por parte de ambos planificar exclusivamente la labor de observación y contextualización. Para ello se empleó el primer mes de estancia en Turkana que sirvió también de adaptación. Durante este primer contacto se hizo un análisis del contexto, de la realidad cultural y social del mismo, se identificaron los líderes comunitarios y se valoraron comportamientos y actitudes de las personas a las que se debía atender.

Tras este primer mes, ya de vuelta en España, se llevó a cabo un análisis de la situación 
en base a los datos aportados y se empezaron a planificar los objetivos y actividades que se querían llevar a cabo cuando regresase para incorporarse definitivamente en Turkana. Inicialmente se plantearon dos ejes básicos de trabajo, el trabajo con parteras tradicionales y con los conocidos como Community Health Workers (CHW).

\section{Inicio de la intervención}

De nuevo en Turkana, convivimos los dos equipos de salud durante unos meses, los que iniciaron el proyecto y los que íbamos a reemplazarles. Tras plantear la idea que llevábamos planificada desde España de desarrollar una Intervención Comunitaria en la que se incorporase la participación activa de la población atendida, la idea no acabó de ser entendida ni asumida, por lo que se prefirió paralizar su puesta en marcha hasta que se produjese el relevo definitivo. Durante el tiempo en que permanecimos los dos equipos optamos por continuar con la importante labor de observación y de recogida de información que posteriormente fue de gran valor para el desarrollo del proyecto. Además nos encontramos con un nuevo inconveniente que hacía oportuno el retraso de su puesta en marcha y fue la ausencia temporal de la líder comunitaria identificada en la primera visita.

Con la incorporación de la nueva enfermera, Autor 3, y la marcha definitiva del anterior equipo empezamos a trabajar.

El primer paso fue reunir al grupo de las matronas tradicionales y convencerlas de la oportunidad de las reuniones ya que el equipo había cambiado y teníamos cosas nuevas que plantear. Una vez convencidas de retomar las sesiones pidieron como es costumbre aquí una gratificación económica por asistir a las reuniones. Esta situación en la que la población pide dinero o comida por asistir a reuniones o cursos en los que se les da formación suele ser su único beneficio y sigue siendo práctica habitual por parte de otras ONGs. Nuestro objetivo fue el de eliminar la dependencia y cambiar la mentalidad de que por cada esfuerzo que se hiciese tuviesen que recibir una gratificación económica aunque fuese en su propio beneficio. Esto se logró de manera muy gradual gracias a la ayuda de la líder que a su vez interactúa como traductora (2007, Carrera JM, Devesa N, Chacón D, Cararach V, Fabre E, Foradada C, Miguel J, Prats P, Rubio R.).

El siguiente paso fue con los CHW. Aunque el planteamiento inicial tuvo que ser modificado por ser excesivamente ambicioso. Por ello, tuvimos que priorizar, y se decidió empezar trabajando en la comunidad semi-nomada y estable que se encuentra dentro de nuestro área de trabajo. Para seguir avanzando tuvimos que identificar más líderes comunitarios, tarea nada sencilla, dado que estos debían reunir cualidades muy poco frecuentes en Turkana, como son hablar inglés o swahili, tener interés por la salud no solo propia sino de los demás, no pedir gratificación económica y ser un referente para el resto del pueblo. Finalmente identificamos al segundo líder, que incorporamos como miembro del equipo de salud, como traductor y como líder comunitario, es decir como Community Health Worker. Identificados ambos líderes se empezó a trabajar con ellos dos aspectos básicos, primeros auxilios e higiene básica.

Consideramos también trabajar con los maestros de la escuela primaria y de infantil. Contactamos con ambos y se habló con ellos de higiene y de cómo incorporarla en los juegos infantiles. Aquí se planteó el objetivo inicial de conseguir una ducha semanal con agua 
y jabón del cuerpo entero y un lavado de manos y cara diario antes de las dos comidas que reciben.

Con estos tres objetivos de trabajo nuestra presencia en las escuelas se consolidó semana tras semana. Se identificaron dos $\mathrm{CHW}$ más y el grupo de matronas aumentó dado que pedimos que cada una de las anteriores trajese a otra que sería su "alumna”.

Los avances empezaron a ser claramente visibles, en el grupo de matronas. Con una buena base sobre la higiene personal se logra cambiar un aspecto del post parto con mucha tradición y que genera mucho miedo como es el tocar al niño justo después del parto. Por tanto, podemos decir que conseguimos introducir el método canguro dentro de las matronas tradicionales en relativamente poco tiempo. Por otro lado el grupo de $\mathrm{CHW}$ empieza a adquirir habilidades en promoción de la salud y prevención de la enfermedad, ya que no solo son capaces de adquirirlas para ellos mismos sino que son ellos mismos los que toman la iniciativa de trasladar sus conocimientos al resto de la población, convirtiéndose en verdaderos promotores de salud.

Día a día se observan cambios dentro de la comunidad. Aunque el cambio de mentalidad que identifique el trabajo en/con la comunidad sin recibir compensación económica o en especias, aún queda lejos, se empieza a ver un cambio real. Pequeños gestos como el crear un grupo de trabajo para construir la valla del centro de salud a cambio de comida, la cual procede del gobierno y a priori debería ser repartida sin exigirles nada a cambio empiezan a ser una realidad. También en la escuela primaria los niños empiezan a no temer al agua $y$ a disfrutar con la ducha semanal. Por su parte el maestro se muestra muy motivado y ya de forma autónoma toma la iniciativa de llevar a cabo las actividades de higiene básica con los niños.

Todos estos avances son compartidos, analizados y evaluados por nosotros mismos y con el Profesor Autor 2 en España con el que mantenemos una permanente comunicación. Lo logrado nos anima y permite plantear un nuevo reto en la Intervención como fue el organizar una reunión con los miembros más representativos del poblado para llevar a cabo un grupo nominal que nos permitiese identificar necesidades sentidas por parte de la comunidad. La reunión en si fue muy útil aunque no acudieron quienes inicialmente habíamos previsto. En un primer lugar nos encontramos con los CHW y el maestro de infantil pero unos minutos más tarde empezaron a sumarse mujeres del pueblo. Con ello nos dimos cuenta de que el planteamiento para el grupo nominal lo habíamos realizado en base a premisas falsas al no identificar y valorar la diferencia conceptual que tienen en torno a la salud y la nula percepción en relación a la toma de decisiones. Esto nos hizo replantearnos los objetivos y la dinámica grupal a seguir que no a abandonar el objetivo de realizarla.

Semanas después conseguimos la ansiada reunión con los líderes políticos y las personas más representativas de la comunidad. De ella salieron grandes ideas y nuevos objetivos. Nos expresaron sus principales necesidades y aspectos que a su modo de ver les podrían ayudar en la prevención de la enfermedad. Las principales preocupaciones identificadas fueron:

- La malaria.

- La falta de agua.

- La falta de letrinas.

- La diarrea.

Cada punto fue analizado individualmente y de manera participativa. Del análisis rea- 
lizado se concluyó llevar a cabo dos nuevas intervenciones: reactivar las relaciones con la comunidad misionera para conseguir agua $y$ activar el trabajo con los CHW sobre la prevención de la diarrea.

Las intervenciones mencionadas anteriormente se concretaron finalmente en los siguientes dos objetivos: Conseguir muertes por malaria 0 y obtener una letrina por familia. A lograr a través del desarrollo de un programa de actuación estructurada y participativa.

Dentro del programa de la malaria se contempla conseguir mosquiteras a bajo precio para poder ser vendidas a la población y lograr de este modo que el mayor numero de habitantes posea una que evite las picaduras (2010, Lanaspa M., Renom M., Bassat Q.), (2004, Alonso, PL. Guinovart, C.), (2006, Sochantha, T. et al.)

Por su parte con el grupo de matronas y en la atención al embarazo en el centro de salud se plantea que toda mujer seguida por nuestro equipo durante el embarazo recibirá una mosquitera a mitad de precio y si el parto es asistido por el equipo esta no tendrá coste alguno para la mujer. Esta medida tiene una doble finalidad para las embarazadas, que puedan acceder a una mosquitera y que sean seguidas en el embarazo y atendidas en el parto.

Por último en la prevención de muertes por malaria se empezó a trabajar con los CHW y toda persona capaz de comprender como realizar el test, para que pudieran realizarlo de manera autónoma, dado que a través de la incorporación del uso de pruebas rápidas por promotores de salud y de estrategias educativas se mejora la oportunidad en el diagnóstico y tratamiento apropiado de la malaria (2013, Mendoza Nohora, M. Cucunubá Zulma, M. Aponte Samanda, N. González, E. Bernal Sindy D.), (2008, Casapia, Mar- tín et al.), (2006, Alvarado Beatriz, E. Gómez Elizabeth, M. Serra, Carvajal R. Carrasquilla, G.).

Por lo que se refiere al programa de las letrinas, el objetivo es dotar de una letrina a cada familia. El coste de crear una letrina tal y como se conceden es alto pero con una nueva técnica que uno de nuestros voluntarios conoce el coste se reduce significativamente y las ventajas se multiplican (2013, Santamaría Rodriguez, L.).

En estos momentos nos encontramos en la recopilación de datos sobre todas estas intervenciones descritas para poder realizar las evaluaciones que permitan identificar la eficacia y eficiencia de las mismas.

De todo lo trabajado podemos concluir que:

- La Cooperación internacional no puede basarse exclusivamente en la atención a la demanda y a la enfermedad ya que genera dependencia y no favorece el cambio de hábitos y conductas que se identifican como nocivas para la salud de la población atendida.

- Es fundamental conocer el contexto de actuación, en el que deben identificarse la cultura, historia, normas, valores, creencias... antes de llevar a cabo ningún tipo de intervención.

- La identificación de líderes comunitarios y de agentes de salud que se incorporen como verdaderos agentes promotores de salud es imprescindible para iniciar cualquier proyecto de intervención comunitaria que pretenda el acceso a la población y la incorporación/modificación de hábitos de conducta relacionados con la salud.

- Las enfermeras están en disposición y tienen las competencias necesarias para ofrecer una adecuada atención centrada en la par- 
ticipación comunitaria que permita identificar las necesidades sentidas de la población e iniciar el trabajo compartido para lograr la autonomía individual y colectiva suficientes para satisfacer las demandas generadas.

- Las intervenciones basadas en la participación de la población atendida son identificadas como positivas e incorporadas de manera mucho más activa y temprana por sus habitantes.

- Los costes de las intervenciones son muy bajos y los resultados que se obtienen representan una garantía de futuro en la promoción de la salud y la prevención de la enfermedad.

\section{Bibliografía}

- Alberdi Castell RM, Cuxart Ainaud N. (2005) Cuidados, enfermeras y desarrollo profesional: Una reflexión sobre las bases del ejercicio profesional. Presencia jul-dic;1(2). Recuperado de http://www.index-f.com/presencia/ n2/23articulo.php

- Alonso, P.L. Guinovart, C. (2004). Malaria: situación, instrumentos de control, recursos y soluciones. Ars Medica. Revista de Humanidades, 2:166-179.

- Alvarado Beatriz, E. y Gómez E. Serra, M. y Carvajal, R. y Carrasquilla, G. (2006). Evaluación de una estrategia educativa en malaria aplicada en localidades rurales del Pacífico colombiano. Biomédica [serie en Internet]: 26 (3): 342-352. Recuperado de: http://www. scielo.org.co/scielo.php?script=sci_arttext\&pid=S0120$41572006000300004 \& \ln \mathrm{l}=\mathrm{en}$

- Álvarez S. (2012). Una introducción a la Cooperación Internacional al Desarrollo. Redur, 10, 285-309.

- Carrera J.M. y Devesa N y Chacón D y Cararach V y Fabre E y Foradada C y Miguel J y Prats P y Rubio R. (2007). Mortalidad materna en África. Prog Obstet Ginecol, 50(7): 407-19.

- Casabona Martínez, I. Lillo Crespo, M. Mora Antón, MD. Cort Casabona, S. (2008). Visión de la enfermería en Ruanda, relato de una experiencia de docente. Cultura de los cuidados, Año XII (24): 82-7.

- Casapia, Martín et al. (2008). Mejora en el diagnóstico y tratamiento oportuno de malaria con el uso de pruebas rápidas por promotores de salud en la Amazonía peruana. Rev. perú. med. exp. salud pública, Lima, 25(4). Recuperado de: http://www.scielo.org.pe/scielo.php?script=sci_ arttext\&pid $=$ S172646342008000400003\&lo

- De Almeida Souza, A. (2009). Enfermería en el discurso politico internacional. Rev Adm Sanit, 7(2):191-206.

- Delgado Caicedo, J. y Barrera Castro, A. (2010). Subiendo al Sur: África y América Latina en las nuevas dinámicas de la cooperación Sur. Humania del Sur, 5 (8): 89-106.

- Jerez C y García E y Saz M y Tamame M.(2010). Colaborar con África: la experiencia del retorno. Index de Enfermería, 19(2-3): 111-114.

- Lanaspa M. y Renom M. y Bassat Q. (2010). La malaria en el mundo en 2010: ¿qué hay de nuevo acerca de esta vieja enfermedad? Rev Pediatr Aten Primaria [revista en la Internet]: 12(48): 685-700. Recuperado de: http://scielo.isciii.es/scielo.php?script=sci_arttext\&pid=S113976322010000600013\&lng=es

- Manjavacas J. Presencia enfermera en la acción humanitaria. Documentos Enfermería. 2011; (41):17-23.

- Mazarrasa L y Montero M.J. (2004). Cooperación internacional española en el ámbito de la salud. Gac Sanit, 18(Supl 1):214-20

- Mendoza Nohora M y Cucunubá Zulma M y Aponte Samanda, E y González Bernal S. (2013). Evaluación de campo de la Precisión de la prueba de Diagnóstico Rápido $S D$ Bioline Malaria Antígeno Pf / $P V^{*}$ en Colombia.Biomédica [serie en Internet]: 33 (4): 587-597. Recuperado de: http://www.scielo.org.co/scielo.php?script=sci_ar ttext\&pid=S012041572013000400012\&lng=en.http:// dx.doi.org/10.7705/biomedica.v33i4.1464.

- Palacios García AL. (2003) Las Enfermeras y el voluntariado. Opinión y participación de profesionales de enfermería en ONG. Index de Enfermería [Index Enferm] (edición digital): 40-41. Recuperado de: <http://0-www. index-f.com.avalos.ujaen.es/index-

- Santamaría Rodriguez, L. (2013). Proyecto de prevención de las enfermedades diarreicas en la comunidad rural de Kasenga, República Democrática del Congo (Trabajo 


\section{Cultura de las Cuidados}

Fin de Master no publicado). Universidad de Valladolid. Facultad de Filosofía y Letras. Recuperado de: http:// uvadoc.uva.es/handle/10324/4628

- Serra R. (2010). Conocer nos ayuda a comprender. Experiencia en África: estancia en un hospital de Costa de Marfil. Arch Memoria, 7(3) Recuperado de: http://www. indexf.com/memoria/7/3703.php

- Sochantha, T. et al. (2006). Mosquiteros tratados con in- secticida para la prevención de Plasmodium falciparum malaria en Camboya: un ensayo aleatorio grupal. Medicina Tropical y Salud Internacional, 11 (8): 1166-1177.

- Tassara C. (2011). Paradigmas, actores y políticas. Breve historia de la cooperación internacional al desarrollo. Revista UNAULA, 31: 41-97.

- Valtueña J.(2007). Investigación sanitaria en los países pobres. Offarm, 26(2): 27-31.

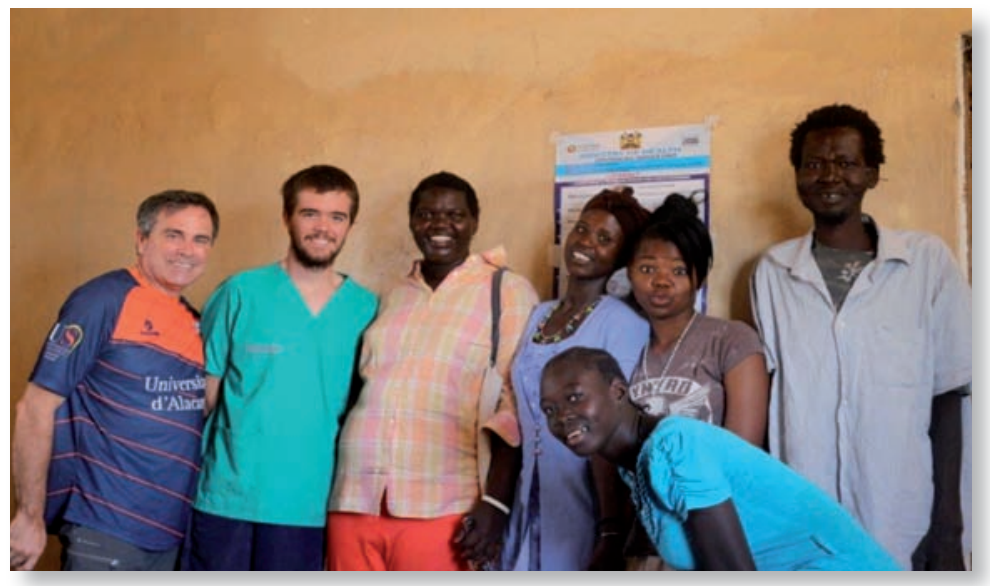




\section{Teoría y Método}

\section{O enfermeiro que atua em Unidades de Terapia} Intensiva: Perfil e Capacitação Profissional ${ }^{\star}$

\section{Las enfermeras que trabajan en unidades de cuidados intensivos: Perfil y Formación Profesional \\ The nurses who work in intensive care units: Profile and Professional Training}

Fabiana Cristina Santos ${ }^{1}$; Silvia Henriques Camelo ${ }^{2}$

*Este artigo foi extraído do Projeto de Iniciação Científica financiado pelo Conselho Nacional de Desenvolvimento Científico e Tecnológico (CNPq)-Brasília-DF- Brasil.

${ }^{1}$ Enfermeira. Mestranda do Programa de Enfermagem Fundamental da Escola de Enfermagem de Ribeirão Preto, Universidade de São Paulo, Ribeirão Preto, São Paulo, Brasil. E-mail: fabianacrs@hotmail.com

${ }^{2}$ Professora. Doutora do Departamento de Enfermagem Geral e Especializada, Escola de Enfermagem de Ribeirão Preto, Universidade de São Paulo. Ribeirão Preto, São Paulo, Brasil. E-mail: shcamelo@eerp.usp.br

Cómo citar este artículo en edición digital: Santos, F.C. y Camelo, S.H. (2015). O enfermeiro que atua em Unidades de Terapia Intensiva: Perfil e Capacitação Profissional

Cultura de los Cuidados (Edición digital), 19(43). Disponible en: <http://dx.doi.org/10.14198/cuid.2015.43.13>

Corespondencia: Fabiana Cristina dos Santos

Endereço: Júlio Volpe, 218- Ulisses Guimarães- CEP: 14177-363. Sertãozinho- São Paulo- Brasil.

Correo electrónico: fabianacrs@hotmail.com

Recibido: 20/05/2015; Aceptado: 15/09/2015

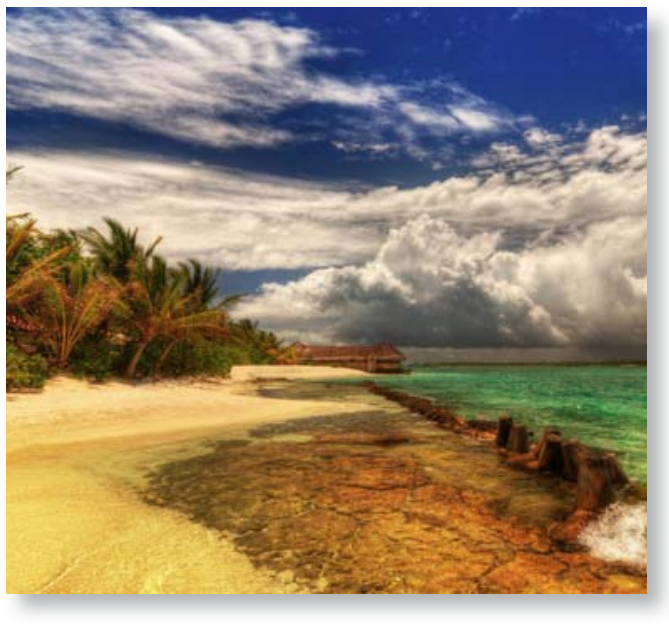

ABSTRACT

Objective: To identify the profile of the professional nurse working in ICU.

Methodology: It is an integrative review and data collection was performed in four electronic databases from January to June 2012. We selected 21 articles, published from 2008 to 2011. We identified two categories related to nurse profile: Social Profile and academic background of the ICU nurses and nurse's training to work in intensive care units.

Results: The results showed female nurses, young, formed of time ranging from one to 25 years. Identifies the need for professional development with technical and scientific update through training, specialization and graduate.

Conclusion: The study should elicit reflection of nurses and managers of health services as the appropriate profile for the development activities in highly complex units.

Keywords: Nurses, Hospital, Intensive Care Units, Human Resources Formation. 


\section{RESUMEN}

Objetivo: Identificar el perfil de la enfermera profesional que trabaja en la UCI.

Metodología: Se trata de una revisión y recopilación de datos de integración se realizó en cuatro bases de datos de enero a junio de 2012. Se seleccionaron 21 artículos, publicados entre 2008 y 2011. Se identificaron dos categorías relacionadas con el perfil de la enfermera: Perfil Social y formación académica de las enfermeras de la UCI y de entrenamiento de enfermería para trabajar en unidades de cuidados intensivos.

Resultados: Los resultados mostraron enfermeras, jóvenes, formados de tiempo que va de uno a 25 años. Identifica la necesidad de desarrollo profesional con la actualización técnica y científica a través de la formación, especialización y posgrado.

Conclusión: El estudio debería provocar la reflexión de los enfermeros y gestores de los servicios de salud como el perfil adecuado para las actividades de desarrollo en unidades de alta complejidad.

Palabras clave: Enfermeras, Hospitales, unidades de cuidados intensivos y la capacitación de los recursos humanos.

\section{RESUMO}

Objetivo: Identificar o perfil do profissional enfermeiro que atua em UTI.

Metodologia: É uma revisão integrativa e a coleta de dados foi realizada em quatro bases eletrônicas no período de janeiro a junho de 2012. Foram selecionados 21 artigos, publicados no período de 2008 a 2011. Identificamos duas categorias relacionadas ao perfil do enfermeiro: Perfil social e formação acadêmica do enfermeiro de UTI e Capacitação do Enfermeiro para atuar em unidades de terapia intensiva.
Resultados: Os resultados mostraram enfermeiros do sexo feminino, jovens, tempo de formado variando entre um e 25 anos. Identifica-se a necessidade do desenvolvimento profissional com atualização técnico-científica por meio de treinamentos, especializações e pós-graduação.

Conclusão: $\mathrm{O}$ estudo deve provocar reflexão dos enfermeiros e gestores dos serviços de saúde quanto ao perfil adequado ao desenvolvimento de atividades em unidades de alta complexidade.

Palavras chave: Enfermeiros, Hospitais, Unidades de terapia intensiva e Formação de recursos humanos.

\section{INTRODUÇÃO}

Frente à evolução e a globalização tecnológica, os profissionais enfrentam grandes desafios no ambiente de trabalho, como lidar com novos conhecimentos e habilidades; adaptação a diferentes formas de trabalho; exigências cada vez maiores à alta produtividade e máxima qualidade dos produtos/serviços em tempo reduzido e maior competitividade no mercado de trabalho. Dessa forma, as instituições hospitalares exigem um perfil de profissional diferenciado que corresponda a essas exigências, provocando transformações das práticas assistenciais e gerenciais.

No âmbito hospitalar, o processo de cuidar e o de gerenciar podem ser considerados como as principais dimensões do trabalho do enfermeiro. Neste contexto, a Unidade de Terapia Intensiva (UTI) se caracteriza por um cenário de inovação e o atendimento especializado de enfermagem a pacientes de alta complexidade, potencializa a necessidade constante de um profissional com determinado perfil para atuar nesta área, harmonizando o serviço entre tec- 
nologia e assistência.

Ao cuidar de pacientes em uma UTI, a equipe de enfermagem defronta-se com o binômio vida e morte, devido às características tecnológicas e científicas deste local, faz-se necessário muitas vezes a priorização de procedimentos técnicos de alta complexidade, fundamental para manter a vida do ser humano (Martins, Robazzi, Marziale, Garanhani \& Haddad, 2009).

$\mathrm{O}$ enfermeiro, independentemente do diagnóstico, deve cuidar de todos doentes, utilizando uma abordagem que lhes assegure integridade, sendo que as exigências do cuidado em uma UTI requerem conhecimentos científicos diferenciados e altamente qualificado sobre as técnicas e o manuseio dos equipamentos ali disponíveis (Silva \& Cruz, 2008), para que possa prestar uma assistência segura, assim como capacitar sua equipe quanto à realização dos procedimentos de forma correta.

O papel do enfermeiro em uma UTI consiste em obter a história do paciente, fazer exame físico, executar ações complexas de enfermagem, ensinando e orientando os enfermos para a continuidade do tratamento e medidas. Devem ainda, aliar à fundamentação teórica, a capacidade de co-liderança, o trabalho, o discernimento, a iniciativa, a habilidade de ensino, a maturidade e a estabilidade emocional (Morton, Fontaine, Hudak \& Gallo, 2007).

Frente a estas considerações, destacamos que o enfermeiro intensivista necessita de um perfil que lhe permita desenvolver suas funções eficazmente, aliando conhecimento técnico científico, humanização e individualização do cuidado proporcionando qualidade na assistência prestada.

Nesse sentido, este estudo apresenta os seguintes questionamentos: Quem são os enfermeiros que atuam em UTI(s)? Qual o preparo e/ou formação acadêmica destes profissionais para executar as tarefas preconizadas nestas unidades?

Identificar o perfil deste trabalhador deve contribuir para provocar reflexão dos futuros profissionais quanto ao seu preparo para atuar nesta área, bem como dos gestores dos serviços e dos centros formadores sobre o seu papel na formação e aprimoramento destes trabalhadores para uma assistência de alta complexidade.

Assim, este estudo teve o objetivo de identificar o perfil sociodemográfico e profissional do enfermeiro que atua em UTI, segundo as variáveis: sexo, idade, formação acadêmica, tempo de trabalho e especialização e/ou capacitação em alta complexidade.

\section{METODOLOGIA}

Para o alcance do nosso objetivo, optamos pelo método da revisão integrativa, visto que ele possibilita sumarizar as pesquisas já concluídas e obter conclusões a partir de um tema de interesse. Ela é a mais ampla abordagem metodológica referente às revisões, permitindo a inclusão de estudos experimentais e não experimentais para uma compreensão completa do fenômeno analisado, combina dados da literatura teórica e empírica, (Whittemore \& Knafl, 2005) além de incluir análise de pesquisas relevantes que dão suporte para a tomada de decisão e a melhoria da prática clínica (Benefield, 2003; Silveira, 2005), possibilitando a síntese do estado do conhecimento de um determinado assunto, além de apontar lacunas do conhecimento que precisam ser preenchidas com a realização de novos estudos (Polit \& Beck, 2006).

A estratégia de busca utilizada foi à consulta às bases eletrônicas: Medical Literature Analysis and Retrieval System Online- Medline, Literatura Latino-Americana e do caribe 
em Ciências da saúde- Lilacs, Scientific eletronic library online- Scielo e Banco de dados bibliográficos especializada na área de Enfermagem do Brasil- BDENF, sendo a coleta realizada no período de outubro a dezembro de 2013.

Para o levantamento bibliográfico dos artigos, utilizamos os Descritores em Ciências da Saúde (Decs): Enfermeiros, Hospitais, Unidades de terapia intensiva e Formação de recursos humanos.

Os critérios utilizados para a seleção de estudos foram: artigos publicados em periódicos nacionais e internacionais, em português, inglês e espanhol, nos últimos cinco anos, disponíveis na integra nas bases de dados selecionadas que abordassem a temática investigada. Foram excluídos trabalhos como teses, dissertações, livros e capítulos de livros que objetivou eliminar publicações que não passaram por rigorosa avaliação e revisão por pares, de modo a selecionar apenas a literatura indexada.

\section{RESULTADOS e DISCUSSÕES}

\section{Características dos artigos}

Foram encontrados 46 estudos, dos quais foram selecionados 24 artigos que corresponderam às questões norteadoras e objetivos propostos, sendo 21 (87,5\%) em português, dois $(8,33 \%)$ em inglês e um $(4,16 \%)$ em espanhol, publicados no período entre 2009 a 2013, conforme a Quadro1.

Os Descritores mais utilizados pelos autores dos estudos foram: Unidades de Terapia Intensiva, Enfermagem e Estresse. Em relação aos delineamentos de pesquisa sete $(29,16 \%)$ estudos utilizaram a abordagem metodológica qualitativa e 17 (70,83\%) quantitativos. Neste sentido, embora haja uma maior quantidade de estudos quantitativos, o objeto de pesquisa ora analisado pode ser estudado por diferentes delineamentos metodológicos.

Após a coleta de dados foi realizada uma análise temática onde podemos depreender duas categorias relacionadas ao perfil do enfermeiro: Perfil social e formação acadêmica do enfermeiro que atua em UTI e Capacitação e preparo do Enfermeiro para atuar em UTI.

Além disto, analisando os dados dos artigos, depreendemos outra categoria relacionada a situações estressantes envolvendo enfermeiros intensivistas a qual denominamos: Fatores de desgaste no trabalho do enfermeiro que atua em UTI.

\section{Perfil sociodemográfico e formação acadê- mica do enfermeiro que atua em UTI}

Os dados mostraram enfermeiros atuando em UTI(s) predominantemente do sexo feminino (Biondo, Silva \& Secco, 2009; Faria \& Cassiani, 2011; Fogaça, Carvalho \& Martins, 2010; Silva \& Ferreira, 2011), podendo observar que a mulher, enquanto enfermeira representa a maioria na prestação de cuidados no ambiente hospitalar, aspecto que reflete a tradição cultural, ressaltando que a questão do gênero está associada à atribuição de tarefas e aos papéis, particularmente na profissão do enfermeiro (Almeida et al., 2004; Castro \& Castro, 2003; Gardenal, Parreira, Almeida \& Pereira, 2002; Pinho, 2002).

Os resultados mostraram enfermeiros na faixa etária entre 23 e 58 anos (Claro, Krocockz, Toffolleto \& Padilha, 2011; Fogaça, Werther \& Martins, 2010; Martins, Robazzi \& Garanhani, 2009; Prebystero, Costa \& Santos, 2010; Silva \& Ferreira, 2011; Silva, Valença \& Germano, 2010), sendo que 28,5\% dos artigos selecionados os trabalhadores apresentavam idade inferior a 40 anos, demonstrando uma população jovem, com possibilidade de am- 
pliação do conhecimento científico e técnico em alta complexidade. A presença de enfermeiros abaixo de 40 anos, atuando em UTI, pode estar relacionado ao indício de que esses profissionais, quando atingem essa idade, são remanejados para outros setores, procuram cargos administrativos, buscam a área de ensino ou até mesmo desistem da profissão (Guerrer \& Bianchi, 2011) demonstrando uma tendência pela procura de áreas de cuidados críticos, em busca de experiência profissional.

Analisando o tempo de formação, autores revelam entre um e 25 anos, o que demonstra que neste setor há possibilidade de encontrar tanto enfermeiros com pouca experiência para lidar com situações específicas e cuidados críticos, quanto aquele com vivência na profissão (Belo, Silva, Nogueira, Mizoguti \& Ventura, 2012; Claro, Krocockz, Toffolleto \& Padilha, 2011), o que possibilita o desenvolvimento de habilidades, segurança e experiência para tomada de decisões.

Quanto ao preparo acadêmico dos enfermeiros para atuar na UTI, alguns temas são abordados durante a graduação como a competência da liderança em enfermagem, que pode auxiliar o exercício deste profissional em cuidados críticos (Balsanelli, Cunha \& Whitaker, 2009). Entretanto, observou-se a insatisfação de enfermeiros em relação à capacitação em temas como farmacologia, durante o curso de graduação (Faria \& Cassiani, 2011), prejudicando a sua atuação junto ao paciente, potencializando situações de risco e erros de medicações.

Os currículos de graduação em enfermagem apresentam de uma forma geral que o cuidar é uma das funções do enfermeiro. Nas UTI(s), ambiente altamente especializado, o cuidado direto ao paciente grave está inclusive prevista na lei do exercício profissional como

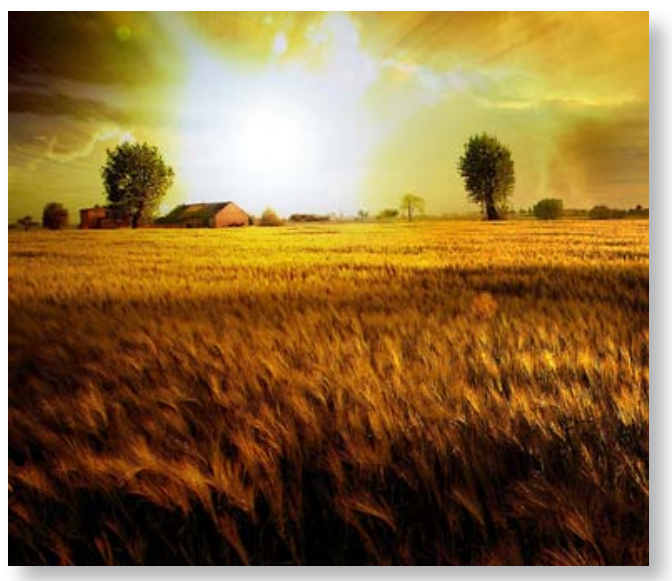

atividade privativa do enfermeiro. Portanto, este profissional deve ter conhecimento sobre recursos tecnológicos como o de especialidades clínicas dos clientes deste setor.

Os cursos de graduação em enfermagem precisam se envolver cada vez mais no processo de formação de profissionais que atendem as especialidades da prática, principalmente no que se refere à aplicação da tecnologia no cuidado e o seu domínio, como ocorre nas UTI(s) (Silva \& Ferreira, 2011).

E em relação ao tempo de trabalho na UTI, vários artigos relataram a experiência do enfermeiro no setor por mais de quatro anos (Balsanelli \& Cunha, 2013; Cardoso, Esteche, Oliveira, Sherlock \& Cardoso, 2010; Costa, Figueiredo \& Schaurich, 2009; Fogaça, Werther \& Martins, 2010). Aqueles profissionais com menor experiência têm chances de discutir suas dificuldades/desafios com aqueles com maior experiência (Preto \& Pedrão, 2009). Estes, por sua vez possuem visão mais apurada da situação que lhe possibilita resolver problemas de uma forma diferente do iniciante.

Para que os enfermeiros com menor experiência profissional preencham os requisitos para trabalhar em UTI(s), é necessário discernimento, responsabilidade e iniciativa, pois, é condição fundamental para os trabalhadores 
em UTI(s) ter no mínimo um ano de atividade contínua nestas unidades (Martins, Robazzi \& Garanhani, 2009), em busca de experiência profissional.

A experiência profissional, o envolvimento institucional e a estabilidade adquirida pelo tempo de serviço são fatores que estimulam nos profissionais a permanência em uma organização, e ainda, o tempo de trabalho em uma instituição pode estar associado à proposta de trabalho da instituição e satisfação individual (Martins, Kobayashi, Ayoub \& Leite, 2006).

$\mathrm{O}$ enfermeiro enquanto coordenador da assistência de enfermagem é esperado, no seu dia-a-dia de trabalho comportamentos que demonstrem as competências necessárias para o desempenho de suas funções (Soares, 2011) dentre elas, destacamos a competência da liderança como organização da assistência prestada ao paciente crítico.

\section{Capacitação profissional do enfermeiro para atuar em Unidades de Terapia Intensiva}

A análise dos artigos possibilitou verificar a importância da capacitação profissional do enfermeiro para atuar em unidades de alta complexidade, visto a necessidade de rever e atualizar os seus conhecimentos a fim de acompanhar as constantes mudanças e exigências do mercado de trabalho neste setor $(\mathrm{Bu}-$ chi \& Mira, 2010; Camelo, Silva, Laus \& Dias, 2013; Preto \& Pedrão, 2009).

A capacitação é um processo que representa para o profissional o domínio de conhecimentos específicos que resultam de formação, desenvolvimento de habilidades, experiência para que possam exercer determinada função, pois, quanto melhor o profissional for capacitado, maior é a probabilidade de serem competentes no exercício de suas funções (Martins, Kobayashi, Ayoub \& Leite, 2006). Em unidade de alta complexidade, esta situação torna-se relevante, pois, além da necessidade do uso de tecnologias emergentes, o enfermeiro deve conhecer estratégias eficazes para uma assistência de qualidade. Neste sentido, a busca pela capacitação deve acontecer naturalmente e constantemente.

O enfermeiro que atua em UTI é o gerente do cuidado prestado ao paciente grave e para desempenhar esse papel, é necessária sua atualização técnico-científica, ética e política, bem como, seu comprometimento e responsabilidade, além de ser negociador e líder (Buchi \& Mira, 2010).

A atualização técnico-científica de um profissional pode ocorrer por meio de treinamentos em serviço (Buchi \& Mira, 2010), cursos de pós- graduação lato sensu (Almeida \& Lamas, 2013; Balsanelli, Cunha \& Whitaker, 2009; Biondo, Silva \& Secco, 2009; Cardoso, Esteche, Oliveira, Sherlock \& Cardoso, 2010; Fogaça, Carvalho \& Martins, 2010) e pós- graduação stricto sensu (Bucchi \& Mira, 2010; Chaves \& Massarollo, 2009; Guerrer \& Bianchi, 2011; Martins, Robazzi \& Garanhani, 2009; Polit \& Beck, 2006;).

Dessa forma, o próprio enfermeiro ou a instituição deve buscar meio ou estratégias para o aprimoramento profissional deste trabalhador. Observou-se que os enfermeiros intensivistas necessitam de treinamentos logo na admissão da unidade, pois, responsabilizam-se pela prestação de cuidados complexos, pela dinamicidade e monitoramento das informações que determinam e alteram a terapêutica. Para alcançar um perfil de enfermeiro desejado algumas metas devem ser atingidas, tais como a prestação da assistência de enfermagem fundamentada nos princípios éticos e legais e com autonomia, a realização de procedimentos essenciais ao paciente da UTI nos primeiros três 
meses, e nos três meses subsequentes, a realização de procedimentos especializados, conforme rotinas na Instituição (Buchi \& Mira, 2010). Além disso, destacam-se cursos de especialização (Balsanelli, Cunha \& Whitaker, 2009; Fogaça, Werther, \& Martins, 2010) como uma das estratégias utilizadas pelos enfermeiros sendo que os cursos oferecem atualização e aprimoramento que permite ao profissional enfermeiro tornar-se competente (Buchi, \& Mira, 2010) e nesse sentido, o desenvolvimento profissional com aquisição de competências e habilidades para atuar junto ao paciente gravemente enfermo, contribuindo positivamente na melhoria da prática assistencial.

A pós-graduação stricto sensu é outro recurso procurado pelos enfermeiros (Bucchi \& Mira, 2010; Guerrer \& Bianchi, 2011; Martins, Robazzi \& Garanhani, 2009; Polit \& Beck, 2006; Soares, 2011), com possibilidade de formação específica na área e experiência significativa dos enfermeiros no campo de atuação para o ensino e a pesquisa.

A frequência dos enfermeiros que atuam em UTI em cursos de pós-graduação tem como consequência dois pontos positivos, primeiro é o estímulo oferecido por esses cursos na elaboração de pesquisas, geralmente derivadas da vivência prática; segundo, por atuarem na área assistencial, a possibilidade de implementação dos resultados obtidos é maior (Chaves \& Massarollo, 2009).

Esse perfil de profissional representa algo importante na assistência de pacientes críticos, já que são necessárias habilidades específicas destes trabalhadores para atuar em UTI(s).

Considerando as características do trabalho de enfermagem executado nas UTI(s), e o perfil de profissional que se faz necessário, leva-nos a pensar sobre possíveis situações complexas e desgastante vivenciadas diariamente por estes trabalhadores, tanto em relação a complexidade da assistência prestada, quanto, no que diz respeito a sua capacitação constante. E analisando os artigos selecionados podemos verificar a existência deste fato, quando se identifica fatores de desgaste envolvendo o enfermeiro que atua em UTI, apresentados a seguir.

\section{Fatores de desgaste no trabalho do enfermei- ro que atua em UTI}

Analisando os artigos selecionados podemos verificar fatores desgastantes nas condições de trabalho relacionadas ao enfermeiro que atua em cuidados críticos. Entre eles estão a insatisfação com o trabalho associada com a sua atividade. Cabe destacar que as funções que executam diariamente passam a serem fontes de estresse, interferindo em sua saúde e qualidade de vida, visto que o enfermeiro assume uma postura de alerta constante devido às características emergenciais próprias desse setor (Monte, Lima, Neves, Studart \& Dantas, 2013; Moreira, Queiroz, Araújo, Araújo \& Caetano, 2009).

A sobrecarga de trabalho exigida dos enfermeiros, o esforço físico para a realização de tarefas, muitas vezes de outros profissionais, relacionado à demanda do serviço e o dimensionamento de profissionais inadequado, tem efeito significativo no trabalho (Coutinho \& Rolim, 2005). A demanda desordenada e excessiva de atividades gera novos estímulos, contribuindo para o surgimento de estressores que agridem a saúde do profissional.

$\mathrm{O}$ ambiente de alta complexidade como o caso da UTI influencia na percepção da qualidade do cuidado, na insatisfação do trabalho e na intenção de deixar o emprego pelos enfermeiros, quando mediadas pelo sentimento de exaustão emocional causada pelo ambiente de trabalho (Panunto \& Guirardello, 2013). 
Outro fator que pode levar ao gasto de energia por parte do enfermeiro é o relacionamento dentro da equipe de enfermagem entre superiores, colegas e pacientes. A busca do equilíbrio entre as relações desenvolvidas pode vir a ser um dos fatores que propicie a diminuição das situações de estresse (Sanguiolliano, 2004). No mundo do trabalho a relação entre auxiliares, técnicos de enfermagem e o enfermeiro deve ser aprimorada e contribuírem em satisfação e bem-estar psicológico no ambiente de trabalho.

Para enfermeiros que atuam em situações críticas, apesar de sua habilidade e efetiva atuação frente à instabilidade da situação dos pacientes graves, as condições de trabalho e atividades relacionadas à administração de pessoal, entre outros, são situações consideradas estressantes (Dias, Boas, Dias \& Barcellos, 2005).

A proximidade com a dor e o sofrimento parece provocar nos enfermeiros uma empatia para o vínculo terapêutico, o que proporciona uma melhor assistência de enfermagem, mas ao mesmo tempo um desgaste emocional íntimo ligado à dificuldade no lidar com a terminalidade (Martins, Kobayashi, Ayoub \& Leite, 2006).

Quando o enfermeiro de depara com evolução negativa do diagnóstico de um paciente crítico e o envolvimento com este paciente e seus familiares (Ferreira \& Martino, 2006) pode trazer para o enfermeiro dificuldades psicossociais em sua vida pessoal e profissional, portanto uma das alternativas para minimizar este desgaste do profissional seriam o suporte e acompanhamento psicológico.

A presença contínua de insatisfação do enfermeiro com a sua atividade profissional, associada aos agentes estressores, sugere o quadro de Burnout, caracterizado como au- mento do grau de insatisfação, interferindo em sua saúde e qualidade de vida (Martins, 2003; Martins, Robazzi \& Garanhani, 2009; Menzani \& Bianchi, 2005; Shimizu \& Ciampone, 2002).

Diante dos achados, a UTI mostrou-se um ambiente estressante para os profissionais da saúde, em especial para o enfermeiro, pela prestação de cuidados ao paciente crítico que exigem responsabilidade e qualificação profissional, acarretando em desgaste físico e emocional. É preciso, entretanto, mobilizar estes profissionais e instituições de saúde para a implementação de estratégias individuais e em grupo, pois, o estresse afeta a vida pessoal e o desempenho profissional dos enfermeiros (Inoue, Versa, Murassaki, Melo \& Matsuda, 2013).

A modificação na vida diária, como realizar atividades de lazer e praticar exercícios físicos são mecanismo de enfrentamento do estresse que o enfermeiro consegue amenizar. A atividade física é a forma primária para combater os efeitos nocivos do estresse e gera sensação de bem-estar físico e relaxamento (Menzani \& Bianchi, 2005).

O desenvolvimento de uma atividade física, a manutenção de uma dieta saudável, repouso e manter as atividades sociais são alguns dos fatores necessários para o controle e o enfrentamento do estresse (Martins, 2003).

\section{CONSIDERAÇÕES FINAIS}

Os resultados mostraram enfermeiros de UTI predominantemente do sexo feminino, jovens, tempo de formado variando entre um e 25 anos e experiência na área superior a quatro anos, com preparo acadêmico insuficiente durante a graduação.

No ambiente hospitalar especializado da terapia intensiva, identifica-se a necessidade e a busca pelo desenvolvimento profissional 
com atualização técnico-científica por meio de treinamentos em serviços, especialização e cursos de pós- graduação.

O estabelecimento do perfil do enfermeiro que atua em UTI requer o reconhecimento de que o paciente crítico tem o direito ao cuidado especializado tendo o enfermeiro que apresentar determinadas características e aptidões para que haja o comprometimento com o paciente, no sentido de atender aos requisitos do cuidado que se processa neste setor, impactando assim qualidade da assistência prestada.

A experiência profissional bem como a qualificação especializada são aspectos que devem ser repensados no atual contexto de contratação dos profissionais enfermeiros para atuarem em setores de alta complexidade.

Entendemos a limitação de estudos desta natureza, entretanto, ressaltamos que esta investigação deve provocar a reflexão dos gestores, centros formadores e futuros enfermeiros quanto ao perfil necessário para o desenvolvimento de atividades de alta complexidade. Outros estudos devem ser realizados no sentido de identificar estratégias da gerência das UTI(s) para a qualificação destes profissionais.

\section{REFERÊNCIAS}

- Almeida, M.C.P., et al. (2004). Perfil da demanda dos alunos da pós-graduação stricto sensu da Escola de Enfermagem de Ribeirão Preto da Universidade de São Paulo. Rev. Latino- Am Enfermagem, 12(2), 153-61. Recuperado de: http://www.scielo.br/scielo.php?script=sci_arttex t\&pid=S0104-11692004000200002.

- Almeida, T.C.F., \& Lamas, J.L.T. (2013). Enfermeiros de Unidade de Terapia Intensiva adulto: avaliação sobre medida direta e indireta da pressão arterial. Rev. esc. enferm. USP, 47(2), 369-376. Recuperado de: http://www. scielo.br/pdf/reeusp/v47n2/14.pdf.

-Balsanelli, A.P., \& Cunha, I.C.K.O. (2013) O ambiente de trabalho em unidades de terapia intensiva privadas e públicas. Acta paul. enferm, 26(6), 561-568. Recuperado de: http://www.scielo.br/scielo.php?pid=S0103$-21002013000600009 \&$ script $=$ sci_arttext.

- Balsanelli, A.P, Cunha, I.C.K.O., \& Whitaker, I.Y. (2009). Estilos de liderança de enfermeiros em unidade de terapia intensiva: associação com perfil pessoal, profissional e carga de trabalho. Rev. Latino-Am Enfermagem, 17(1), 28-33. Recuperado de: http://www.scielo.br/ scielo.php?pid $=$ S010411692009000100005\&script $=$ s ci_abstract\&tlng=pt.

- Belo, M.P.M, Silva, R.A.M.C, Nogueira, I.L.M, Mizoguti, D.P., \& Ventura, C.M.U. (2012). Conhecimento de enfermeiros de Neonatologia acerca do Cateter Venoso Central de Inserção Periférica. Rev. bras. enferm, 65(1), 42-48. Recuperado de: http:// www.scielo.br/scielo.php?script $=$ sci_arttext\&pid $=$ S0034-71672012000100006.

- Benefield, L.E. (2003). Implementing, evidence-based practice in home care. Home Healthc nurse, 21(12), 80411. Recuperado de: http://www.ncbi.nlm.nih.gov/pubmed/14665967.

- Biondo, C.A, Silva, M.J.P., \& Secco, L.M.D. (2009). Dysthanasia, euthanasia, orthotanasia: the perceptions of nurses working in intensive care units and care implications. Rev. Latino- Am Enfermagem, 17(5), 613-619. Recuperado de: http://www.scielo.br/scielo.php?script=sci_arttex t\&pid=S0104-11692009000500003.

- Bucchi, S.M., \& Mira, V.L. (2010) Reelaboração do treinamento admissional de enfermeiros de Unidade de Terapia Intensiva. Rev. Esc. Enferm. USP, 44(4), 1003-10. Recuperado de: http://www.scielo.br/scielo.php?script=sci_ arttext\&pid=S0080-62342010000400021.

- Camelo, S.H.H, Silva, V.L.S, Laus, A.M., \& Chaves, L.D.P. (2013). Perfil profissional de enfermeiros atuantes em unidades de terapia intensiva de um hospital de ensino. Cienc. enferm, 19(3), 51-62. Recuperado de: http://www.scielo.cl/scielo.php?script=sci_ arttext\&pid=S0717-95532013000300006\&lng=pt\&nrm $=\mathrm{iso} \& \operatorname{lng}=\mathrm{pt}$.

- Cardoso, S.N.M, Esteche, C.M.G.E, Oliveira, M.M.C, Sherlock, M.S.M, \& Cardoso, MVLML. (2010). Desafios e estratégias das enfermeiras na unidade de terapia 
intensiva neonatal. Rev Rene, 11(4), 76-84. Recuperado de: http://www.revistarene.ufc.br/revista/index.php/revista/article/view/426.

- Castro, J.L, \& Castro, J.L. (2003). Estudo do perfil dos gerentes dos hospitais públicos do Rio Grande do Norte. En: Ministério da Saúde (BR). Observatório de Recursos Humanos em Saúde no Brasil: estudos e analises. Rio de Janeiro: FIOCRUZ. Recuperado de: http://www.obsnetims.org.br/uploaded/6_10_2014_0_livro_Observatorio_de_recursos_humanos_no_Brasil.pdf.

- Chaves, A.A.B, \& Massarollo, M.C.K.B. (2009). Percepção de enfermeiros sobre dilemas éticos relacionados a pacientes terminais em Unidades de Terapia Intensiva. Rev. Esc. Enferm. USP, 43(1), 30-6. Recuperado de: http://www.scielo.br/scielo.php?script=sci_arttext\&pid $=$ S0080-62342009000100004.

- Claro, C.M, Krocockz, D.V.C, Toffolleto, M.C., \& Padilha, K.G. (2011). Eventos adversos em Unidade de Terapia Intensiva: percepção dos enfermeiros sobre a cultura não punitiva. Rev. Esc. Enferm. USP, 45(1), 167-72. Recuperado de: http://www.scielo.br/scielo.php?script=sci_artt ext\&pid=S0080-62342011000100023.

- Costa, S.C, Figueiredo, M.R.B, \& Schaurich, D. (2009). Humanização em Unidade de Terapia Intensiva Adulto (UTI): compreensões da equipe de enfermagem. Interface- Comunic., Saude, Educ, 13(1), 571-80. Recuperado em: http://www.scielo.br/scielo.php?pid=S141432832009000500009\&script=sci_arttext.

- Coutinho, R.L.C., \& Rolim, K.M.C. (2005). Caracterização de enfermeiros e da prática assistencial em unidade de terapia intensiva neonatal. Rev Rene, 6(3), 78-86. Recuperado de: http://www.revistarene.ufc.br/revista/ index.php/revista/article/view/944.

- Dias, S.M.M., Boas, A.A.V., Dias, M.R.G., \& Barcellos, K.C.P. (Agosto, 2005). Fatores desmotivacionais ocasionados pelo estresse de enfermeiros em ambiente hospitalar. En: VIII SEMEAD Seminário em Administração FEA-USP. Faculdade de Economia, Administração e Contabilidade, Ribeirão Preto, Brasil. Recuperado de: htpp://www.ead.fea.usp.br.

- Faria, L.M.P., \& Cassiani, S.H.B. (2011). Interação medicamentosa: conhecimento de enfermeiros das unidades de terapia intensiva. Acta paul. enferm, 24(2), 264-70. Recuperado de: http://www.scielo.br/pdf/ape/v24n2/17. pdf.

- Ferreira, LR.C., \& Martino, M.M.F. (2006). O estresse do enfermeiro: análise das publicações sobre o tema. Rev Ciênc Méd Campinas, 15(3), 241-8. Recuperado de: http://www.puc-campinas.edu.br/centros/ccv/revcienciasmedicas/portugues/informacao.asp?Protocolo $=342$.

- Fogaça, M.C, Carvalho, W.B., \& Martins, L.A.N. (2010). Demandas do trabalho e controle: implicações em unidades de terapia intensiva pediátrica e neonatal. Rev Bras Enferm, 63(4), 529-32. Recuperado de: http://www.scielo.br/scielo.php?script=sci_arttext\&pid $=$ S0034-71672010000400005.

- Fogaça, M.C, Werther, B.C., \& Martins, L.A.N. (2010). Estudo preliminar sobre a qualidade de vida de médicos e enfermeiros intensivistas pediátricos e neonatais. Rev. Esc. Enferm. USP, 44(3), 708-12. Recuperado de: http://www.scielo.br/scielo.php?script=sci_arttext\&pid $=$ S0080-62342010000300022.

- Gardenal, C.L.C, Parreira, I, Almeida, J.M., \& Pereira, V.M. (2002). Perfil das enfermeiras que atuam na assistência à gestante, parturiente e puérpera, em instituições de Sorocaba/SP (1999). Rev. Latino-Am Enfermagem, 10(4), 478-84. Recuperado de: http://www.scielo.br/ scielo.php?pid=S0104-11692002000400003\&script $=$ sci_ arttext.

- Guerrer, F.J.L., \& Bianchi, E.R.F. (2011). Estrés de los enfermeros de UCI em Brasil. Enfermería Global, 10(2), 1-9. Recuperado de: http://revistas.um.es/eglobal/article/view/121791/114441.

- Inoue, K.C, Versa, G.L.G.S, Murassaki, A.C.Y, Melo, \& Matsuda, L.M. (2013). Estresse ocupacional em enfermeiros intensivistas que prestam cuidados diretos ao paciente crítico. Rev. bras. enferm, 66(5), 722-729. Recuperado de: http://www.scielo.br/scielo. php?pid=S0034-71672013000500013\&script $=$ sci_arttext.

- Martins, M.C. (2003). Situações indutoras de stress no trabalho dos enfermeiros em ambiente hospitalar. Millenium-Revista do ISPV, 28. Recuperado de: http://www. ipv.pt/millenium/Millenium28/18.htm. 
- Martins, C, Kobayashi, R.M, Ayoub, A.C., \& Leite, M.M.J. (2006). Perfil do enfermeiro e necessidades de desenvolvimento de competência profissional. Texto Contexto Enferm, 15(3), 472-78. Recuperado de: http://www.scielo.br/ scielo.php?pid=s0104-07072006000300012\&script $=$ sci_ arttext.

- Martins, J.T, Robazzi, M.L.C.C., Marziale, M.H.P., Garanhani M.L., \& Haddad, M.C.L. (2009). Significados do gerenciamento de unidade de terapia intensiva para o enfermeiro. Rev Gaúcha Enferm, 30(1), 113-9. Recuperado de: http://www.seer.ufrgs.br/RevistaGauchadeEnfermagem/article/view/8883.

- Martins, J.T; Robazzi, M.L.C.C., \& Garanhani, M.L. (2009). Sentimentos de prazer entre enfermeiros de unidades de terapia intensiva. Cienc. Enferm, 15(3), 45-53. Recuperado de: http://www.scielo.cl/pdf/cienf/v15n3/ art_06.pdf.

- Menzani, G., \& Bianchi, E.R.F. (2005). Determinação dos estressores dos enfermeiros atuantes em unidades de internação. Enferm Global, 4(2), 1-09. Recuperado de: http://revistas.um.es/eglobal/article/view/461/490.

- Monte, P.F, Lima, F.E.T, Neves, F.M.O, Studart, R.M.B, \& Dantas, R.T. (2013). Estresse dos profissionais enfermeiros que atuam na unidade de terapia intensiva. Acta paul. enferm, 26(5), 421-427. Recuperado de: http://www.scielo.br/scielo.php?pid=S0103$-21002013000500004 \&$ script $=$ sci_arttext.

Moreira, R.A.M, Queiroz, T.A, Araújo, M.F.M, Araújo, T.M, \& Caetano, J.A. (2009). Condutas de enfermeiros no tratamento de feridas numa Unidade de Terapia Intensiva. Rev Rene, 10(3), 83-89. Recuperado de: http://www.revistarene.ufc.br/ revista/index.php/revista/article/view/538.

- Morton, P.G., Fontaine, D.K., Hudak, C.M., y Gallo, B.M. (2007). Cuidados críticos de enfermagem: uma abordagem holística. Rio de Janeiro: Guanabara Koogan.

- Panunto, M.R., \& Guirardello, E.B. (2013). Professional nursing practice: environment and emotional exhaustion among intensive care nurses. Rev. LatinoAm. Enfermagem, 21(3), 765-772. Recuperado de: http://www.scielo.br/scielo.php?script=sci_arttext\&pid $=$ S0104-11692013000300765.
- Pinho, D.L.M. (2002). O trabalho da enfermagem e a gestão da informação: uma análise ergonômica das atividades das enfermeiras no contexto hospitalar. (Tese Doutorado). Instituto de Psicologia. UNB. Brasília.

- Polit, D.F., \& Beck, C.T. (2006). Using research in evidence-based nursin practice. En Essentialals of nursing research: methods, appraisal and utilization (pp. 475-494). Philadelphia: Lippincott Williams \& Wilkins.

- Prebystero, R, Costa, M.L.V., \& Santos, R.C.S. (2010). Os enfermeiros da unidade neonatal frente ao recém-nascido com dor. Rev Rene, 11(1), 125-132. Recuperado de: http://www.revistarene.ufc.br/revista/index.php/revista/ article/view/355.

- Preto, V.A., \& Pedrão, L.J. (2009). O estresse entre enfermeiros que atuam em Unidade de Terapia Intensiva. Rev. Esc. Enferm. USP, 43(4), 841-8. Recuperado de: http://www.scielo.br/scielo.php?pid=S008062342009000400015\&script=sci_arttext.

- Sanguiolliano, L. A. (2004). Stress dos enfermeiros em um hospital privado e as consequências no seu estado de saúde. (Dissertação Mestrado). Escola de Enfermagem de Ribeirão Preto, Universidade de São Paulo, Ribeirão Preto.

- Shimizu, H.E., \& Ciampone, M.H.T. (2002). As representações sociais dos trabalhadores de enfermagem não enfermeiros (técnicos e auxiliares de enfermagem) sobre o trabalho em Unidade Intensiva em um hospital-escola. Rev. Esc. Enferm. USP, 36(2), 148-55. Recuperado de: http://www.scielo.br/pdf/reeusp/v36n2/v36n2a06.pdf.

-Silva, I.A.S, \& Cruz, E.A. (2008). Trabalho da enfermeira intensivista: um estudo da estrutura das representações sociais. Rev. Esc. Enferm. USP. 42(3), 554-62. Recuperado de: http://www.scielo.br/scielo.php?script=sci_arttex t\&pid=S0080-62342008000300020.

- Silva, L.C.S.P, Valença, C.N., \& Germano, R.M. (2010). Estudo fenomenológico sobre a vivência da morte em uma unidade de terapia intensiva neonatal. Rev Bras Enferm, 63(5), 770-4. Recuperado de: http://www.scielo.br/ scielo.php?pid=S0034-71672010000500012\&script=sci_ arttext.

- Silva, R.C., \& Ferreira, M.A. (2011). Características dos enfermeiros de uma unidade de terapia 
tecnológica: implicações para o cuidado de enfermagem. Rev Bras Enferm, 64(1), 98-105. Recuperado de: http://www.scielo.br/scielo.php?pid=S0034$71672011000100015 \&$ script $=$ sci_arttext.

- Silveira, R.C.C.P. (2005). O cuidado de enfermagem e o Cateter de Hickman: a busca de evidencias. (Dissertação Mestrado). Escola de Enfermagem de Ribeirão Preto, Universidade de São Paulo. Ribeirão Preto. Recuperado em: http://www.teses.usp.br/teses/disponiveis/22/22132/tde-15082007-153503/pt-br.php.

- Soares, J.M.S. (2011). Perfil de competências de enfermei- ros de uma instituição hospitalar da rede privada. (Dissertação Mestrado). Escola de Enfermagem, Universidade de São Paulo. São Paulo. Recuperado em: http://www. teses.usp.br/teses/disponiveis/7/7140/tde-20062011155254/pt-br.php.

- Whittemore, R., \& Knafl, K. (2005). The integrative review: update methodology. J. Adv Nurs, 52(5), 546-53. Recuperado de: http://www.readcube.com/ articles/10.1111\%2Fj.1365-2648.2005.03621.x?r3_ referer=wol\&tracking_action=preview_click\&show_ checkout=1\&purc

QUADRO 1. Distribuição dos artigos publicados nos últimos cinco anos, relacionados ao perfil de enfermeiros de UTIs, segundo periódicos, título, autores e ano de publicação. Ribeirão Preto, 2014.

\begin{tabular}{|c|c|c|c|}
\hline TÍTULO & AUTORES & ANO & PERIÓDICO \\
\hline $\begin{array}{l}\text { O estresse entre enfermeiros que atuam } \\
\text { em Unidades de Terapia Intensiva }\end{array}$ & $\begin{array}{l}\text { Preto \& } \\
\text { Pedrão }\end{array}$ & 2009 & $\begin{array}{l}\text { Revista da Escola de Enfermagem } \\
\text { da USP }\end{array}$ \\
\hline $\begin{array}{l}\text { Percepção de enfermeiros sobre dilemas } \\
\text { éticos relacionados a pacientes terminais } \\
\text { em Unidades de Terapia Intensiva }\end{array}$ & $\begin{array}{c}\text { Chaves } \\
\text { \& massarollo }\end{array}$ & 2009 & $\begin{array}{l}\text { Revista da Escola de Enfermagem } \\
\text { da USP }\end{array}$ \\
\hline $\begin{array}{l}\text { Estilos de liderança de enfermeiros em } \\
\text { unidade de terapia intensiva: associação } \\
\text { com perfil pessoal, profissional e carga de } \\
\text { trabalho }\end{array}$ & $\begin{array}{l}\text { Balsanelli } \\
\text { Et al }\end{array}$ & 2009 & $\begin{array}{l}\text { Revista Latino-Americana de En- } \\
\text { fermagem }\end{array}$ \\
\hline $\begin{array}{l}\text { Dythanasia, euthanasia, orthotanasia: the } \\
\text { perceptions of nurses working in intensive } \\
\text { care units and care implications }\end{array}$ & $\begin{array}{l}\text { Biondo } \\
\text { Et al }\end{array}$ & 2009 & $\begin{array}{l}\text { Revista Latino-Americana de En- } \\
\text { fermagem }\end{array}$ \\
\hline $\begin{array}{l}\text { Humanização em Unidade de Terapia In- } \\
\text { tensiva Adulto (UTI): compreensões da } \\
\text { equipe de enfermagem }\end{array}$ & $\begin{array}{l}\text { Costa } \\
\text { Et al }\end{array}$ & 2009 & $\begin{array}{l}\text { Interface- Comunicação, Saúde, } \\
\text { Educação }\end{array}$ \\
\hline $\begin{array}{l}\text { Sentimentos de prazer entre enfermeiros } \\
\text { de Unidades de Terapia Intensiva }\end{array}$ & $\begin{array}{c}\text { Martins } \\
\text { Et al }\end{array}$ & 2009 & Ciencia y Enfermería \\
\hline
\end{tabular}




\begin{tabular}{|c|c|c|c|}
\hline $\begin{array}{l}\text { Condutas de Enfermeiros no tratamento } \\
\text { de feridas numa unidade de terapia in- } \\
\text { tensiva }\end{array}$ & $\begin{array}{l}\text { Moreira } \\
\text { Et al }\end{array}$ & 2009 & $\begin{array}{l}\text { Revista da Rede de Enfermagem do } \\
\text { Nordeste }\end{array}$ \\
\hline $\begin{array}{l}\text { Desafios e estratégias das enfermeiras da } \\
\text { Unidade de Terapia Intensiva Neonatal }\end{array}$ & $\begin{array}{l}\text { Cardoso } \\
\text { Et al }\end{array}$ & 2010 & $\begin{array}{l}\text { Revista da Rede de Enfermagem do } \\
\text { Nordeste }\end{array}$ \\
\hline $\begin{array}{l}\text { Os enfermeiros da Unidade Neonatal } \\
\text { frente ao recém-nascido com dor }\end{array}$ & $\begin{array}{c}\text { Presbytero } \\
\text { Et al }\end{array}$ & 2010 & $\begin{array}{l}\text { Revista da Rede de Enfermagem do } \\
\text { Nordeste }\end{array}$ \\
\hline $\begin{array}{l}\text { Reelaboração do treinamento admissional } \\
\text { de enfermeiros de Unidade de Terapia In- } \\
\text { tensiva }\end{array}$ & $\begin{array}{l}\text { Bucchi \& } \\
\text { Mira }\end{array}$ & 2010 & $\begin{array}{l}\text { Revista da Escola de } \\
\text { Enfermagem da USP }\end{array}$ \\
\hline $\begin{array}{l}\text { Estudo preliminar sobre a qualidade de } \\
\text { vida de médicos e enfermeiros intensivis- } \\
\text { tas pediátricos e neonatais }\end{array}$ & $\begin{array}{c}\text { Forgaça } \\
\text { Et al }\end{array}$ & 2010 & $\begin{array}{l}\text { Revista da Escola de Enfermagem } \\
\text { da USP }\end{array}$ \\
\hline $\begin{array}{l}\text { Demandas do trabalho e controle: impli- } \\
\text { cações em unidades de terapia intensiva } \\
\text { pediátrica e neonatal }\end{array}$ & Fogaça et al & 2010 & Revista Brasileira de Enfermagem \\
\hline $\begin{array}{l}\text { Estudo fenomenológico sobre a vivência } \\
\text { da morte em uma unidade de terapia in- } \\
\text { tensiva neonatal }\end{array}$ & $\begin{array}{l}\text { Silva } \\
\text { Et al }\end{array}$ & 2010 & Revista Brasileira de Enfermagem \\
\hline $\begin{array}{l}\text { Características dos enfermeiros de uma } \\
\text { unidade tecnológica: implicações para o } \\
\text { cuidado de enfermagem }\end{array}$ & Silva \& Ferreira & 2011 & Revista Brasileira de Enfermagem \\
\hline $\begin{array}{l}\text { Eventos adversos em Unidade de Terapia } \\
\text { Intensiva: percepção dos enfermeiros so- } \\
\text { bre a cultura não punitiva }\end{array}$ & $\begin{array}{l}\text { Claro } \\
\text { Et al }\end{array}$ & 2011 & $\begin{array}{l}\text { Revista da Escola de } \\
\text { Enfermagem da USP }\end{array}$ \\
\hline $\begin{array}{l}\text { Interação medicamentosa: conhecimento } \\
\text { de enfermeiros das unidades de terapia } \\
\text { intensiva }\end{array}$ & $\begin{array}{l}\text { Faria \& } \\
\text { Cassiani }\end{array}$ & 2011 & Acta Paulista de Enfermagem \\
\hline Estrés de los enfermeros de UCI em Brasil & Guerrer \& Bianchi & 2011 & Enfermería Global \\
\hline
\end{tabular}




\section{Cultura de las ᄃuidados}

\begin{tabular}{|c|c|c|c|}
\hline $\begin{array}{l}\text { Conhecimento de enfermeiros de Neona- } \\
\text { tologia acerca do Cateter Venoso Central } \\
\text { de Inserção Periférica. }\end{array}$ & Belo et al & 2012 & Revista Brasileira de Enfermagem \\
\hline $\begin{array}{l}\text { Estresse ocupacional em enfermeiros in- } \\
\text { tensivistas que prestam cuidados diretos } \\
\text { ao paciente crítico. }\end{array}$ & Inoue et al & 2013 & Revista Brasileira de Enfermagem \\
\hline $\begin{array}{l}\text { Estresse dos profissionais enfermeiros que } \\
\text { atuam na unidade de terapia intensiva. }\end{array}$ & Monte et al & 2013 & Acta Paulista de Enfermagem \\
\hline $\begin{array}{l}\text { O ambiente de trabalho em unidades de } \\
\text { terapia intensiva privadas e públicas }\end{array}$ & $\begin{array}{l}\text { Balsanelli \& } \\
\text { Cunha }\end{array}$ & 2013 & Acta Paulista de Enfermagem \\
\hline $\begin{array}{l}\text { Enfermeiros de Unidade de Terapia Inten- } \\
\text { siva adulto: avaliação sobre medida direta } \\
\text { e indireta da pressão arterial }\end{array}$ & $\begin{array}{l}\text { Almeida \& } \\
\text { Lamas }\end{array}$ & 2013 & $\begin{array}{l}\text { Revista da Escola de } \\
\text { Enfermagem da USP }\end{array}$ \\
\hline $\begin{array}{l}\text { Professional nursing practice: environ- } \\
\text { ment and emotional exhaustion among } \\
\text { intensive care nurses }\end{array}$ & $\begin{array}{l}\text { Panunto \& } \\
\text { Guirardello }\end{array}$ & 2013 & $\begin{array}{l}\text { Revista Latino-Americana de En- } \\
\text { fermagem }\end{array}$ \\
\hline $\begin{array}{l}\text { Perfil profissional de enfermeiros atuantes } \\
\text { em unidades de terapia intensiva de um } \\
\text { hospital de ensino }\end{array}$ & Laus; Chaves & 2013 & Ciência y Enfermería \\
\hline
\end{tabular}

Fonte: Elaborado pelos autores. 


\section{Normas técnicas para o processo de esterilização de materiais em unidades de saúde: uma proposta da enfermagem}

\section{Normas técnicas para el proceso de esterilización de material en unidades de salud: una propuesta de enfermería}

\section{Technical standards for the process of material sterilization in health units: a proposal of nursing}

Márcia Danieli Schmitt ${ }^{1}$, Pâmela Nadia Binda ${ }^{2}$, Karen Cristina Jung Rech ${ }^{3}$ y Rosana Amora Ascari ${ }^{4}$

${ }^{1}$ Enfermeira. Pós-Graduada em Centro Cirúrgico, Central de Materiais de Esterilização e Sala de Recuperação Pós-Anestésica pelo Centro Sul Brasileiro de Pesquisa, Extensão e Pós-Graduação (CENSUPEG). Residente em Gerência de Serviços de Enfermagem

pela Universidade Estadual de Londrina (UEL). Chapecó, Santa Catarina - Brasil.E-mail: marciaschmitt@hotmail.com

${ }^{2}$ Enfermeira. Membro do Programa de Extensão Educação Continuada em Saúde UDESC. Chapecó, Santa Catarina - Brasil. E-mail:pame_sissi@hotmail.com

${ }^{3}$ Enfermeira. Pós-Graduada em Enfermagem do Trabalho pelo Centro Sul Brasileiro de Pesquisa, Extensão e Pós-Graduação (CENSUPEG). Membro do Programa de Extensão Educação Continuada em Saúde UDESC. Chapecó, Santa Catarina - Brasil. E-mail:karen_lua3@hotmail.com

${ }^{4}$ Enfermeira. Doutoranda em Enfermagem do Programa de Pós-Graduação em Enfermagem da Universidade Federal do Rio Grande do Sul (PPGEnf/UFRGS). Professora colaboradora do CENSUPEG e Professora Assistente do Departamento de Enfermagem da Universidade do Estado de Santa Catarina (UDESC). Membro do Grupo de Estudos sobre Saúde e Trabalho (GESTRA/ UDESC). Coordenadora do Programa de Extensão Educação Continuada em Saúde UDESC.. Chapecó, Santa Catarina - Brasil. E-mail: rosana.ascari@hotmail.com

Cómo citar este artículo en edición digital: Schmitt, M.D., Binda, P.N., Jung Rech, K.C. y Ascari, R.A. (2015). Normas técnicas para o processo de esterilização de materiais em unidades de saúde: uma proposta da enfermagem.

Cultura de los Cuidados (Edición digital), 19(43). Disponible en: <http://dx.doi.org/10.14198/cuid.2015.43.14>

Correspondencia: Rosana Amora Ascari. Universidade do Estado de Santa Catarina.

E-mail: rosana.ascari@hotmail.comou rosana.ascari@udesc.br

Recibido: 23/05/2015; Aceptado: 12/09/2015

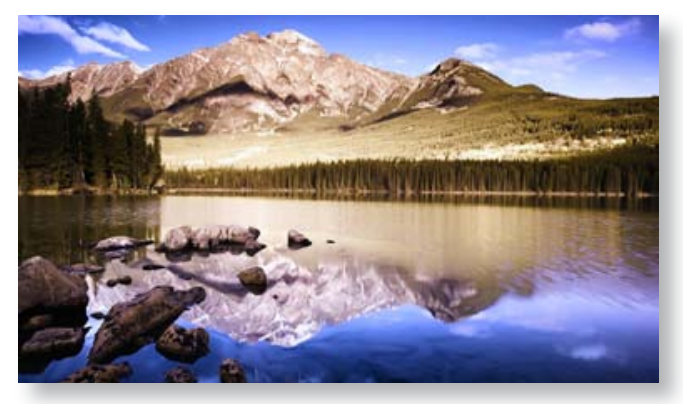

ABSTRACT

Objective: To organize a Technical Standard for the standardization of the sterilization process in Basic Health Units (BHU).

Method: An exploratory and descriptive study for the construction of guidance on the sterilization process, developed in partnership with the Continuing Education Program in Health, University of the State of Santa Catarina - UDESC, which followed the ethical recommendations of Resolution 466 / 2012 of the National Research Ethics Commission.

Results: It approaches issues related to the unidirectional material flow, standardization of the forms of cleaning and packaging, labeling, sterilization types, validation tests and record the sterilization process.

Conclusions: The technical standard will form the basis for training new employees, minimizing public costs wrapped in reprocessing dental, medical and hospital supplies and ensuring better health quality to users of the Unified Health System (UHS). 
Keywords: Technical Standards. Safety Management. Healt Management. Sterilization. Nursing.

\section{RESUMEN}

Objetivo: Organizar uma guia de Normas Técnicas para la estandarización del proceso de esterilización en Unidades Básicas de Salud (UBS).

Método: Se realizo um estudio exploratorio y descriptivo para la construcción de la guia de orientación sobre el proceso de esterilización, desarrollado en colaboración con el Programa de Educación Continua en Salud, Universidad del Estado de Santa Catarina (PECES / UDESC), que siguió las recomendaciones éticas de la Resolución 466 / 2012 de la Comisión Nacional de Ética de la Investigación.

Resultados: Se evidencian cuestiones relacionadas con el flujo de material unidireccional, la estandarización de las formas de limpieza y envasado, el etiquetado, los tipos de esterilización, las pruebas de validación y registrar el proceso de esterilización.

Conclusiones: La guia de orientación de normas técnicas constituirán la base para la formación de los nuevos empleados, lo que minimiza los costos públicos envueltos en el reprocesamiento, suministros médicos y hospitalarios dentales y garantizar una mejor calidad de la salud de los usuarios del Sistema Único de Salud (SUS).

Palabras clave: Normas Técnicas. Administración de la Seguridad. Gestión en salud. Esterilización. Enfermería.

\section{RESUMO}

Objetivo: Organizar uma Norma Técnica para a uniformização do processo de esterilização em Unidades Básicas de Saúde (UBS).

Método: Estudo exploratório e descritivo para a construção de diretriz sobre o processo de esterilização, desenvolvido em parceria com o Programa de Educação Continuada em Saúde da Universidade do Estado de Santa Catarina -UDESC, o qual seguiu as recomendações éticas da Resolução 466/2012 da Comissão Nacional de Ética em Pesquisa.

Resultados: Abordou-se questões relacionadas ao fluxo de materiais unidirecional, padronização das formas de limpeza e empacotamento, rotulagem, tipos de esterilização, testes de validação e registro do processo de esterilização.

Conclusões: A norma técnica servirá de base para treinamento de novos colaboradores, minimizando os custos públicos envoltos no reprocessamento de materiais odonto-médico-hospitalares e, assegurando melhor qualidade sanitária aos usuários do Sistema Único de Saúde (SUS).

Palavras chave: Normas Técnicas. Gerenciamento de Segurança. Gestão em Saúde. Esterilização. Enfermagem.

\section{INTRODUÇÃO}

Segundo a Associação Brasileira de Enfermeiros de Centro Cirúrgico, Recuperação Anestésica e Centro de Materiais de Esterilização (CME) a: "esterilização é o processo pelo qual os microrganismos são mortos a tal ponto que não seja mais possível detecta-lo no meio de cultura-padrão onde previamente haviam proliferado" (Sobecc, 2009). Portanto, o objeto não esta estéril na presença de qualquer microrganismo, não existindo assim, esterilização parcial (Padovese e Graziano, 2011).

A finalidade da esterilização é controlar a infecção, assim, considera-se que a assistência indireta prestada pela enfermagem que atua em CME tem igual importância da assistência 
direta prestada pela enfermagem ao paciente (khater e Uyeno, 2012).

As atividades realizadas para o reprocessamento de materiais odonto-médico-hospitalares expõe os profissionais a riscos ocupacionais (riscos químicos, físicos e biológicos) e a desorganização do processo de trabalho nesse setor influencia de maneira negativa a humanização dos trabalhadores e a qualidade do serviço prestado (Khater e Uyeno, 2012).

Visando a segurança do paciente e dos profissionais envolvidos no processamento de produtos para a saúde, a Resolução da Diretoria Colegiada - RDC no 15, de 15 de março de 2012, estabeleceu requisitos de boas práticas para o funcionamento desses serviços. Em seu Art.27 é estabelecido que "Todas as etapas do processamento de produtos para saúde devem ser realizadas por profissionais para os quais estas atividades estejam regulamentadas pelos seus conselhos de classe" (Brasil, 2012, p.6).

O Conselho Federal de Enfermagem COFEN, através da Resolução no 424/2012, normatiza as atribuições dos profissionais de enfermagem em CME e em empresas processadoras de produtos para saúde, cabendo aos Enfermeiros Coordenadores, Chefes ou Responsáveis por CME, entre outras coisas "Planejar, coordenar, executar, supervisionar e avaliar todas as etapas relacionadas ao processamento de produtos para saúde" (Cofen, 2012, s.p.).

A Politica Nacional de Atenção Básica determina atribuições especificas para cada categoria profissional, cabendo ao enfermeiro entre outras coisas, participar ativamente do gerenciamento de insumos necessários para o funcionamento das Unidades de Saúde da Família (Brasil, 2006).

Em pesquisas realizadas em 2011 acerca do processo de esterilização em 25 Unidades
Básicas de Saúde (UBS) num município do oeste catarinense, perceberam-se fragilidades a respeito do fluxo de materiais nas áreas destinadas à esterilização, diversidade de invólucros utilizados, falha na rotulagem do material e ausência da realização de testes para garantir esta esterilização (Ascari et al, 2012; Maldaner et al, 2013; Berlet et al, 2014). Além disso, os serviços de saúde pesquisados não dispunham de registro dos lotes e matérias reprocessados para o rastreamento destes em caso de necessidade (Berlet et al, 2014).

Considerando que as UBS do município em questão não dispõe de uniformização do processo de esterilização, nem de descrição de Normas Técnicas (NT) para nortear este processo, o que aumentam as chances de exposição profissional a riscos ocupacionais e põe em risco a qualidade dos serviços prestados aos beneficiários do Sistema Único de Saúde (SUS), o presente estudo apresenta uma proposta da enfermagem para organização de diretriz acerca da esterilização de materiais odonto-médico-hospitalares em Unidades Básicas de Saúde (UBS).

\section{MÉTODO}

Trata-se de um estudo exploratório e descritivo com abordagem qualitativa para o desenvolvimento de norma técnica sobre o processo de esterilização em UBS vinculadas à Secretaria de Saúde de um município no oeste catarinense.

Após várias leituras sobre o reprocessamento de materiais odonto-médico-hospitalares, com base em manuscritos científicos disponíveis on-line na Biblioteca Virtual em Saúde (BVS), no Scientific Eletronic Library online (SCIELO), Biblioteca Cochrane, Base de Dados de Enfermagem (BDENF), Literatura Latino-Americana e do Caribe em ciências 
da Saúde (LILACS), Medical Literature Analysis and Retrieval Sistem online (MEDLINE), Google Scholar, Latindex, Cumulative Index to Nursing and Allied Health Literature (CINAHL, Ebsco) e PubMed Central ${ }^{\circledR}$ (PMC) para a construção de diretriz sobre o processo de esterilização, os pesquisadores sentiram necessidade de compreender os objetivos da NT, genericamente conhecido por "protocolo" para a área de esterilização.

Neste sentido, os pesquisadores concluíram que a NT deve proporcionar aos trabalhadores um roteiro para atuação uniforme, bem como a definição de conceitos específicos desta área, permitindo maior controle na qualidade dos materiais reprocessados. Além disso, a NT possibilitará nortear o treinamento de novos colaboradores e servir de material para consulta em caso de dúvidas acerca das áreas que compõem a área física de esterilização, forma de limpeza, preparo e empacotamento, métodos de esterilização, guarda e distribuição dos artigos, bem como os testes e registros pertinentes ao reprocessamento de materiais Odonto-Médico-Hospitalares.

Este estudo foi desenvolvido no período de março a dezembro de 2013 em dois momentos. No primeiro momento os pesquisadores entraram em contato com a Secretaria de Saúde para expor a intenção de desenvolvimento de NT sobre o processo de esterilização em UBS vinculadas à secretaria municipal de saúde, o qual foi visto com bons olhos pela coordenação das Estratégias Saúde da Família (ESF) e pela coordenação da Atenção Básica da referida secretaria, ocasião em que se firmou um compromisso tácito de cooperação para revisão desta NT e viabilização de implantação em uma unidade piloto a ser selecionada a posterior.

No segundo momento os pesquisadores organizaram uma busca na literatura para ampliar o conhecimento sobre o processo de es- terilização, suas etapas e diretrizes a fim de garantir qualidade na descrição deste processo. Esta etapa contou com suporte do Programa de Educação Continuada em Saúde da Universidade do Estado de Santa Catarina (PECES/ UDESC), o qual contribuiu com a participação de docentes e discentes do curso de graduação em enfermagem, na ampliação da busca de material científico em base de dados on-line. Após a seleção de artigos pela equipe executora do PECES/UDESC no período de março a junho de 2013, os artigos selecionados foram encaminhados de forma digital para os pesquisadores, os quais avaliaram os manuscritos selecionados e os que apresentavam o desenvolvimento de boas práticas na esterilização de materiais foram considerados para o embasamento teórico desta NT.

A elaboração da NT deu-se nos períodos de julho a novembro de 2013, ocasião em que foi encaminhada à Secretaria Municipal de Saúde para avaliação pelo coordenador das UBS e da Atenção Básica. Em dezembro de 2014 a NT retornou com poucas sugestões para adequação à realidade local, as quais foram acatadas pelos pesquisadores.

$\mathrm{O}$ presente estudo seguiu as recomendações éticas da Resolução 466/2012 da Comissão Nacional de Ética em Pesquisa e por se tratar de pesquisa bibliográfica, todas as fontes utilizadas para a construção desta NT foram referenciadas ao término deste manuscrito.

\section{RESULTADOS E DICUSSÃO}

Para o desenvolvimento da NT para a área de esterilização em unidades básicas de saúde fez-se necessário conhecer a estrutura física das áreas destinadas à esterilização de materiais.

A planta física deve permitir um fluxo unidirecional dos artigos a serem reprocessados. Para tanto, recomenda-se que haja uma barreira entre a área suja e área limpa, e sempre 
que possível outra barreira entre a área limpa e área estéril (Guadagnin, Tipple e Souza, 2007).

A Agência Nacional de Vigilância Sanitária (ANVISA), através da RDC no 50 de 21 de fevereiro de 2002, descreve as atividades que devem ser desenvolvidas no CME. Os elementos que compõe a área física da CME, conhecido por área destinada ao processamento de materiais, são: recepção e expurgo, preparo e empacotamento, esterilização, guarda e distribuição de materiais (Brasil, 2002).

\section{Fluxograma dos artigos na CME e descrição das áreas de CME}

A CME é uma unidade no ambiente hospitalar responsável pelas seguintes ações: expurgo, limpeza e preparo, esterilização, guarda e distribuição dos materiais estéreis ou não estéreis das unidades de serviços que prestam atendimento ambulatorial ou não para o paciente. Este ambiente facilita o controle e padronização de técnicas da equipe de enfermagem no que diz respeito ao preparo e limpeza, assegurando a qualidade do material utilizado (Moura, 2011).

Figura 1 - Fluxo de Processamento de Artigos na $\mathrm{CME}$

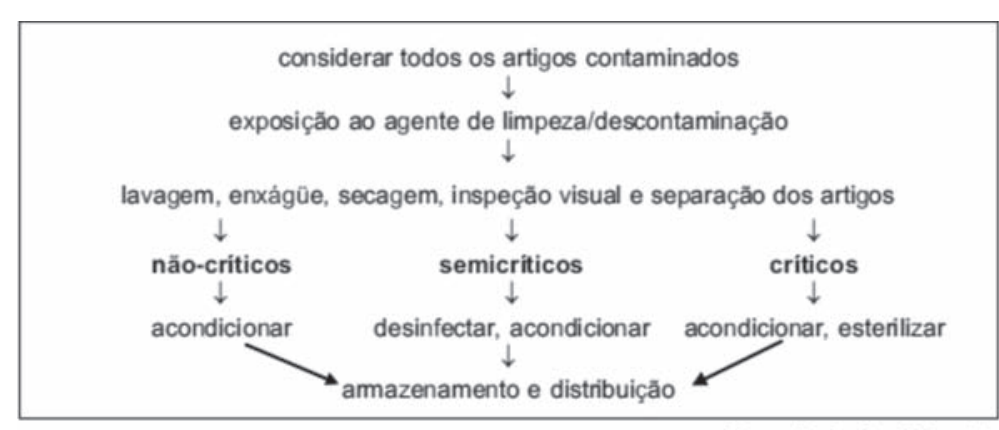

Fonte: (São Paulo, 2007, p.14)

de materiais contaminados provenientes das unidades consumidoras (Costa 2009).

Nessa área é desenvolvida a atividade de recepção, conferência e registro dos materiais; separação, desmontagem e imersão dos artigos em uma solução que contenha detergente enzimático; lavagem manual dos materiais individualmente; preparação dos materiais para a limpeza automatizada em máquina ultrassônica; preparação dos cestos com materiais na lavadora termodesinfectadora e seleção do ciclo de limpeza; inspeção dos materiais e relavagem quando ainda apresentarem sujidades; secagem dos materiais manualmente; preparação dos artigos para secagem automatizada e encaminhamento dos materiais para os serviços terceirizados (Costa, 2009).

A composição da área do expurgo segundo Kavanagh et al (2011), pode ser composta por um pia de granito que contenha três cubas de inox com duas torneiras e um misturador e duas cubas de inox, sendo uma com torneira três bicos de metal e outra com uma torneira e cinco bicos de metal para enxaguar borracha de aspiração, uma lavadora ultrassônica, um vaso sanitário com válvula hidra, uma janela com bancada de granito para o recebimento do material contaminado, três portas, três prateleiras, uma mesa de inox auxiliar, dois suportes para saco de hamper, uma bancada de madeira, três estrado de madeira.

A sala de recepção e limpeza dos materiais é

\section{Área de recepção e expurgo}

A área de recepção e expurgo é caracterizada como uma área destinada à recepção, conferência e limpeza ou lavagem e separação um dos locais mais contaminados da CME, pelas diversidades de materiais sujos com secreções16. Pode-se dimensionar o local de acordo com as suas funções, como por exemplo: 
- A área de recepção deve dispor de um ambiente de no mínimo $4 \mathrm{~m}^{2}$, com uma bancada de $1,0 \times 0,9 \mathrm{~m}$, alem de equipamentos de transporte com rodízios, recipiente perfuro cortantes e para resíduos biológicos, além da questão dos registros dos materiais recebido (Graziano, 2011).

- A Sala de Recepção, devolução, conferência do material deve ser dimensionada de acordo com a carga de trabalho, e o número de materiais diários, possuindo um acesso exclusivo para os materiais ainda não processados (Graziano, 2011).

- A área de limpeza deve ter área mínima de $15 \mathrm{~m}^{2}$, com torneira com água fria e quente, uma bancada com pia com as seguintes dimensões: $0,80 \mathrm{~m}$ de comprimento, $0,50 \mathrm{~m}$ de profundidade e 0,60 m de largura; equipamento de transporte com rodízio, ponto de água potável para enxágue com filtro de 0,2 micra, guichê de transferência dos produtos da área de limpeza para a área de preparo, recipiente perfurocortante, suporte para resíduo biológico, pistola de água com pressão para lavagem dos materiais com lúmen de ar comprimido ou oxigênio para secagem (Graziano, 2011).

As instituições devem padronizar horários do recebimento do material das unidades visando à organização da dinâmica do trabalho, favorecendo o funcionário no desenvolvimento das rotinas técnicas.

O escalado para esta função deve receber o material em horários preestabelecidos, conferindo e anotando as quantidades recebidas em cada secção. É imprescindível e obrigatória à utilização de Equipamento de Segurança Indi- vidual (EPI) durante todas as etapas do processo como as luvas de borrachas resistentes, luvas de procedimento, touca-turbante, propé impermeável, avental impermeável, óculos de proteção, protetor auricular, máscara e roupa privativa (Kavanagh et al, 2011).

\section{Área de preparo de materiais}

Segundo a RDC n50 de 2002 da Agência Nacional de Vigilância Sanitária, a área mínima para a área de preparo de matérias é de $12 \mathrm{~m}^{2}$, neste local os materiais já limpos são inspecionado, montados, acondicionados e identificados para a esterilização (Moura, 2011; Kavanagh et al, 2011).

As atividades de recepção dos materiais oriundos do expurgo; descarregamento dos equipamentos de limpeza e termodesinfecção; secagem dos materiais; inspeção visual dos artigos; verificação da integridade, funcionamento, lubrificação manual dos mesmos; separação e substituição dos artigos não conformes para avaliação e condutas; reposição e substituição das peças necessárias; montagem, conferência, embalagem dos materiais de assistência ventilatória; recepção e conferencia da roupa não estéril, montagem, embalagem e rotulagem dos pacotes são realizadas na área de preparo de materiais (Moura, 2011).

A sala de preparo é composta por prateleiras, mesas com gavetas, cadeiras giratórias, telefone, suporte de rolos de embalagem, suportes de fitas, seladoras, suporte de parede para folhas de embalagem (Kavanagh et al, 2011).

Neste ambienta recomenda-se o uso dos seguintes EPI: touca-turbante e luvas de procedimento. A sala deve ter o tamanho necessário para armazenar a quantidade e a diversidade dos materiais, a iluminação deve ser adequada para conferir a triagem, revisão e seleção dos materiais, combinando com a luz artificial 


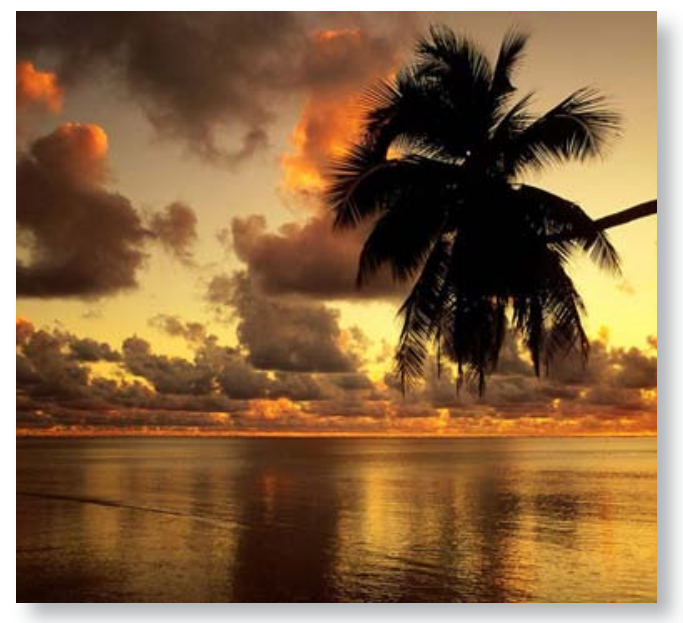

para evitar sombras e reflexos. Todo o material lavado e seco no expurgo deverá ser preparado utilizando embalagens descartáveis de acordo com o tamanho, forma e utilização do material padronizado pela comissão de controle de infecção. É necessário realizar o levantamento do uso diário de material pelas unidades de saúde, elaborando um controle interno do material, para evitar o acumulo de materiais esterilizados. As embalagens já fechadas dos materiais devem ser identificadas durante o preparo do pacote contendo o nome do funcionário, o tipo de artigo e a data de processamento (São pauolo, 2007; Kavanagh et al, 2011).

\section{Área de desinfecção de materiais (ácido pera- cético)}

$\mathrm{Na}$ área destinada a desinfecção de produtos para saúde, está relacionado com a utilização de produtos químicos cujos princípios ativos devem ser preconizados pelas legislações vigentes do Ministério da Saúde (MS). O ácido peracético é uma mistura de água, ácido acético, oxigênio e peróxido de hidrogênio se caracterizando como um desinfetante de alto nível, e uma das suas vantagens é a inexistência de resíduos, e ação rápida, ele age desnaturando e oxidando as proteínas, enzimas e outros metabólicos existentes nos materiais realizando as rupturas da permeabilidade da membrana celular (Minas Geraiss, 2010).

A sala de desinfecção química deve dispor uma área mínima de $4 \mathrm{~m}^{2}$, contendo uma bancada com cuba de lavagem dimensões: $0,80 \mathrm{x}$ $0,60 \mathrm{~m}$ e $0,50 \mathrm{~m}$ de profundidade), com ponto adicional de água com filtro e rodízio de transporte (GRAZIANO, 2011).

\section{Área de esterilização}

Esta área se destina à esterilização dos materiais após o preparo. A sala de esterilização de produtos para saúde deve ser dimensionada de acordo com o quantitativo e dimensão dos equipamentos, acrescida de $2,5 \mathrm{~m}^{2}$ para a circulação, além de prever a distância mínima de 0,50 m entre os equipamentos (São Paulo, 2007, Graziano, 2011).

A temperatura da área de esterilização deve ser inferior a $24^{\circ} \mathrm{C}$, e os profissionais devem usar os EPI's, como luvas grossas de tecido e de cano longo para evitar queimaduras como as luvas de Kevlar $^{\circledR}$ e touca turbante (Kavanagh et al, 2010).

Esta área deve dispor de incubadoras de indicadores biológicos e sistema para guarda dos registros dos monitoramentos do processo de esterilização e deve ser realizado diariamente com indicadores químicos e físicos (São Paulo, 2007).

\section{Área de guarda e distribuição}

Esta área tem por finalidade centralizar todos os artigos processados e esterilizados até sua posterior distribuição ás unidades consumidores, deve ser uma área restrita ao acesso e de uso exclusivo (Graziano, 2011). Deve ser composta por prateleiras, armários e cestos aramados, escadas e transporte com rodízio, as prateleiras devem estar disposta entre de 20 
$\mathrm{cm}$ a $25 \mathrm{~cm}$ do chão, $0,45 \mathrm{~cm}$ do teto e $5 \mathrm{~cm}$ das paredes laterais (Graziano, 2011).

Os produtos esterilizados devem ser armazenados em local limpo e seco, sob proteção da luz solar direta e submetidos à manipulação mínima (Ascari et al, 2012; Berlet et al, 2014; São Paulo, 2007). Os pacotes devem ser manuseados apenas quando estiver completamente fria, a distribuição de produtos para saúde processados na CME deve ser feito em recipientes fechados e em condições que garantam a manutenção da identificação e a integridade da embalagem (Maldaner et al, 2013). Para o armazenamento, utilizar armários fechados e devidamente identificados quando requisitados. Nesta área deve-se ter o cuidado de não permitir, no momento da distribuição, o cruzamento de artigos estéreis com artigos não estéreis (São Paulo, 2007).

\section{Descrição das atividades e atribuições da equipe de enfermagem}

Para o enfermeiro que atua na CME o gerenciamento da unidade é sua principal atividade, no que envolve as questões de planejamento, elaboração de instrumentos administrativos e operacionais, a supervisão, tomada de decisão, são elementos prescindíveis para a qualidade da assistência (Bartolomei e Lacerda, 2006).

\section{Atribuições gerais do enfermeiro}

Segundo a resolução COFEN no 421, de 15 de fevereiro de 2012, esta entre as atribuições do enfermeiro participar da elaboração de Protocolo Operacional Padrão (POP) para as etapas do processamento de produtos para saúde, com base em referencial científico atualizado e normatização pertinente, disponibilizando aos funcionários para consulta, também deverá participar da elaboração de sistema de registro (manual ou informatizado) da execução, para o monitoramento e controle das etapas de limpeza e desinfecção ou esterilização. É de responsabilidade do enfermeiro da CME propor e utilizar indicadores de controle de qualidade do processamento de produtos para saúde, acompanhar e documentar, as visitas técnicas de qualificação da operação e do desempenho de equipamentos da CME, ou da empresa processadora de produtos para saúde (Cofen, 2012).

Deve garantir a utilização de EPI, de acordo com o ambiente de trabalho da CME, elaborar termo de referência, ou emitir parecer técnico relativo à aquisição de produtos para saúde, equipamentos e insumos a serem utilizados, e atualizar-se, continuamente, sobre as inovações tecnológicas relacionadas ao processamento de produtos para saúde (Cofen, 2012).

Podemos citar ainda como atribuições gerais do enfermeiro dentro da unidade de esterilização a coordenação dos processos de trabalho, como também a os registros de passagem do plantão do período. Além disso, cabem a ele, questões de orientação sobre a rotina de trabalho na $\mathrm{CME}$, supervisionando as atividades em cada área, como o funcionamento dos equipamentos e materiais utilizados os avaliando e acompanhando a manutenção dos mesmos, checar os registros de esterilização e acompanhando e realizar os testes com os produtos, insumos e equipamentos (Costa e Fugulin, 2011).

Destaca-se a importância da verificação da incubação dos indicadores biológicos e anotação em livro próprio dos resultados. A supervisão do recebimento e o uso e devolução dos materiais consignados também é de responsabilidade deste profissional (Costa e Fugulin, 2011).

Questões de gestão e gerenciamento da unidade são atividades indispensáveis pelo 
enfermeiro, como a elaboração da escala diária de trabalho da equipe, realização e programação de capacitações e treinamentos, além da participação das compras de materiais e insumos para a unidade, avaliação e previsão do estoque de materiais consumidos pelo hospital, e a conferencia da programação diária de cirurgias a serem realizados disponibilizando roupas e materiais estéreis suficientes (Oliveira e Chaves, 2009).

A avaliação do desempenho dos profissionais também representa uma função de destaque, onde o enfermeiro também participa de questões gerenciais e administrativas do setor, como a participação de programas de prevenção de riscos ocupacionais e o desenvolvimento de pesquisas na central de materiais (Oliveira e Chaves, 2009).

\section{Atribuições gerais do técnico de enfermagem}

As atribuições do técnico de enfermagem dentro do setor estão relacionadas a receber o material oriundo dos outros setores, conferir, lavar, secar e embalar estes instrumentos, identificando de forma correta (Silva, Pimentel e Hermini, 2006).

Cabe também a esse profissional, anotar na folha de produção de materiais, identificar os hampers, preparar as cargas para a esterilização, esterilizar os materiais e retirar da autoclave e armazená-los de forma adequada. Além de distribuir os materiais estéreis nos setores, realizar a incubação e a leitura dos indicadores biológicos, a limpeza dos cestos, paredes, prateleiras do arsenal semanalmente, além de realizar a limpeza terminal de acordo com a rotina da unidade, a retirada de materiais com o prazo de validade da esterilização vencidos e a realização do teste de Bowie-Dick diariamente (Silva, Pimentel e Hermini, 2006).

\section{Invólucros recomendados de acordo com o tipo de esterilização}

De acordo com a Resolução RDC no 15 de 15 de março de 2012 da ANVISA, o invólucro deve permite a entrada e saída do ar e do agente esterilizante e impede a entrada de microrganismos, devendo estar regularizadas junto à ANVISA, para uso especifico em esterilização (Brasil, 2012).

Uma embalagem considerada ideal deve atender alguns requisitos para garantir as funções primárias de permitir e manter a esterilização do material: como permitir a penetração e remoção do agente esterilizante, promover barreira adequada aos microrganismos e seus veículos, deve resistir a rasgos, abrasões e perfuração, além de permitir o método de selagem eficiente que possibilite perceber a violação do pacote, proporcionando abertura de forma asséptica e não delaminar, a embalagem deve ser atóxica, inodora e não liberar corantes na sua utilização (Graziano, 2011).

A embalagem deve ser isenta de rasgos, furos, fissuras, dobras ou ter a sua espessura reduzida, possuir um nível aceitável de limpeza, não liberando partículas, ter relação com o custo-benefício do material, garantindo a proteção ao profissional durante o manuseio, repelir umidade, e se possível deve conter indicadores químicos. Disponibilizada em vários tamanhos,, a embalagem deve ser apropriada para o método de esterilização escolhido (Graziano 2011).

O responsável pela CME deve participar do processo de escolha da embalagem, para controlar a qualidade do material esterilizado, observando o custo-benefício do processo. A recomendação da escolha do invólucro se embasa no método de esterilização praticado. A figura 2 evidencia a compatibilidade entre o tipo de invólucro e o método de esterilização. 
Figura 2 - Compatibilidade entre embalagens e métodos de esterilização

\begin{tabular}{|c|c|c|c|c|c|c|}
\hline Embalagem & $\begin{array}{l}\text { Vapor } \\
\text { sob } \\
\text { pressão }\end{array}$ & $\begin{array}{l}\text { Calor } \\
\text { seco }\end{array}$ & $\begin{array}{l}\text { Óxido } \\
\text { de } \\
\text { etileno }\end{array}$ & $\begin{array}{l}\text { Plasma de } \\
\text { peróxido } \\
\text { de } \\
\text { hidrogênio }\end{array}$ & $\begin{array}{l}\text { Vapor a baixa } \\
\text { temperatura } \\
\text { de } \\
\text { formaldeído }\end{array}$ & $\begin{array}{l}\text { Radiação } \\
\text { ionizante }\end{array}$ \\
\hline Tecido algodão & Sim & Não & Năo & Não & Não & Não \\
\hline Contêiner rígido & Sim & Não & Sim & Sim & Sim & Sim \\
\hline Vidro refratário & Sim & Sim & Não & Não & Não & \\
\hline $\begin{array}{ll}\text { Papel grau } \\
\text { cirúrgico }\end{array}$ & Sim & Não & Sim & Não & Sim & Sim \\
\hline Papel crepado & Sim & Não & Sim & Não & Não & Sim \\
\hline Filmes & Sim & Não & Sim & Não & Sim & Sim \\
\hline Tyvek® & Sim & Não & Sim & Sim & Sim & Sim \\
\hline $\begin{array}{l}\text { Não } \quad \text { Tecido } \\
\text { (SMS) }\end{array}$ & Sim & Não & Sim & Sim & Sim & Sim \\
\hline Caixas metálicas & Sim & Sim & Sim & Sim & Sim & Sim \\
\hline
\end{tabular}

FONTE: (Graziano, 2010, p 98).

A escolha do invólucro para empacotamento depende das características dos artigos e do processo de esterilização a ser escolhido. As embalagens são necessárias para proteção dos artigos críticos após sua esterilização e devem atender as especificações do equipamento para garantir que o artigo foi esterilizado com segurança, considerando a permeabilidade para penetração e eliminação do agente esterilizante.

O papel grau cirúrgico ou laminado de polietileno ou polipropileno deve atender as recomendações e ser o material de escolha da unidade de esterilização. O tipo de embalagem de algodão cru ou musselina pode ser utilizado em campos duplos (duas camadas de tecido), conforme legislação Associação Brasileira de Normas Técnicas (ABNT). A cada utilização dos tecidos, os mesmos devem ser lavados, para a retirada de poeira e recomposição das fibras. As caixas metálicas para calor úmido devem ser perfuradas na sua parte superior ou inferior ou em ambas, e ser de uso exclusivo para esterilização em autoclave (Brasi, 1994).

A seleção das embalagens utilizadas no processo de esterilização de materiais deve levar em conta critérios de utilização como o tipo de esterilização e o material em que será envolvido, sempre observando as recomendações da $\mathrm{ABNT}$, na literatura foram encontrados os seguintes tipos de embalagem e sua validade varia de sete dias a 2 anos.

- Tecido de algodão: composto por tecido $100 \%$ algodão ou gramatura; é de baixo custo e memória, mas não é resistente à umidade e vulnerável a contaminação. Sua durabilidade é de até 65 reprocessamentos (Souza et al, 2010).

- Contêiner rígido: com filtro microbiano ou filtro Tyveck ${ }^{\oplus}$ são caixas de metal inoxidável, o alumínio dispõe de sistemas de filtros para saída de ar e entrada do vapor, dispensando o uso do invólucro externo e são termorresistentes; economizando tempo no preparo (dispensa a etapa da embalagem); segurança no transporte e manuseio; alta resistência; mecanismo de lacre; compatibilidade com os métodos de esterilização; reuso; e possibilidade de prazo de armazenamento longo (Souza et al, 2010).

- Vidro refratário: é reutilizável, possui alta proteção mecânica, mas seu uso é restrito (Souza et al, 2010).

- Papel grau cirúrgico: com face em filme plástico de Polietileno/ Poliéster ou filme de 
Polipropileno disponível em gramatura e em diversas formas e tamanhos, em bobinas ou envelopes; é de baixo custo e fácil visualização, com indicador químico monoparamétrico impregnado (Souza et al, 2010).

- Papel crepado: composto de $100 \%$ de celulose tratada é impermeável à água, álcool, PVPI, éter, $100 \%$ biodegradável, reciclável e maleável com alta filtragem microbiana. Apresenta baixa resistência mecânica, podendo furar ou rasgar com maior facilidade (Souza et al, 2010).

- Tyvek ${ }^{\circledR}$ : constituído em $100 \%$ polietileno em tripla camada, apresenta compatibilidade com diversos processos de esterilização, possui alta resistência mecânica, é de fácil visualização e pode ser impregnado com indicador biológico. Seu custo é elevado (Souza et al, 2010).

- Não Tecido (SMS): união de três camadas de não tecido $100 \%$ Polipropileno; tem excelente barreira antimicrobiana, alta permeabilidade aos agentes esterilizantes, maleabilidade, resistência mecânica à tração e à abrasão. Tem como desvantagens, a dificuldade de detecção da integridade da embalagem e não ser biodegradável (Souza et al, 2010).

- Caixas metálicas: é inoxidável, composta por alumínio, polímeros ou a combinação destes e são termo resistentes. Além disso, propicia melhor organização na sala de operação, em decorrência da diminuição do volume de invólucros, resistência mecânica; economia de espaço no armazenamento. Porém, tem custo elevado, apresenta risco de falha na vedação e exige inspeção visual constante (Souza et al, 2010).

\section{Testes recomendados para a validação do processo de esterilização}

Os testes recomendados são os testes químicos e biológicos, além da manutenção dos equipamentos e os registros do processo de esterilização (verificação mecânica). Os testes químicos indicam se ocorreu uma falha em potencial no processo de esterilização por meio da mudança de sua coloração, como o teste Bowie e Dick que devem ser utilizados diariamente no primeiro ciclo de esterilização em autoclaves (Canann et al, 2010).

Os testes biológicos consideram todos os parâmetros de esterilização, utilizam-se monitores e parâmetros críticos, tais como temperatura, pressão e tempo de exposição e, cuja leitura é realizada em incubadora, obtendo resultado em três horas, trazendo maior segurança na utilização dos materiais (Canann et al, 2010).

Os indicadores mecânicos ou físicos fazem parte o tempo (relógio e timer) das autoclaves, a temperatura, a pressão alcançada, e os relatórios impressos pelas máquinas, mas não representam uma resposta adequada para o controle da esterilização (Brasil, 2001).

Já os indicadores químicos, são substratos contidos em tiras de papel, que reagem a uma determinada temperatura, mudando de cor e são divididos em seis classes: Classe 1 - indicadores de processo como as fitas adesivas, utilizados em cada pacote. Demonstram apenas a passagem dos pacotes pelo processo. Como as fitas adesivas utilizadas externamente que mudam de cor (fitas zebradas). Classe 2 - indicadores para uso em testes específicos é utilizados em situações relevantes para o equipamento de esterilização, como é caso do teste de Bowie \& Dick (Minas Gerais, 2010).

$\mathrm{O}$ indicador de Classe 3 - indica de apenas um parâmetro, monitora um dos parâmetros críticos do processo de esterilização; Classe 4 - indicador de multiparâmetros ou multivariável, monitora dois ou mais parâmetros da esterilização. Classe 5 - indicadores integradores rastreiam todos os parâmetros críticos do processo de esterilização dentro de um intervalo 
especifico. E a Classe 6 - indicadores de simulação de ciclo, reagem a todos os parâmetros críticos (Minas Gerais, 2010).

Os indicadores biológicos são os únicos que asseguram a qualidade efetiva da esterilização, e todo seu processo deve ser documentando e deve ser realizado em todas as vezes que a máquina passar por alguma manutenção. Uma vez que os microrganismos são diretamente testados quanto ao seu crescimento ou não após a aplicação do processo (Barilli et al, 2009).

Estes indicadores podem ser divididos em categorias como os de $1^{\circ}$ geração - envelopes que contem tiras de papeis impregnadas de esporos (leitura em laboratório com 2 a 7 dias de incubação); Os de $2^{\circ}$ geração - incubados à $56^{\circ} \mathrm{C}$, por 48 horas, são ampolas que contem esporos secos e calibrados chamados de autocontidos. E os de $3^{\circ}$ geração - deve ser incubado por um período de 1 a 3 horas a $56^{\circ} \mathrm{C}$ e em seguida ser exposto à luz ultravioleta, a ausência de fluorescência indica que as condições de esterilização foram atingidas - a diferença para o de $2^{\circ}$ geração está na metodologia para detectar o crescimento bacteriano (Canann et al, 2010).

\section{Recomendação de registros acerca do pro- cesso de esterilização}

Cabe ao profissional da enfermagem realizar as atividades relacionadas à recepção, conferência e registro de materiais contaminados encaminhados pelas unidades assistenciais, realizando o registro do recebimento de materiais contaminados provenientes das unidades e a conferência dos mesmos pelo enfermeiro responsável (Costa, 2009).

Nos registros precisam conter o nome do material, tipo de esterilização, lote da esterilização, a validade do produto e o responsável pelo empacotamento do material. A cada ci- clo de esterilização faz-se necessário o registro com o lote, o seu conteúdo, o tempo de esterilização e a temperatura atingida pelo equipamento. As autoclaves mais recentes emitem esses registros de forma digital e impressa, os quais devem ser armazenados em local apropriado, além desses quesitos também os registrados o nome do operador do equipamento, os resultados dos testes biológicos realizados e dos indicadores químicos, e qualquer intercorrência que aconteceu no decorrer do processo de esterilização (Romano e Quelhas, 2009).

A qualidade do processo de esterilização depende do monitoramento do processo, a observação e o registro das atividades realizadas garantem a eficiência do processo, podendo-se avaliar todas as fases da esterilização com a finalidade de detectar possíveis falhas e aonde e como acontece. Recomenda-se o monitoramento biológico semanalmente das centrais de esterilização sendo obrigatório o uso de um livro de registros para a anotação dos resultados.

\section{Normas e rotinas de encaminhamento de materiais termossensíveis para esterilização em óxido de etileno (ETO)}

O Óxido de Etileno (ETO) é um gás utilizado como agente esterilizante de materiais médico-hospitalares, especialmente para materiais e artigos termossensíveis, sendo um produto altamente tóxico, facilmente inflamável e explosivo, além de ser carcinogênico, mutagênico, teratogênico e neurotóxico. Portanto, toda empresa que realiza esterilização por ETO, deve solicitar licença de funcionamento especifica para esse tipo de esterilização, através da Vigilância Sanitária Estadual, Municipal ou do Distrito Federal (Brasil, 1999).

Os materiais encaminhados para esterilização por ETO devem ser entregues limpos, seco, sem resíduo de material aderente, e 
quando tiver várias peças, estas precisam estar montadas.

Recomenda-se o armazenamento de caixas apropriadas, fechadas e identificadas, além do registro dos materiais a serem encaminhados para esterilização.

Devido à complexidade e o custo que envolve os equipamentos e instrumentais, é de grande importância todas as instituições de saúde utilizar um referencial teórico para conduzir o processo de esterilização de materiais, investindo na qualificação dos profissionais envolvidos nesse processo (Paurosi et al, 2014).

\section{CONSIDERAÇÕES FINAIS}

Os órgãos reguladores de produtos para saúde vêm aprimorando a qualidade técnica dos produtos para saúde, o que requer um reprocessamento de materiais odonto-médico-hospitalares com o menor risco possível tanto para os trabalhadores quanto para os usuários dos serviços de saúde.

Considerando a legislação vigente, $\mathrm{RDC} \mathrm{n}^{\circ}$ 15 de 15 de março de 2012, a qual prevê um fluxo de materiais unidirecional, padronização das formas de limpeza e empacotamento, do tipo de esterilização, aplicação de testes de validação do processo de esterilização que contemple os métodos físico, químico e biológico e registro adequado de todas as etapas deste processo, a presente norma técnica poderá ser utilizada pelos serviços de saúde de atenção básica para treinamento de novos colaboradores, auxiliando as unidades básicas de saúde na definição das áreas que compõem um centro de material e esterilização, das formas de limpeza, na escolha dos invólucros de acordo com o método de esterilização praticado, na identificação/rotulagem do produto para saúde, na aplicação de testes de validação, bem como no registro e rastreamento dos produtos processados, minimizando os custos públi- cos envoltos no reprocessamento de materiais odonto-médico-hospitalares, e principalmente, assegurando melhor qualidade sanitária aos usuários do SUS.

\section{REFERENCIAS}

- Ascari, R.A., Silva, O.M., Azevedo Junior, L., Berlet, L.J., Maldaner, C., Mai, S. (2012). Fluxo de materiais odontomédico-hospitalares durante seu reprocessamento em unidades básicas de saúde. Udesc em Ação, 6 (1), 1-16.

- Brasil. Agência Nacional de Vigilância Sanitária (ANVISA). (2002). Resolução - RDC $n^{\circ} 50$ de 21 de fevereiro de 2002, que aprova o regulamento técnico destinado ao planejamento, programação, elaboração, avaliação $e$ aprovação de projetos físicos de estabelecimentos assistenciais de saúde. Brasilia: ANVISA. Disponível em: http://portal.anvisa.gov.br/wps/wcm/connect/ ca36b200474597459fc8df3fbc4c6735/RDC+N\%C $2 \% \mathrm{BA} .+50,+\mathrm{DE}+21+\mathrm{DE}+\mathrm{FEVEREIRO}+\mathrm{DE}+2002$. pdf?MOD=AJPERES

- Brasil. Agência Nacional de Vigilância Sanitária (ANVISA). (2012). Resolução - RDC $n^{\circ} 15$, de 15 de março de 2012, que dispóe sobre requisitos de boas práticas para o processamento de produtos para saúde e dá outras providências. Brasilia: ANVISA. http://bvsms.saude.gov.br/ bvs/saudelegis/anvisa/2012/rdc0015_15_03_2012.html

- Brasil. Ministério da Saúde. Coordenação de Controle de Infecção Hospitalar. (1994). Processamento de artigos e superfícies em estabelecimentos de saúde. 2. ed. Brasília, Ministério da Saúde. Disponível em: http://www.anvisa. gov.br/servicosaude/controle/processamento_artigos. pdf

- Brasil. Ministério da Saúde. Secretária de Assistência à Saúde. Coordenação-Geral das Unidades Hospitalares Próprias do Rio de Janeiro. (2001). Orientações gerais para Central de Esterilização. Brasília: Ministério da Saúde. Disponível em: Disponível em: http://www. cro-rj.org.br/biosseguranca/Orientacoes $\% 20$ Gerais $\% 20$ para $\% 20$ Central $\% 20 \mathrm{de} \% 20$ Esterilizacao.pdf

- Brasil. Ministério da Saúde. Secretaria de Atenção à Saúde. Departamento de Atenção Básica. (2006). Política nacional de atenção básica. Brasília: Ministério da Saúde. 
Disponível em: http://bvsms.saude.gov.br/bvs/publicacoes/politica_nacional_atencao_basica_2006.pdf

- Brasil. Agência Nacional de Vigilância Sanitária (ANVISA). (1999). Portaria Interministerial 482 de 16/4/1999. Esterilização por óxido de etileno. Brasilia: ANVISA. Disponível em: http://www.sobed.org.br/web/arquivos_antigos/pdf/37.pdf

- Barilli, A.L.A., Nascimento, G.M., Pereira, M.C.A., Liporaci, M.M.P.M., Lazzarini, M.P.T. (2009). Prefeitura Municipal de Ribeirão Preto-SP. Secretaria Municipal da Saúde. Comissão de Controle de Infecção. Subcomissão de Qualificação de Esterilização em Autoclaves da CCI-SMS. Manual de Qualificação de Esterilização em Autoclaves. Ribeirão Preto: Secretaria Munbicipal de Saúde. Disponível em: http://www.ribeiraopreto.sp.gov.br/ssaude/ comissao/desin/m-pdf/m-autoclave-gibi.pdf

- Batolomei, S.R.T., Lacerda, R.A. (2006). Trabalho do enfermeiro no Centro de Material e seu lugar no processo de cuidar pela enfermagem. Rev Esc Enferm USP, 40 (3), 412-417.

- Bertel, L.J., Ascari, R.A., Silva, O.M., Trindade, L.L., Krauzer, I.M., Jacoby, A.M. (2014). Factors that influence the quality of the sterilization process. J Nurs UFPE on line, Recife, 8 (7), 1997-2003.

- Canaan, J.M.M., Pestana, K.C., Silva, M.I., Raddi, M.S.G. (2010). Avaliação do processo de esterilização por autoclavagem utilizando indicadores biológico e químico. Seminário Anual do PGSST-UNESP. Universidade Estadual Paulista Júlio de Mesquita Filho. Disponível em: file://C:/ Users/Rosana/Downloads/autoclave\%20(4).pdf

- Cofen - Conselho Federal de Enfermagem. (2012). Resolução COFEN No 424/2012. Brasília: CFE. Disponível em: http://novo.portalcofen.gov.br/resoluo-cofenn-4242012_8990.html

- Costa, J.A. (2009). Atividades de Enfermagem no Centro de Material e Esterilização: subsídios para o dimensionamento de pessoal. Escola de Enfermagem da Universidade de São Paulo. São Paulo. Disponível em: www.teses.usp. br/teses/disponiveis/7/7131/tde.../Janaina_Anchieta.pdf - Costa, J.A., Fugulin, D.M.T. (2011). Atividades de enfermagem em centro de material e esterilização: contribuição para o dimensionamento de pessoal. Acta Paul.
Enferm, 24 (2), 249-256.

- Guadagnin, S.V.T., Tipple, A.F.V., Souza, A.C.S. (2007). Avaliação arquitetônica dos centros de material e esterilização de hospitais do interior do estado de Goiás. Rev. Eletr. Enferm, 9 (3), 656-673.

- Graziano, K.U., Silva, A., Psaltikidis, E.M. (orgs.). (2011). Enfermagem em Centro de Material e Esterilização. Barueri, SP: Manoele. (Série Enfermagem).

- Kavanagh, C.M.G. (2011). Elaboração do manual de procedimentos em central de materiais e esterilização. 2 ed. São Paulo: Editora Atheneu.

- Khater, M., Uyeno, C.G.A. (2012). A humanização em foco na assistência indireta da equipe de enfermagem. III Congresso de Humanização e II Jornada Interdisciplinar de Humanização. Disponível em: http://anais.congressodehumanizacao.com.br/files/2012/08/PDF-33.pdf

- Maldaner, C., Berlet, L.J., Ascari, R.A., Klein, M.L., Savian, B.A., Silva, O.M. (2013). Invólucros para esterilização de materiais odonto-médico-hospitalares. Rev Saúde Pública Santa Catarina, 6 (3), 61-70.

- Minas Gerais. Secretária Municipal de Saúde de Contagem-MG. Grupo de Estudos em Centro de Material e Esterilização da Secretária Municipal de Saúde de Contagem. (2010). Comissão Municipal de Controle de Infecção em Serviços de Saúde - CMCISS. Manual de Processamento de Artigos em Serviços de Saúde. Minas Gerais: Contagem. Disponível em: http://novo.contagem. mg.gov.br/arquivos/downloads/manual_cme.pdf

- Moura, M.L.P.A. (2011). Enfermagem em centro de material e esterilização. 10 ed. São Paulo: Editora Senac São Paulo.

- Oliveira, N.C., Chaves, L.D.P. (2009). Gerenciamento de recursos materiais: o papel da enfermeira de unidade de terapia intensiva. Rev. Rene, Fortaleza, 10 (4), 19-27.

- Padoveze, M.C., Graziano, K.U. Aspectos conceituais e microbiológicos relacionados ao processamento de materiais utilizados na assistência à saúde. In: Graziano, K.U., Silva, A., Psaltikidis, E.M. (Org.). (2011). Enfermagem em Centro de Material e Esterilização. São Paulo: Manole.

- Paurosi, D.R., Ascari, R.A., Silva, O.M., Ascari, T.M. (2014). Diretrizes operacionais para uma central de Ma- 


\section{Cultura de las Cuidados}

terial e esterilização odontológica: Uma proposta da enfermagem. Revista UNINGÁ Review, 17 (2), 5-10.

- Romano, J.C., Quelhas, M.C.F. (2014). Monitoramento dos Métodos de Esterilização. Disponível em: http://www. hospvirt.org.br/enfermagem/port/testes.html

- São Paulo. Secretaria Municipal da Saúde. Comissão de Controle de Infecção. (2007). Protocolo de Processamento de Artigos e Superfícies nas Unidades de Saúde. São Paulo: Ribeirão Preto-SP. Disponível em: http://www. ribeiraopreto.sp.gov.br/ssaude/comissao/desin/esterilizacao.pdf

- Silva, M.C.F.G., Pimentel, E.C., Hermini, A. (2014). Centro de atenção integral à saúde da mulher. Gerenciamento da CME. Disponível em: ftp://ftp.caism.unicamp.br/
pub/CME/CME\%2034\%20-\%20Gerenciamento \%20 da\%20cme.pdf

- Sobecc - Sociedade Brasileira de Enfermeiros de Centro Cirúrgico, Recuperação Anestésica e Centro de Material e Esterilização. (2009). Práticas Recomendadas SOBECC / Sociedade Brasileira de Enfermeiros de Centro Cirúrgico, Recuperação Anestésica e Centro de Material e Esterilização. $5^{\mathrm{a}}$ edição. São Paulo: SOBECC.

- Souza, A.S., Sória, D.A.C., Araújo, J.O., Silva, M.T., Andrade, N.C. (2010). Embalagens para esterilização: suas aplicações e recomendações na prática hospitalar. Rev. Pesquisa: Cuidado é Fundamental, 2 (Ed. Supl.), 316-319. Disponível em: http://www.seer.unirio.br/index.php/cuidadofundamental/article/view/931/pdf_139

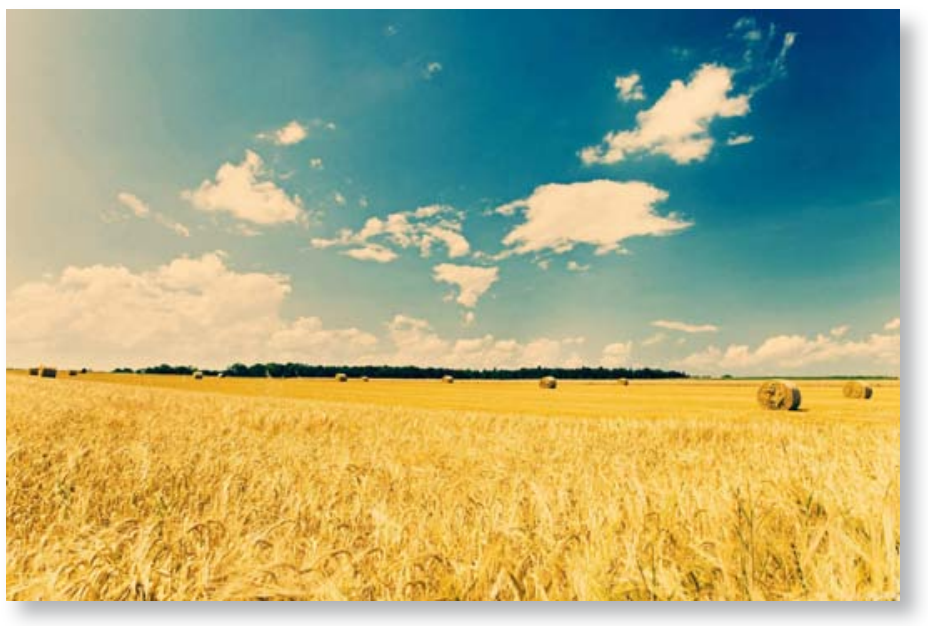




\section{Misceláned}

\section{Biblioteca comentada}

\section{FAMILIAS Y ENFERMEDAD FÍSICA}

\section{Manual de intervención familiar y multifamiliar}

\section{Varela, N., Escudero, V. y López, S. (2012) Familias y enfermedad física. Madrid: Editorial Grupo 5.net \\ CEU Facultad Ciencias de la Salud. Universidad de Alicante \\ Cómo citar este artículo (reseña) en edición digital: Cibanal, L. (2015). Familias y enfermedad física (Reseña). Cultura de los Cuidados (Edición digital) 19, 42. Disponible en: http://dx.doi.org/10.14198/cuid.2015.42.15>}

Correspondencia: (remitirse al correo electrónico)

Correo electrónico: luis.cibanal@ua.es

Recibido: 13/11/2015/ Aceptado: 2/12/2015

El libro que presentamos es un manual muy útil para todos los que trabajamos con las personas que sufren cualquier enfermedad. Aborda la enfermedad de forma sistémica, es decir en el abordaje del paciente no podemos excluir o dejar al margen a la familia. Familia y paciente forman un sistema, $y$ por tanto cualquier dolor, sufrimiento, preocupación, etc. de cualquier miembro va a repercutir en todo el sistema familiar. Todos viven la enfermedad de su familiar enfermo, todos los miembros sienten su repercusión. Este es un aspecto sumamente importante que con muchísima frecuencia olvidamos los profesionales de la salud.

Los autores de este libro nos hacen tomar conciencia de que la enfermedad y los problemas en general, no se producen solamente en un órgano aislado, sino que se generan y evolucionan en un contexto de relaciones humanas, y este axioma es especialmente rel- evante cuando la enfermedad conlleva un grado importante de dependencia del paciente.

Como bien nos señala este libro, vivimos en una sociedad en la que cada vez existen más personas con necesidad de cuidados prolongados y continuos en el hogar. Las enfermedades crónicas y degenerativas, la desinstitucionalización de las enfermedades mentales y las reducidas estancias hospitalarias son algunas de las causas. Ante estas situaciones, en las que antes o después, todos vamos a desarrollar algún grado de dependencia, la familia constituye una importante fuente de apoyo emocional y social del paciente, asume la pesada carga de los cuidados y representa el principal recurso para afrontar los desafíos y demandas que la enfermedad o la discapacidad exigen.

Las consecuencias de vivir con una persona dependiente o con una enfermedad de larga duración se hacen sentir en todo el sistema fa- 
miliar, por lo que es necesario reconocer el dolor y sufrimiento de todos los miembros, y por consiguiente no sólo hay que abordar el padecimiento del enfermo sino el de toda la familia, pues es toda la familia la que está sufriendo la enfermedad. Dado que la calidad de vida de la familia se ve afectada y el cuidado continuo y prolongado que precisa una enfermedad crónica pone en riesgo el funcionamiento e incluso la salud física y emocional de cada uno de los miembros, es necesario (por los profesionales de la salud) abordar cómo vive cada uno de los miembros la enfermedad, con el fin de evitar que no solo un paciente, sino toda la familia enferme.

Todos nosotros somos conscientes y constatamos cómo la presencia de la enfermedad altera el normal desarrollo de la familia: se modifican las habituales costumbres, hay que redistribuir las tareas y responsabilidades, muchas veces se abandonan actividades, proyectos, tiempos de ocio, etc. La economía familiar tiene que responder a nuevos gastos y posibles pérdidas, etc. La atención continuada al enfermo en el hogar conlleva pérdida de contactos, restricciones de la libertad personal y cierto aislamiento. En el plano emocional surgen sentimientos de culpa, impotencia, tristeza, rabia...Se vive una continua fuente de estrés $\mathrm{y}$ agotamiento tanto por parte del enfermo como de toda la familia.

Es un hecho evidente la importancia que tiene la familia en los resultados de salud y en el manejo de la enfermedad. La calidad marital, las habilidades de afrontamiento, la organización familiar, el que haya una buena comunicación dentro de la familia son factores que van a contribuir positivamente en el curso $y$ pronóstico de la enfermedad, así como en la calidad de vida familiar.
Por desgracia los profesionales de la salud no estamos acostumbrados a abordar la enfermedad del paciente de forma sistémica. Los profesionales y el sistema de salud con frecuencia pasan por alto las necesidades de la familia y, tradicionalmente se les deja al margen para que, por sí solas, resuelvan las exigencias de la enfermedad crónica. Esto se traduce en la escasa existencia de intervenciones psicosociales centradas en los problemas, necesidades y tensiones de los familiares durante la fase crónica de la enfermedad.

Este manual pone el foco en cómo se afectan recíprocamente enfermedad y familia. Tanto la enfermedad crónica como la discapacidad tienen efectos profundos en cada uno de los miembros de la familia y en la familia como un todo. Esos efectos, con frecuencia, representan una fuente de estrés y sufrimiento para las familias y contribuir negativamente en la funcionalidad y bienestar de las mismas, lo que reincide en el resultado de los cuidados y en el manejo de la enfermedad.

Este manual no solo nos ayuda a tomar conciencia de trabajar con los pacientes de forma sistémica, sino que también nos da una serie de procedimientos detallados, así como de sesiones prácticas para trabajar con las familias que tienen un miembro con enfermedad física crónica. Así mismo nos ofrece una herramienta para potenciar las relaciones familiares como una fuerza de gran valor para generar cambios y adaptaciones en las relaciones que afectan al curso de la enfermedad y son afectadas a su vez por ésta.

Manual de interés para los profesionales de diversos ámbitos involucrados en la atención a pacientes con enfermedad física y a sus cuidadores: enfermería, psicología, educación social, trabajo social, medicina y terapia ocupacional. 

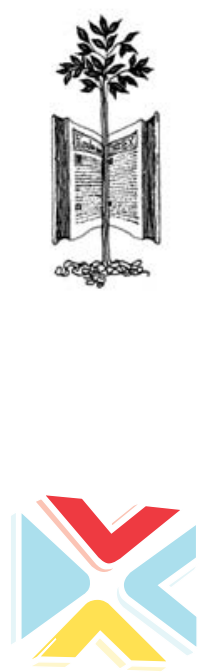

CONSEJO DE ENFERMERÍA DE LA

COMUNIDAD VALENCIANA

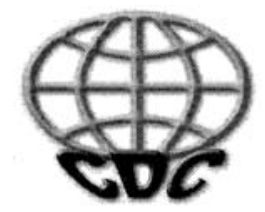

ASOCIACIÓN NACIONAL DE HISTORIA Y ANTROPOLOGÍA DE LOS CUIDADOS

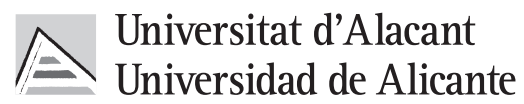

Facultad de Ciencias de la Salud 